



MEDICAL CONTRIBUTIONS TO THE STUDY OF EVOLUTION 



\title{
MEDICAL CONTRIBUTIONS
}

TO THE

\section{STUDY OF EVOLUTION}

\author{
BY \\ J. G. ADAMI \\ M.D., F.R.S., F.R.C.P.
}

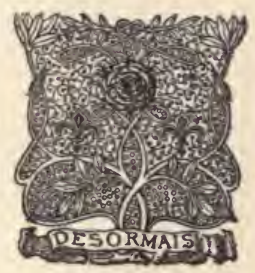

LONDON

DUCKWORTH AND CO.

3 HENRIETTA STREET, COVENT GARDEN, W.C. 
All rights reserved 


\title{
QH 371 \\ A4
}

TO

\author{
SIR T. CLIFFORD ALLBUTT \\ K.C.B., F.R.S., F.R.C.P. \\ \&c. \\ PHYSICIAN, PHILOSOPHER, FRIEND \\ WHO AS REGIUS PROFESSOR \\ PRESIDED OVER THE DELIVERY OF THE EARLIEST \\ OF THESE STUDIES \\ IT AND ITS OFFSPRING
}





\section{PREFACE}

WHEN at the beginning of the Great War the invitation was tendered to me to deliver the time-honoured Croonian Lectures before the Royal College of Physicians of London, it was long months before I could determine my subject. During these months the burden of administrative work in connection with the Canadian Army Medical Service became progressively greater. Research in the laboratory was out of the question. My official duties at that period dealt largely with returns and statistics of invalidism, but soon it became apparent that months, if not years, must elapse before the vast mass of material being collected by the Medical Research Committee at the British Museum would be fully available. Inevitably, therefore, I was led to fall back upon previous studies, and, when still debating, a chance discussion with a leading British biologist convinced me that the time was ripe to bring together and sum up the conclusions regarding Adaptation which as a student of pathology I had reached gradually in the years preceding the War. I judged from the discussion above referred to that that earlier work was not known to biologists in general. Varied as is his reading and brilliant his memory, this distinguished biologist was evidently wholly ignorant concerning it. It seemed also that it would be serviceable to present the conclusions reached, not so much from the point of view of their medical bearing, as from that of their biological significance, in order that both morphologist and physician might observe the direction in which medical research is surely leading 
us with reference to matters that form the basis of general biology. Hence the Croonian Lectures upon Adaptation and Disease, delivered in June 1917, which form the first part of this volume.

Elsewhere I have dealt with this subject of adaptation for the benefit of the student of medicine $;^{1}$ in dealing with the same subject more from the point of view of the biologist, I had of necessity to refer to and repeat data and deductions employed in my earlier writings. The views here enunciated have been arrived at in orderly sequence from the year 1891 onwards, and it has been difficult to review that sequence without employing the facts and arguments by which the successive steps were attained.

While making this confession I have at the same time found myself confronted with the difficulty that, in compressing my treatment of the subject into four lectures, much that should have been dealt with in fuller detail, and with greater wealth of examples, has owing to the exigencies of space and time been unavoidably passed over very rapidly. To remedy this, and at the same time to demonstrate that no newly developed doctrine is here taught, but one arrived at and published many years ago, it has seemed advisable to reprint in their entirety ${ }^{2}$ certain earlier papers and addresses, all bearing upon adaptation and tissue modification, which establish and amplify the successive stages of my argument. These are useful as documents in the case. Personally, re-reading them after a lapse of many years, and so with some sense of detachment, they have struck me as to a certain extent entertaining. May their other readers have the same opinion, and obtain a like satisfaction!

It may be held that an apology is due to not a few well-known

1 Notably in the two editions of my Principles of Pathology in 1908 and 1910 , but those are works of some thousands of pages; it is perhaps natural that biologists in general have been deterred from consulting them.

2 Save for slight structural alterations, advisable in converting delivered addresses from the spoken to the printed form. These alterations have been duly noted whenever it has seemed possible that there has been introduced thereby the slightest departure from the sense of the original. 
British biologists, many of them for long years my personal friends, on the ground that my Croonian Lectures implied that I regard them all as " academic." This, let me hasten to assure them, is very far from being the case. If these lectures be read with reasonable care it will be seen that no such charge is made. I was concerned not to cover the whole ground of modern investigations upon the problems of evolution, but to show the bearing of medical research upon matters pertaining thereto. I realize full well that it would have strengthened my case to refer to the work and views of Walter Heape, Professors E. W. MacBride, A. Dendy, and M. Hartog-to mention only those known to me from old association-as confirming my earlier conclusions. I realize this after the event more fully than before, when I had in mind others who from their position and reputation have, rightly or wrongly, been regarded popularly as yet more leading representatives of British biology.

Nor had I in mind American biologists. To have referred to them would have necessitated entrance at length into the Mendelian controversy, for all the morphologists in the States, I am inclined to think, are at the present moment keenly engaged over this matter. Possibly in the future, I shall have a word to say upon the important studies of Castle, Osborne, Whitman, Morgan, Jennings, and others, and the interpretation of the same in the terms of the biophoric concept. In the meantime may I assure my American confrères that I cannot call to mind one of them whom I would accuse of being "academic." On the contrary, never has there been a period when American biologists have manifested so great an individual independence, so notable a diversity of opinion, so pronounced a desire to arrive individually at the truth, irrespective of the schools and their teachings.

The time indeed has passed when any biologist should justly be labelled as either a Lamarckian or a Darwinian. With abundant material presented to him and freedom of individual judgment, it is scarce possible that the student of to-day should accept unreservedly the teaching of either Lamarck or Darwin. 
He who is concerned at arriving at the truth is impatient of such labels : it is the truth he seeks, not the confirmation of the views of any one predecessor, however great be the admiration for his work and however large the debt he owes to him.

Yet as regards the ancient controversy, this perhaps should be said, that in so far as between Darwin and Lamarck the essence of the teaching of the latter is that variation is an active process, a reaction on the part of living matter to its environment, the conclusions reached in these pages undoubtedly favour the Lamarckian view. Nevertheless, to accept them does not mean that the principle of natural selection is thereby excluded, or that the two principles are mutually antagonistic, but only that the influence of external forces is the primary process in the production of variation, and that natural selection is secondary, culling out those grades and forms of variation which are least economical and represent the less perfect adaptation on the part of individuals to the conditions in which the family or species finds itself for the time being. Seen thus, evolution, whether what we regard as progressive or as regressive, is the outcome of an active process of continuous adjustment between organisms and their environment.

The survival of the fittest, it will be seen, does not depend upon chance variation. A given environment leads to variation in a particular direction, provided that the change in surroundings is not so great as to be beyond the adaptive powers of the organism. Where "chance" enters is in the nature of the new environment to which the individual, and the race, may be exposed. To the extent that the individual is unable to control his surroundings, to that extent is the race exposed to chance. It does not appear to have been sufficiently realized hitherto that here essentially it is that chance is operative. Conjugation and amphimixis, it is true, are a cause of individual variation, but from the point of view of the race are distinctly conservative processes, tending to maintain the mean.

When the first of the series of Croonian Lectures was pub- 
lished in the pages of the British Medical Journal, together with an abstract of the second, the biologist whose attitude with reference to adaptation was the origin of those Lectures, saw fit to criticize them more suo. That my readers, with the Lectures before them, may reach their own conclusions regarding the validity of the criticism, it has been deemed proper to publish the correspondence as an Appendix.

It is my pleasant duty to acknowledge my indebtedness to Messrs. Macmillan \& Co. for their permission to reprint here the greater portion of a chapter from an article published originally in Sir T. Clifford Allbutt's System of Medicine, and republished subsequently in book form under the title Inflammation; to Messrs. Lea Brothers \& Co. (now Messrs. Lea \& Febiger) of Philadelphia, for permission similarly to publish an extract from an article on "Inheritance and Disease" contributed to Sir William Osler's Modern Medicine, to the Harvey Society of New York, and the Editors of International Clinics, British Medical Journal, the Lancet, New York Medical Journal, Montreal Medical Journal and its successor the Journal of the Canadian Medical Association, the Journal of Pathology and Bacteriology, Medical Chronicle, and Clinical Journal, to reprint articles contributed to their pages. To my friend, Captain R. G. Mathews, C.A.M.C., I am indebted for kindly co-operation in the preparation of the illustrations.

London, August 1917. 



\title{
CONTENTS
}

\author{
PART I
}

\section{ADAPTATION AND DISEASE}

BEING THE CROONIAN LECTURES DELIVERED TO THE ROYAL COLLEGE OF PHYSICIANS, LONDON, JUNE 1917

\begin{abstract}
CHAPTER I
PAGE

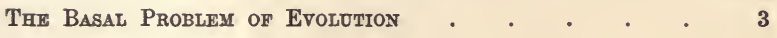

\section{CHAPTER II}

Adaptation in the Bacteria and the Evolution of the Infectious Diseases . . . . . . . . 15

\section{CHAPTER III}

Adaptation IN THE Bacteria (continued) • . . $\quad 28$

\section{CHAPTER IV}

Adaptation to Disease-producing Agencies in the Higher

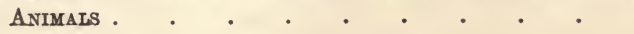

\section{CHAPTER V}

The Inheritance of Acquired Conditions in the Higher Animals . 
CHAPTER VI

The Physico-Chemical Basis of Immonity and of Evolution. THE BIOPHoric CoNCEPT . . . . . . 70

\section{CHAPTER VII}

Review of Certain Conclusions resulting from the BioPHORIC CONCEPT . . . . . . . .

\section{CHAPTER I}

On the Variability of the Bacteria and the DevelopMENT OF RACES (1892) . . . . . . .

\section{CHAPTER II}

On Theories of Inheritance with Special Reference to the Inheritance of Acquired Conditions in MaN (1901)

\section{CHAPTER III}

Adaptation AND Inflammation (1905) • . . . . 161

\section{CHAPTER IV}

The Mremins and Potential Fluid Crystaluine Bodies of THE ORGaNISM (1906) . . . . . . .

\section{CHAPTER V}

The Dominance of the Nucleus (1906) . . . . 188

\section{CHAPTER VI}


CHAPTER VII

PAGE

CHAPTER VIII

On Habits, Stmptoms, and Disease (1911). . . . 235

CHAPTER IX

Parenteral Digestion and Immunity (1914) : . $\quad 250$

PART III

ON GROWTH AND OVERGROWTH

CHAPTER I

ON Growth aNd Overgrowth, aNd ON THE RELationship between Celi Differentiation and Proliferative Capactty (1900) . $\quad . \quad$. . . . . . 263

\section{CHAPTER II}

On the Causation of Cancerous and other New Growths (1901)

\section{CHAPTER III}

On the Classification of Tumours (1902) . . . . 305

\section{CHAPTER IV}

Stncytioma (Deciddoma) Maligndm: its Bearing upon the Essential Nature of Malignancy (1902) . • . 326

\section{CHAPTER V}

Unipotentiality, Ploripotentiality, and Totipotentiality of Cells: a Note upon the Classification of Tumodrs (1907) 


\section{CHAPTER VI}

On the Relationshtp between Tumours Proper (Blastomas) aNd HYPerblastosis (1913) . . . . . . 340

\section{APPENDIX I}

The Experimental Production of Specific Variation in TrpHoid Bacilil, BY F. B. Bowman, M.B. (Tor.), MaJor, C.A.M.C.

\section{APPENDIX II}

Sir E. Ray Lankester rebukes Rudeness : a Correspondence in the Pagres of the Brttish Medical Journal .

$\operatorname{INDEX} \cdot \quad \cdot \quad \cdot \quad \cdot \quad \cdot \quad \cdot \quad \cdot \quad \cdot 363$ 


\section{ILLUSTRATIONS}

\section{PLATES}

I. Fossil and recent blue-green Algae (after Walcott)

II. The Myelins: doubly refracting fatty globules from the adrenal cortex and liver . . . . . . . 168

III. The Myelins: Myelin forms from soap; Ductile Crystals (after Lehmann)

IV. The Myelins : Distortion of fluid crystals and aberrant forms of myelin globules . . . . . . .

V. Schema of the stages of fertilization of the ovum (after Boveri)

VI. Schema of tissue relationships . . . . . 312

VII. Diagram of a lepidic and a hylic tissue . . . 316

\section{FIGURES IN THE TEXT}

ria.

1. Diagram of chemical constitution of an amino-acid nucleus of a protein . . . . . . . . 75

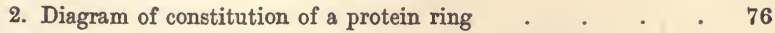

3. Diagram of the affinities of a compound of two carbon atoms (after Bayliss) . . . . . . . . 77

4. Diagram of cell to show nuclear skein with chromomeres . 78

5. Diagram of mode of growth and deduplication of the biophoric molecule . . . . . . . . 81

6. Diagrammatic representation of the nature of enzyme action $\quad 86$

7. Diagram of simple dissociation of peptone molecule $\quad$ - 87

8. Diagram of interaction of substratum and receptor through intermediation of enzyme . . . . . . . 
9. Diagram of alteration in constitution of biophoric molecule .

10. Graphic formula of the Pyrimidine ring . $\quad$ - $\quad$. 89

11. Diagram of production of multiple side-chain elements . $\quad 90$

12. Diagram of interchange of allelomorphic side-chains between biophores of paternal and maternal origin . . .

13. The different forms of chromosomes in the human spermatocyte (after Moore and Arnold) . . . . .

14. Cells of the salivary gland to show production and discharge of "plasmosomes" (after Maximow) . . . .

15. Aberrant mitoses (after v. Hansemann and Pianese) • . 201

16. Diagram of constitution of protein ring . . . . 207

17. Diagram of relationship between nuclear biophores and cytoplasmic proteins . . . . . . . . 208

18. Chromosomes, chromomeres and "ids" . . . . . 214

19. Diagrammatic representation of constitution of protein or peptone nucleus . $\quad . \quad$. $\quad . \quad$. $\quad . \quad$. 222

20. Diagram of growth of biophoric molecule . . . . 228 


\section{PART I}

\section{ADAPTATION AND DISEASE}

THE CONTRIBUTION OF MEDICAL RESEARCH TO

THE STUDY OF EVOLUTION 



\section{CHAPTER I}

\section{INTRODUCTORY : THE BASAL PROBLEM OF EVOLUTION}

I HAVE selected this subject of Adaptation and Disease, not merely because of its importance to physicians, but also, and to an even greater extent, because of its broad biological significance. The time is ripe, and more than ripe, for attention to be directed to the bearing of the investigations of the bacteriologist on the one hand, and of the student of immunity on the other, upon what are some of the most important problems of general biology. For some little time I have been impressed by the fact that the latter-day investigations in medical science are of the very highest significance to the general biologist, 1 and that with singularly rare exceptions the professional biologist - be he zoologist or botanist-has been superbly indifferent to them and to their bearing upon the basal problems of heredity and variation, and this notwithstanding the fact that investigations into heredity and variation are, and must always be, his greatest concern.

For this indifference and neglect there are, or may be, several extenuating circumstances. We ourselves are largely to blame in that we are more concerned with the bearing of our results upon our own medical work than with their wider biological significance. This wider significance, if it is referred to at all, finds incidental note. The titles of our articles, that is, are not such as attract the attention of the biologist, nor do we publish in the journals to which he is addicted. Not to mention foreign publications, the Journal of Pathology and Bacteriology, the Journals of Experimental Medicine, of Hygiene, In-

1 Five years ago this was the subject of my opening address as President of the Biological Section of the Royal Society of Canada. Trans. Roy. Soc. Canada, 3rd series, 1912, vol. vi. section 4, p. 1. 
fectious Diseases, of Medical Research are as unknown territory to him as the Quarterly Journal of Microscopical Science, the Journal of Morphology, or the Proceedings of the Linnean Society are to us. We would sooner think of writing a letter to the Times than to that academic go-between of men of science, Nature.

And then, again, just as, in the old unhappy far-off days, a Bart's man disbelieved that any good surgery could come out of Thomas's or George's, and the Thomas's or George's surgeon returned the compliment; just as the British medical man disbelieved such articles as appeared in the American medical journals, or, to come nearer to our own times, just as the Germans of late years, with rare and distinguished exceptions, regarded themselves as the sole recipients of pathological truth, treating British, French, and American pathologists in general as very Nazarenes, so, it has to be confessed, there is a tendency for the academic biologist to be indifferent to, if not actually to resent, and throw discredit upon the work of those who, not belonging to his particular class, are therefore to be regarded as of the nature of outsiders. This is not a revelation of the spirit of pure science, but a comforting demonstration that men of science are, nevertheless, pure human beings. Underlying this spirit is a natural and in many respects wise caution in accepting the observations of workers with whose quality and standing the individual is unfamiliar. But this hesitancy may be carried too far.

If I speak with a little feeling, it is because I still cannot forget the reception accorded by zoological confrères to the most original, and at the same time most sound physiologist of his period, my old teacher and friend Walter Gaskell, when he was led by his studies upon the functions of the nervous system-studies which have so profoundly influenced modern medicine- to trace the development of the same, and doing this, after long years of close study of its comparative morphology, to reach conclusions regarding the origin of the vertebrate which were not in harmony with the doctrines of descent then currently accepted. So far as I, an outsider, could determine, each link in the chain of Gaskell's reasoning was supported by appeal to observed facts, and by microscopical studies of singular interest; so far as I, a pathologist, could test his conclusions, 
I found that incidentally they explained, as no other or earlier work had explained, the inter-relationship between the sympathetic system and the endocrine system, between the pituitary, thyroid, adrenals, and genital organs. Nor, so far as I can weigh evidence, can I find that any essential link in the chain has been shown to be out of place. Yet the attitude of the morphologists as a body was that of the Levite of the parable. His brother physiologists could not take up the cudgels on Gaskell's behalf : it was for the morphologists to determine the value of the morphological evidence upon which his conclusions were based, and the morphologists in general declined to notice it, but, as though they regarded it as presumptuous for him, a physiologist, to enter their territory, they passed by on the other side. And the years followed the years, and Gaskell died feeling sore that the most sustained piece of work of his life had been side-tracked by those whom it should most have interested.

Do not misunderstand me, and think that I am making a specific attack upon zoologists and botanists. As I have pointed out, we of the medical profession are tarred with the same brush. All I would urge is that just as we who are most interested in the advance of medical science accept gladly the results and the discoveries of workers in all branches of science, applying them to the elucidation and treatment of disease, so, in return, when investigators into the problems of medicine make notable advances, these be accepted willingly and utilized by the workers in other branches. It is not a matter of what we owe to those other branches in the first place; that is freely admitted. The renascence of medicine in our generation is due to the labours of men like Ferdinand Kohn the botanist, Pasteur the physical chemist, and Metchnikoff the zoologist, but if the dwarf, perched on the shoulders of the giant, ${ }^{1}$ sees further and sees more than does the giant, it is not well to neglect his observations on the ground that he is a dwarf.

1 As might be expected, this metaphor was not original with Burton in the Anatomy of Melancholy. I find that Firmin-Didot (Alde Manuce, Paris, 1875, p. 343) cites Haureau (Histoire de la philosophie scholastique, Paris, 1872) as deriving it, according to Joannes Sarisberiensis (Metalogicus, vol. iii. cap. 4) from Bernard of Chartres in the twelfth century. 


\section{The Nature of Variation}

The supreme biological problem of our times has been that of the ways and means of evolution. The fact of evolution all thinking minds accept. But as to how evolution has been, and is being, brought about is a very different matter. There is still as much debate as there was in the year following the publication of the Origin of Species. Upon consideration it will be seen that the fight truly centres upon the cause or causes of variation-whether the tendency to vary is something inherent in living matter, numerous variations being produced through this inherent tendency, of which those that are best fitted for their environment alone survive and are perpetuated : or whether variation is primarily and essentially brought about by the influence of forces acting from without upon a relatively labile living matter; whether, that is, variation 1 is primarily inherent, proceeding from within, or primarily acquired, proceeding from without.

This, I would emphasize, is the basal problem of evolution, but oddly enough it has been largely neglected, the fight through all the years waging around what, after all, is a secondary problem, that, namely, as to whether properties acquired by the parent are capable of being transmitted to and reproduced in the offspring. Long years prior to Darwin, you will remember, Lamarck propounded that they were, as did Erasmus Darwin and Lord Monboddo; Darwin wanted to believe that this was possible, but could obtain no clear evidence, and brought in finally a verdict of "non proven." Herbert Spencer made this transmission one of his "principles of biology," but Weismann violently opposed the doctrine, carrying with him the bulk of latter-day biologists, until to-day Bateson, replete with his studies upon Mendelian properties, reaches the antipodal suggestion that when a new property manifests itself in any individual of any species it is not new, not due to addition, but to subtraction and loss of properties already possessed: there is nothing new under the sun, and,in his opinion, evolution-like the squidprogresses backwards; what appears to be a new property is, on

1 By an oversight this was delivered as "variability" at the Royal College of Physicians and so printed in the pages of the British Medical Journal. Pace Sir Ray Lankester (for whose criticism consult the correspondence at the end of this volume), my meaning was as obvious as was the oversight. 
the contrary, primaeval, is the epiphany of a property possessed by the forerunners of the species which all along has lain latent, present but unable to manifest itself in consequence of the coexistence of inhibitory factors.

That I may not be thought to exaggerate or misstate, let me quote, in the first place, from his address on Heredity delivered to the International Medical Congress here in London in 1913:

"Perverse as such a suggestion may appear, I do not think we should close our minds to the possibility that these dominants arise by a process of loss of some inhibitory factor. . . . Let me call your attention also to the inference which this suggestion would have on the conception of evolution. We might extend the same reasoning to all cases of genetic evolution, and thus conceive all alike as due to loss of elements present in the original complex."

That clearly this was not a passing fancy is shown by the address delivered by him at Melbourne in the summer of 1914, as President of the British Association for the Advancement of Science.

"We are even more sceptical," said Mr. Bateson, "as to the validity of an appeal to changes in the conditions of life as direct causes of modification, upon which, latterly at all events, Darwin laid much emphasis. . . ."

"Abandoning the attempt to show that positive features can be added to the original stock (the italics are mine), we have further to confess that we cannot often actually prove variation by loss of factors to be a real phenomenon." Nevertheless this must be so, and he quoted the case of the "Coral King "Primula given off from the "Crimson King," concluding that here " the salmon (pigment) must have been concealed as a recessive from the first origin of the variety," and continued: "Variation both by loss of factors and fractionation of factors is a genuine phenomenon of contemporary nature. If we have to dispense, as seems likely, with any addition from without, we must begin seriously to consider whether the course of evolution can at all seriously be represented as an unpacking of an original complex which contains within itself the whole range of diversity which living things present." And further:

"At first it may seem rank absurdity to suppose that the primordial form or forms of protoplasm could have contained 
complexity enough to produce the divers types of life. But is it easier to imagine that these powers could have been conveyed by extrinsic additions? Of what nature could these additions be? Additions of material cannot surely be in question" (the italics are mine).... And he winds up :

"In spite of seeming perversity, therefore, we have to admit that there is no evolutionary change which in the present state of our knowledge we can positively declare to be not due to loss."

Now Professor Bateson is scarce a believer in the multiple origin of animal and plant forms : we know, indeed, that years ago he traced man and all vertebrate forms from the invertebrates through an out-of-the-way animal, Balanoglossus, and incidentally in his Melbourne address he mentions this solution of the problem only to reject it ; wherefore, pushed to its logical conclusion, the Batesonian doctrine means this, that the primal unit, or units, of protoplasm from which all living animal and plant forms have descended possessed within them in a latent form the "Anlagen," or, not to be beholden to our enemies, the originals, of every organ and distinctive portion of an organ or part, even down to the conformation and coloration of individual hairs and scales, and feathers and leaves, and petals and stamens, of all the manifold forms of life subsequently derived therefrom: that which was to outward seeming the most simple form of life was, verily, in constitution the most marvellously complex-and that actually what we regard as the higher forms of life are the lower, owing their development not to progressive accretions of properties, but to the reverse, so that reversion, instead of being a degenerative manifestation, a loss of properties acquired by the species, is, on the contrary, a recovery of higher and completer powers. Did ever any exercise of mediaeval scholasticism lead to more perverse conclusion?

The truth seems to be that Professor Bateson and the Mendelians, so far as regards the problems of evolution, are working in a cul-de-sac. Valuable and fascinating as are their observations for the establishment and amplification of the law discovered by Gregor Mendel of cross-breeding of members of a species, that law only deals with the interplay of allelomorphs, id est, with the combinations and permutations of what for 
simplicity sake may be termed positive and negative unit properties possessed by the species : it only establishes the extent of the variation possible within the boundary of the species, and granting the existence of a definite number of allelomorphs, the number of possible strains obtainable within the limits of the species. But here it stops-save that of late workers have recognized the possibilities of fractionation of allelomorphs, and so of increase in the number of permutations and combinations. Accepting Mendelian data (and let me say I accept them wholeheartedly), I fail to see how any amount of interplay between properties already possessed by the species will result in the production of individuals which are outside the species. At most we produce different strains which, by cross-fertilization with other strains, produce individuals reverting to the usual type or types. If you invest in a kaleidoscope at a toy-shop, with the mirrors set at an angle of $60^{\circ}$, no amount of rotation will produce other than a six-sided pattern, or increase the number of colours in the pieces comprising the pattern. Only from without can new elements of other colour be added, thereby producing patterns of a new order: only from without can the angle of the two mirrors be altered so as to produce, say, a four- or a twelve-sided pattern. The interplay of allelomorphs is not evolution, nor is it capable of throwing light upon the progressive development of new species. When Professor Bateson, from the vantage ground of his studies of the last fifteen years or so, begins to lay down the law regarding evolution, I cannot but help being reminded of Bombus, the bumble-bee-I would not say "in vacuo bombinans," for that was said of a zoological monstrosity, and Professor Bateson is no chimæra, ${ }^{1}$ but--blundering out of the fields and hedgerows into a greenhouse, and bumping its head noisily again and again against the glass because of its incapacity to drive into that head the fact that transparency and penetrability are not necessarily associated phenomena.

Nor is he alone. It so happens that some eighteen months ago, at the request of a mutual friend, a Fellow of the Royal College of Physicians, I found myself drawn into a lively discussion with the Nestor of British biologists. I had not sought

1 Rabelais, Pantagruel, bk. ii. cap. 7. I owe the reference to my friend Mr. Louis Taylor. 
the fight, but, once in, confess that I enjoyed the opportunity of measuring my lance against so doughty a knight. The discussion arose over a statement by the Fellow in question that the biologists of to-day had much to learn by turning their attention to the results being gained in medical laboratories. And, sure enough, after protesting with not a little vigour that the boot was on the other foot-that we medical men in our ignorance of biological progress were rediscovering and regarding as our own what had been gained by zoologists and botanists a generation or so previously-Sir Ray Lankester proceeded to justify absolutely my friend's original contention by urging that one fallacy in all Lamarckian doctrine ${ }^{\mathbf{1}}$ is that adopted by Herbert Spencer, namely, what he called "direct adaptation." There is really, he laid down, no such thing. The supposed mysterious, and as it were miraculous, property of direct adaptation is always due to survival by selection of organisms which varied in many directions-the production of corneous epithelium, of increased hairiness, etc., being favourable variations, which hence have become inherent in tissues of all animals. $^{2}$

1 I confess that I do not like being dubbed a Lamarckian, and that because, as commonly accepted, Lamarckianism is supposed to deal purely with the direct acquirement of alteration in structure through ase and environment, and Herbert Spencer, by using the term "direct equilibration," is largely responsible for this vulgar error. The phenomena we pathologists deal with present modification of structure merely as a secondary change : our phenomena underlie structural alteration. But in justice to Lamarck it deserves note that he expressly lays down "whatever the environment may do, it does not work any direct modification in the shape and organization of animals. But great alterations in the environment of animals lead to great alterations in their needs, and these alterations in their needs necessarily lead to others in their activities. Now if the needs become permanent, the animals then adopt new habits, which last as long as the needs that evoked them "- and it is the new habits, he points out, which induce the structural alteration. (I quote from Hugh Elliot's excellent translation of the Philosophie zoologique-Lamarck, Zoological Philosophy, Macmillan, 1914, cap. 7.) Granting this, I hold that the physicochemical explanation which will be put forward in the course of these lectures is something more precise and more limited in its scope than the " habits" of Lamarck.

3 As Sir Ray Lankester has accused me of garbling his statement (see Appendix II.), and has not seen fit to withdraw the charge, I have no hesitation in quoting his exact words : "One fallacy in all Lamarckian doctrine is that adopted by $\mathrm{H}$. Spencer, viz. what he called 'direct adaptation.' There is really no such thing. The supposed mysterious, as it were miraculous, property of direct adaptation is always due to survival by selection of organisms which varied in many directions - the production of corneous epithelium, of increased hairiness, etc., being favourable variations, and hence have become inherent in tissues of all animals. But no more!" 
Here then we see the two foremost British biologists of our day, the one in doubt whether change in environment can be a direct cause of modification, and, filled with these doubts, willing to accept as a postulate that positive features cannot be added to the original stock, whereby he is led to an utterly perverse hypothesis; the other equally denying that there can be external influences of such a nature that specific variationi.e. variation in particular directions-may be induced, and taking the stand that variation is multitudinous, the favourable variation alone having the opportunity to be propagated and reproduced.

Now if there be one fact that is constantly being impressed upon the student of immunity and the worker in pathogenic bacteriology, it is that " direct adaptation " (i.e. specific modification in response to a specific alteration in environment within limits which will presently be laid down) is one of the basal phenomena of living matter. Our studies make it impossible for us to be blind to the fact that environment is capable of exerting a profound influence upon living beings, bringing about modifications of function and even of structure in particular directions. But evidently our experience and the diverse observations upon which that experience is based are unknown to the academic biologists, although some biologists are beginning to see light. Thus it delighted me to run across the following admission in a valuable work published within the last few weeks-Professor D'Arcy Thompson's Growth and Form: ${ }^{1}$ "So long and so far as 'fortuitous variations' and the 'survival of the fittest' remain engraved as fundamental and satisfactory hypotheses in the philosophy of biology, so long will these "satisfactory and specious ' causes tend to stay 'severe and diligent enquiry' to the great arrest and prejudice of future discovery." With this strong opposition on the one hand, and encouragement on the other, it has seemed to me a useful task to bring together and marshal in order the data bearing upon these matters as they present themselves to us, workers in medical science.

1 Growth and Form, by D'Arcy W. Thompson, F.R.S., Camb. Univ. Press, 1917 , p. 6. 


\section{The Method of Attack}

There are two ways by which problems of this nature are a priori most likely to be solved, namely, by experiments upon the very simplest and, again, upon the most complex forms of life. I see that Dr. Bayliss as a physiologist casts doubts upon the value of the former as compared with the latter, ${ }^{1}$ pointing out that their very simplicity is in the majority of cases a disadvantage, and quoting Claude Bernard to the effect that the lower (unicellular) forms of life possess all the essential properties which exist in the (multicellular) forms higher in the scale, but possess them in a confused state, distributed, as it were, throughout the organism. The one organic cell fulfils a variety of purposes which in the higher organisms are relegated to distinct groups of cells. While freely admitting this contention as regards the study of function, it has to be pointed out that for problems of adaptation and heredity the unicellular organisms possess the supreme advantages of rapid reproduction, coupled in the very lowest forms (according to our present knowledge, or want of knowledge ${ }^{2}$ ) with a complete absence of the disturbing influence of sex and conjugation. There is, that is, a greater likelihood of obtaining results, and the experiment becomes simpler, where we can in the course of a few hours subject one hundred generations to a particular alteration of environment, than when weeks, months, or years elapse before one new generation shows itself. In the latter case, to obtain results, either the alteration of environment must be made intensive to a degree that is likely to interfere with various vital functions, or, exhibited in a less intensive form, must act over unduly long periods. I know that certain biologists are unwilling to regard the products of asexual binary division of the bacteria, or the torulae of yeast (the results of budding), as true generations, and deny the right to regard the individual bacillus as an individual. One very distinguished biologist went so far as to declare to me that a long cultivation of a bacterial growth is "one continuous individual," in other words,

1 W. M. Bayliss, Principles of Physiology, 1915, p. 291.

2 For myself, with sex so widespread an attribute of living beings, I confess that I am wholly prepared to find that the schizomycetes, or some of them, exhibit a sexual, or conjugation, phase. 
that not merely do all the millions of bacilli in a single colony, say of the Bacillus tuberculosis, constitute one individual, but that one individual Bacillus tuberculosis is spread all over the habitable world, and that tuberculosis and not the tubercle bacillus is the entity. This is an impossible position : it formulates that the "divisa" are "indivisum." The very idea of individual connotes independent existence, or, if we take a wide survey and include forms like the compound myxomycetes, hydrozoa and polyzoa, potentially independent existence. When a bacillus grows and divides and each half floats away, there is no longer one individual, and whether, as among the bacteria, the division is binary, or, as in man, one of the many billions of cells that constitute the body undergoes a similar binary division, and one of the products floats away and becomes fertilized, in both cases we deal with the development of a new generation. By the same process of reasoning, basing ourselves upon the doctrine of the continuity of the germ plasm, we might with equal logic declare that all living beings constitute one continuous individual!

And as regards the advantage in researches upon the bacteria of being freed from the perturbing factor of sex, let me interject that starting with Weismann and his doctrine of amphimixis, but more particularly during the last fifteen years under the influence of the Mendelians with their studies upon cross-breeding, we have been inclined to lay far too much stress upon the part played by sexual conjugation in the production of variation. In nature, in general, the tendency, if not the function, of sexual conjugation is to preserve the mean, not to induce the extreme, is to perpetuate the species rather than favour the variety: sexual conjugation only preserves and intensifies a variation when circumstances favour the segregation of individuals of the two sexes each possessing the variation, or, I would add, when those circumstances actually lead to the appearance of the variation in more than one individual in a particular locality. Even if a property be dominant, with indiscriminate mating and without segregation, such new property is apt to show itself proportionately in fewer and fewer individuals in successive generations. In simpler language, turn a highly-bred mastiff or terrier or beadle loose in a canine population, and his descendants descend to plain " yellow dog." It follows, therefore, 
that on the whole we are more likely to obtain results where this levelling action of conjugation is wanting.

I propose, therefore, to take up first the evidence of adaptation as affecting the pathogenic bacteria, next, of adaptation as it affects man and the higher animals, and, lastly, to discuss the application of the data brought forward to our conception of disease and disease processes on the one hand, of the evolutionary process on the other. 


\section{CHAPTER II}

\section{ADAPTATION IN THE BACTERIA}

\section{The Evolution of the Infectious Diseases ${ }^{1}$}

Ir is absurd in these days to imagine that the infections have always been with us : absurd to expand the Batesonian hypothesis and imagine that when the woman gave the man the fruit of the tree-or whenever man became man-with that most becoming knowledge of his nakedness he acquired the germs of all bodily ills : that while lues may already have infected his ancestors and their relatives the higher apes, the germs of typhoid, cholera, gonorrhoea, and other purely human ailments were already there, only waiting for his appearance to enter into his body, as into a house newly swept and garnished.

\section{The Antiquity of Zymotic Diseases}

Admittedly some diseases have been with us from the remotest historical times, aye, and we have evidence, from prehistoric times. The earliest Greek medical writings afford us an unmistakable picture of tuberculosis. If we may accept Bishop Ussher's chronology, the fifth and sixth chapters of the First Book of Samuel show-as I believe I was the first to point out, in the light of our modern knowledge of the natural history of this disease ${ }^{2}$-that the Oriental plague was active over three thousand years ago, presenting the same striking characters as it manifests to-day. At a still earlier historical era, in fact in the earliest

1 This chapter follows the lines (though with considerable modification) of an address given by me before the Medical Society of the State of Vermont at its annual meeting at Rutland, Vt., in Feb. 1915, and published in the 1914 volume of the Transactions of that Society.

2 Montreal Medical Journal, xxiv., 1896, 995. 
of all known writings, namely in the Ebers papyrus, descriptions are given of leprosy, and the Ebers papyrus is said to be of the twelfth dynasty, so that leprosy has been known for some four thousand years.

It is through my old friend, Sir Armand Ruffer, whose recent death we deplore, a man who accomplished much for Egypt, and through his studies in what he described as palaeopathology, that we owe the knowledge of prehistoric disease in man. Mummies of yet earlier dynasties-and pre-dynastic-said to date back as far as four thousand years B.c. or six thousand years ago, demonstrate the most respectable antiquity of Bilharziosis, not to mention such everyday disturbances as Rheumatoid Arthritis and Pyorrhoea alveolaris. The characteristic eggs of Bilharzia are still distinguishable in the dried-up tissues of pre-dynastic mummies, so that anaemia and haematuria constituted a plague of Egypt before the Pharaohs as they do to-day when the Sultans and their suzerainty have passed away. ${ }^{1}$ Tuberculosis, too, was there already. He demonstrated the bacilli in tissues in mummies from the Herst collection at Cairo belonging to the twentieth dynasty or so.

Diseases which are not peculiar to man have indeed been diagnosed in fossil remains. Thus, according to Moodie, ${ }^{2}$ caries has been noted in Permian fishes, pyorrhoea in the jaw-bone of an early tertiary three-toed horse, and arthritis and osteomyelitis in the remains of cave bears.

\section{The ANTiquity of the Bacteria}

This, after all, is only what might be expected : these lower forms of life preceded mammals and man, and bacteria must have been among the very early forms of particulate life. So

1 Just as the earliest known written document is medical, so my late colleague in Anatomy at McGill University, who, while this is passing through the press, from being Director of Recruiting and Brigadier-General has become Minister of National Service and Sir Auckland Geddes, has impressed upon me that the earliest known human fossil is pathological, pointing out that the remarkable thickness of the Piltdown skull, coupled with the characteristic ontline of the temporal ridge, can only find their explanation by a diagnosis of Acromegaly, and suggesting that it is thanks to this disease and its results that we owe the survival of these remains through the ages. We do not, however, claim Acromegaly as a result of zymotic disease.

2 Trans. Chicago Pathological Society, x., 1916, 84. 
long ago as 1879, Van Tieghem called attention to the evidence of bacterial existence, if not the actual presence of bacteria, in the silicified vegetable remains from the coal measures of St. Étienne. Since then, in a series of admirable memoirs, Renault 1 has confirmed and extended those observations. That marine Algae play an important part in certain geological horizons, notably in connexion with oolitic and dolomite structures, was laid down by Professor Garwood ${ }^{2}$ in 1913.

But even before this date a brilliant investigator, Drew, who died all too young, had in 1911 studied the calcareous muds now being deposited in the lagoons on the coast of Florida, and had shown that in the warm tropical waters of the Gulf the commonest living form is a denitrifying bacillus which, by the removal of the nitrogen from the water, leads to a combination between calcium and dissolved carbon dioxide, with, as result, the precipitation of the insoluble calcium carbonate. $\mathrm{He}$ isolated and cultivated this form and obtained in vitro the deposit of calcium carbonate from the sea water. In the following year he found the same Bacterium calcis extraordinarily abundant in the chalky mud of the Great Bahama reef, as many as 160 million bacilli being present in $1 \mathrm{c.cm}$. of the surface ooze. ${ }^{3}$

These observations indicate, therefore, that bacteria, even to a greater extent than the larger marine Algae, have been responsible for the deposit of the vast beds of chalk and limestone in which no coralline or other fossils are to be detected. And now, in the oldest of all stratified rocks, in the pre-Cambrian or Algonkian deposits of America, Dr. Walcott, the head of the Smithsonian Institute, has discovered fossilized chains and clusters of cells which from their appearance and his description belong to the Cyanophyceae, the blue-green Algae closely related to the bacteria, and with these other clusters of coccus-like cells which may, or may not, be bacteria. ${ }^{4}$

He likewise concludes that "it is quite probable that the bacteria were the most important factor in the deposition of

1 Renault, B., "Sur quelques micro-organismes des combustibles fossiles," Bull. de la Société de l'Industrie minérale, St-Etienne, vols. vii. and xiv., 1899, 1900 (with folio atlas of 20 plates of untouched photographs).

2 Geological Magazine, x., 1913, pp. 440, 490, and 545.

s Papers from Tortugas Laboratory, Carnegie Institute of Washington, v., $1914,44$.

If bacteria then they are much larger than the micrococci of to-day. 
the Algonkian limestones," 1 and that thus bacteria are to be regarded as largely responsible for the oldest of all known sedimentary rocks.

\section{The Geological Parallel}

Bacteria have been there, almost $a b$ initio, but this does not, therefore, mean that all orders of pathogenic bacteria have always been with us, or that while certain infections are of an eminently respectable antiquity, this is necessarily true of all zymotic disease. Recognizing the unity of natural phenomena we must, I take it, hold that zymotic phenomena run parallel with geological. I mean this, that certain species, and indeed certain genera, have existed unchanged through countless ages to the present day. To-day we find the brachiopod Lingula living buried in the sand between the tide marks in the Tropics : we find identical fossil remains in the Cambrian rocks, usually (though wrongly) described as the earliest geological formations in which fossil remains have surely been discovered. As I have just pointed out, algae and bacteria are now known to antedate them by a long period. Here, then, is an animal which has persisted unchanged, over countless millions of years. The pearly Nautilus, with its exquisitely chambered shell, is still found in certain bays in the south-west Pacific: as Sir Archibald Geikie declared: "This is a genus which has persisted through the greater part of geological time," for identical chambered shells are found as fossils reaching back to the Silurian epoch. Limulus, the King crab, which is no crab but an arthropod, regarded by. Gaskell as in the line of ancestry of the vertebrates and of man, is closely related to the Devonian Eurypterids, the fossil remains of that period differing in but secondary characters from the shells of Limulus of to-day.

And so it is with shrimps like Anaspides ${ }^{2}$ and yet other crustaceans, and with fishes such as Ceratodus, the King fish of Australia, which have remained apparently unaltered over extraordinarily long periods of geological time. But while this is so, we know equally well that during the same period other

1 Walcott, C. D., "Precambrian Algonkian Algal Flora," Smithsonian Miscellaneous Collections, vol. 1xiv. No. 2, 1914.

${ }^{2}$ I owe these latter examples to my colleague at MeGill University, Professor A. Willey, F.R.S. 


\section{PLATE I}

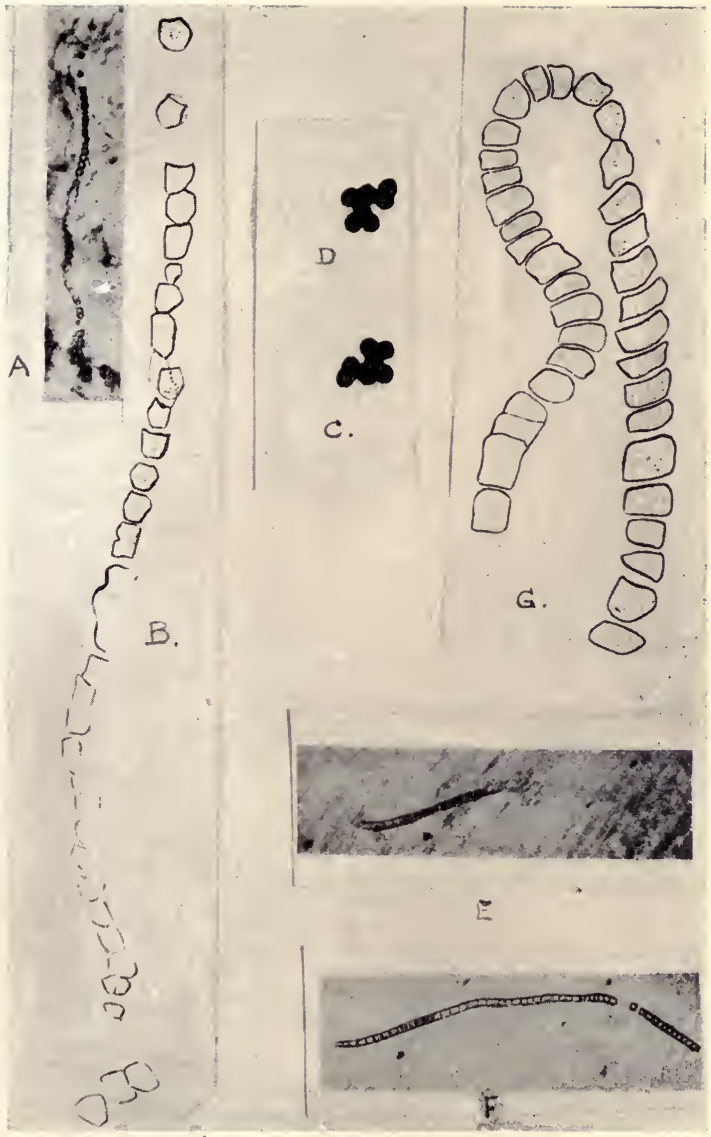

Fossil Blue-green Algae (Walcott).

A. Camasia spongiosa $\times 350$. A blue-green alga from the Algonkian Limestone. Chain of cells as photographed and partly outlined.

$B$. The same, higher magnification $\times 1400$. Outline sketch.

C. A group of seven supposedly round cells from the Algonkian Limestone as they occur free in the matrix $\times 350$. U.S. National Museum, Catalogue No. 60722.

$D$. The same, touched and outlined.

E. A blue-green alga (Schizothrix) from a recent calcareous deposit at Green Lake, Onondaga Co., New York, $\times 350$. For comparison.

$F$. Photograph of same after treatment with hydrochloric acid.

$G$. Outline drawing of another chain $\times$ ca. 1200 from a recent calcareous deposit, after treatment with hydrochloric acid. For comparison. 

forms have undergone wide and progressive variations. I know no more convincing demonstration of the truth of evolution than the wonderful series of fossils collected by Marsh at the National History Museum in New York, showing the progressive stages from the four-toed Eohippus no bigger than a mastiff, to the one-toed horse of historical time. Of late, I believe, an equally instructive series of fossils, starting from a small tapir-like ancestor leading up to the modern elephant, has been obtained from Egypt, and has been housed at South Kensington. Here is the point which I would emphasize: the vast majority of fossils are remains of species and genera which have passed away.

Now what is true in respect to these fossils would seem to obtain in respect to zymotic diseases and their causative agents. Some extend back unaltered in their characters to the very earliest periods : others appear and cause wide devastation for a few generations, and then are known no more. It is difficult to ascribe to faulty observation only the fact that many of the plagues and epidemics of classical times are unrecognizable to-day: the simpler and more sensible view to take is that many of them were diseases which have died out. Nor are we without modern instances to this effect. Of these the tritest is the "Sweating sickness" (Sudor anglicus) which, first noted in England in the autumn of 1485, led to a high mortality, affecting not so much the poor and ill-fed, as those in comfortable circumstances. It was an extraordinarily acute visitation, death ensuing often in the course of a few hours : some are described as passing into their death-agony while walking in the street, without time being afforded for them to be shrived. It came in epidemic form with heavy mortality, and spread rapidly. The attacks, characterized by high fever, profuse sweating and little pain, are described as lasting for twenty-four hours. Of this disease there were outbreaks in $1485,1507,1517,1528$, and finally in 1551. Creighton, it is true, suggests that it was introduced from the Continent by the rabble of mercenaries who came over with Henry VII., that, in fact, it is the same disease as the Picardy sweat. Unfortunately for this hypothesis there is no evidence of the prior existence of such a disease in Picardy or elsewhere on the Continent, and the Picardy sweat was not heard of until two hundred and thirty years after the "Sudor anglicus" 
was first recorded, and when it did appear it was an endemic, and not a violently epidemic, disorder.

Two diseases in this connexion inevitably come to minddiseases so characteristic in their manifestations and natural histories, that had they presented themselves in Europe in the Greek and Roman eras, they could not have escaped the notice of the Aristotles and Plinys, let alone the purely medical writers. I refer to Syphilis and Cholera.

Regarding Syphilis the problem is difficult to solve, nor can it be said that an agreement has been reached as to the date of its first appearance. This would, however, appear to stand out clearly-(1) that not a trace of the disease was found in 10,000 skeletons examined by Elliot Smith ${ }^{1}$ from burial-grounds of ancient Egyptians ; (2) that as pointed out by Dr. Norman Moore in the course of the discussion at the Royal Society of Medicine in 1912, Galen with his keen observation and excellent description of the nervous conditions known to him is absolutely silent as to the eminently characteristic symptoms of locomotor ataxy and general paralysis of the insane. There could be no more authoritative evidence that the disease as we know it did not exist in ancient Rome. Syphilis, therefore, originated or reached Europe at some later period. The discussion now centres as to when that was, and there are the two parties, the one favouring the American origin, through the returned sailors of Columbus, the other denying this, and taking a generally agnostic position. Opposed to the American theory is that excellent anthropologist Dr. Hrdlicka of Washington, who in his extensive studies of hundreds of pre-Columbian human remains has not come across a trace of syphilis, while post-Columbian bones show that the disease wrought fearful havoc among the American Indians; and now comes Sudhoff ${ }^{2}$ with strong documentary evidence from civic ordinances in Germany in 1495-the year of the fall of Naples-in favour of the view that the disease was already well known and causing alarm in Germany at a time when it was just being recognized in Italy.

It would be out of place here to enter deeply into the value of these respective contentions and to discuss whether Haiti or

1 Vide Sir H. Morris, "Discussion on Syphilis," Proc. R. Soc. Med. S., 1912. See also Elliot Smith, Lancet, 1908, ii. 521, and 1909, ii. 1596.

2 Graphische und typographische Erstlinge der syphilitische Litteratur, Munich, 1912. See also his Aus der Frühgeschichte der Syphilis, Leipzig, A. Barth, 1912. 
Germany is to be regarded as the original home of syphilis. Whichever view be accepted it is clear that we deal with an infection which is not coeval with the appearance of man. Either we deal with a disease which made its first appearance within historical time, or a disease which appeared in America long after the New World became separated from the Old - and there, it may be, appeared in Haiti and the West Indies after these were separated from the mainland. If the former view be correct we have a further example of the phenomenon immediately under review-if the latter, another of the many examples of diseases peculiar to one district, which may or may not eventually spread to other parts of the world. As Major Strong and the Harvard Commission have recently shown, there are human diseases peculiar to South America. There is a "blastomycosis" peculiar to the San Joaquin Valley in California. We know that Measles was unknown to the Pacific Islands prior to the eighteenth century, that cholera, endemic in the delta of the Ganges, similarly only spread along the trade routes to the rest of the world early in last century.

\section{The Parallete of Geographical Distribution}

This last group of cases-and it might be added to extensively -is exactly parallel to what has been ascertained regarding the geographical distribution of animals. To afford an easily grasped illustration I may note what we may term the epizootic which followed the introduction of the European rabbit into Australia, or the English sparrow into North America. Now rabbit and sparrow are relatively old species: the reason why they had not hitherto been present in areas eminently adapted for their existence, is that they made their appearance in the Old World at some period subsequent to the separation of the New World and Australia from the Old. There are, I know, other considerations to be taken into account: I might, that is, have selected more convincing examples from among the abundant data regarding the geographical distribution of animals, but these will serve as familiar examples.

The very fact, therefore, that certain highly infectious diseases may be traced to a previous or existing limited and localized incidence, is a proof that their origin is to be dated 
to a period subsequent to the dispersal of peoples over the habitable globe.

\section{The New Diseases of the Great War}

But to return to the main point, that of the evolution of new infections. No one can fail to be impressed with the fact that while among the millions of our troops engaged, three of the terrible plagues of former campaigns have been virtually suppressed-small-pox, enteric, or typhoid, and typhus-other and less fatal epidemics have manifested themselves, and some of these are hitherto undescribed and unrecognized conditions. Either they are new diseases, or old diseases assuming a new form under changed conditions of environment. There has been some doubt as to whether all the cases called Trench fever are of the same nature, whether under the name we deal with one or more than one disorder, but this has during the last few months been dissipated, as the symptomatology of the disease has become clearly defined; to the best of my knowledge here is a disease, or group of diseases, that is new to us. The same is true of "Trench shin."

\section{The New Diseases of Animals}

Nor is our evidence confined to man and human infections. It is, for example, difficult to believe that a disease leading to so great a mortality, and with symptoms and lesions so characteristic as are those of Hog Cholera, could have occurred in previous generations without being observed and described. But so far as I can discover this disease was unknown until the 'sixties, when it made its appearance in the United States, and thence it has spread over the civilized-and hog-eating-world.

How, then, are we to picture to ourselves the evolution of an infective disease? Are there any data which permit us to deduce reasonably sure conclusions as to the nature of the process? I believe that there are, and that the observations of the last few years, and more particularly certain observations made here in London, have given the key. 


\section{The Nature of the Infections and of Pathogenic Microbes}

We must take as our first postulate that every infectious disease is brought about by the growth within the body, and diffusion throughout the system, of toxines 1 of one or other particular species of micro-organism. This being so, it is deserving of note that these pathogenic microbes do not form an order by themselves, but, on the contrary, are singularly diverse in their affiliations. Still influenced by the work of the last quarter of the nineteenth century, we are apt to forget this, and classing the whole subject under the heading of pathogenic bacteriology, to overlook this notable diversity. How few remember that a generation before pure cultures of any bacteria were obtained and tested, Schoenlein demonstrated the relationship and the constant presence of a mould in Favus. How few again recall Goodsir's work of the 'forties and his association of a Sarcina with gastric atony. Flagellate and ciliate protozoa, sporozoa and yet other genera of protozoa, forms like the spirochaetes, which certainly are not bacteria, but still are not surely classified, seeming to be midway between protozoa and protophytes: filterable viruses which, if protophytic, are evidently of more than one order and, again, are not bacteria as generally accepted, even if, according to Hort, some of them represent a phase in the life-cycle of certain forms included among the bacteria. With scarce an exception every genus of micro-organism has its representative or representatives among the pathogenic microbes, or, put otherwise, every pathogenic microbe has closely related forms or species differing from it in little beyond the fact that the one is virulent, the other non-virulent.

\section{On Allied Species of Virulent and Non-virulent Mrcrobes}

Next it is to be noted that these allied species are found suggestively growing in the cavities or on the mucous surfaces of the body, in the same habitat as the virulent forms, or again in water and food-stuffs which are taken up by the individual.

1 There is to my knowledge only one clear-cut example of an organism which, growing upon one of the surfaces of the body without penetration into the tissues, sets up disease by the diffusion inwards of its toxines-the Bacillus botulinus, which is responsible for one form of meat-poisoning. Strictly speaking, this organism induces an intoxication and not an infection. 
Non-virulent diphtheroid bacilli are so common in the throat as to be the curse of Army bacteriologists: the same may be said regarding harmless diplococci which can only be differentiated from meningococci by a relatively elaborate technique : only within the last few weeks the frequent presence of these "parameningococci," affording the "group agglutins" as distinct from the specific agglutins of the meningococci proper, in one military district was on the verge of causing serious trouble; as Andrewes and others have pointed out, the majority of streptococci obtainable from the throat are non-virulent, and yet with them, as I shall point out later, there appear to be an extraordinary number of strains of streptococci obtainable from the throat of varying grades of virulence ; non-virulent spirilla flourish in water just as do the closely-related but virulent cholera spirilla : from the alimentary canal there may be isolated non-pathogenic members of the typhoid-coli group, only distinguishable by physiological or bio-chemical tests from typhoid bacilli, certainly not by any morphological test : harmless gramnegative diplococci morphologically indistinguishable from gonococci are obtainable from the vulva: acid-fast bacilli closely related to the tubercle bacillus of cattle are found in hay, butter, etc.; only after some years of study have the non-pathogenic amoebae of the intestine been clearly differentiated from the Entamoeba histolytica of dysentery - and the list might be greatly extended.

This state of affairs in itself leads to the conclusion that pathogenic microbes at some period, or periods, have originated from the microbes saprophytic upon the body surfaces, or existing commonly in the water and food-stuffs; that they have originated by adaptation of these forms to growth, not merely on, but within the tissues.

\section{The Doctrine of Fixity of Bacterial Species}

This is the simplest, most rational conclusion, but I must point out to you that for long years the dominant German school of bacteriologists upheld vigorously the doctrine of fixity of bacterial species, closing their eyes to the steadily growing volume of data which tended to establish the potential variability of the bacteria. The great leader of German bacterio- 
logists, Koch, in particular supported the doctrine. For twenty years or so he laid down that the tubercle bacillus which he had discovered was identical in its properties from whatever animal it was isolated, whether from man, the ox, or bird, opposing Straus and others when they called attention to the marked distinction in the properties of the human and avian types. You will remember how suddenly and dramatically he turned round at the great Tuberculosis Congress in London, announcing that the human and bovine forms of bacillus were absolutely distinct species-incidentally without any acknowledgment of the work done by American workers, Theobald Smith, Dinwiddie and Frothingham, in establishing these differences between the two types, and incidentally, also, he being a Government servant, to the apparent material advantage of the agrarian party in Germany. Many of my readers will recall the consternation of the hygienists and of the various governmental Agricultural Departments when he pointed out that, being distinct species, there was little or no danger of the disease being conveyed from cattle to man by the milk. It has cost Great Britain alone thousands of pounds and years of work of a Royal Commission to demonstrate Koch's error, and show that notwithstanding recognizable and characteristic differences between the typus humanus and typus bovinus, nevertheless intermediate forms exist, and that the typus bovinus can obtain a lodgment and develop lesions, more particularly in susceptible children during the milk-drinking period. Koch would never have perpetrated his successive blunders but for his firm conviction that environment is incapable of altering the properties of bacteria.

Koch's attitude in this matter has affected me from the fact that from the time of my thesis for the M.D. at Cambridge I have taught the variability of the bacteria, ${ }^{1}$ as again from the fact that in 1899, many months before Koch's notorious pronouncement, I had, in an address delivered to the Canadian Medical Association at Toronto, ${ }^{2}$ brought together all the data bearing upon the difference between human and bovine tuberculosis and their causative agents, and at a request which reached

1 Vide the article upon the "Variability of the Bacteria" reprinted as Chapter I. of Part II. of this volume.

2 On the significance of Bovine Tuberculosis and its eradication and prevention in Canada (read before the Canadian Medical Association, Toronto, August 30, 1899), Philadelphia Medical Journal, December 30, 1899. 
me through the German Consul in Montreal, had forwarded copies of my address to Berlin. Listening to Koch's speech, I could not but feel that he had utilized and perverted the data I had brought together. Basing myself upon those data, and upon experiments which showed that inoculations of the human bacillus would not set up tuberculosis in cattle, I had urged the Canadian Government not, as Koch suggested, to cease the endeavour to eradicate tuberculosis among cattle, but on the contrary to set aside a restricted area, such as Prince Edward's Island, kill or remove all cattle affording the tuberculin reaction, and then to proceed to raise pedigree and other herds in these protected areas, guaranteed free from Tuberculosis, wherewith to supply the rest of Canada, and if need be the world, with sound stock, the danger of these cattle becoming infected from tuberculous human attendants being, as I pointed out, practically nil. And as the Canadian authorities, pending the findings of the British Royal Commission, took no action, I venture to repeat the recommendation in England as regards the Channel Islands and the Isle of Man. As it is, I believe that the former are already relatively free from bovine tuberculosis. It would not be a difficult matter, therefore, to ensure that the whole original stock of Jersey and Guernsey cattle become absolutely free from this devastating disease, and that the value of the herds become markedly augmented.

Saying this it would seem that I myself support the doctrine of the fixity of bacterial species, and even of bacterial strains, that I believe not in the adaptive qualities of the bacteria, but in their conservatism. The truth is that I believe in both. As regards these two strains, there are some very interesting data the relationship of which has still to be worked out. Thus, as regards other animals such as the rabbit, the typus bovinus is the more virulent, and while the typus humanus cannot be conveyed to cattle save by the exhibition of unduly massive doses in young and little resistant animals, the typus bovinus can be conveyed to human beings in a more natural course. But here again it is the young and less resistant individuals that are susceptible. Nevertheless if, as Krumweide of New York and others have shown, some 25 per cent of tuberculous children under five years afford the bovine type, how is it that this type is almost unknown in adults? The evidence at our 
disposal indicates that quite a large proportion of cases of active tuberculosis are but the recrudescence of tuberculosis gained in childhood. May there not be a fallacy, therefore, in the argument that cases affording bacilli of the human type have been infected by other human beings ? The relative rarity of bacilli of the bovine type in adults demands either that $(a)$ the bovine infection acquired in childhood is peculiarly fatal, so that all affected die in their early years (and this is wholly contrary to the evidence at our disposal); or (b) that on the contrary, in a large number of cases, it gradually dies out and is replaced at a later date by infection from another human being with the typus humanus (and of this again there is no clear evidence); or $(c)$ that gradually, through long residence in a human environment, the bovine form takes on the character of the human strain. The fact that we from time to time encounter intermediate strains seems to favour this third view. But to my knowledge no decisive observations have so far been made. 


\section{CHAPTER III}

THE NATURE OF THE ADAPTATIVE PROCESS IN THE BACTERIA

IN fact, studying the bacteria, two apparently opposite and contradictory facts are to be made out: on the one hand they are extraordinarily conservative to the extent that, given the same environment, the same food-stuffs, habit of life, temperature conditions, etc., they manifest the same characters, and even, within certain limits when the environment is altered, they retain their original characters with a certain obstinacy. Typhoid bacilli from cases of Enteric show scarce recognizable differences, ${ }^{1}$ whether occurring in England, Australia, North America, or Japan. And on the other hand, alter their environment beyond certain limits-their food-stuffs, temperature of growth, etc.and their characters are liable to alter. Grow the diphtheria bacillus, for example, in peptone broth, in milk, or upon peptone broth agar, and this at the same temperature, and at the end of twenty-four hours the differences are recognizable under the microscope. Nothing, in fact, is more easy to demonstrate than this capacity on the part of bacteria as a class to vary according to alteration in environment.

\section{Fluctuations, Mutations, and Modifications}

Winslow divides these variations exhibited by bacteria into three orders, (1) fluctuations, (2) mutations, and (3) impressed variations. Some term these last, modifications. Personally,

1 Several years ago Ehrlich pointed out to me the difference between the results of his diazo reaction in our Montreal cases of typhoid as compared with his results in Germany, and suggested that we might be dealing with distinct strains of the B. typhosus. Sir William Osler tells me that similarly he is impressed by the difference in the bodily reactions to tertian malaria as acquired in the Salonica area, and as he was familiar with it in Maryland. 
despite its heresy, my opinion is that the majority-if not allof the last two are substantially of the same order.

As fluctuations are designated those familiar variations in one or other quality which distinguish the individuals of the same sept or clan from one another. The various members of the families to which each of us belong, while human beings, are not identical, but vary within certain limits in height, breadth, weight, length of arm, and so on. The various descendants of a single individual, though they may approximate in these particulars to the parents, vary from that parent in a very obvious manner. Taken together the members of a tall family or strain may, as a group, average above the normal, or of a stumpy strain below the normal, but, with this, there is individual variation in height. And so it is with bacteria. With these fluctuations we need not concern ourselves-they are in the strictest sense individual: descendants placed in the same environment need not exhibit them : a man $5 \mathrm{ft} .5 \mathrm{in}$. in height, for example, marrying a woman of $5 \mathrm{ft} .1 \mathrm{in}$. may have children all of them over $5 \mathrm{ft} .5 \mathrm{in}$. in height.

By mutation we mean a very different phenomenon. From causes we cannot as yet wholly fathom, a Shakespeare may be the offspring of a country butcher : in a field of clover a plant may show itself with quadripartite in place of tripartite leaves. The same phenomenon is to be observed among bacteria, but studying these forms devoid of sexual conjugation, the question is whether we deal with one or two orders of events. Let me give an example to the point. It has been pointed out by Barber 1 that while the ordinary culture of Bacillus coli shows separate short, stumpy bacilli, occasionally while examining smears from such we encounter filamentous chains of cells. He points out that all the bacilli have grown floating in the fluid medium : all appear to have been subjected to the same influences, and yet here and there a bacillus when it divides has its progeny remaining united instead of floating away to lead an independent existence. He found that by isolating a filamentous form and breeding from it he could obtain a new race constantly showing a filamentous arrangement, with cultural characters distinguish-

1 Kansas University Science Bulletin, iv., 1907, No. 1. Only recently in the British Medical Journal of Jnne 16, 1917, Mr. Ainley Walker has called attention to the same phenomenon. 
ing it from the ordinary B. coli and with fermentative powers more active than normal. If we accept his argument, here is a typical example of a true mutant, for the development of which the only satisfactory explanation is, that there has been some accidental protoplasmic inequality in some one cell division, and that one of the two resultant cells has by this inequality gained in excess-or lost-some one protoplasmic constituent; thereby a new equilibrium has had to be established between the organism and its surroundings, this adaptation showing itself in some alteration of properties.

I fancy that we all look askance at any invocation of "accident" to explain natural phenomena, regarding this as a negation of natural law, as something reprehensible, evasive, and almost dishonest, in that the more we study nature the more it is impressed upon us that there is a cause for everything. In this very instance it may be pointed out that while all organisms floating in a fluid medium appear to be subjected to the same influences, as a matter of fact they are not. In such medium organisms at the surface are exposed to an environment which differs widely from that of organisms totally submerged, and the analogy may be drawn between what occurs here and the tendency exhibited by many yeasts to exhibit septal, filamentous forms on surface growths, and isolated torula forms when submerged.

That in the Bacteria Mutations are Impressed Variations

So far as I can determine the majority of instances of bacterial mutation depend or follow upon a preliminary alteration of environment, and these alterations must be regarded as the controlling factors, resulting in impressed variations. Numerous cases are on record in which, by growing bacteria in media containing certain sugars, eventually they have gained the power to split up and ferment these sugars, or in media, like milk, containing fats, have developed lipolytic powers; have, that is, adapted themselves to feed upon the new food-stuff. Close upon thirty years ago the late Sir Lauder Brunton and Macfadyean ${ }^{1}$ reported experiments of this nature, showing that by growth in the presence of particular sugars certain species

1 Proceedings of the Royal Society, xlvi., 1889, 542. 
of bacteria acquired the power of fermenting them. In 1897 Miss Peckham ${ }^{1}$ succeeded in modifying the typhoid bacillus so that it would produce indol, one of the diagnostic features of this micro-organism being that it is a non-producer of indol. In 1906 my late colleague Dr. Klotz, ${ }^{2}$ now Professor of Pathology at Pittsburgh, studied the assumption of these sugar-fermenting powers, and the loss of the same, by a member of the typho-coli group, the B. perturbans. The following year Twort ${ }^{3}$ demonstrated that he could cultivate paratyphoid bacilli so that they will ultimately ferment saccharose, typhoid bacilli to ferment lactose and dulcite, dysentery bacilli to ferment saccharose. Interestingly enough these observations date back to the founder of the science of bacteriology, to Pasteur and his classical observations upon fermentation. You will remember how he discovered that ordinary tartaric acid is optically inactive because it is a combination of equal amounts of the two, dextro- and laevorotatory, isomers, and that he obtained the laevo-rotatory form in a pure state by the action of moulds, which used up the dextrorotatory acid leaving the other isomer untouched. But doing this, he noted that if he continued the experiment the rotation to the left reached a certain point and then steadily diminished; in other words, that after using up the food of election the mould now turned itself to assimilate and use up the laevo-rotatory food. Now, as a general rule, dextro-rotatory organic substances alone are produced and utilized by living animals.

The steps by which bacteria have been found to gain these powers of adapting themselves to and utilizing unaccustomed food-stuffs are most instructive, and are best shown by the observations of Massini, ${ }^{4}$ Penfold, ${ }^{5}$ and other observers of the last few years. These observers employed a solid medium, a peptone broth agar medium (containing, as usually made, a little muscle sugar), upon which the bacteria studied can be grown readily, and to this they added in the process of preparation the particular foreign sugar or glucoside, and made surface growths of the bacteria. Where this is done it is found that the surface

1 Journal of Experimental Medicine, ii., 1897, 549.

2 Journal of Infectious Diseases, ii. (Supplement), 1906, 35.

3 Proc. Royal Society, Biol. lxxix., 1907, 329.

- Arch. f. Hygiene, 1xi., 1907, 250.

s Journ. of Hygiene, xii., 1912, 195. See also Müller, R., Centrlb. f. Bakt. xlii., 1908, 157, and ibid. Abt. 1 Orig. lviii., 1911, 97. 
colonies at first show no change from the usual type of growth, but after several days little papillae appear on the surface of the colonies. These have a more opaque white appearance, and, if litmus has been added to the medium as an indicator, the papillae take it up and assume a reddish colour, this indicating the production of acid in the papillae, whereas it is not being produced elsewhere in the colonies. The Typhoid bacillus, for instance, does not normally ferment isodulcite, but if the Typhoid bacillus be planted upon isodulcite agar, in five days these papillae appear-and in these papillae the bacilli are " mutants" ; they have gained the power of fermenting this sugar. Test the bacilli from the non-papillated portions of the colonies, and they have gained no such power. If bacilli be carefully removed from one of the papillae and be plated on isodulcite agar, it is found that a race of Typhoid bacilli has been gained, all the members of which have this new power of immediately fermenting isodulcite. The bacilli constituting the non-papillated areas are unchanged; they cause no dissociation of the isodulcite, although if plated similarly on isodulcite agar, their colonies will repeat the phenomenon : in five days scattered papillae will show themselves which present the new property.

These, again, at first appear to be excellent examples of what may be termed true or "chance" mutations. Obviously not all the bacilli in the colonies take on the power of utilizing isodulcite, dulcite, or other sugar, as a food-stuff, only certain individuals. But on further study the further facts are to be noted-first, that the phenomenon is constant-take any typhoid bacillus, treat in this way, and in five days or so the dulcitefermenting papillae will show themselves; and, secondly, these dulcite-fermenting individuals present themselves constantly in a particular relationship and superficial position. Bacilli which are at or near the surface of the agar and obtain from it abundant food have had no need to adapt themselves to the new food-stuff. It is those furthest away, separated from the agar by several layers of bacilli, that manifest this new property, those which from their position receive only the diffused foodstuffs which have passed by their more fortunately placed comrades lower down. It looks very much as though, in the struggle for existence, these bacilli that have found themselves deprived of their accustomed food-stuffs have taken to absorbing 
and dissociating the unusual food-stuff faute de mieux, that, in short, we have here a repetition of Pasteur's original observation that when the accustomed food-stuff is used up, the unaccustomed will be attacked, just as we to-day are making a virtue of necessity and are thriving upon potato-and wheatsubstitutes. As a matter of fact, if the experiment be modified so that all the multiplying individuals are subjected to the same environment-if, that is, instead of employing a solid medium a fluid medium containing the new glucoside be taken and the bacilli be grown on this, then the conditions of experiment can be so arranged that not some but all the bacilli acquire the property of fermenting the unusual glucoside. All, that is, acquire the new property.

\section{On Impressed as distinct from Chance Variations}

If $I$ remember aright, this was first demonstrated in 1913 or 1914. Unfortunately I am away from my library and notes, and have been unable to find the reference. In my dilemmafor I did not wish to make the vague statement that this was so without affording a reference-my colleague Major F. B. Bowman, Officer in Command of No. 2 Canadian Mobile Laboratory ${ }^{1}$ at Folkestone, with great kindness came to my rescue and willingly conducted the very simple experiment - an experiment so simple that it can easily be repeated. The underlying principle of it is that the bacteria must not be supplied with an abundance of alternative food-stuff. They are accustomed to obtain their carbon from amines (proteins) when carbohydrates are not present. Do not, therefore, use a peptone broth of the usual concentration. Some years ago I pointed out that with members of the typhocoli group $10 \mathrm{ccm}$. of peptone broth added to a Winchester quart of sterilized water affords upon inoculation a pronounced turbidity in twenty-four hours, in other words, an active growth of the bacilli.

Major Bowman, therefore, made up such a diluted peptone bouillon-or "Soupe maigre"-with 1 per cent added of the unusual glucoside in this case Isodulcite, or Rhamnose, ${ }^{2}$ along

1 Now No. 1 Canadian Central Laboratory.

2 For which I am indebted to Professor Rosenheim of King's College and (through Captain Tulloch) to Professor Mackenzie of Aberdeen. 
with Azolitmin as an indicator. He inoculated a relatively large quantity of this medium with a pure culture of B. typhosus obtained from the Army Medical College at Millbank, having previously tested the strain and having found that it was absolutely typical in its fermentation reactions (producing acid, but no gas, with Glucose and Mannite, while Lactose, Saccharose, Dulcite and Isodulcite gave negative results).

Each day he made plates from the main culture upon azolitmin-isodulcite-peptone-agar, with the following results : The main culture in $100 \mathrm{ccm}$. of 1 per cent azolitmin dilute broth showed no change until the fifth day, when the blue solution took on a slight change, showing that some acid was being produced. At the same time the agar transplants of the fourth day exhibited a pinkish tint of the medium showing beginning fermentation, while the agar transplants of the fifth day at the end of twenty-four hours showed a distinct pink halo around every colony-as did also the plate of the sixth day. (I give Major Bowman's note as Appendix II., explaining that up to the last moment I hunted for the lost reference, and thus only gave him time to perform the experimentum crucis. Nor indeed, knowing how fully occupied he was with routine military work, could I ask for or could he offer more.)

And here is the point: add typhoid bacilli to distilled water containing 1 per cent isodulcite, and they are not killed off, that is to say, they undergo no greater reduction in number than if added to pure distilled water. If we dealt with chance variation and the survival of the fittest, some of the colonies on the agar at the end of four or five days would be unchanged, others would show surrounding reddening of the azolitmin medium. But all show the reddening.

Here then, contrary to Bateson, we have evidence of positive acquirement from without, and, contrary to the Lankesterian dogma, we can so arrange our experiment as to obtain, not evidence of variation in many directions, the favourable variants alone surviving, but evidence that organisms placed in a given environment all vary in one identical direction with clockwork regularity. It is no matter of haphazard : we can of a certainty induce the particular variation in a particular bacterial species.

Or if Professor Bateson desires a perfect example of variation by loss of factors, we can afford him an equally telling 
example which, by the constancy of the results obtained, is infinitely superior to his sportive production of a salmon-coloured "Coral king" Primula. It is the classical example adduced long years ago by Pasteur and his lieutenants, Roux and Chamberland-a bacteriological commonplace, since it is the basis of Pasteur's method of vaccination against anthrax, which, commercially speaking, has saved France hundreds of thousands of sheep and cattle and many millions of francs. By exposing cultures of anthrax bacilli to a heat a degree or two below that which will kill them, or again by the action of minute quantities of certain antiseptics added to the medium of growth, races of anthrax bacilli are obtainable which have wholly lost the power of spore production. These races may be grown for months and years-for thousands and, indeed, hundreds of thousands of generations-upon the ordinary media of the laboratory without regaining this striking and characteristic property. Were a culture of this strain given to a systematic botanist without information as to its origin, he most assuredly could classify it as a distinct species. Here again is no matter of chance variation in many directions-all the individuals of the colony subjected to the particular temperature become asporogenous.

\section{On Exaltation of Virulence}

Now if these things be true regarding other properties, they must be largely true regarding the virulence and pathogenic powers of bacteria. We know in the first place that virulence, when it is the property of any bacterial species, is capable of great modification. This, we observe, is not a matter of chance. We know methods by which we can surely exalt or depress that virulence. We know that by "passage " of a virus through a succession of animals of one species we can rapidly intensify the virulence for animals of that species, while simultaneously we may by this procedure reduce its virulence for animals of another species. We can, with Marmorek, take a culture of streptococci so weak that only the most susceptible animals are influenced by it, and then only by the exhibition of relatively enormous amounts of the culture to the new-born (which have least powers of resistance); but recovering the cocci from these 
we can by careful passage through selected animals so augment the virulence that eventually the hundredth or the thousandth of a drop of a twelve-hour culture, or even much less than this, may cause the death of strong adults in six hours or less.

It is quite possible that these streptococci may eventually afford us the best material for demonstrating the development of pathogenic from harmless bacteria. They are singularly widespread in nature: they are common on the skin, where the temperature is lower than it is in the passages of the body ; they are constantly present in the mouth, and, as pointed out by Andrewes, the majority of cultures obtained from the mouths of healthy individuals are harmless when inoculated into lower animals. Certain it is, also, that after long years of work and the investigations of numerous trained observers, we seem to be almost as far off as ever from establishing the dividing lines between different species-if species proper they are-of streptococci. Of late, it is true, we are accustoming ourselves to recognize and attribute particular properties to Streptococcus faecalis, Streptococcus equinus, haemolytic streptococci, etc.; we have no doubt regarding the existence, and, what is more, the utility of recognizing these "strains." But if we depend on fermentation tests (and it is only by biochemical and not by morphological properties that we can distinguish between the forms), then, as shown by Ainley Walker, continued growth in the laboratory results in changes of the fermentation tests, so that there is as much evidence that we deal with the different strains of one species which exhibit differences in consequence of their previous habitat, environment, and history, as there is that they constitute distinct species. For a time it looked as though Rosenow, of Chicago, had definitely settled this point, and by passage through animals had converted non-haemolytic into haemolytic strains, and even streptococci into pneumococci (which have many properties in common). But Holman, of Pittsburgh, has brought forward such forcible criticism of Rosenow's results, calling attention to the frequency of combined growths of more than one strain or species of streptococci, and the need for pure cultures gained from isolated cocci, that before Rosenow's work can be accepted in its entirety, this laborious confirmatory work must be undertaken. Saying this, I firmly believe that Rosenow is along the right lines-and pragmatically 
speaking, his observations and hypotheses gain confirmation from the clinical observations of Billings ${ }^{1}$ and the Chicago school. I like to flatter myself with the thought that an address which I delivered in Chicago in $1899^{2}$ was the starting-point for these activities.

\section{The Experimental Conversion of non-Pathogentc into} Pathogento Microbes

Years ago Vincent, one of the most distinguished of French bacteriologists, to whom we owe the recognition of the relationship between the Bacillus fusiformis and Vincent's angina, or better, Vincent's disease, ${ }^{3}$ described how by placing broth cultures of a perfectly harmless, non-pathogenic microbe from the soil, the Bacillus megatherium, in hermetically sealed celloidin capsules, and inserting the capsules within the tissues of lower animals, he was able to accustom, or adapt, them to growth within the organism of warm-blooded animals. ${ }^{4}$ By simple subcutaneous or intramuscular injection of a few $\mathrm{ccm}$. of a broth culture of this bacillus into the rabbit, for example, no harmful results ensue : the bacilli are rapidly destroyed. Placed in delicate celloidin capsules the bacilli gain nourishment from the diffused lymph, and are at the same time protected from the phagocytic action of the leucocytes. By this means he announced that the bacilli gradually gained pathogenic properties. That was close upon twenty years ago, and unfortunately I cannot hear that this experiment of Vincent's has been repeated and confirmed. When some years ago, in my laboratory at McGill, Dr. Charles Higgins employed this method with tubercle bacilli of the typus humanus, inserting celloidin capsules containing a glycerine broth culture of these into the tissues of the calf, even after some months he obtained no clear evidence of modification. The capsules became surrounded by dense fibrous tissue, and where the cultures did not die out they showed no assumption

1 Local Infection, Appleton, 1916.

2 "Latent Infection and Subinfection," American Medical Assoc. Journal, Dec. 1899.

a Better, because, as Vincent himself pointed out, the organism may be associated not merely with a tonsillitis (angina), but also with a special form of stomatitis and gingivitis, while also the conjunctiva may be affected, and the organism may grow upon the glans penis, setting up a balanitis.

' Ann. de l'Inst. Pasteur, xii., 1898, 785. 
of the characters of the typus bovinus. Vincent is so careful an observer that I do not like to reject his work. At the same time I confess I should feel more satisfied had it been confirmed by other workers. ${ }^{1}$

It is here in London, at University College, that what appears to be the crucial demonstration has been afforded by a pair of well-known and capable workers, and that by the employment of a most ingenious method. Every medical man nowadays is familiar with the name at least of anaphylaxis, even if he is unable to grasp the nature of the paradoxical phenomenonthe phenomenon, that is, of inducing not immunity, but the reverse condition of increased susceptibility to foreign proteins, by the injection of the same into the tissues. If minute doses of any protein foreign to the organism-even if it be so harmless a one as egg white-be introduced parenterally, i.e. into the tissues as contrasted with alimentary canal, and some eight days or more later a second and larger dose be similarly introduced, instead of tolerance having been established, the very reverse condition is found to have been set up. Grave constitutional symptoms supervene, and in animals like the guineapig death may ensue with startling rapidity in the course of a minute or two. I believe that I was the first to point out, ${ }^{2}$ and that with Professor Vaughan's entire concurrence, that these phenomena are explained by that observer's most remarkable studies upon the dissociation products of proteins. As he has abundantly demonstrated, ${ }^{3}$ treated with alcohol rendered alkaline by the addition of caustic soda, all true proteins, including the bodies of bacteria (or their protein constituents), become dissociated into an intensely toxic and a non-toxic moiety. The explanation, therefore, of anaphylaxis-and this is confirmed by Abderhalden's later work-is that it is the first stage in the production of immunity: the organism has reached the stage of producing enzymes which dissociate the proteins into a toxic and a non-toxic moiety, but has not attained to the later stage in which specific enzymes are developed, dissociating the toxic

It deserves note that the bacteriology of soil bacteria has been worked out very imperfectly, and it is evident that more than one species has been described as $B$. megatherium. It may therefore be that the B. megatherium of other workers is not the same organism as that employed by Vincent.

2 Principles of Pathology, 1st ed. i., 1908, p. 509.

See Vaughan, Protein Split Products. Philadelphia, Lea and Febiger, 1913. 
moiety into harmless derivatives. And these anaphylactic phenomena are obtainable, let me repeat, by the introduction of bacterial proteins into the tissues, and even of living bacteria.

So long ago as 1904, W. V. Shaw, ${ }^{1}$ and later Schloss and Foster 2 in 1913, called attention to the fact that in monkeys arthritis only occurs after a second intravenous injection of streptococci, the first setting up no obvious changes. In 1911 my late colleague in Montreal, Dr. Duval, ${ }^{3}$ now Professor of Pathology at Tulane University, New Orleans, when studying the bacteriology of leprosy made the curious observation that while by a single inoculation of the bacilli which he had isolated and cultivated he was unable to produce lesions in monkeys (Macacus rhesus), lepra nodules containing the bacilli could be obtained as the result of inoculations repeated at short intervals. He and Couret conclude (p. 303): "That the infection is more likely to follow where sensitization is first established is definitely proved by the specific experiments that we have carried out upon a variety of laboratory animals. The first injection, we assume, sensitizes the animal, and may consist of either killed or viable lepra bacilli."

Now, starting from these phenomena of anaphylaxis, Thiele and Embleton, ${ }^{4}$ working at University College, were led to the happy idea of introducing harmless bacteria into the tissues, and then in a week or ten days later giving a second injection of the same bacteria. Those first injected being non-pathogenic became disintegrated, and liberating their proteins were found so to influence their host that upon a second injection into the now susceptible animal, the bacteria, instead of being destroyed, took on active growth, and what is more, the anaphylactic state, by permitting the active growth within the weakened organism, was found by them to lead to an associated adaptation to the unaccustomed environment.

The Bacillus mycoides is an absolutely harmless microorganism common in garden soil, and growing in nature only at a low temperature. It is in fact destroyed at body heat.

1 Journ. Path. and Bact. ix., 1904, 158.

Journ. Med. Research, xxix., 1913-14.

Sourn. of Exper. Med. xiii., 1911, 374, and Duval and Couret, ibid. xv., 1912, 292.

'Zeitschr. f. Immunitätsforschung u. exper. Therapie, xix., 1913, 643. 
Following the classical experiment on adaptation of Dallinger ${ }^{1}$ in the 'seventies, they first gradually accustomed the bacilli to grow at body temperature by cautiously increasing the temperature of growth, degree by degree, over a considerable period, until they would multiply instead of being killed at $37 \cdot 5^{\circ} \mathrm{C}$. Next they sensitized animals by injecting into them a fair dose of the killed bacilli. Ten or fifteen days later they gave a second injection of the live bacilli, recovered the bacilli from the tissues of the animals, and repeated the process with another animal of the same species.

Doing this they found that the bacillus which had been motile lost its flagella, acquired a capsule, became stumpier and thicker, and, to their astonishment, acquired all the characters of the anthrax bacillus, both morphologically and in the lesions it produced. The harmless, naturally non-pathogenic bacillus became in fact so virulent that a small amount of the culture introduced into guinea-pigs killed them in twelve hours.

Nor is this the only non-pathogenic organism that these observers have induced to become pathogenic by this method of preliminary anaphylaxis. They have obtained parallel results with other non-pathogenic microbes (B. phlei, B. smegmatis, etc.).

Their work has been confirmed independently by Kniest Faber, ${ }^{2}$ who noted that employing virulent streptococci he obtained arthritis in rabbits upon a first injection, but with a weakly pathogenic form such as Streptococcus mitis var. viridans he found that in order to set up the lesions of arthritis he had to give rabbits two sensitizing doses; that these doses had to be narrowly specific; he had, that is, to employ the particular strain of streptococcus. Preliminary intravenous injections of the S. mitis set up no arthritis, but if he injected it direct into the knee-joint, so setting up a localized arthritis of the one joint, allowed this to subside, and now gave an intravenous injection of the same organism, there followed immediately an acute arthritis of the treated joint. This form

1 Proc. Roy. Soc. xxvii., 1878, 332. Dallinger, it may be recalled, gradually, over long months, raised the temperature at which the flagellate infusorian, Dallingeria drysdalei (Kent), would grow and multiply, from $60^{\circ} \mathrm{F}$. to $158^{\circ} \mathrm{F}$. $\left(=70^{\circ}\right.$ C.)-i.e. some $20^{\circ} \mathrm{C}$. higher than that causing the death within a few minutes of ordinary (untreated) vegetative infusoria.

2 Journ. of Exper. Med. xxii., 1915, 615. 
of sensitization throws an interesting light upon the relapses so frequently noted in streptococcal infections.

Observe what this signifies. It signifies that there is a means whereby organisms that are saprophytic and non-pathogenic, living upon the surface of the body, whether on the skin or upon the moist mucous membranes, can become pathogenic, invading and living within the tissues. What is necessary is that these organisms first become habituated to growth at the body temperature and then gain entrance through some solution of continuity, and that, gaining entrance, they in the first place induce the anaphylactic stage, so that when some week or more later organisms of the same species gain entrance into the supersusceptible tissue, whether through a lesion or through conveyance by phagocytic leucocytes, they now are able to multiply within the tissues, and multiplying acquire pathogenic properties; in other words, adapt themselves to their environment, gain the power of assimilating and dissociating the proteins of the body, in which process they bring about the production of disintegration substances, of toxic proteins or amino-acids, in other words of toxines.

But, it may be asked, if the process is so simple as this why do we not observe time and again the evolution of new diseases ? In answer to this question I would urge that the matter is not so simple as it seems. In the first place it will be observed that a particular concatenation of circumstances is requisite, namely, a first entrance of bacteria into the tissues through some lesion, and then, when the anaphylactic stage is at its height, a second entrance of the bacteria in much larger numbers, for anaphylactic phenomena only show themselves when the second exhibition of the protein (in this case of the bacteria) is larger than the first, and when a definite interval of at least seven days intervenes before that second exhibition. As is well shown in Pasteur's method of inoculation against rabies, when a virus is inoculated at successive daily intervals no anaphylactic phenomena are manifested. And in the second place it must be remembered that ordinarily the habitual growth of bacteria upon the surface of the body favours the production, not of anaphylaxis, but of immunity. It is by now well established that from the mucous surfaces of the body bacteria are being constantly introduced into the tissues, in driblets as it were, through the agency of leucocytes 
which wander out on to the mucous surfaces, take up bacteria of various orders, and wander back again into the tissues-a process which leads to the gradual habituation of the organism to the dissociation products of the bacteria thus incepted, or in other words, to a progressively increased capacity to dissociate and digest the bacteria. Now, where immunity is already established, anaphylaxis (the preliminary stage, as I have pointed out, in the process) cannot be redeveloped.

Accepting these very striking studies of Thiele and Embleton -and as I have pointed out they gain confirmation from the independent observations of several observers-we see how from time to time infectious or epidemic diseases may arise de novo through the evolution of more specialized pathogenic forms from the more widely diffused saprophytic micro-organisms growing upon the surfaces of the body. We can understand, for example, how it was that Diphtheria came into prominence only at the beginning of last century, when Bretonneau of Tours, Napoleon's great army doctor, afforded his classical description. It is impossible to believe that a disease with such obvious clinical manifestations and such sharply-cut features should have been present infecting man from the beginning of history without a single physician in all the centuries recognizing and describing the throat condition, or the rapid devastation set up by the disease. Diphtheria gains its simplest explanation as being due to the acquirement within recent times of virulent properties by some previously harmless diphtheroid bacillus growing in the throat and upper respiratory passages. And so it has been with Syphilis, with "Trench shin," Trench fever, Sweating sickness, and, if with these, then with infections in general.

I admit that there may be contributory causes, that particular environments may favour the origin or reappearance of particular diseases, as again that local tissue environment may determine particular selective development of virulence. As regards the former we have the remarkable history of Epidemic War Nephritis, so well brought out at a recent meeting of the Medical and Therapeutic section of the Royal Society of Medicine, with its first known appearance in North America as an epidemic beginning in the spring when, during the War of the Rebellion, the campaign in the central region became a matter largely of trench warfare; the absolute disappearance of this particular 
type of acute nephritis for over fifty years, to make its reappearance in 1915 in the trench warfare along the western front. This is a very remarkable history, but until the causative agent is determined we can do no more than suggest that here is a disease which shows itself when man finds himself in a particular environment, dying out when that environment is departed from. As Professor Welch of Johns Hopkins pointed out some years ago in his Huxley lecture, ${ }^{1}$ there is evidence that if man can adapt himself to altered environment, so can microbes; that if man can protect himself against the toxic action of the bacteria with which he is surrounded, so on their part bacteria can protect themselves against man by increasing their virulence and altering their properties according to circumstances.

It is in this connexion that the recent series of studies by Professor Rosenow upon the elective localization of streptococci are of extraordinary interest. ${ }^{2}$ Briefly, by employing deep tubes of fluid culture medium, which permit streptococci to grow at the oxygen tension most favourable to the particular strain, and by inoculating young growths which still retain the final qualities impressed upon them by development in particular tissues and localities, he has been able to show that strains obtained from the gall-bladder in cases of cholecystitis, when inoculated intravenously into animals of the laboratory, are peculiarly apt to localize themselves in the walls of the gall-bladder and there set up cholecystitis; isolated from the joints in man, to set up arthritis, from duodenal ulcers to set up gastric and duodenal ulcers, from multiple neuritis in man to be recovered from the nerve-trunks in the inoculated animal, in myalgia from the muscles. Growth, that is, in a particular tissue in man, endows the streptococcus with an elective affinity for the same tissue in other animals. With abundant material to work upon, first at the Memorial Institute, Chicago, and later at the Mayo Foundation, Rochester, Illinois, injecting various strains of streptococci into animals of the laboratory, and making routine cultures from various tissues, he found that the average incidence of the cocci in or obtained from muscle was 27 ; with cultures from cases of

1 British Med. Journ., 1902, ii. 1105. In the same year Ainley Walker had made the same suggestion (Journ. of Pathology, viii., 1902, 34).

2 See more particularly Journal of the American Medical Association, 1xv., 1915, p. 1687, and lxvii., 1916, 662 ; Journal of Infectious Diseases, xix., 1916, Nos. 3 and 4 (September and October); and Journal of Immunology, i., 1916, 363. 
myalgia this rose to 93 per cent. Cultures of cocci are rarely gained from the spinal cord of the inoculated animals (4 per cent); thirty-six animals inoculated with cultures from a case of sporadic anterior poliomyelitis yielded 78 per cent of positive results, i.e. of growths of streptococci obtainable from the spinal cord.

With these examples before us is it possible for medical men not to believe in "direct adaptation"? According to the environment so do bacteria assume special properties. 


\section{CHAPTER IV}

ADAPTATION TO DISEASE-PRODUCING AGENCIES IN THE HIGHER ANIMALS

BEFore passing to the other end of the scale of living forms, and studying the phenomena of infectious disease in the terms of adaptation, and other adaptations to disease-producing agencies as observed in man and the higher animals, let us pause for a moment and endeavour to summarize the conclusions which may reasonably be drawn from the data brought forward up to this point.

1. The evidence is abundant and conclusive that bacteria are capable of being modified by alterations of environment of certain orders, chemical and physical.

2. The modifications in question that have been brought forward conform with Herbert Spencer's " direct equilibrations ": a particular alteration of environment of certain orders leading inevitably to a particular modification whether of function or of form.

3. By employing appropriate methods it can be shown that not some but all the microbes subjected to particular orders of alteration of environment exhibit the particular modification : the hypothesis of "chance variation" in a particular direction with survival of the fittest is incapable of explaining the phenomena.

Yet other conclusions are to be drawn, but for the time being these suffice for my immediate purpose.

There are two interesting and, I think, basal observations upon adaptation which, affecting protozoal forms higher in the scale than the bacteria, deserve note before passing to consider adaptation in multicellular organisms. The one we owe to the 
botanist Stahl, ${ }^{1}$ who a third of a century ago made the pioneer observations upon what we now term chemiotaxis. He noted that the plasmodium of the myxomycete Fuligo, which at first moves away from a 2 per cent solution of common salt, will after a time (more especially if it has suffered from lack of water) adapt itself to the solution, advancing its pseudopodia into it. In other words, we have here a definite example of direct adaptation during the lifetime of the individual, of change of habit in these lower forms of life based upon physical changes in the surface layers of the individual. The other consists of certain observations of Musgrave and Clegg ${ }^{2}$ upon intestinal amoebae. They noted that these in the large intestine ingest selectively, feeding upon only one of the many surrounding species of bacteria, and that they could succeed in growing the amoebae on the surface of agar plates if they effected a combined growth of the amoebae and this one species of bacillus. By the gradual addition of pure cultures of another bacterial species, with which at first growth may not be possible-indeed, with this form alone afforded in the first place the amoebae died out-the amoebae at first became accustomed to the foreign forms, taking up occasional individuals, until eventually they could be grown in association with the second form alone, to the total exclusion of the first. Here again we observe accustomance and progressive utilization, and in no sense a chance variation. The same observers note that inoculating amoebae plus bacilli into the livers of rabbits they induced abscesses which yielded both amoebae and bacilli, but inoculating the pus from the first abscess into a second rabbit they now obtained abscesses containing amoebae alone: in other words, the amoebae had now adapted themselves to growth in and upon the tissues of the rabbit-an observation which throws light upon the frequency with which entamoebae are obtained in a pure state from hepatic abscesses in man.

It will be seen that so far I have laid comparatively very little stress upon the inheritance of these acquired characters and the development of races or strains endowed with special properties, the result of acquirement. I have done this purposely, being convinced that the proper method of attack upon

1 Botanische Zeitung, 1884, Nos 10 and 12, and Flora, Ixxvi., 1892. 247.

2 Reports of the Bureau of Government Laboratories, Manila, 1904, No. 18. 
the problems before us is to study first the phenomena of individual acquirement of properties. Only when we have gained some knowledge of the factors operative in cases of individual acquirement can we with any security proceed to discuss the inheritance of acquired characters.

Now it is in respect to these new acquirements in the higher animals that we obtain the deepest insight into the process involved, and that through the abundant, not to say overwhelming, studies of the last quarter of a century upon immunity. There is a vast literature upon this subject. Some of the most notable achievements in science, both of the last and of the present century, have been in this province of immunity: the names of the great workers in this domain are known to all men - of Pasteur, Koch, Behring, Roux, Metchnikoff, Ehrlich, Almroth Wright. Tuberculin, diphtheria antitoxin, and the arrest of typhoid fever by inoculation are matters about which every intelligent being is supposed to know something; they are even common subjects of conversation at the dinner-table, be it in London or Glasgow, in Washington or Seattle, in Johannesburg, Dawson City or Adelaide. Yet I do not know of a single general biologist who has dwelt adequately upon their significance in this connexion.

For consider the following facts and think what they signify. There is a certain bean, known as the Jequirity or prayer bean, the seed of Abrus precatorius, from which a highly active and highly poisonous principle can be extracted, abrin, which has been resolved into two proteins, an albumose and a globulin, both, when injected into animals, producing symptoms of like nature. A closely allied active principle, ricin, is obtainable from the castor oil plant, and this has been carefully studied by Professor Cushny, ${ }^{1}$ who has determined that in this case the toxic substance is a globulin, and this so powerful that one gram is adequate to kill one million and a half guinea-pigs, with necrosis of the tissues at the site of injection, acute congestion, inflammation and oedema of various tissues. It is significant that the action is not immediate: the animals appear to be in good health for four or five days ; then symptoms supervene suddenly and there is death in a very short period. There is in short a

1 Arch. f. exp. Pathol. xli., 1898, 439 ; see also in conjunction Osborne and Mendel, Am. Journ. of Physiol. x., 1904, 36. 
curious parallelism with the period of incubation followed by acute disease as seen in bacterial injections.

We owe to Ehrlich a series of observations which further enforce the parallelism. Feed mice or other small animals upon small non-lethal doses of ricin, and slowly increase the dose, and eventually the animals can be given with impunity one hundred times the fatal dose. Or again, with great care, inoculate the animals subcutaneously with minute but progressively increasing doses, taking care to allow any signs of disturbance to pass away before a new dose is given, and by this means the little animals can be made to stand five thousand times the lethal dose.

Now the castor oil plant and its poison are not objects which the ordinary European rabbit or mouse is accustomed to encounter. If we take the blood or other body fluids of control, normal, animals we find that they are absolutely powerless to neutralize the poisonous principle. Take on the other hand the blood serum of the treated and immunized animal and mix that blood serum with the lethal dose of ricin, or ten, or a hundred, or a thousand times the lethal dose (according to the grade of immunity induced), and the poison is rendered inert. That is to say, inject the mixture into another animal of the same species and no effects are induced. Clearly in the immunized animal the blood now contains antitoxic substances, bodies which combine with the toxin or break it down, rendering it inert and harmless.

And these substances have not been produced in the blood, or from the toxin, by some form of chemical activity undergone in the blood itself. Once an animal has been immunized it may be bled and re-bled until many times the normal amount of circulating blood has been removed from it-and notwithstanding the blood continues to be antitoxic. Obviously, in the first place, the antitoxin is produced by the cells of the body, the tissues, or certain of them. Obviously the amount of antitoxin produced is not in direct proportion to the amount of toxin injected; in other words, once the cells, stimulated by minute doses of ricin, have acquired the property of elaborating an antiricin, they continue to produce it for weeks and months. The cells have acquired a new power, that of elaborating antiricin, and they continue to elaborate and discharge this body long after the original stimulus has disappeared. 
Here then is a perfectly clear cut example of direct individual adaptation in the higher animals fulfilling wholly the essential conditions that -

1. We deal with the acquirement of a new property; the acquirement cannot possibly be regarded as the calling into activity of a property previously possessed, either by the individual or by the species: this power to neutralize ricin is something absolutely new.

2. The acquirement is something positive, something additional; there can here be no alternative hypothesis of loss of inhibiting factors.

3. There can here be no possibility of ascribing the new property to the persistence of a chance variation: the power to develop antiricin and discharge it into the blood can be produced in any mouse or rabbit with absolute certainty.

4. There is here no alternative explanation of the survival of the fittest.

I give this as a first example because in it we have no additional factor of proliferative activities on the part of the microbes which in the case of the development of immunity against bacteria and their products may, to those not familiar with bacteriology, be apt to confuse the picture. But what is true with regard to these phytotoxins may be exactly paralleled in the reaction that can be induced in the higher animals against bacterial poisons-bacteriotoxins. We do not in nature find guinea-pigs, for example, subject to diphtheria : by cutaneous inoculation of pure cultures of the diphtheria bacillus these animals can be given a fatal form of the disease, and what is more, the ectotoxins, the substances given off by these bacilli when they are grown in fluid media, are intensely poisonous for these little animals : Roux and Yersin found that $0.0002 \mathrm{mg}$. of the dried-and impure-toxin, obtained by salting it out from the fluid of growth, would surely kill a guinea-pig of 250 grams within three days, or otherwise one gram would kill five million guinea-pigs of like weight. Now exactly as with ricin the exhibition of minute, progressively increasing doses leads to the production of a high order of immunity, and with this the blood serum is found to contain the antitoxin in relatively very large quantities. In other words, the tissues have elaborated, and 
elaborated in excess, a body substance which neutralizes the toxin, and what is more, once started they continue for weeks and months to elaborate the "antibody." 1

As to how these antitoxins are produced: it used to be thought that there was a direct conversion of toxin into antitoxin. But this cannot be. Kroon ${ }^{2}$ has shown that in the horse a single toxin unit (of tetanus) can lead in the process of immunization to the production of $1,000,000$ antitoxin units. ${ }^{3}$ Toxins, it is true, may have some such function in the first place, but later it is the cells themselves which assimilate the necessary constituents and build up and discharge the antitoxins.

For this also has been clearly determined-namely, that it is the cells that take up and fix the toxins which produce the antitoxins. Ehrlich it was who drew the important distinction between those substances which simply diffuse into the cell and those which diffusing become fixed in the cell, calling attention to the fact that antibodies are not formed against members of the former group, against, for example, alkaloids. The members of this group disappear from the blood, but by alcohol and other extractives they can be removed from the tissues. This is not true with regard to the second group, or, more accurately, substances of this second order may be extracted from certain tissues but not from others, and it is the latter apparently which, fixing the toxin, produce the antitoxin. The conjunctiva ordinarily is most sensitive to abrin, which sets up a violent conjunctivitis, but if this be administered locally in minute but progressively increasing amounts, the conjunctiva can be rendered insensitive or immune to this phytotoxin. Römer ${ }^{4}$ rendered the conjunctiva of one eye in the rabbit insensitive to abrin, killed the animal, and now triturated the conjunctiva of each eye with a poisonous dose of abrin. The animal inoculated with the mixture from the untreated eye died, that inoculated with the preparation of the immunized eye survived, or otherwise there was clearly a local production of antitoxin by the

1 Let me admit that this is a barbarous hybrid. There is, however, a certain felicity about it, considering that it is a provisional word which should disappear when we know, as we do not know at present, the exact chemical or physical nature of this class of substances.

Müchener med. Wochenschr., 1898, 321 and 362.

See also McFarland, Textbook of Bacteriology, 3rd ed.

- Archiv f. Ophthalmologie, lii., 1901, 72. 
cells of the treated eye which neutralized the toxin and rendered it inert. And with tetanotoxin the same has been abundantly proved. This toxin in most animals combines specifically with nerve substance. Take a toxic dose and emulsify it with triturated brain substance, and the mixture is inert. ${ }^{1}$ As Metchnikoff pointed out, ${ }^{2}$ the tortoise is not affected by tetanus toxin : after inoculation none is taken up and fixed by the brain or other organs, and no amount of injection of the tetanotoxin will induce the production of antitoxins. Ford ${ }^{3}$ also has shown by other methods that antitoxin production only occurs in individuals whose cells have the power of binding the toxin. The full significance of these observations I hope to discuss in the concluding lecture of this series.

But ectotoxin production is a property possessed by a minority of the pathogenic bacteria. The whole group of typho-coli organisms - the causative agents of typhoid and paratyphoid fevers and bacillary dysentery and allied intestinal disorders,the tubercle and glanders bacilli, cholera spirilla, and the whole group of pathogenic micrococci, whether Gram-positive, like the streptococci and pus-producing cocci, or Gram-negative, like the gonococcus and meningococcus, and the list could be greatly extended: all these, when grown outside the body, do not excrete toxic substances. Yet the body can be immunized against these also, though here the immunity is of a different order. It is not antitoxic, but bacteriolytic. The fluids of the body gain the power of dissolving and digesting the bacteria. The development or acquirement of this power has been gained by all the millions of soldiers in the present war who have been given antityphoid inoculations or, as has been the regulation for more than a year, T.A.B. inoculations-inoculations of mixed vaccines of the Typhoid, Paratyphoid A. and Paratyphoid B. micro-organisms. All this, of course, is perfectly familiar to every one in these days of the great war. By subcutaneous inoculation of carefully measured doses of so many million bodies of dead bacilli, the tissues and fluids of the individual acquire the habit of immediately digesting living bacilli of the particular species employed, and rendering their dissociation products harmless.

1 See Wassermann and Takaki, Berliner klin. Wochenschr. xxxv., 1895, 5.

2 Traité de l'Immunité, Paris, 1901. 3 Zeitschr.f Hygiene, xl 1902, 363. 
And we can easily demonstrate the fact, either within the body itself or in the test-tube. Take the peritoneal fluid of a normal untreated guinea-pig and introduce cholera spirilla into it, and they will immediately begin to multiply. Take another guinea-pig and inoculate it subcutaneously with minute doses of dead cholera spirilla at intervals of a few days, gradually increasing the amount inoculated, and follow this by repeated inoculations of live cholera spirilla ; and now either $(a)$ withdraw some of the peritoneal fluid of the highly immunized guinea-pig and add to a drop of this a suspension of living cholera spirilla, or $(b)$ inject living spirilla direct into the peritonea] cavity, and with a pipette withdraw from time to time a drop of the peritoneal fluid and examine under the microscope, or even (c) take a normal guinea-pig, inject into it five or ten times the fatal dose of cholera spirilla and follow this by injecting, also intraperitoneally, 1 or $2 \mathrm{c.cm}$. of the blood serum of the immunized guinea-pig and from time to time remove a drop of fluid from the peritoneal cavity and examine under the microscope, preferably in each case upon the warm stage. Whichever means of experiment is employed, it is seen that the spirilla lose their motility, swell up, become rounded, then become progressively smaller, and, as Pfeiffer (to whom we owe the reaction) expresses it, they undergo solution "like sugar in water." Any member of this group of pathogenic microbes may be selected with like results. Radziewski, ${ }^{1}$ for example, has observed the phenomenon with B. typhosus, B. pyocyaneus, B. pneumoniae, Streptococcus pyogenes, and Bacillus anthracis. Clearly in the process of immunization the tissues of the body, or certain of them, have gained the property of elaborating bacteriolytic ferments, or substances which digest and dissolve the bacterial bodies-substances not present in the untreated or control animals, and coincidently the treated animal becomes immunized, becomes capable of withstanding and destroying, with little or no general reaction or bodily disturbance, many times what otherwise would be a surely fatal dose. And here is the striking fact: this reaction is in general narrowly specific, so narrowly specific that it is employed by the German School to distinguish between, for example, closely related species of spirilla. If a guinea-pig be inoculated with the cholera spirilla from man, its body fluids

1 Zeitschr. f. Hygiene. xxxvii., 1901, 1. 
have no effect upon the Spirillum metchnikovi which sets up an intense diarrhoea in fowls, or with other non-pathogenic spirilla obtained from water. Only rarely in animals immunized against other species of bacteria do we note the existence of a group reaction-a certain amount of digestion exercised by the concentrated serum upon allied forms, though when the serum is diluted the reaction becomes narrowly specific. For present purposes I need not enter into the evidence afforded that for this bacteriolytic action the coexistence of two bodies is essential, namely the complement present in the body fluids of the normal (and also of the immunized) animal and the immune body, or amboceptor elaborated by the treated animal in the process of immunization, nor into Metchnikoff and Bordet's demonstration of the presence of these two factors. All that is necessary is to call attention to one of the commonplaces of bacteriology that immunization is adaptation, and that while in some cases it is of the nature of exaltation of properties already possessed, in others it is clearly the acquirement of a new property.

\section{Phagocytosis}

I need scarcely say that by a different means of approach, namely through the intimate study of cell function, the admirable studies of Metchnikoff, extending from the early 'eighties of the last until the beginning of this century, ${ }^{1}$ teach the same lesson. Those studies brought together in his two works upon the Comparative Pathology of Inflammation and upon Immunity ${ }^{2}$ demonstrated in a very beautiful manner that in the repair of injury, the destruction of microbes and the production of immunity, the leucocytes play a foremost part, and what is more, that the development of immunity is intimately associated with the accustomance, education, or adaptation of certain orders of leucocytes and other cells. Cells which at first are not attracted towards microbic foci eventually become actively attracted, cells which at first show little or no signs of incepting bacteria eventu-

1 His later studies upon senility and the prolongation of life, while highly suggestive, were not, in my opinion, of the same high scientific value.

${ }^{2}$ La Pathologie comparée de l'inflammation, Paris, Masson, 1892. English translation by Starling, 1893. L'Immunité dans les maladies infectieuses, Paris, Masson, 1901. English translation by Binnie, Cambridge University Press, 1905. 
ally take these up freely and digest them. As I have pointed out elsewhere, ${ }^{1}$ while Metchnikoff, perhaps naturally, minimized the part played by other factors in the inflammatory process, the fact remains that phagocytosis and the acquirement of phagocytic powers play a highly important part in the successful resistance to infection. As shown by Sir William Leishman's simple and beautiful experiment (which formed the basis of Sir Almroth Wright's opsonic technique), there is not one pathogenic microbe which cannot be shown to be taken up and digested sooner or later by the polymorphonuclear leucocytes of the human blood.

Into the more intimate mechanism of this and other acquirements I purpose to enter in the concluding lecture of this series.

In the next place, to carry on my argument, it is to be observed that this is not a temporary acquirement by the individual. The length of time during which the organism continues to elaborate actively these new "antibodies" varies, it is true, according to the micro-organism, but in all cases the amount elaborated is over and above the amount of " antigen " involved, and the production continues long after the antigen, be it toxin or be it bacterial bodies, is used up. For months after a man has been given one or two doses of dead typhoid bacilli his blood serum either contains specific antibodies-agglutinins-or has a different physical constitution; and in some cases where there is not artificially but naturally acquired immunity, that is to say where a man has gone through a severe attack of typhoid fever, agglutinating power has been noted for five years and more after recovery. In fact, this retention of properties by the inoculated or vaccinated men has necessitated the develop-

1 Inflammation, an Introduction to the Study of Pathology, being the reprint (revised and enlarged) of an article in Sir T. Clifford Allbutt's System of Medicine, 4th ed., Macmillan \& Co., Ltd., 1909. This gives an epitome of Metchnikoff's observations. I had the good fortune to be working in Metchnikoff's laboratory at the Institut Pasteur in the winter of 1890 , at the time when he gave his first comprehensive review of his studies upon Phagocytosis and their bearing upon Inflammation, Infection, and Immunity. With his permission I translated the lecture and published it in the British Medical Journal, 1891. Following the publication of the lecture $I$ remember that $I$ had a correspondence with Sir J. Burdon Sanderson in the pages of that journal. It is curious to-day to recall that he could not accept the phagocytosis theory of immunity, on the ground that the education and adaptation of the leucocyte demanded an individual intelligence on the part of the individual cell. 
ment of a completely new technique in our Army Service now that all soldiers are inoculated against typhoid and the two paratyphoid fevers. As Major Dreyer has more particularly emphasized, the mere fact of agglutination is no longer of any diagnostic value. The whole army agglutinates the specific bacilli of all three diseases. Smallpox, naturally acquired, usually confers a lifelong immunity; vaccination, as conferring a mild and modified disease with lessened general reaction, confers immunity for five years or so, although with each repetition of the vaccination the indications are that the period of immunity is materially lengthened.

Now we know that the leucocytes (which evidently are the cells most concerned in the production of "antibodies ") have but a short period of active existence: once they pass into the blood they do not multiply there. We must therefore conclude that the toxins in the first place act upon the mother or germ cells of the lymph nodules and bone marrow, that these gain the new powers and pass them on to successive generations of daughter cells. The same principle must obtain for other active cells of the body.

\section{The LaW of HaBit}

Here we observe the working of a law which to my knowledge, if recognized, has not been dealt with adequately by the biologists in general, a law which, it may be, is coming into the ken of the physical chemists in their studies upon the effects of recurrent stresses upon the crystalline structure of steel and other metals. In a notable address delivered in 1896 Weigert, ${ }^{1}$ the Frankfort pathologist, laid down the law of inertia, the law that once a cell is stimulated to perform a certain act it continues to perform that act for some time after the stimulus has ceased to act. Fraser Harris, ${ }^{2}$ now Professor of Physiology at Halifax, Nova Scotia, in 1900 took up the subject more fully, calling attention to the inertia of rest, as exemplified by the latent period of stimulated muscle, as well as the inertia of active function. For myself there is here something beyond

1 Deutsch. med. Wochenschr., 1896, 635. See also Gesammelte Abhandlungen, 1906, 1.

2 British Medical Journal, 1900, ii. 741, and The Frunctional Inertia of Living Matter, London, Churchill, 1908. 
mere momentum : the functional activity once started, at least in the order of events which come under my ken, continues too long to be comparable with physical momentum. I think I see the setting in motion of a serial or cyclic process of intercellular reactions and counteractions, the one reaction starting the other-a process not contemplated by the physicist when he speaks of either inertia or momentum. I prefer therefore to employ for the present a non-committal term, and to speak of the "law of habit."

Once again, we see this law in action from the bottom to the top of the tree of life. Take, for instance, a culture of a pigment-producing microbe, such as the B. prodigiosus, which grows normally at room temperature, producing on moist bread and other farinaceous foods colonies and plaques that are bloodred: subject the culture for a few minutes to a temperature just below that which will destroy the bacilli, or to a temperature which kept up for another five minutes would kill all the members of the colony. Now from this tube make cultures upon potato flour or starch paste-in fact, upon the most favourable medium -and these first cultures are absolutely colourless. According to the temperature chosen and the time of exposure so, it may be that in three or four days the colonies assume a faint pinkish tinge, or it may be that repeated cultures and weeks of growth on the optimum medium and at optimum temperature have to happen before the pigment production is re-established, thousands of colourless generations having elapsed. More is needed than merely optimum environment. It is as though the biophoric molecules of the bacilli have been converted to a simpler constitution by the heat, or certain specific side-chains destroyed, or it may be certain enzymes in the bacterial body, so that, while the living molecules are still capable of multiplying, the habit of pigment production is lost, and although all the components are present in the foodstuffs presented, only very gradually are they built together to produce the pigment. And the same is equally true, as I have already indicated, with regard to positive acquirements : it takes days and sometimes weeks before bacteria take on the active dissociation of a foreign sugar, or glucoside, or alcohol, or fat, but once this power is acquired it is apt equally to be retained for generations in the absence of that particular fermentescible substance, just, to recall, as the 
bacillus tuberculosis, typus humanus, may exist for months in the body of the calf without losing its specific or typical properties.

But here, also, we see the action of another general law, which I owe to my old teacher James Ross the neurologist, of Manchester, the law namely that properties which have been most recently acquired are those which are most easily lost, with its corollary that the longer a given environment acts upon the individual and the race, the more firmly fixed become the properties acquired in consequence of that environment. Ross used to point out that it is the muscles which distinguish anthropoids from other mammals-those of the thenar and hypothenar eminences-which first atrophy in systemic nervous disease. I have pointed out elsewhere ${ }^{1}$ that this law is constantly in evidence when we study cases of reversionary (phylogenetic reversion) and familial degenerations. What are the limits within which this law is effective I hope to touch upon later.

\section{HABIT AND Symptoms}

We see these laws in action in the highest animals. There can be no more striking examples of the action of the Law of Habit than the abundant observations upon the production of " antibodies" by the system once the cells have been stimulated to elaborate them. But, as I pointed out some years ago, ${ }^{2}$ we encounter examples in all directions. We find that after an acute inflammation, be it of the lungs or the sinuses of the nose, we encounter cases in which the discharge continues weeks and months after the causative agent has disappeared and the discharges have become sterile. To us as physicians it is important to keep this in mind, for the recognition of this class of cases materially aids prognosis : it has to be remembered that not infrequently what is commonly regarded as symptomatic of functional, not to say anatomical, disturbance may after all be one or other manifestation of habit, and therefore wholly curable, provided the habit can be interrupted. May it not be that an agitation that is progressing to-day in the daily and

1 Principles of Pathology, vol. i. 2nd ed. p. 177.

"See the address upon "Habit, Symptoms, and Disease," Chapter VIII. of Part II. of this volume. 
Sunday press, and in certain exalted circles which have their centre in Park Lane, would never have arisen if we, physicians and surgeons, had a fuller grasp of this truth ? In other words, I am inclined to believe that not a few cases of apparent organic joint disease are habit conditions. I have pointed out that mucous colitis has the earmarks of a habit condition, while as to tics and other convulsive movements of nervous origin, and hysterical manifestations, if not based upon habit then due for their continuance to habit, their name, like that of the Gadarene devils, is legion. As to these nervous cases, it has been recognized from Lamarck ${ }^{1}$ onwards that it is easier for nervous stimuli of different orders to travel along well-worn paths, and that thus there becomes established a condition in which a minimal afferent impulse travelling without interruption along a particular path suffices to set in action first one and then another of a group of co-ordinated nerve centres, so that a minimal stimulus may eventually produce a maximal result. On the other hand, the act of inhibition, or arrest of the passage of a given impulse, if repeated, would seem to oppose so strong an obstruction to the passage of impulses along a particular path that soon a maximal stimulus will produce no result. Here there is no anatomical change, only a matter of habit. Put the patient under an anaesthetic or otherwise remove the inhibitory block, and now stimulus is followed by the normal reflex muscular act. Also, the longer the individual has been the prey of a habit, the more difficult it is to bring about the return to the normal. Here again our war experiences with "shell shock" and the "fear neuroses" (as distinct from shell concussion) are proving this point up to the hilt in the striking difference obtained by immediate treatment behind the front, as contrasted with treatment of the same order in special hospitals in England, initiated weeks, and it may be months, later. ${ }^{2}$

Some of my readers may recall that $I$ have applied this law of habit to explain the metaplasias, the conversion under altered environment of tissues of one order into those of another-of normal connective tissue into bone or cartilage, of stratified

1 Zoological Philosophy (translation by Hugh Elliot), Macmillan \& Co., Ltd., 1914, pp. 349, 350.

- Vide Sir John Collie's lecture at the Royal Institute of Public Health, reported in the Times of June 14, 1917. 
into columnar epithelium, and vice versa, as again to explain the neoplasias or true tumours, ${ }^{1}$ here calling attention to the partial antagonism between functional activities of the cells, in which the food-stuff's absorbed are utilized in the production of energy in the exercise of function, and the vegetative activities, in which the food-stuffs absorbed are employed in the building up of increased cell substance and utilized for growth and proliferation. The time at my disposal forbids that I should enter at length into the data supporting the "habit of growth" theory of neoplasia, but as bearing upon cell inheritance of acquired properties I cannot forbear calling attention to a form of cancer of which I have come across at least two well-marked examples, and of which there are several other cases by Van Hansemann and others on record. I refer to primary squamous epithelioma of the gall-bladder. ${ }^{2}$ Normally there is no squamous epithelium, but only columnar epithelium in the gall-bladder. There is no squamous epithelium anywhere in the neighbourhood. But it is a familiar fact that 90 per cent or over of cases of cancer of the gall-bladder are associated with the presence of gall-stones. It has also been noted by several observers that the continuous irritation set up by the presence of gall-stones leads to the metaplastic conversion of areas or plaques of the columnar-celled mucosa, more particularly of the fundus of the gall-bladder, into a stratified squamous epithelium. And here is the interesting point : we encounter cancers of the gall-bladder, not of the pure adenomatous or cylindrical-celled type, but containing definitely epitheliomatous areas. In other words, in these cases the metaplastic squamous epithelium, originating from a columnar-celled mucosa, has had its new character so firmly impressed upon it that when it is stimulated to new growth it does not revert to an adeno-carcinomatous type, but retains the impressed variation and gives rise to epitheliomatous squamous-celled downgrowths : an acquired variation becomes hereditarily transmissible among these cells, just as must be the case when the production of antibodies lasts for months and years.

1 See the address on "The Causation of Cancerons and other New Growths" reprinted as Chapter II. of Part III. of this volume.

2 For the different forms of new growth, their classification and histogenesis, see the address on "The Classification of Tumours " in Part III. of this volume. 


\section{CHAPTER V}

\section{THE INHERITANCE OF ACQUIRED CONDITIONS IN THE HIGHER ANIMALS}

DIRECT adaptation, or direct equilibration in the Spencerian sense, can be proved to occur in a certain order of cases, both at the lower end of the scale and at the upper, and this adaptation may manifest itself as an acquirement of additional properties, as well as by loss of properties already possessed by the individual. But now, to advance further, it is necessary to bring forward the evidence obtained from medical research that acquirements, whether of defect or of excess, if they may be so termed, are passed on to the next generation.

There can be no question that they are in the case of the bacteria, but here so intimate and so direct is the relationship between the organism and the environment that while, as already stated, the longer the environment has acted on a given species of microbe the longer the microbe retains the impressed property, I cannot state dogmatically that there is any biochemical property that is specifically fixed, still less, therefore, that any acquirement remains fixed.

With reference to the higher animals we recognize full well that the problem to be answered is girt with numerous restrictions, that conjugation and amphimixis in general act as a factor tending to neutralize and dissipate the evidence of such heredity, that in mammals we have narrowly to distinguish between conditions of germinal origin (which alone are truly inheritances) and those acquired during the uterine phase of existence; again between conditions of germinal origin and those impressed upon the offspring during extra-uterine existence. Take the question of the inheritance by the children of the tuberculous of a tuberculous diathesis: how are we to assure ourselves that, when the 
mother is affected, the children have not been imperfectly nourished in utero and thus rendered more susceptible to tuberculosis and to all other forms of infection, or in the case of alcoholism that the lowered vitality of the children is not due to the lack of care and general home misery which so often accompanies maternal alcoholism, and becomes pronounced when both parents are alcoholics? For absolute evidence we are reduced to the study of conditions in which the soma of the male parent has been subjected to particular influences, and have to observe, first, whether those influences have, judged by the condition of the progeny, had influences of any order upon his germ cells, and secondly, whether under any conditions the influences which act upon the soma, or more accurately the tissues in general of the male parent, produce identical disturbances in the children. Clearly there are the two conditions of what may be termed indirect and direct or identical inheritance.

Now, in the first place, we have clear evidence that the germ cells are not, after the Weismannian conception (as usually accepted), so sacrosanct that they are insusceptible to influences which affect the body at large. Even though their growth is restricted still they have to grow, and they have to maintain existence, and growing they must absorb and assimilate material brought to them by the blood and diffusing from the blood into the lymph. If that lymph contains soluble toxic substances, the germ cells are not precluded from absorbing them as do the other cells of the body-and, like those other cells, from being influenced by them. I have brought these examples forward on previous occasions, and they have never been rebutted; on the contrary, the evidence of this order is steadily increasing.

Take first the oldest carefully studied example, that afforded by Constantin Paul ${ }^{1}$ in the 'fifties, in his studies upon the effect upon workers exposed to lead: of 32 pregnancies in which the husband alone was exposed to lead, there resulted 12 abortions; and of the 20 children born alive, 8 did not survive the first year, 4 died during the second year, and 5 during the third year. And the lead appears to have a particular influence upon the nervous system, for numerous other observers have called attention to the frequency of epilepsy, idiocy, and imbecility in the children of workers in lead. Nor need I recall that lead

1 Arch. gén. de médecine, xv., 1860, 513. 
acts directly on the nervous system of the adult, producing lead encephalopathy, retinal disturbances, etc.

Next we have Lizé's parallel observations upon the workers exposed to the fumes of nitrate of mercury in the manufacture of looking-glasses, ${ }^{1}$ etc. : 12 pregnancies in which the father alone was exposed, resulting in 4 abortions and 8 children born alive, of whom 3 died before the fourth year and 1 alone was vigorous. What can these figures mean other than that the metallic salts absorbed into the system have affected the germ cells of the father?

Carrière ${ }^{2}$ inoculated a series of guinea-pigs, male and female, with the soluble products of the tubercle bacillus. I have placed his results in a tabular form: they are very instructive.

\section{Effect of Inoculation of Parental Guinea-Pigs with TUBERCULIN-Carrière}

BrRTHS

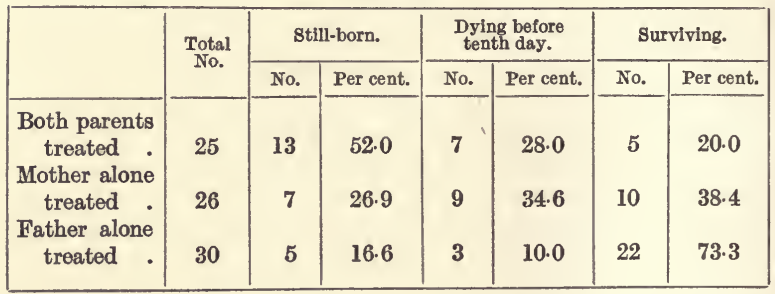

The results here are of the same order as those obtained by Paul and Lizé: there is the heaviest mortality, the greatest number of still-births, the smallest number of those surviving infancy where both parents have been subjected to the particular soluble poison prior to conception. Next in order is the morbidity and mortality when the mother alone is inoculated, but where the father alone has been inoculated there is still evidence that a high percentage - over 25 per cent —of the offspring are affected.

Nor do these observations by Carrière stand alone: Lustig, ${ }^{3}$

1 Union médicale, 1862, 106.

2 Arch. de méd. expér. xii., 1900, 782.

Sentralblatt f. Pathologie, xv., 1904, 210 and 756. 
employing chickens, and Watson, ${ }^{1}$ working under Mott in London and employing guinea-pigs, obtained results of the same order by successive inoculations of the phytotoxin, abrin, to which I have already referred. Both observers noted the resultant diminished fertility, increase in the number of still-births, and lowered vitality of those of the offspring that survived birth, and both, like Carrière in the case of tuberculin, note particularly that the offspring, instead of being immunized to the individual toxin, are on the contrary distinctly more susceptible. Their observations are on a par with the frequent clinical finding that the children of those suffering from advancing tuberculosis are more liable to succumb to tuberculosis than are those of healthy individuals. We have here the explanation of the tuberculous diathesis. ${ }^{2}$

The most conclusive observations, however, are those of Professor Stockard ${ }^{3}$ of Cornell Medical College, New York; and this in a field in which, although generations of medical men have been convinced that they saw definite effects of a drug descending upon the offspring, nevertheless social surroundings have so complicated the subject that it seemed almost impossible to arrive at a sure conclusion. It is indeed significant as to the value of the pure statistical method and of Biometrics as applied to the problems of evolution that Professor Karl Pearson 4 deduced from his Edinburgh statistics that the children of alcoholics in the Scotch capital are, if anything, superior in capacity to those of abstainers.

Any one who has had dealings with a guinea-pig knows how small and well guarded is its mouth, so that forced and exact feeding of these animals is out of the question. By a very

1 Watson, British Medical Journal, 1905, ii. 1091.

2 Let me confess that I am prepared to find that the cautious administration of smaller doses of toxin over longer periods will have the contrary effect, that of developing increased resistance in the offspring.

3 Arch. f. Entwick.-Mechanik, xxxv., 1912; Archives of Internal Medicine, x., 1912; and American Naturalist, xlvii., 1913.

- See correspondence between Professor Pearson and the late Sir Victor Horsley in the British Medical Journal, 1911. All the same let me admit that I am not a little attracted by Dr. Archdall Reid's contention that alcoholism, by causing the further degeneration and eventual extinction of weakling strains, if ruinons to the individual of these strains, is of ultimate benefit to the race. But this does not signify that per contra alcohol is of benefit to the sound stock, or that, as Professor Pearson's Edinburgh figures might infer, the more temperate inhabitants of the Scottish capital are a weaklier lot than those who partake freely of the national beverage. 
ingenious method Professor Stockard overcame the difficulty. He constructed a special box-chamber in which he could subject these animals to the fumes of alcohol, and he induced chronic alcoholism by subjecting them for six days per week to these fumes until they showed signs of intoxication. Treated males were paired with treated females, normal males with treated females, and treated males with normal females. The experiment was very complete. Altogether, in his first series of 40 matings 25 gave no result, or the mothers aborted early and ate their young. The remaining 15 matings gave 25 young (in place of about 60). Of the 25, 8 were still-born, 7 lived for a few days after birth and then died in convulsions, 4 were in utero when the mother was killed (and of these one was deformed). Six only survived.

Professor Stockard has supplied me with the following figures regarding the results of mating of alcoholized fathers with normal mothers. There were 24 such matings :

14 were either negative or gave early abortions;

5 gave still-born litters (in all, 8 young);

5 only gave living litters (in all, 12 young).

Of the 12 living offspring from these 24 matings :

7 died in convulsions soon after birth;

5 survived, but when two months old were only half the size of control normal guinea-pigs of the same age.

Thus, under the influence of paternal alcoholism 24 matings only produced as many surviving young as might be expected from a single pairing of healthy guinea-pigs.

But this is not all. Professor Stockard has continued these observations, and, calling attention more particularly to the stigmata of degeneration observed in the offspring of this alcoholic parentage, has demonstrated that if members of the second generation which themselves have never been subjected to the fumes of alcohol be now mated together, their offspring, members of the third generation, exhibit the same stigmata to a still more pronounced degree. ${ }^{1}$

He observed that those of the offspring of alcoholized males and normal females which reached maturity were in general undersized and nervous, and here is the point: if these secondgeneration animals were brought up under normal conditions,

1 Proc. Soc. for Exper. Biol. and Med. xi., 1914, 136. 
that is to say, without alcoholization, and then unrelated bucks and does of this second generation were mated together, instead of their offspring showing a return to or towards the normal, on the contrary the result was worse than when they were mated with wholly normal animals, and their condition was worse than that of their parents. There was a marked tendency to progressive degeneration. In this third generation gross defects presented, and deformities; 17 per cent of them showed, for example, defects of vision, were either eyeless or with opaque corneas or complete cataracts. Mating together unrelated members of this third generation, the outcome was yet more unfavourable, four dying soon after birth and three being completely eyeless. In other words, two alcoholized great-grandfathers influenced the progeny certainly unto the fourth generation.

We have here the clearest evidence known to me of the inheritance of acquired defects-evidence that fits in wholly with our routine medical experience of the dangers of marriages in families in which there exist already stigmata of degeneration, diatheses of various orders, and, more particularly, neuroses, liability to migraine, hysteria, epilepsy, and the like-cases in which there are not necessarily gross anatomical defects, but rather indications of want of full development of those properties of latest phylogenetic acquirement, of the higher mental and co-ordinative powers, and of racial immunity towards the diseases which specially affect man. We note, familiarly, that the children of such marriages are delicate, more liable than other children to succumb to the infections of childhood, more irritable and liable to nervous explosions, if not to one or other nervous disorder, manifesting itself not necessarily in childhood, but in adolescence, when strains which have little or no influence upon normal individuals lead to exhaustion and nervous breakdown in one or other direction, according to the nature of the strain.

With these experiments of Stockard before us it is absurd to postulate that these defects of resistance are atavistic, due to properties which have always been possessed by some one or other strain which has been introduced into the family. To-day we must recognize that infections of one or other order and intoxication are capable of telling upon the parental germ plasm, and that, at some definite point in the line of descent, conditions 
acting from without upon the germ cells have led to the acquirement of conditions of defect. To us as medical men it is a minor point whether there is inheritance of the exact defect seen in the parent who has been subjected to a given form of intoxication; the essential fact is that soluble poisons acting upon the tissues in general of the parent can act also upon and modify the germ cells, so that at some definite period such change occurs in the constitution of those germ cells that the constitution of the offspring is permanently affected, and that its germ cells in their turn are incomplete in molecular structure.

It is not a little interesting that alcohol, lead, and bacterial toxines in general have a profound, we might almost say specific effect upon the nervous system in the adult or adolescent individual, and that they are so peculiarly liable to influence the nervous system of the offspring. To this aspect of the matter I shall refer later.

Such "parallel induction" of defects in both the body cells and germ cells has been repeatedly noted of recent years by workers in experimental genetics, the case that has afforded the greatest amount of discussion being that of Salamandra maculosa, as studied over a long series of years by Kammerer and recorded in the Archiv für Entwickelungsmechanik. This is a salamander which normally hatches its eggs in the water, in which they develop into tadpoles with gills. Very gradually Kammerer accustomed the parent forms to live entirely on land in a damp atmosphere, and with this, in place of producing some sixty to seventy eggs the females became viviparous, giving birth to at most six or seven young, with the tadpole or gill-bearing stage completely suppressed, and breathing by lungs. That here the environment to which the parents have been subjected tells not merely on the growing embryos, but upon the germ cells, is evidenced by the fact that when the members of this second generation are supplied freely with water they produce tadpoles, it is true, but now the metamorphosis from the waterliving and gill-breathing to the land-living and lung-breathing stage, instead of taking months, as in the case of the normal spotted salamander, occurs in the course of a few days.

Walter, ${ }^{1}$ I observe, objects that this is not a case of inherit-

1 Genetics, an Introduction to the Study of Heredity, New York, The Macmillan Company, 1913, p. 90 . 
ance of acquired character, but that the normal gill-breathing form represents a case of arrested development, i.e. of "neotenia." To prove this it is necessary to show that the salamander is the degenerate representative of some form no longer amphibian, which, after having been accustomed to a purely terrestrial existence, has taken to laying its eggs in the water, and that the long gill-breathing tadpole stage is a reversion. Is there the least evidence that this is so ? He argues that change from gill-breathing to lung-breathing is not an acquired character, but a purely germinal character that may be either blocked or released by changing conditions of environment. ${ }^{1}$ Surely this is contrary to all we know or imagine regarding the Amphibia. We have always been taught that breathing by lungs represents evolutionary advance fitting the vertebrate for terrestrial existence, and not a retrogression. The complete suppression of the gill-breathing stage cannot be regarded as other than something acquired, although, as this is of the nature of a cutting-out of a developmental stage, while on the one hand it may be regarded as progressive acquirement, on the other it does not strictly come under the heading of the positive acquisitions.

Also belonging to this border-line group of inheritance of defects due to "parallel induction" are to be cited the cases of increased susceptibility to specific toxines, to which I have already referred-the observations of Lustig, Watson, and Carrière with reference to abrin and tuberculin. To these may be added the interesting observation of Schenck ${ }^{2}$ and others that the offspring of hypersensitized fathers and normal mothers are themselves hypersensitized and exhibit anaphylactic phenomena, for, as I have pointed out, anaphylaxis is a stage in the development of immunity; and, regarding immunity as a digestive process, as the acquirement of an added power of dissociation of specific toxines and conversion of the same into food-stuffs, the demonstration is in itself a proof that we may confidently expect by fuller studies along these lines to establish firmly, what several observers have already reported, namely the inheritance of

1 Walter quotes in support Marie von Chauvin's demonstration that the gill-breathing salamander, Axolotl, can, by habituating it to progressive reduction of the water in its aquarium, be converted into Amblystoma.

2 Münchener med. Wochenschrift, 1910, 2514. 
acquired immunity, the inheritance not merely of conditions of defect, but of positive acquirements.

Here we come to the boundary of the territory already acquired, unless, indeed, during the last three years of war, quiet workers in the United States, whose observations I have been unable to follow, have carried the demonstration yet further. Years ago ${ }^{1} \mathrm{I}$ pointed out the need to distinguish in this relationship between extrinsic and intrinsic influences upon the germ cells. Toxines are instances of the first order-introduced from without they act upon the germ cells at the same time as they influence the tissue cells in general. As examples of the intrinsic and indirect, I instanced the effect of influences from without telling upon the function of one or other organ and so disturbing general metabolism that either the absence of normal metabolites or presence of abnormal metabolites circulating in the blood might bring about alteration in the constitution of the germinal biophores, with resulting alteration in the constitution of the offspring. In this way, I pointed out, gouty and rheumatoid states and defect and excess of internal secretions may tell upon the germ cells. It is thus that we best explain the development of diatheses. I pointed out in $1912^{2}$ that " if the cells of particular organs are highly susceptible to hormones and other active principles of the secretions of other organs, is it not likely that the parent germ plasm, the cell matter which by its active growth is capable of giving origin to all these organs and tissues, should likewise be susceptible to their action, and influenced by their excess or deficiency? Nay, should we not expect that bodies of this nature, developed by the cells in their activity, should act with greater ease upon the living substance of the germ cells than extraneous drugs are likely to act? As a matter of fact, alterations in such glands as the thyroid, the pituitary, the adrenal cortex, the pineal, are found to have a profound influence upon the sexual function." 3 Influences acting upon these organs of internal secretion, and conditions acquired by these organs, may well so modify them that the offspring in

1 On the Inheritance of Acquired Conditions, 1901, reprinted as Chapter II. of Part II. of this volume. Article "Inheritance and Disease" in Modern Medicine by Sir William Osler and T. McCrae, vol. i., 1907, p. 109 . See also Principles of Pathology, vol. i. 2nd edit., 1910, p. 199.

" "A Study in Eugenics," The Lancet, 1912, ii. (Nov. 2).

s I had laid this down in 1901. (Consult Chapter I. of Part II.) 
their development show excess or deficiency in the function of the glands implicated in the parents, and "so conditions acquired by the parents reproduce themselves in and become inherited by the offspring." I am glad to see that one zoologist, my old friend Professor E. W. MacBride, has joined himself with me in this opinion, and with me sees in this possibility or probability the solution of a long-standing difficulty. ${ }^{1}$

"Lamarck's contention was that the identical changes caused in the structure of an individual animal or plant, by the action of a novel environment, ... a are transmitted by generation to that offspring, and continue to appear in successive generations derived from that offspring even when the cause which set up the original modification of structure ceased to act. . . . Darwin ... did categorically state that he attributed the origin of congenital variation (by the natural selection or survival of which he held that new species originate) to the action or influence of changed conditions upon the parental body, and through it upon the reproductive germs." 2

It will be seen that the results of medical research here quoted support strongly Darwin's contention, though at the same time they indicate a group of cases in which the direct adaptation of a particular endocrine organ may, through the action of its internal secretion, bring about an identical change in the same organ of the offspring. There is, that is to say, one possible group of cases for which the Lamarckian theory holds true, and that, oddly enough, as MacBride points out, along the lines of Darwin's discarded hypothesis of pangenesis. Only it is not by specific corpuscular determinants or pangens but by secretions and the chemical activity of the same that the organs of the body, or certain of them, are capable of influencing the germ cells and bringing about a chemical and relatively permanent change in their constitution.

After long years of heavy fighting we have, as it were, conquered our Vimy or Messines Ridge; and, although for a time we are held up, we can, as it were, indulge in a "Pisgah view," and see where and how the next advance is to be made.

1 Embryology of the Invertebrates, vol. i., 1914, and Presidential Address, Zoological Section, British Association, 1912.

2 Sir E. Ray Lankester, The Kingdom of Man, Rationalist Press Association, cheap reprints, No. 50,1912 , p. 74. 


\section{CHAPTER VI}

\section{THE PHYSICO-CHEMICAL BASIS OF IMMUNITY AND OF EVOLUTION}

IF we endeavour now to gather together the conclusions which may reasonably be reached from a consideration of the data afforded in the previous chapters, they appear to be the following:

(i.) Instead of there being no such thing as direct adaptation or equilibration of the individual to his surroundings in the Spencerian sense, this surely exists and can be demonstrated.

(ii.) In the lowest forms of life, among the bacteria, it can be demonstrated that not only is this adaptation individual, but that acquired properties of certain orders are inherited through numerous generations, even when the cause which set up the original modification has ceased to act.

(iii.) It can further be demonstrated that the inheritance is not due to the survival and perpetuation of those individuals only which present the favourable variation. All the members of a given strain of bacteria subjected to a given modification of environment can be made to vary in the same direction, and acquire and transmit the same new property.

(iv.) Immunization of the higher animals is direct adaptation. There could, in fact, be no clearer demonstration of the process of direct adaptation than has been afforded by the abundant researches upon the production of immunity.

(v.) It is clearly proved that there are drugs and toxines which, acting on the tissues of the body, act also on the germ cells, causing modification of the latter, of such a nature that the offspring resulting from these germ cells are modified.

(vi.) The clearest evidences of this action are in connexion with drugs and toxines which lead to conditions of defect, but acquired special susceptibility and anaphylactic reaction are 
also inherited, indications that new properties gained by the germ cells can also be inherited.

(vii.) The generative system is embryogenetically related to the endocrine system, and is profoundly influenced by the internal secretions of that system. The indications are that influences from without affecting the organs of internal secretion and modifying their secretions may through the hormones, etc. of the internal secretions so influence the germ cells that the offspring are affected in the same direction as the parent, and that thus acquired metabolic disturbances in the parent, whether of the nature of defects or acquirements, are capable of being inherited.

To the academic biologist the suggestion of a direct action of external agencies as the prime cause of variation is as shocking and as improper as would be the suggestion of a risqué story to some dear and prim old maiden lady. To the biologist of to-day ${ }^{1}$ the conclusions above noted are heterodoxy pure and simple. And yet it is along these lines that medical research is surely leading us. And what is more, these conclusions harmonize with the experiences that come to us day after day in studying our patients and their families.

\section{The Morphological Concept of Unit Properties}

Believing that we are in the right, where is it that the biologists have gone wrong?

1 I admit that this is too sweeping a statement. It was written with a vivid memory of my correspondence with Sir Ray Lankester a few months previously, and the attitude taken by him.

I do not think I can be accused of unduly advertising my wares or of too keen a desire to claim priority when I have allowed sixteen years to elapse before calling the attention of biologists in general to my address of 1901 (here republished in Part II.). The conclusions then reached by me regarding metabolites, and, as we subsequently became accustomed to term them, hormones, and their influence on the germ cells, have since then been enunciated by several prominent biologists, by Heape, Bourne, Cunningham, MacBride, and Dendy, although in each case without note of my earlier contribution, which, it should be added, appeared not in an obscure local periodical, but in a leading organ of the medical profession under a title that had no uncertain sound. The only British biologist who to my knowledge has referred to my views is Professor Arthur Thomson (Heredity, London, John Murray, 1912), but he also appears to be unaware that I preceded Professor Yves Delage by some two years in offering a physicochemical hypothesis in place of determinants. On p. 454 he dismisses the subject by stating: "We find ourselves quite unable to entertain (the view) that it is possible to dispense with any postulate of representative particles." 
I venture to suggest that, from the morphological trend of their studies, in striving to form a mental picture of the process of evolution, morphologists have perforce conjured up separate individual particles or molecular structures, each of which is the bearer of an individual property or group of properties. Their conceptions have perforce been in the terms of specific atomies.

We see this tendency elaborated-and, in his great sanity, cast aside-by Charles Darwin in his pangenesis hypothesis. It was exhibited again $d$ merveille by Weismann with his ids, idants, determinants, and the like, pure figments of the imagination which, nevertheless, have influenced and affected all our generation. It has shown itself and been carried forward in full vigour by the Mendelians; one has only to consult their diagrams to see how obviously their conceptions and explanations assume a structural form. It is because he cannot picture in his mind an atomy or structure making its first appearance in the germ cell, like Venus arising out of the sea-foam, and henceforth becoming a portion of the hereditable substance of that cell, that Professor Bateson finds it impossible to imagine the positive acquirement of new properties by the individual, and so is driven to the remarkable hypothesis quoted in my first lecture.

But before all, it is the Freiburg philosopher who has led our generation of biologists into Nephelococcygia_- "Cloud Cuckoo Land." Much as we owe to him for arresting the vague generalizations upon heredity prevalent until the 'eighties, and for his confirmation, experimental and otherwise, of Galton's doctrine that conditions such as mutilations and use acquirements are not inherited, I myself am inclined to think that Weismann's teaching has, on the whole, done more harm than good. $\mathrm{He}$ was a pure morphologist, and his hypothesis was purely morphological. Had he been familiar with the physical chemistry of his day he could not have ventured to publish it; had he been a physiologist with any appreciation of function he must have modified it extensively. It is, in short, an impossible hypothesis, and in a very extraordinary manner all its main postulates are found contrary to experience. As I pointed out ten years ago, ${ }^{1}$

1 In the chapter upon Inheritance and Disease in Osler and McCrae's System of Medicine, part of which is reprinted ("The reductio ad absurdum of Weisman's Theory") in Part II. of this volume, Chapter VI.; see also Principles of Pathology, lst edit., 1908, p. 119. 
our knowledge of the size of the molecule of albuminous matter renders the existence of thousands of individual molecular determinants in the minuter portions of the nucleus a matter of sheer impossibility : they could not be packed in the space. If $\mathrm{I}$ remember aright it was Herbert Spencer who pointed out that in one feather of the peacock's tail there are 480,000 regions or parts capable of independent variation, and that therefore, so Weismannism demands, in each of the many microscopic "ids" or chromomeres in the nuclear chromatin of the peahen's ovum there must be 480,000 determinants for a tail feather alone. How many for the rest of the body passes computation!

It is this faulty and untenable morphous or morphological concept of unit-properties and hereditary entities that makes it as difficult for Professor Bateson to picture how new accretions (whereby he images new discrete determinants) can make their appearance in the germ cell, as it was for the late King George of glorious memory and muddled to imagine how the apple got into the dumpling.

\section{The Constitution of Living Matter}

Suppose now we start from known facts and known phenomena, and endeavour upon these to build up our idea of the structure and nature of the germ cell, and so of organic basis of heredity, variation, and evolution.

What, in the first place, do we know of the constitution of living matter? Will this help us? I think it will. We know that whatever form of life we investigate, be it in animal or plant, mammoth or microbe, whatever form we analyse, and whatever tissue of that form we analyse, leaving out of account water and certain common vehicular salts to which no specific vital functions can be attributed, just one order of highly complex organic compounds is common to and to be isolated from all forms of living beings, and these are the proteins. This characteristic universal presence of these highly complex organic compounds in itself indicates that they are intimately associated with vital functions. It is true that when we isolate them chemically they are inert, in other words in the living 
organism with its many activities they are evidently present in another form; living matter, therefore, as I have expressed it elsewhere, contains as an essential constituent proteidogenous rather than proteid matters.

\section{The Structure of the Proteins}

But the structure of these proteins, as worked out first by Curtius and Schutzenberger, and as more fully demonstrated by Emil Fischer through the actual synthesis and building up of bodies of protein nature in the laboratory, is highly significant. They are molecules so large that they will not pass through fine filters, giant molecules but a little below the limit of visibility under the highest powers of the microscope. Take one of the simpler crystallizable proteins, namely Haemoglobin, its composition appears to be approximately $\mathrm{C}_{712} \mathrm{H}_{1130} \mathrm{~N}_{214} \mathrm{O}_{245} \mathrm{FeS}_{2}$, in fact, the average molecular weight of proteins has been estimated at about 15,000 , or, roughly, one thousand times that of a molecule of water. And the haemoglobin from each species of vertebrate is a different chemical substance, nay more, our researches in immunity indicate that there may be differences between the haemoglobins of two members of the same family. Certainly no two analyses of separate samples of crystalline haemoglobin obtained from the same species give identical results. By digestion, as every board school child knows, we break these proteins down into peptones and albumoses. By further disintegration Kossel and others have broken down these peptones and protones into their constituent amino-acids, bodies belonging to the fatty acid series-aminated fatty acids. What Fischer has done has been to manufacture these aminated fatty acids (acetic, propionic, etc.) in the laboratory, and then he has accomplished the reverse process of linking these together, until with five, ten, fifteen, and more linked together he has obtained bodies affording the chemical tests for peptones.

Now these amino-acids have one striking property-they are amphoteric; they possess both acid and basic properties, acid because of the contained $\mathrm{COOH}$ group or groups, basic through the $\mathrm{NH}_{2}$ group or groups. Thus we conceive these peptones 
as composed of polymerized molecules, formed in the main of amino-acid molecules linked together by their otherwise unsatisfied $\mathrm{NH}$ and $\mathrm{CO}$ affinities. Thus, to modify Hofmeister's illustration, we may represent a portion, at least, of the peptone molecule as follows:

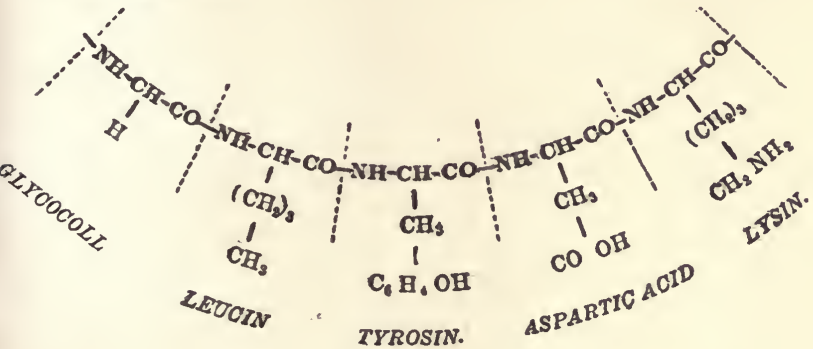

FIG. 1.

Each section between the dotted lines represents an aminoacid nucleus. I speak of these as glycocoll, leucin, etc., but it will be seen that in the leucin nucleus, for example, an $\mathrm{H}$ of the $\mathrm{NH}_{2}$ group is replaced by the $\mathrm{CO}$ of the glycocoll nucleus, and the hydroxyl of the $\mathrm{COOH}$ group by the $\mathrm{NH}$ of the tyrosin nucleus. In Fischer's terminology the nucleus is leucyl, not leucin. The peptone molecule is thus represented as composed of a main chain in serial repetition of glycocoll molecules,

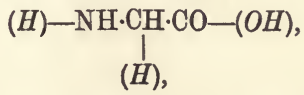

in which the $\mathrm{NH}$ affinity on the one side and the $\mathrm{CO}$ on the other have been satisfied by linkage with a like molecule, while an $\mathrm{H}$ of the $\mathrm{CH}_{2}$ is substituted (in the figure) by methyl-paraoxybenzene, acetic acid, butylamin, etc. We have, that is to say, a main glycocoll chain with a series of free-swinging chains capable of being replaced or modified by processes of oxidation or the action of enzymes. ${ }^{1}$

1 So as not to introduce complications I have here purposely left out of account a consideration of the relationship of the purin nuclei or radicles to such chains; it is necessary, however, to keep in mind that the latter are important constituents of the nuclear matter, and of what later I shall refer to as the biophores. 


\section{The Complexity of the Proteins}

But the complex protein is composed of and breaks down into peptones. We can therefore represent it either as a chain or a ring of linked peptone molecules, or simply as in Fig. 2,

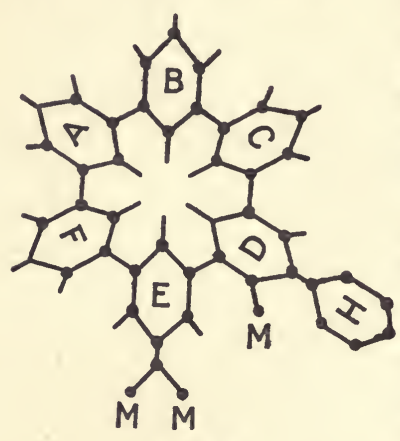

FIG. 2. in which the hexagons $\mathrm{A}$ to $\mathrm{F}$ represent each a peptone nucleus with its ring of glycocoll nuclei, with, however, the "swinging side-chains," as I have termed them, indicated as in the main unsatisfied, save at M, M, M, and $H$. This represents but the central skeleton of the protein molecule, a frame in which to place one's mental picture of its nature and complexity. Imagine that complexity when, in the haemoglobin molecule, for example, there is somewhere inserted among the 700 or so carbon atoms just an atom of iron and two atoms of sulphur. The nuclei or radicles of which these are essential constituents must have one particular place among the other nuclei composing the ring or chain. Consider also the number of vulnerable linkages - free-swinging side-chains that may be detached by compounds in the neighbourhood having stronger affinities and be replaced by others, thus altering the constitution of the protein molecule as a whole. In the much simpler bodies with which the organic chemist is in the main concerned-bodies, for example, like those of the benzole derivatives or the carbohydrates-we know how the transfer of a given radicle from, say, the alpha to the delta position upon a ring brings about profound change in the chemical and physical properties of the compounds. Bodies, for example, of identical molecular weight, which on analysis contain the same number of atoms of carbon, hydrogen, and oxygen, and on analysis afford identical radicles, may be found to differ to a remarkable degree. When two carbon atoms are united together there are, or may be, six free affinities, and when these are 
satisfied by six different univalent groups, twelve different arrangements are possible. ${ }^{1}$

Even if for the time we leave out all consideration of introduction of new orders of "swinging side-chains" think of the number of permutations and combinations that are possible when, instead of two, there are in the ordinary protein
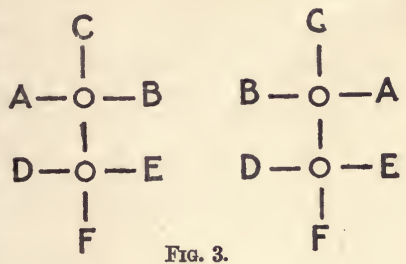
molecule hundreds of carbon atoms.

\section{The Biophores}

If, therefore, we regard the biophores or molecules of living and heritable matter in the germ cells as, if not proteins, at least proteidogenous, giving rise to proteins when dead or killed in the process of analysis, obviously it is not necessary to demand a separate determinant, a separate molecule for each specific property; it is simpler to regard properties inherent in the biophores as the expression of the constitution of those biophores, of the mode of linkage of the various nuclei, together with the number of those nuclei and the nature of their swinging sidechains. This conception is within the bounds of physical possibility, and Weismann's ids, idants, determinants, and the like, certainly are not.

Let us therefore accept as a working hypothesis this conception of the chemical constitution of the essential living matter of the individual, namely that it is, as I express it, proteidogenous, giving upon analysis bodies of proteid nature, and that these biophores or molecules endowed with vital and heritable properties are composed of rings or it may be chains of aminoacid nuclei in series, each nucleus composed of a central amphoteric glycocoll group, to which are attached varying orders of side-chains.

We know, in the first place, that in conjugation or amphimixis the one element of the two germ cells, male and female, that is contributed in approximately equal portions is the nuclear

1 Seo Bayliss, Principles of Physiology, p. 268. 
chromatin. We cannot help being impressed by the extraordinary sequence of events all tending to this end result. No other element common to the two germ cells is partitioned out so meticulously. There is no other element common to the two cells that is doled out with the same equivalence. Next, making a careful survey of heritable and inherited properties, we are forced to the conclusion that the likelihood is equal, that the offspring inherits either from the male or from the female parent. The conclusion is inevitable that the biophoric molecules are conveyed in and by the nuclear chromatin. In the bacteria which are so lowly that they possess no central nucleus we observe nevertheless that chromatin-like granules are scattered through the body substance, and that in binary division these chromatin-

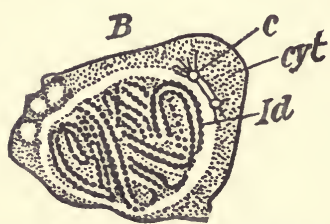

FIG. 4.-Cell undergoing mitosis; skein stage to show the duplication of the chromatin thread with beading of the same, which is seen in some species. Weis. mann regarded these beads or chromomeres $(I d)$ as representing his Ids. c, centrosome; cyt, cytoplasm. like granules undergo a certain simple accumulation or arrangement, to the end that each of the daughter cells is endowed with half of this specific chromatinlike material.

Or otherwise, whereas in these lowest forms the living cell substance is made up of granules of chromatin, each surrounded by an area of cytoplasm, higher up in the scale these granules of biophoric matter are collected into a central node, the nucleus, which is separated from the circumambient external medium by the cytoplasm or cell body. We may indeed speak of a triple protection, namely the cell wall or membrane, the cytoplasm, and the nuclear membrane, all of them on the whole acting as conservative agents, tending to preserve the biophores from sudden change from without.

\section{Vital Processes of the Cell}

But to continue, as it were, to rehearse our catechism, while on the whole conservative, this system is exposed to constant change, owing to the fact that it is not inert but is constantly 
reacting with that external medium, receiving matter from the same either (1) in bulk (phagocytosis), or (2) by diffusion, or (3) by surface absorption, and discharging other matter into the same (excretion). And if we study carefully these processes of assimilation and discharge it is to be made out that the outer cell membrane is semi-permeable, preventing the entrance of certain substances, permitting the entrance of others, whether directly, or after a preliminary dissociation of the same into simpler molecules by means of its extracellular secretions. And once these food-stuffs are taken into the cytoplasm, there again they are, if necessary, broken down still further into yet simpler molecules by intracellular enzyme action.

It is being more and more surely established that these enzymes are of nuclear origin, ${ }^{1}$ resulting from the discharge of certain constituents from the nuclear substance, but this is not a necessary part of my argument. The essential point is that the food-stuffs, protein, carbohydrate, and hydrocarbon, are not utilized by the cell as such, but are dissociated, and it is these disintegrated and dissociated molecules that are utilized by the cell in one of two ways, either to supply energy for the performance of work, or on the other hand for growth.

\section{The Nature of Growth}

I feel almost apologetic for taking up time over such elementary matters. And yet these are matters that, while absolutely basal, are absolutely neglected by ordinary biologists. Take, for example, this matter of growth. With all the extraordinary width of his learning, D'Arcy Thompson ${ }^{2}$ has just achieved a work of some 750 octavo pages on Growth and Form, full of most interesting observations and data, and with a

1 See Pt. II. Chap. V., "The Dominance of the Nucleus."

2 Growth and Form, Cambridge Univ. Press, 1917, p. 203. [It is but just to D'Arcy Thompson to point out that his title was meant by him to signify - and that by a figure of speech which, while wholly permissible, may be construed otherwise - "Form in relationship to growth"; in other words, while he occasionally touches upon matters physiological the work is essentially morphological, " an easy introduction to the study of organic Form," as he terms it in his Preface. Perhaps I may be forgiven if it was just these occasional physiological excursions that arrested my attention rather than the more severely mathematic and physical groundwork of his volume.] 
distinction of style that is a pure delight, but with little more than a page devoted to the essential nature of growth of living matter, and that page upon the text that the older naturalists laid. stress upon the fact or statement that inorganic bodies (crystals) grow by agglutination, organic bodies by intussusception. The living cell, he states, ${ }^{1}$ grows very much as a piece of glue swells up in water, by "imbibition" or by interpenetration into and throughout its entire substance. From his statement growth might be nothing beyond the absorption of water by a semifluid, colloid mass. Now one has only to consider a moment to see that " intussusception," "imbibition," "intercalation," are nothing more than bald and blank terms. They are inane; they cannot possibly explain how two molecules of living matter appear where there was but one before, two grains of wheat where one was put into the ground. Growth is one of the great underlying phenomena of living matter, and zoologists and botanists have, in a simple Topsy-like manner, been satisfied that the phenomenon occurs, and have been amply content to rest with the demonstration of the stages of mitosis and cell division.

But what has happened to the cell substance that precedes and impels mitosis? Obviously there is an increase in the amount of living matter, and this translated into physical terms means a multiplication of the molecules of living matter, or, as I term them, the biophores or biophoric molecules. ${ }^{2}$ If we regard these complex proteidogenous molecules as a chain, or more simply as a ring of amino-acid radicles, there is but one way in which this can multiply, namely by the same method as obtains in the growth of a crystal. Let us take the simplest case, that of the crystallization of sodium chloride out of watery solution. We know that when the solution or dilution of the sodium chloride reaches a certain point the salt separates into its constituent ions of sodium and chlorine. But while separated these maintain a certain relationship or association. It is remarkable that the chlorine ions do not escape or volatilize into the air. When the concentration of the solution reaches

1 Loc. cit. p. 203.

2 I employ this term, introduced by Weismann, rather than manufacture a new term, because our fundamental conception is identical, although it is necessary to point ont that our ideas as to the constitution of the biophores do not entirely harmonize, he regarding them as collections of molecules, I as individual molecules. 
a certain point each ion of chlorine unites with a corresponding ion of sodium, and aided by a sharp point or inequality of the surface of the containing vessel, the process of crystallization begins. The very existence of one crystal is seen to cause other junctions to occur in its immediate neighbourhood, and indeed just that one series of junctions necessary to form sodium chloride. Despite the presence of other salts in solution we gain pure or almost pure crystals of the one substance. We have in this way growth of solid sodium chloride.

Growth of living matter, if more complicated, because the structure of the biophores is more complicated, must nevertheless be of the same order. Its nature is best suggested by the following diagram.

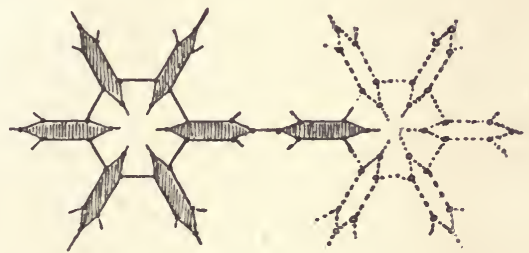

FiG. 5. - Diagram of growth of biophoric molecules.

Namely, granted that the already existing biophore finds itself in a medium - the nuclear cell sap-containing the necessary radicles, should that by one of its attachments attract to itself one of its component radicles, there is then started a process by which in orderly sequence the other radicles become attached, until there is built up a compound molecule, identical with the pre-existing molecule, in association with which it has become developed.

This conception-namely, that the growth of the biophores, or otherwise of the molecules of living matter, is essentially of the same nature as is that of crystals-is materially aided by the recognition that crystallization does not of necessity demand the production of rigid rectilinear figures, that, as Lehmann ${ }^{1}$ was the first to point out in 1904, there are in nature abundant examples of fluid, non-rigid, crystalline forms, and, as Aschoff

1 O. Lehmann, Flüssige Crystalle, Leipzig, 1904. 
and I were the first to note ${ }^{1}$ in 1906 , the animal organism affords abundant examples of these fluid crystals. As D'Arcy Thompson well remarks, ${ }^{2}$ "the phenomenon of liquid crystallization does not destroy the distinction between crystalline and colloidal forms, but gives added unity and continuity to the whole series of phenomena."

1 Adami and Aschoff, Proc. Royal Soc. B., 1906, 359, and Adami, "The Myelins and Potential Fluid Crystals of the Organism," Harvey Lectures, 2nd series, 1908, 117 (here reprinted as Chapter IV. of Part II.), and Aschoff, Verhandl. Deutsch. Pathol. Gesellsch. x., 1907, 166.

- Growth and Form, p. 204. 


\section{CHAPTER VII}

\section{REVIEW OF CERTAIN CONCLUSIONS}

But if we accept these views regarding the existence of biophoric molecules and the essential nature of growth as involving a multiplication of the same by a process akin to crystallization, we are inevitably led to certain very interesting conclusions, which may here be rapidly passed in review. Each, it is true, might well be expanded into a chapter, but the limitations set by this course of lectures demands that $I$ do little beyond indicating the headings.

(i.) The Continuity of the Germ Plasm.-Weismann conceives his biophores and determinants as handed down direct from parent to offspring, so that the germ plasm is potentially eternal, and that of a thousand generations back is contained in the germ cells of the generation of to-day and has its influence upon the configuration of the body of the individual derived from those germ cells. This he speaks of as the "continuity of the germ plasm."

But, obviously, this is not a continuity of substance, as Weismann implies, but merely a potential continuity of molecular arrangement and constitution. For growth and multiplication of the living molecules, for one conjugated ovum and spermatozoon to give rise to the countless millions of sperm cells of the male of any of the higher animals, ${ }^{1}$ there must be such active reproduction of the parental biophores that the chance of one of the original biophores of a grandparent finding itself in the nucleus of a sperm cell must be infinitesimal. The likelihood is that while such, it is true, control the constitution of the new

1 According to Loeb, the average seminal ejaculation in man contains 226,000,000 sperm cells. Consult further Marshall, Physiology of Repro. duction. 
biophores, they sooner or later, in the metabolic processes of the cell, become dissociated and broken down.

(ii.) On the Functional (Katabiotic) and Vegetative (Bioplastic) Activities of the Cell and the Individual.-In unicellular organisms the growth of the individual presents itself merely as increase in size : in multicellular organisms, while there may be increase in size of the component cells to a certain extent, growth is brought about in the main by cell proliferation and increase in the number of the component cells. But both in protozoa and metazoa (and protophyta and metaphyta, if the terms be permissible) there are limits to this process. Here I would but rapidly refer to what constitute these limits, namely, they are conditioned by the relationship or interaction between the individual and its environment. Broadly speaking, the individual continues to grow until an economical mean is established between the amount of food-stuffs afforded by the environment and the absorptive surface that the individual can present to that environment. It is, as I have pointed out, ${ }^{1}$ a false conception to regard the multicellular organism as a colony of individual cells which remain united for self-defence and mutual advantage. Rather it must be recognized that where the unicellular mass of protoplasm undergoes enlargement, the greater the mass the smaller relatively becomes the surface area, and this diminution proceeds in a rapidly increasing ratio, until growth is arrested by the fact that the amount of food-stuffs absorbed cannot keep pace with the needs of the organism. Nuclear and cell division and multicellularity constitute the simplest mechanism whereby the nuclear and cell surface areas can be increased in a yet greater ratio, and the greatest effective working of the individual obtained by decentralization. We may thus regard the mass or size attained by the mature individual of any species as representing the sum total of protoplasmic matter of the constitution peculiar to that species which is capable of existing as an entity under the particular conditions of its environment, the multicellular individual acquiring its greater size and more complex activities by means of nuclear, followed by cell division.

From physical considerations I thus arrived at the same view as that mentioned by Whitman in America (1893) and Sedgwick

1 Principles of Pathology, 1st ed., 1908, vol. i. p. 35. 
in England (1895), and best summed up by a modification of the aphorism of the botanist De Bary quoted by D'Arcy Thompson: "It is the individual that forms cells, not cells that form the individual." This is diametrically opposed to the teaching of Virchow in his Cellularpathologie that " Every animal appears as a collection of vital units, each of which bears in itself the full character of Life."

In either case, whether in the unicellular or in the multicellular organism, the individual continues to grow and exhibit predominantly vegetative activities until it reaches this limit of economical relationship between itself and its environment. In the very earliest stages the vegetative activities alone are evident: as the above-mentioned limit is approached these become less and less, and the cells are more and more engaged in functional activities, that is to say, they utilize the food-stuffs received, not in building up more living matter, but for the performance of work and liberation of energy. And to the extent that growth necessitates a building-up process from the food-stuffs presented to the cell, and function necessitates a breaking down and burning up ${ }^{1}$ of the same food-stuffs, to this extent the vegetative or-as Weigert terms them-bioplastic, and the functional, or katabiotic, activities are opposed processes.

(iii.) Metabolism.-It may be thought that in mentioning these matters I am wandering far afield, and through a singularly arid field at that, nay more, that I do but touch upon or outline matters which to be grasped in all their bearings need a much fuller presentation. I touch upon them purposely in order to emphasize that these matters of adaptation and evolution have of necessity to be approached from the aspect of function and the dynamics of living matter, rather than from the point of view of cell statics. "Function," it has been said, " precedes structure," and it is the study of cell function that must afford the key.

If next we proceed to enquire into the state of our knowledge of the chemistry of these active processes occurring within the cell, we reach a further stage, for the more we study the processes of absorption of food and utilization of the same-the metabolic processes whether, as Gaskell termed them, of anabolism, building

1 It is not (as one is apt to imagine) the dissociation of the food-stuffs that liberates energy, but the burning up of the same, i.e. the oxidation of the dissociated food-stuffs. 
up, or katabolism, breaking down-the more it is borne in upon us that the greater number-some would say all-are the outcome of enzyme action.

(iv.) On Enzyme Action.-This is not the place to discuss the nature of enzyme action in detail. For the most authoritative treatment of the subject Professor Bayliss's works should be consulted. Suffice it to say that the simplest and now generally accepted view is that there exist in the cell, and are discharged from it, intermediary bodies-katalysts-which promote and hasten chemical dissociations and associations without themselves being involved in the final stage, and that the simplest diagrammatic representation of their action is as indicated in the diagram in which $\mathrm{F}$ represents the go-between, the body

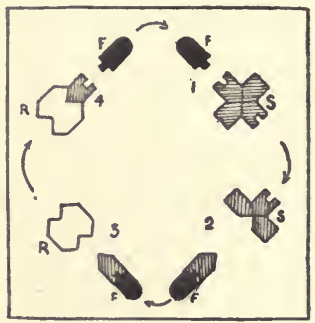

Fra. 6. endowed with enzyme action, S the substratum or body which undergoes dissociation, and $\mathrm{R}$ the receptor or body which is aggrandized, with which the dissociated moiety or part of the substratum enters into union. There are, I hold, always these two phases of dissociation and association in each instance of ferment activity, even if $R$ be but a Hydrogen or Hydroxyl ion. The process is comparable with the katalytic process of manufacture of concentrated sulphuric acid from sulphurous anhydride, through the agency of nitrous acid. The nitrous acid $\mathrm{HNO}_{2}$ takes up a molecule of $\mathrm{O}$ from the air, becoming nitric acid, and acting as carrier gives this over to the sulphurous anhydride $\mathrm{H}_{2} \mathrm{SO}_{3}$, converting this into sulphuric acid $\mathrm{H}_{2} \mathrm{SO}_{4}$, with this becoming free itself to take up another molecule of oxygen and repeat the process with another molecule of sulphuric anhydride. And the process continues until a certain equilibrium is reached between the amount of anhydride and of sulphuric acid present, unless the $\mathrm{H}_{2} \mathrm{SO}_{4}$ be removed so soon as formed, in which case eventually a trace of nitrous acid can convert a maximum, or theoretically infinite, amount of anhydride. And this action is under certain conditions reversible.

Now, as I have already stated, the evidence is conclusive that none of the ordinary food-stuffs-the proteins, carbohydrates 
and fats-are utilized by the living cell as such : through enzyme action, whether extracellular or intracellular, they are broken down into simpler substances, into their component radicles. The evidence is accumulating yearly more and more that, if not the enzymes themselves, at least the zymogens, the bodies from which the enzymes are derived, originate in, and are discharged from, the nucleus, the dynamic centre of the cell. ${ }^{1}$ Already there is evidence that certain of the amino-acids, and it may well be of groups of conjugated amino-acids, constituting Fischer's polypeptids, manifest enzyme action. Their amphoteric constitution in itself favours the possession of these properties.

We can visualize the process thus: Let $\mathbf{A}$ represent a peptone or polypeptid molecule of food-stuff small enough to be absorbed or diffused from the external medium into the cytoplasm of the cell. This may either (1) be broken down into simpler radicles, $a^{\prime}, a^{\prime \prime}, a^{\prime \prime \prime}$, and those radicles utilized by a direct dissociation process for the growth of the pro-
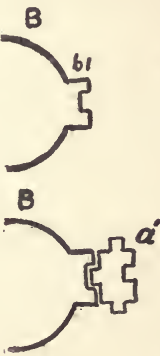
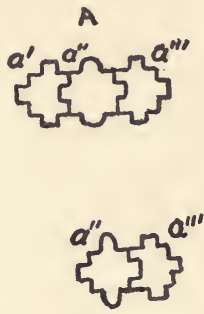

Fia. 7.

teins of the cytoplasm (B, Fig. 7) or, it may be, the nuclear biophoric molecules themselves; $B$, through an

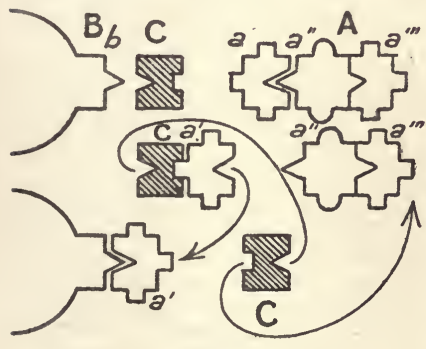

FIG. 8. unsatisfied linkage $\left(b^{\prime}\right)$, exercising a stronger attraction for certain of the constituent radicles of $A$, such as $a^{\prime}$, in which case $a^{\prime}$ becomes part and parcel of $\mathrm{B}$, and $a^{\prime \prime}$ and $a^{\prime \prime \prime}$, whether combined or loosened, are left free in the cytoplasm. Or (2) where the conformation (that is to say, constitution) of $\mathrm{A}$ and of $\mathrm{B}$ (or better $\mathrm{A}^{\prime}$ and $\mathrm{B}^{\prime}$ ) is not such as to permit of this direct attraction and linkage, it may 1 See the address upon "The Dominance of the Nucleus," Pt. II. Chap. V. 
happen that free radicles, $\mathrm{C}$, suspended in the cytoplasm may possess the necessary linkage, and in that case these will act as catalysts or enzymes, first attracting away the radicle $a^{\prime}$ from $\mathbf{A}^{\prime}$, and then in turn by superior attraction being impelled to give it up to satisfy the linkage " $b$ " of $B^{\prime} .1$

\section{Possibilities arising out of above View of Enzyme Action}

But if this conception and visualization of enzyme action approaches the fact, do you see where it leads us ? I am not going to take up all the lines of thought and possibilities opened up by this conception, but only those bearing directly on my theme.

1. In the first place the remains of $A$ left free in the cytoplasm, if of amphoteric type, may in itself act as a catalyst.

2. In the second we are given an understanding of the mechanism whereby foreign proteins may be utilized by the cell. Those proteins are complexes with multiple linkages: they are composed of combinations of the various amino-acids, and the number of amino-acids is limited. It is, therefore, inevitable that existing enzymes, whether extracellular or intracellular, will loosen and detach certain of the radicles, thus dissociating the protein and affording food-stuffs capable of being utilized by the cell. But doing this, to take the simplest case, the relative numbers of molecules of the different amino-acids presented to the cell-and to its nuclear biophores-will differ from the normal, and, if the exhibition of the foreign protein

1 This conception of attraction and separation of radicles from a compound is, I admit, difficult to accept when-as we are apt to do-in the mind's eye we picture the molecules of the different salts, e.g. simple salts, like $\mathrm{NaCl}$ or $\mathrm{KNO}_{3}$, as solid, well defined substances. It must, however, be remembered that in the cell we deal with substances in solution, that the more dilute this solution, the greater the liability towards ionization, towards a loosening of the constituents of a compound one from the other. Under the conditions, therefore, in which enzyme action proceeds, we may safely predicate that a relatively slight attractive force is needed to detach molecules or radicles from one compound, causing them to become associated (also loosely) with other molecules, and to be in turn detached from this relatively loose combination. In solution, that is, we have a state of unstable equilibrium, and without entering into a discussion of the relative strength of electric charges of the molecules, or discussing whether we deal with adsorption phenomena or true chemical combination, we can, I think, compromise by agreeing that the conditions in which enzyme action proceeds are those which favour the occurrence of loose molecular combinations. 
continues, so gradually will there be developed a tendency for the proportion of the radicles constituting the biophoric molecules to vary, those deficient in number being replaced by those that are abundant.

Or again, the simpler complexes due to the breaking down of the foreign protein may not be identical in constitution with those which prior to the exhibition of the foreign protein had been attracted to and had constituted certain particular sidechains of the biophoric molecules. In this way again the constitution of the biophores may become altered. This we may visualize as follows (Fig. 9):
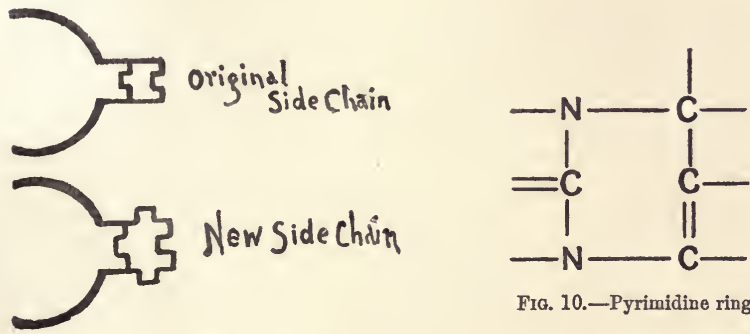

Fic. 10.-Pyrimidine ring.

Fig. 9.

I would recall how a slight difference in the relative attachments of the side-chains, say, of the Pyrimidine ring (Fig. 10) alters the chemical properties of the compound: ${ }^{1}$ in like manner what may appear to be but a slight modification in the constitution of a biophoric side-chain may be expected to lead to material differences in the reactions of the whole molecules, that is, in the case of germinal biophores, of the individual.

1 I came to these views honestly through a respectable collateral heredity. My mother's brother, the late Dr. D. J. Leech, of Manchester, as the subject of his Croonian Lectures at the Royal College of Physicians in 1893 discussed the pharmacological action of the nitrates, comparing and contrasting the action of the nitrates, $-\mathrm{O}-\mathrm{N}=0$, the nitrates, $-\mathrm{O}-\mathrm{N} \leqslant \mathrm{O}$, the nitro compounds, $-\mathrm{N} / \mathrm{O}$, the nitrosamines, $=\mathrm{N}=\mathrm{N}-\mathrm{O}$, and the oximes, $=\mathrm{N}-\mathrm{O}-\mathrm{H}$. He was one of the first English pharmacologists to dwell upon the modification in the action of drugs brought about by slight differences in the order of attachment or composition of radicles. (See the British Medical Journal, 1903, and his collected papers upon "The Pharmacological Action and Therapeutic Uses of the Nitrates," edited by Dr. R. B. Wild, Manchester, 1902.) 
(v.) The Mechanism of Immunity.-One more postulate needs to be laid down. You will remember how I pointed out in my second lecture that the introduction of toxines, whether phytotoxins like abrin, or bacterial toxins like those of diphtheria and tetanus, lead to the abundant if not over-production of antitoxins on the part of the cells.

The simplest explanation of this continued production is that when the toxin (which has all the earmarks ${ }^{1}$ of an enzyme) enters the cell, it combines with and detaches certain side-chains. Whether the cell in consequence becomes destroyed or, on the other hand, succeeds in neutralizing the toxin, depends upon two factors-the number of toxin molecules that gain entrance, and the rate at which the cell can reproduce the lost side-chains. Just as a damaged crystal if placed in a saturated solution of the particular salt repairs itself, so we have to assume the capacity on the part of the living molecules to build up lost parts. So long, that is, as the toxin in the cytoplasm acts as a catalyst detaching the particular side-chains, for so long will the molecular complexes build up side-chains until from the law of habit this building up exceeds the immediate need of the cell, and the side-chains being in excess are excreted to become the antitoxins of the blood serum. We must, that is, regard these side-chains as now built up in series from the simpler cytoplasmic molecules

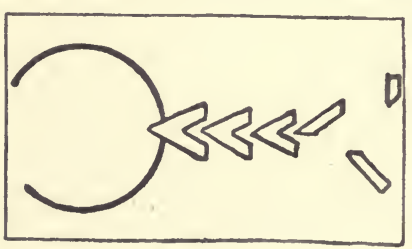

Fic. 11. of the cell-sap, and when so built up easily liberated. Here parenthetically it deserves note that the bodies which are antitoxins for man are toxins for the bacteria -all, in fact, depends upon the point of view.

That this conception of the mechanism of immunity and progressive adaptation ${ }^{2}$ is substantially correct has, I urge, been shown by the later admirable studies of Professor Victor C. Vaughan of Ann Arbor, Michigan, and Abderhalden of Berlin. Vaughan was

1 Corrected from "properties" in the lecture as delivered, this being the more accurate statement.

2 A conception laid down by me in 1908 in my Principles of Pathology, though there following naturally upon my article upon "Inheritance" pablished in 1901 . 
the first to show that every true protein when digested with several times its bulk of absolute alcohol in the presence of 2 per cent of sodium hydroxide, splits up into a poisonous and a non-poisonous moiety, the former soluble in alcohol, the latter insoluble. The poisonous moiety, when introduced into the system by any path other than through the alimentary canal, is rapidly fatal in relatively minute doses, setting up symptoms identical with those seen in the anaphylactic stage. I have pointed out (p. 38) that anaphylaxis, or hypersusceptibility, is the first phase in the production of immunity. On the principle, therefore, that like results are produced by like substances we arrive at the conclusion that this hypersensitiveness or anaphylaxis is essentially due to the disintegration of the introduced proteins with rapid liberation of the poisonous moiety.

But the first dose of a foreign protein introduced into the tissues sets up none of the phenomena, the second does. Evidently in the course of the few days necessary for anaphylactic phenomena to manifest themselves the organism has gained a new power, that of splitting up the foreign protein. Abderhalden demonstrated the first stages in this process. In 1910 he and his pupils published a remarkable series of "Serological studies by means of the optical method." Starting from the fact that the different proteins and peptones, when in suspension, present each in the polariscope a specific index of rotation, he demonstrated first that enteral digestion of proteins, i.e. the introduction of the same through the intestinal tract, has absolutely no effect upon the physical condition of the blood serum: its rotatory power is unaltered. But parenteral injection of any of the more common proteins, i.e. by the subcutaneous or intravenous route, leads to a very different state of affairs : the index of rotation of the removed blood plasma undergoes progressive alteration, a clear indication that the protein is being broken down, and this is confirmed by the fact that by dialysis peptones can be separated off from the plasma.

Within forty-eight hours, therefore, after the introduction of a foreign protein, the system has responded either by elaborating a proteoclastic enzyme, or, it may be, by a rapid increase in the production and discharge of already existing proteoclastic enzyme present in certain cells. But what I would particularly emphasize is that in this first phase the enzyme is not specific. 
It is a general or indifferent proteoclastic ferment. The blood plasma at this stage will act not only on the particular protein inoculated, but also on other proteins, will break down indifferently bodies such as globulin, casein, gliadin, gelatin, and their peptones with the production of slightly toxic bodies.

It might be laid down that this indifferent ferment first produced is the cause of the anaphylactic phenomena. Against this view is the fact that Abderhalden's ferment is recognizable in twenty-four to forty-eight hours, whereas anaphylactic phenomena are not obtainable until the sixth to the tenth day, and again, the anaphylactic phenomena are specific: it is only the protein first introduced that on subsequent injection sets up disturbance. Abderhalden's proteolytic and peptolytic enzymes are active in respect to any protein. We have evidence, therefore, of the development of two stages: (1) elaboration and discharge into the blood within forty-eight hours of indifferent proteoclastic and peptolytic enzymes; (2) the gradual production within six or eight days of more high-developed specific enzymes having the power of rapid dissociation of the particular protein introduced, with liberation in the course of a few minutes of sufficient toxic disintegration products to set up grave symptoms. The rapidity with which the phenomena may show themselves, and that upon the introduction of extraordinarily small second doses of any particular protein, suggests that there is a selective taking up of the protein by particular cells, in the first place, with production and storage of the specific enzyme, so that the moment the second dose is absorbed by these cells there is an explosive disintegration and direct action of the poisonous disintegration product.

But now by cautious reinjection of the foreign protein we can pass through the anaphylactic to the succeeding stage of immunity. Having accomplished this the introduction of the foreign protein no longer leads to acute poisoning. Any one who has observed Pfeiffer's phenomenon-who has seen living typhoid bacilli swell up and dissolve "like pieces of sugar" in the blood serum or peritoneal fluid of a highly immunized guinea-pig - cannot but be impressed by the extraordinary and specific digestive powers that have been acquired by the body fluids through this process of immunization. We see here a further evolution of the same process-a third stage-namely, 
the eventual development by the cells of the organism of further enzymes, which disintegrate the poisonous moiety of the protein disintegration products, and so carry on the degradation of the foreign protein to a harmless stage; which break up the association of radicles still further, so that now they are converted into more elementary constituents which, instead of disturbing the cell activities, can, perchance, be utilized as food-stuffs. As my colleague Dr. Fraser Gurd ${ }^{1}$ has shown, in the immunized animal the earlier enzymes are not replaced, they are still active and abundant, but evidently after they have broken down the specific protein, with the liberation of the poisonous substance, this is immediately acted upon by the new specific enzymes and rendered innocuous. ${ }^{2}$

(vi.) Cell and Tissue Differentiation: Ontogeny.-With this clear indication, therefore, before us of the way in which the cell substance can become modified and adapt itself according to need, it is not necessary, with Weismann, to postulate the existence of two orders of living matter, germ plasm and somatoplasm. It suffices to hold that there is one common biophoric material, or at most biophoric material in part derived from one, in part from the other parent, and to recognize that as the fertilized cell divides and redivides and the resultant cells find themselves in different relationships, so do they become modified and differentiated, giving origin to the various tissues, the eventual germ cells being so developed and so placed that they are exposed to the minimal amount of differentiation.

If embryogeny or, more exactly, ontogeny-the development of the individual-is a recapitulation of the phylogeny-of the evolution of the race-it is this not as an historical reminiscence and nothing more. It is this only so far as it is a necessity, only so far as; for the unfolding and elaboration of the cell structure of the various tissues up to the stage in which the adult of a particular species will find itself in equilibrium with its surroundings, the biophores distributed to those cells must, of necessity, in the course of their growth and multiplication, pass through a particular succession of equilibrations, of modifications, of accretions and losses. Where a given modification can

1 Amer. Jour. Trop. Dis. and Prevent. Med. i., 1914, 776, and Jour. Med. Res. $\mathrm{xxxi.,} \mathrm{1914,} 205$.

2 For a fuller study of these matters see the paper upon " Parenteral Diges. tion " in Pt. II. Chap. IX. 
be attained by a short cut, there certain phases of the phylogeny fail to be recapitulated. In short, the development of any particular tissue may aptly be compared with the synthesis of one of the higher organic compounds. That cannot be accomplished by taking so much Carbon, Hydrogen, Nitrogen, etc., mixing and heating them together, but demands a long process of building up-it may be a score or more successive processes of combinations, associations and dissociations-before the final product is attained; the constant endeavour of the chemist being to simplify the process, to arrive at the same results by finding some reaction which will cut out half a dozen or more of the steps and lead more rapidly and more economically to the same result.

(vii.) Amphimixis.-This mention of the contribution of the two parental germ plasms to the fertilized germ cell, or zygote,

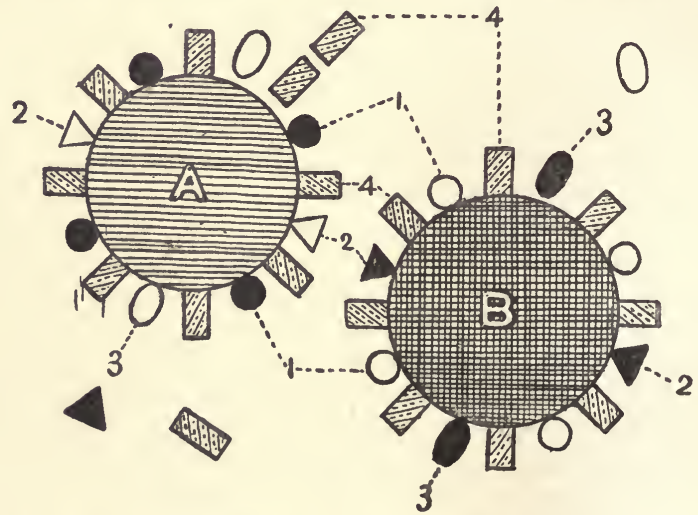

FIG. 12.-A, biophore of paternal, B, biophore of maternal origin ; 1, 2, and 3, varions allelomorphic side-chains; 4 , side-chains common to both orders of biophores.

leads to certain important considerations. If the metabolic activities of the cell are of the order here stated, and if, as is evident from the studies of cytologists and embryologists, equivalent amounts of heritable material-or biophores from the two parents-reach the zygote and, in the subsequent process of active cell division of the embryo, are contributed to each 
cell, i.e. to each cell nucleus, again the static conception cannot be permissible. We must realize that these two orders of biophores, existing in each cell of the body and activating each cell, are throughout life undergoing growth, building up sidechains and radicles, and that there is a constant recurrence of processes of association and discharge from each molecule out of and into the nuclear sap. But if this is the case and the two orders of active living molecules lie side by side in the fluid medium of the nucleus, it is impossible to imagine, according to the current Mendelian doctrine, that the two do not interact one upon the other, that the two orders of side-chain substances and dissociation products keep severely apart. We may safely say that there must be interaction: that where tissue cells are undergoing active growth and metabolism and radicles and groups of radicles built up by biophores of the one order become dissociated from those biophores, if they are of an order common to both paternal and maternal biophores, they may be employed indifferently in the building up and growth of biophores of both orders; if of an order peculiar to, say, the paternal biophores, may under certain conditions be attracted to and built into the growing maternal biophores. We can imagine environmental conditions favouring the predominant growth of just the one group of biophores so that the cells of some one tissue take on the characters of the cells in the one parent, or, more easily, in actively working tissue-cells, such an interchange and selection of allelomorphic radicles that eventually one common type of modified biophoric molecule may govern the cell (Fig. 12).

And at a slower rate due to their more latent state, this same interchange, we must predicate, is capable of occurring in the biophores of the germ cells, so that eventually a succession of heterozygous generations will give rise to forms without the pure dominant gross characteristics, but showing an approximation to intermediate properties $;^{1}$ or, again, eventually, the interchange of radicles may be such that the various dominant radicles belonging to both orders of biophores be attracted to, built into the growing molecules, and reproduced by the biophores derived from the one parent-whereas the biophores of the other origin in

1 As in Correns's observations upon the hybridization of the two strains of Mirabilis jalapa, alba and rosea, in which the heterozygotes of the F. generations are not of strong dominant rose colour but of a paler dilute pink. 
their growth would show a greater affinity for the radicles whose constitution lead to the appearance of recessive qualities.

The existence of determinants as entities, as I have demonstrated, cannot on physical grounds be accepted, and if in their place we accept differences in the constitution or arrangement of individual radicles composing essential portions of the combined and complex molecules of living matter, it is still possible to interpret the facts of Mendelism and indeed interpret not a few phenomena which by the hypothesis of determinants cannot be explained. ${ }^{1}$

\section{SUMmary}

However, I realize that here I advance into regions outside the boundaries of current medical thought. To sum up, it may be said that, according to this hypothesis, each species must be regarded as having for its essential living matter a distinct organic compound, a compound as distinct as any inorganic salt, but differing from that simpler inorganic salt in that, whereas the central ring or chain is of relatively fixed constitution, the radicles composing that ring or chain are capable of attracting and then of reproducing a series of side-chains which may vary, so that within the species there may be various strains, just as we may speak of various strains of crystalline haemoglobin being obtained from different samples of human blood.

Let me freely admit that the diagrams here afforded are very crude. With the necessarily condensed presentation of my subject they have seemed to me essential. To those unfamiliar with the advanced organic chemistry of to-day, to have attempted illustrations of the successive stages of my argument by elaborate graphic chemical formulae would have been worse than useless. I shall be satisfied if I have rendered it clear that it is possible to replace an impossible hypothesis based upon supposititious independent and transposable determinants by one based upon what we know of the composition and physical

1 Of set purpose, as being outside the scope of my earlier work and of medical research, I did not in the course of these lectures refer to the newer studies of the last few years upon differentiation of the individual chromosomes. Such differentiation with localization of groups of unit characters in particular chromosomes is, I would point out, distinct from Weismann's determinants. I hope to take up this matter later. 
structure of the main and outstanding constituent of living matter-the proteins - a hypothesis that renders it possible for us to understand how digestion or, more broadly, metabolism is the keynote of the whole matter; how through this universal system of dissociation of food-stuffs into their elemental radicles it is possible for the cell to utilize and accustom itself to new and foreign food-stuffs; how doing this, the constitution of the living molecules may become altered; and how Professor Bateson's incapacity to comprehend the possibility of progressive acquirements by the individual and his germ cells is due to his static method of approach to the subject. To one who regards life, not from the morphological point of view, in terms of form, but from the physiological, in terms of function-who regards life as a moving equilibrium, who regards it as in essence "a state of persistent and incomplete recurrent satisfaction and dissatisfaction of . . . certain proteidogenous molecules," 1 and metabolism as the primary and basal characteristic of living matter-for such an one there exists no such stumbling-block.

\section{Progressive Accretion of Properties}

Just as Weismann's hypothesis of heredity breaks down owing to the sheer physical impossibility of all the determinants it demands being packed into the microscopic nuclear chromosome, so the Batesonian hypothesis of a backward evolution by the progressive removal of inhibitory factors, like the baseless fabric of a vision, fades into nothingness once it is confronted with the demonstration that positive, direct acquirements can surely be brought about. Both hypotheses, indeed, enter into the limbo of the past, as examples of the Spencerian tragedythat of a deduction destroyed by a fact.

I imagine that it will be your experience-it certainly has been mine-that it is those whose gentle birth is least obvious, and genealogy most dubious, those who hang on to the borderline of good family, who most vaunt themselves regarding their descent. They do not realize that in these days it is a man's ascent that ennobles him, not his descent, even if, paradoxically, ascent is not possible without good rich blood: it is the progressive accretion of properties, not the progressive loss. But,

1 Adami, Principles of Pathology, 1st ed., 1908, vol. i. p. 55. 
says Professor Bateson, in nature it is the opposite : it is by the progressive loss of properties that from being an amorphous mass of protoplasm man has become man. Life, according to him, first appeared upon earth enshrined in matter of maximum complexity, so complex that it was without form and void, and only as through the vast aeons of geological time this matter fell into order and simplified itself, and successive species developed, did we eventually in these latter days arrive at the simplest and least complex of all creatures-man, simple man.

Does it not appear to you that this is Topsy-turvydom? Is it not on the face of it more probable that the reverse has been the case, that the earliest matter that could be recognized as living was the simplest? It is not that the earliest living matter possessed all the determinants of all the organized parts of all future forms of life, but that its constitution was such that it possessed from that constitution, and in consequence of its metabolic activities, the potentiality to undergo progressive modifications of that constitution, which modifications manifested themselves, as an outcome, in progressive changes of structure. The potentiality was there, not the determinants.

\section{Conclusion}

One last word. I feel that as one on active service some apology may be required from me for having taken your time, and, it may be said, my country's time, in dealing in the course of these lectures with a matter so wholly foreign to the war, to military medicine and military duties. Were what I have placed before you wholly new, had I collected, thought out, and elaborated the material of these lectures during the two years since I received the invitation to deliver the course, an apology would, I think, rightly be in place. As a matter of fact these lectures are little beyond what I have taught and written in the fifteen years and more preceding the war : they are a digest and compend of those earlier writings and conclusions, brought up to date by means of modern instances confirmatory of or expanding that earlier work. Four hours before delivering the last of these lectures, in order to complete my references, I went to the Library of the Royal Society of Medicine in Wimpole Street and took out the volume of the British Medical Journal for 
1901, containing an address delivered by me at Brooklyn, New York, in May of that year. ${ }^{1}$ That address I had not looked up for a decade or so, and it was with not a little surprise that I found laid down there the physico-chemical conception of inheritance here given, and the doctrine of direct inheritance of metabolic conditions, such as gout and of disturbances of the internal secretions. Rather, therefore, the apology should be that I have plagiarized myself in so wholesale a manner. I shall, however, be satisfied if it is demonstrated that the work of medical men of this generation, of pathologists and bacteriologists - work formed upon the observations and methods of the great biologists of the past-is repaying the debt to biology by establishing principles which are basal for general biological advance.

1 Seo Pt. II. Chap. II. 



\section{PART II}

\section{ON VARIABILITY AND ADAPTATION}





\section{CHAPTER I}

\section{ON THE VARIABILITY OF BACTERIA AND THE DEVELOPMENT OF RACES 1}

From a medical as from a biological point of view, the variability of micro-organisms is a subject of the highest interest. If it can be clearly demonstrated that modifications of varying degrees of permanency can be induced in sundry species of bacteria, that "new races" are capable of being developed under the influence of conditions that are easily recognizable and easily controlled, then not only do we gain further knowledge of the laws governing evolution, but-what for us is of more immediate import-we become enabled to clear up not a few of the difficulties constantly presenting themselves in the study of zymotic, or mycotic, disease. The class of difficulties to which I refer is so familiar that here I need give but the briefest indication thereof. It is notorious, for instance, that successive epidemics of one disease, say, scarlatina or influenza, are characterized by well-marked differences in symptomatology, and in the intensity of effects upon the individual; it is notorious also that during the progress of one epidemic remarkable changes are to be made out in the virulence of the malady. Often at the onset the cases are so mild, the symptoms so vague, that diagnosis can only be pronounced with exceeding caution. Such doubtful early cases may be followed by a succession in which the disease is typical and of increasing virulence, and eventually is reached the period of decline of the epidemic, and now again the cases assume a dubious aspect with indefinite atypical symptoms. Or take a disease which now unfortunately

1 Reprinted from the Medical Chronicle, September 1892. 
has become more or less endemic, namely, diphtheria, and observe the series of progressive cases that is to be made out from the simple sore throat associated with the mildest constitutional effects, through slight cases of croup to those terribly malignant attacks in which the manifestation of the disease and death are almost synchronous.

If the micro-organisms of disease have constant attributes, if the species of bacteria are fixed, their characters unvarying, then all these differences in the nature and intensity of the symptoms produced by any one micro-organism at diverse periods and in diverse individuals can only be due to subtle meteorological changes, to differences in the power of resistance to microbic invasions displayed by the individual, and to the dose, if I may so term it, of infective material incepted by the individual. Now, without doubt, all these factors are of very great importance, but at the same time it cannot be denied that they do but vaguely advance our knowledge. Up to the present the study of atmospheric influences as affecting zymotic diseases, while impressing upon us one or two main truths, has, in other respects, involved us in a maze of contradictions, and while the last few years have greatly extended our knowledge of the nature of the conflict between the organism and the microbe, clinical experience is constantly bringing before us the paradoxical phenomenon of disease, in its severest form, attacking individuals in whom one would hold the constitutional powers of resistance to be at their highest. So, too, difficulties in the way of exact determination are insuperable, clinically, with reference to the "dosage" of infective material.

But if, while granting freely that all the above-mentioned factors play each a part, it can be shown that modifications of the powers of micro-organisms can be induced, both within the organism and outside it-alterations in appearance, in the ferments and other products of their vital activity and (among pathogenic microbes) in virulence; alterations, not temporary, but continuing through generations; alterations that are capable of being demonstrated in the test-tube and under the microscope-then we reach one stage further in actual advance in our knowledge of infectious disease, and from this advance gain a firmer standpoint from which to appreciate the other factors.

Largely influenced by the admirable researches of the German 
bacteriologists, and in this country by the teaching of Dr. Klein, the tendency of the medical world has been to regard the species of micro-organisms, and especially of pathogenic micro-organisms, as fixed. If in each case of a given disease a given microbe is discovered with specific cultural characteristics: if the more closely zymotic disease is studied the more clear becomes the evidence of its infectious nature, of its passage either directly or indirectly from person to person, while the more the subject is studied the weaker becomes the evidence of the spontaneous origin of infectious disease: then the greater is the difficulty of arriving at any other conclusion than that pathogenic microbes belong to species that are fixed and possess unchanging attributes. I need not say how valuable, not to say necessary, it has been in a young science like bacteriology to hold this view of the fixity of species, and, speaking broadly, this view must still be held. In the great majority of cases the micro-organisms gained from the tissues of the patient suffering from any one zymotic disease approximate sufficiently closely to the type for us to say with absolute confidence that no specific alteration is to be discovered in them. But while acknowledging this much it must be confessed that there has been a tendency to overlook differences in the mode of growth of pathogenic microbes-generally, it is true, minute, though not always so-and to dwell upon differences in the resistance of the organism more than upon differences in the pathogenic properties of the microorganisms whenever, in an individual case, or in an epidemic, the symptoms have varied from the ordinary. While bacteriologists in general admit, to a greater or less extent, that bacteria show variations, I know of no work in which the facts in connexion with such variations have been brought together; it may, therefore, be useful at the present time if I gather together some of the many researches into the variability of microbes, and show that this variability can clearly be made out.

Undoubtedly where a number of facts are brought together, all pointing in one direction, there is a danger that by some these facts will be held to support an extreme theory, and one that cannot surely be gained from them-the theory, in this case, that non-pathogenic bacteria can easily become pathogenic, and that zymotic disease may, as a frequent event, arise de novo. While, possibly, further research may prove that in a certain 
limited number of cases a harmless saprophyte is capable of developing into a pathogenic microbe, at the present moment ${ }^{1}$ the facts are wanting to support this hypothesis. The extreme conclusion to be reached now is that there are species of pathogenic micro-organisms whose virulence is capable of manifesting great modification, and that such modification is fitted to explain some of those differences in the course of zymotic disease which must have arrested the attention of all medical men.

\section{ON certain Characteristios of the Bacteria as a Whole AFFECTING THE LIABILITY TO VARIATION}

At the very onset we should expect to find the bacteria peculiarly well adapted for the study of the most elementary problems of evolution; their organization, as compared with other forms of life, is so simple, the generations-if generations they may be called ${ }^{2}$ - succeed each other with such extraordinary rapidity, and, what is of yet greater importance, our study of these forms would seem to be wholly freed from the perturbing influence of sex. On the one hand there can, in the bacteria, be no tendency towards the production of races through sexual agency; on the other the reverse tendency is equally absent, namely, the tendency of conjugation to preserve the mean, to lead to the development of individuals approximating to the type.

Here, then, in studying these unicellular asexual bacteria, we investigate the simplest and most fundamental principles of heredity and evolution, and the influence of environment becomes most evident. Weismann, who in the higher forms of life would make the development of individual differences and the inheritance of the same almost wholly dependent upon the phenomena which accompany the fusion of the male and female reproductive cells, freely acknowledges that to the

[i.e. in 1892.]

2 The word generation as applied to the Schizomycetes is not a little unsatisfactory-yet I know no other word at present in use that is capable of replacing it. Apart from the sexual significance that may attach to it, this word embraces the idea of parentage. Now, among the bacteria there is no true parentage, for what happens in the process of fission is that the bacillus divides into two portions, each of which becomes a separate individual, but neither can be regarded as the parent form; each equally with the other represents, and, to a certain extent, is, the earlier single individual. 
protozoa we must look for the origin of " hereditary individual variability," and, dealing with them, emphasizes this influence of environment. If, for instance (he states), a protozoon, by constantly struggling against the mechanical influence of currents in water, were to gain a somewhat denser and more resistant protoplasm, or were to acquire the power of adhering more strongly than other individuals of its species, the peculiarity in question would be directly continued on into its two descendants, for the latter are at first nothing more than the two halves of the former. It therefore follows that every modification which appears in the course of its life, every individual character, however it may have arisen, must necessarily be directly transmitted to the two offspring of a unicellular organism. ${ }^{1}$

And in connexion with the bacteria we can modify the environment at will to an extent that is far beyond our power in regard to higher organisms ; we can alter the media of growth, can make these more or less nutritious, can make them acid, neutral, or alkaline; can alter the superincumbent air to such an extent that if desired we can in many cases bring about growth in vacuo or in an inert atmosphere of hydrogen or carbonic acid; we can add or remove this or that normal or abnormal food-stuff to or from the medium of growth, or can add salts and antiseptics, and observe the effects upon the microbes studied; we can observe the mutual effects of concurrent growth of two or more forms, and the effects which the product of growth of a microbe exert upon it, or again can modify the temperature within the widest limits. With no other forms of life are such extraordinarily diverse modifications of environment possible.

I propose now to set forth in regular order the facts at our disposal with regard to the production and existence of variations of microbes. To give all is, from their very extent, impossible in this connexion, but sufficient may be given to show very clearly that this variation is far more widespread than is generally supposed, and that we can safely attribute to this variability many of the difficulties already mentioned met with in the clinical study of infective disease.

It is unnecessary for me to enter into the earlier history of the subject, into the controversy that raged around "poly-

1 Essays upon Heredity, Oxford, 1889, p. 278. 
morphism " and round Nägeli's theory as to variability, ${ }^{1}$ for at the time that these were most discussed the subject was not ripe for treatment. The methods of investigation were imperfect, pure growths could not with certainty be obtained, and consequently the arguments advanced pro and contra rested upon insecure bases. Still Lankester's observations ${ }^{2}$ on the change of form of the Clathrocystis, or Beggiatoa, roseo-persicina, and later Kurth's "Observations on the Bacillus Zopfii," 3 have stood the test of time, and may be said to have laid a solid foundation upon which rests our present knowledge of variation among microbes.

\section{Transient Variability}

We possess now such a mass of separate observations upon transient variability of bacteria that it is difficult to know how much to say on this subject here, how much to leave unsaid. Every one who of late years has studied bacteriology must have come across numerous cases of this nature. Every one admits that according to the age of a growth, according to the nature of the medium of growth, changes in form and properties are common. They may be slight, but if looked for are almost sure to be found. I would proceed to mention cases in which such changes are very marked.

(1) Change of Form.-The Bacillus Zopfii, ${ }^{3}$ for example, when grown on various nutrient media manifests itself at first in the form of long twisting tortuous filaments ; at a later period these give place to chains of bacilli of fair size, and eventually in an old growth the bacilli are replaced by what some would consider as cocci, others as spores. We need not now concern ourselves about this controversy. The important point is that, transferred to a fresh "soil," the bacillary form, just like the spore or coccus form, develops into typical long convoluted threads.

Even more definite changes of shape are producible by slight

1 Nägeli, Die niederen Pilze, Munich, 1877.

2 Lankester, Quart. Journ. Micr. Science, xiii., 1873, p. 408. [It may interest Sir Ray Lankester to observe that I have been familiar with the observations upon his peach-coloured bacterium for a quarter of a century and more, and have given him due credit. The reason why I did not refer to these in my Croonian Lectures is obvious: he has consistently ascribed the modifications in form to indirect and not to direct equilibration.]

3 Krth, Botanische Zeitung, 1883. 
alterations in the medium of growth. Take, for instance, the Eberth-Gaffky bacillus of enteric fever. This is a bacillus of fair size-three to five times as long as it is broad, with rounded ends, and, thanks to the possession of long vibratile cilia along its sides, it is normally endowed with great rapidity of motion. It has, further, the property of resisting the action of fairly large amounts of carbolic acid in the medium of growth-a property which has been utilized by Vincent to separate it out from other microbes, and to gain pure diagnostic cultures from the faeces of those affected by the disease, or from contaminated water. If beef-broth be taken containing about 1 part of carbolic acid in 600, the Eberth-Gaffky bacillus, almost alone among the bacteria, will grow in it at a temperature of $42^{\circ} \mathrm{C}$., rendering the broth turbid in the course of a few hours. But if a drop of this be examined, one finds not the characteristic motile bacillus, but shorter forms and often diplococci, and these are non-motile. In fact, there is an absolute want of resemblance to the type bacillus. Yet if a culture of these be made in the ordinary beefbroth of the laboratory, devoid of carbolic acid, there is an almost immediate return to type. ${ }^{1}$ But there is a much simpler method of gaining polymorphism in connexion with this microbe. Employing a series of potatoes of diverse origin, it is found that upon some the growths of the microbe are atypical not only in naked-eye appearance but also under the microscope, developing into long filaments. This atypical growth has been commented upon by numerous observers, including Fränkel and Simmonds, ${ }^{2}$ Buchner, ${ }^{3}$ Schiller, ${ }^{4}$ and Kamen. ${ }^{5}$ Buchner's observations render it probable that this atypical growth is in close relationship to the known varying acidity of the potato.

Still more striking are the results obtained by Charrin ${ }^{6}$ in the case of the small bacillus of blue pus, which within the body of an infected animal, or grown in beef-broth, is what may be termed a microbacillus-a minute short bacillus, the individuals being often attached in pairs end to end.

If $\beta$-naphthol be added to the beef-broth in the proportion

1 Vincent, Comptes rendus de la Soc. de Biologie, 1890, No, 5.

2 Fränkel and Simmonds, Zeitschrift f. Hygiene, ii., 1887, p. 138

s Buchner, Centralblatt f. Bakteriologie, iv., 1888, p. 353.

- Schiller, Arbeiten aus dem kais. Gesundheitsamt, v.

5 Vide Petruschky, Centralblatt f. Bakteriologie, vi., 1889, p. 657

- Charrin, La Maladie pyocyanique, Paris, Steinheil, 1889. 
of 0.02 per cent, after forty-eight hours long straight bacilli are to be made out, broader than the type, and from three to five times as long, If, instead, alcohol be added (about 4 per cent), at the end of twenty-four hours the change is even more pronounced; besides large bacillary forms, similar to those last mentioned, there may be somewhat curved filaments from ten to fifteen times as long as the type, if not longer. If 0.015 per cent potassium bichromate be added, then, even after fifteen hours, one can make out long undulating filaments stretching across the whole field of the microscope. And if the growth be acted upon by 0.7 per cent boric acid for six days, then in place of the microbacillus we see "comma" forms, S-shaped forms, and close spirals; while 0.1 per cent creasote acting for some weeks causes the production of micrococci and diplococci.

There could be no better example than this of the polymorphism induced by environment. In all these cases, however, we are not dealing with permanent variations. Return to "ordinary" media brings about in all a return to what may be styled "type." I say what may be styled "type," inasmuch as the broth, potatoes, and other materials employed by the bacteriologist are the common soils in and upon which can be grown most bacteria, but they are not of necessity their natural habitat, and when environment evidently plays so important a part in determining the shape of bacteria it is quite possible that what we consider as typical are, in many cases, not the usual (or primitive) but are acquired forms.

(2) Changes in Pigment Production.-But shape is far from being the only property of microbes that is modified by environment, and very striking results are to be gained by a study of those microbes which, in the course of their growth, produce pigment-the chromogenic bacteria. ${ }^{1}$ Of these a very large number lose the faculty of pigment formation in the absence of oxygen, many again when grown in the absence of diffuse light, and all under the action of the direct rays of the summer sun. An alteration in the medium of culture has also its effect. Thus the Bacillus ruber of Kiel (better known in this country as the " rouge de Kiel," the name under which our attention was first drawn to it by Laurent ${ }^{2}$ ), the Micrococcus indicus, the Micro-

1 Schottelius, Kolliker's Festschrift, Leipzig, 1887.

2 Laurent, Annales de l'Inst. Pasteur, iv., 1890, p. 465. 
bacillus prodigiosus, and yet other forms which produce a red colouring matter vary in the intensity of their colour production according to the acidity or alkalinity of the medium of growth. The most beautiful example of temporary modifications of easy production by alteration of environment is supplied in Gessard's very full study of the Bacillus pyocyaneus.1 Ordinary beef-broth sown with this bacillus soon takes on a greenish-blue slightly fluorescent appearance, and the blue colour becomes more marked if there be a relatively large surface exposed to the air, or if at intervals the culture be shaken, and the pellicle of surface growth be made to sink to the bottom of the vessel. Evidently then there are at least two pigments produced, and Gessard succeeded in causing the independent development of either. For he found that upon solidified white of egg the bacillus gives rise to the bright green colour alone, while upon the agar-agar, to which glycerine and a fair quantity of peptone had been added, no green is developed, the medium rapidly becoming tinged throughout an intense deep blue. It may be added that the absence of free oxygen causes the development of a colourless growth. These observations, I repeat, can be easily confirmed.2

(3) Modifications of Ferment Production.-Similarly modifications can be induced in the ferment production of microbes. Thus many micro-organisms, which elaborate a ferment capable of liquefying gelatine, do not manifest that power if glycerine be added to the medium of growth, or (from a different cause) lose that power, as Cartwright Wood has shown ${ }^{3}$ in the case of the Cholera spirillum, of the Bacillus prodigiosus and the Micrococcus indicus, if minute quantities of carbolic acid be added to the culture medium. Again, as indicated by Lauder Brunton and Macfadyean, ${ }^{4}$ the bacteria which form a peptonizing enzyme on proteid soil can also produce a diastatic enzyme on carbohydrate soil.

(4) Modifications of Pathogenicity. - With regard to the

1 Gessard, Annales de l'Inst. Pasteur, iv., 1891, p. 737; and v., 1891, p. 65.

2 Adami, Meeting of East Anglian Branches of British Medical Assoc. Cambridge, Lancet, July 24, 1891.

s Cartwright Wood, Proc. Royal Soc. Edin. xvi., 1889; and Laboratory Report, R.C.P. Edin. ii., 1890, p. 253.

- Lauder Brunton and Macfadyean, Proceedings Royal Society, xlvi., 1890 p. 542. 
temporary loss of pathogenic power-of virulence-the case is rather different. It would seem to be most difficult to bring about a loss of virulence that does not tend to be permanent. That is to say, very special methods have to be employed whose action is exerted upon more than one "generation" of the microbes, such as passage through a series of animals less and less susceptible to the invasion of the given microbe in order to exalt organisms, like the pneumococcus of Talamon-Fränkel, whose virulence can only be retained outside the body by constant removal to fresh media; others, like the typhoid bacillus, which, according to Chantemesse and Widal, ${ }^{1}$ are so susceptible that a loss of virulence is almost immediate. This, after all, is only what is to be expected if, as seems most probable, the pathogenic property is that which has been latest acquired. A late acquisition is most easily altered, and the tendency to reacquirement of the same is least evident. Intensification of pathogenic properties can, however, be induced by other means than by passage through animals. Hueppe's observations would seem to show that the Bacillus cholerae asiaticae grown anaerobically gains in virulence.

This principle-that it is difficult to stamp a modification firmly upon a species of bacterium, as, indeed, upon any animal or vegetable species-is exemplified throughout the long series of attempts that have been made to produce new races of microorganisms, and now, when I proceed to recount some of the more successful of these attempts, the principle will be seen to be constantly in evidence.

\section{Modifications of Longer Duration}

From the transient modifications which $I$ have noted above it is easy to pass to a series of instances in which the return to the normal only follows after an increasing number of generations, in which numerous generations retain the acquired characteristics, and the original properties only gradually reassert themselves. Take, for example, almost any of the chromogenic bacteria. If a minute quantity of a high-coloured typical growth be removed and spread over the cut surface of a sterilized potato it will be found that the individual colonies which result

1 Chantemesse et Widal, Annales de l'Inst. Pasteur, ii., 1888, p. 54. 
present differences in pigment production; the majority reproduce the type, but some are even deeper in colour than the original, others paler, others colourless. If from one of these colourless colonies fresh potato growths be made, a large number of coloured colonies develop, but also a large number of colourless, and the more frequently this selective process is repeated the greater becomes the proportion of the resulting colourless colonies. Yet even after a very great number of growths made in this way there is always a tendency for certain individuals and their progeny to revert to type. Slight alterations in the nutrition of the individuals probably induced the first differences in pigment production, and the induced modifications tend to reproduce themselves through many "generations." 1

The same occurs if a culture of one of these non-pathogenic forms be heated for a few minutes to a point approaching that at which immediate death of the special microbe is brought about. After this treatment there may be numerous "generations" produced, incapable of pigment production. Illustrating this and the preceding order of appearances, I showed a series of specimens at the Nottingham meeting of the British Medical Association in July (1892). The series included cultures of the Bacillus ruber, Plymouth; Bacillus ruber, Kiel ; Microbacillus prodigiosus, Bacillus indicus, and Sarcina erythromyxa. To yet more marked effects of high temperature I shall revert at a later period.

Again, old cultures of most micro-organisms become attenuated, and although these attenuated forms still propagate themselves, it may be weeks-that is to say, almost countless "generations"--before there is a return to primitive appearance and primitive properties. Thus old growths of Koch's cholera spirillum, or the Finkler-Prior spirillum of Cholera nostras, ${ }^{2}$ or, again, of the Vibrio metchnikovi ${ }^{3}$ yield colonies which have an absent or greatly reduced power of liquefying gelatine, and only very slowly and under favourable conditions does this power manifest itself once more. From old cultures of the Bacillus pyocyaneus, the Pink torula, and many more chromogenic microbes, I find, in common with other observers, that

1 See more particularly Charrin and Gessard, loc. cit.

2 Firtsch, Archiv für Hygiene, viii., 1888, p. 369.

3. Pfeiffer, Zeitschr. für Hygiene, vii., 1889, p. 347. 
colourless or faintly-coloured growths are obtainable, which for long show no reversion to type.

It would seem that, without there being necessarily any attenuation, there may be modifications persisting for long periods. It has been noted by many observers that for some considerable period after Staphylococcus pyogenes aureus has been separated out of pus and cultivated, the colonies are colourless, and that only eventually may the golden-yellow pigment become produced. During the last long vacation I was a victim to this order of affairs, for having obtained a micrococcus from some pus gained from a case at the Addenbrooke Hospital, I made two successive cultures of the pure growth during the course of a week, and the second of these I employed to distribute to the bacteriological class as the Staphylococcus pyogenes albus. The cultures made by the class developed the goldenyellow pigment, and proved that we were dealing, not with the " albus," but with the "aureus." It may be added that, save for colour difference, the two forms are indistinguishable.

\section{The Production of Races}

From such cases as these we can pass on almost imperceptibly to the development of what may be termed races. I will presently discuss the qualifications that must be applied in employing this expression. For immediate purposes it is enough to state that a slight modification of environment acting over a sufficient number of "generations "- that is to say, acting for a sufficiently long period-or a powerful stimulus applied temporarily to the individual bacteria of one "generation," may lead to modification of the properties of any species which, so far as we can see, are permanent so long as the microbes so acted upon are cultivated under ordinary conditions upon the usual media of bacteriological research.

To make this statement perfectly clear, I may give an example. The Bacillus ruber of Kiel grows well upon a piece of sterilized potato at the ordinary temperature $\left(15-25^{\circ} \mathrm{C}\right.$.), the culture becoming a deep crimson red. If now the culture be kept at a temperature of $37^{\circ} \mathrm{C}$. for two days, and a new piece of potato be inoculated from this and kept another two days at the same temperature, and a series of six to ten cultures be made thus; 
or if, on the other hand, a potato culture be exposed to a temperature of $55^{\circ}$ to $57^{\circ} \mathrm{C}$. for a few minutes, in either case fresh cultures made in series upon potato at the ordinary temperature may for months remain absolutely colourless.

It is scarcely necessary to say that the classical example of this order of phenomenon is to be found in the remarkable observations of Pasteur, Chamberland, and Roux upon the attenuation of the anthrax bacillus. ${ }^{1}$ The anthrax bacillus may be kept (in broth) at a temperature of $42.5^{\circ}$ to $43^{\circ} \mathrm{C}$. for a week or more without there being any noticeable diminution of the virulence of the growth. But after this the virulence slowly and steadily diminishes. Made under ordinary conditions from a growth treated thus for twelve days cultures will no longer, when inoculated, cause the fatal disease in sheep. After thirty-one days the cultures are so feeble that the very susceptible guinea-pigs survive, and mice alone are killed. In forty days or so the bacilli subjected to the above-mentioned temperature are enfeebled to the point of death, and no further cultures from the original broth are possible. What is more, each successive growth obtained daily after the eighth day from a culture subjected to the Pasteur process, if periodically resown, under ordinary conditions (in alkaline beef-broth at $35^{\circ}$ to $37^{\circ} \mathrm{C}$.), retains permanently, for months and years, the grade of diminished virulence that had been impressed upon the original culture.

Several other methods have been suggested for attenuating the anthrax bacillus, all of them possessing the advantage of being more expeditious, ${ }^{2}$ but all, save one, labour under the disadvantage that the lowering of virulence produced is unstable, and upon continued cultivation the successive growths vary and are liable to regain the pathogenic property of the original culture. The exception is Roux's method, ${ }^{3}$ in which, by the addition of minute quantities of potassium bichromate or carbolic acid to the culture medium, a race is, after a short time, developed which has lost the power of spore-formation. According to the duration of the action of either antiseptic, and the amount of

1 Pasteur, Chamberland, and Roux, Comptes rendus, xcii., 1881.

2 See Toussaint, Comptes rendus, xci., 1880 ; Chauveau, Comptes rendus, xevi., 1883, p. 678; and Wossnessensky, Comptes rendus, xcviii., 1884, p. 314.

: Roux, Annales de l'Inst. Pasteur, iv., 1890, p. 1. 
either which is present, so are the daughter cultures of particular degrees of virulence. These asporogenous races appear to retain their characters indefinitely under normal bacteriological conditions.

Here again it must be pointed out that " permanent" races are by no means necessarily attenuated races. Starting from a culture of the Bacillus anthracis, so weak that only young mice are affected, it is possible, by passage of the virus through a series of animals whose resistance to the disease is in an ascending scale, to gain a series of races of gradually increasing virulence, and as Malm has shown ${ }^{1}$ it is possible to pass beyond the virulence of the type and obtain a race that will kill not only sheep but the very refractory dog. ${ }^{2}$

Another example to the same effect may be gained from Pasteur and Thullier's researches into swine erysipelas (Rouget des porcs, or Rothlauf). ${ }^{3}$ This fatal and most infectious disease is caused by a minute bacillus first isolated by Löfller. Rabbits also succumb to the malady, but not so very readily. It is found that passage through these latter animals causes the virus steadily to augment in strength until a stage is reached most fatal to rabbits, but cultures obtained at this stage induce but a transient illness in pigs, which, consequently, can be inoculated or "vaccinated" against the disease. Here exaltation of virulence for one animal and attenuation for the pig can be produced by keeping cultures at $37^{\circ} \mathrm{C}$. for a long period.

Equally instructive cases may be gleaned from researches upon non-pathogenic micro-organisms. Let me take first the Microbacillus prodigiosus. It was found by Wasserzug 4 that the addition of antiseptics to the medium of culture, in quantities sufficient to retard growth, led not only to the loss of colour production, but also to accompanying remarkable changes in form : some individuals become much elongated, others develop

1 Malm, Annales de IInst. Pasteur, iv., 1890, p. 520.

2 I may here call attention to a statement in Professor C. Fränkel's Bakterienkunde (edition of 1891, p. 177): "Es ist ... bisher noch nicht gegluckt, eine dauernende Verstärkung der Bakterien, eine haltbare Zunahme ihrer naturlichen Virulenz herbeizufuhren ... auf Tiere... eine raschere und andere Wirkungsweise an den Tag zu legen, als sonst an ihnen bemerkt wurde." While these statements, in face of French researches, were, to say the least, already very debatable a year ago, they certainly now cannot be regarded as other than quite incorrect.

Pasteur and Thullier, Comptes rendus, xcvil., 1883, p. 1113.

- Wasserzug, Annales de l'Inst. Pasteur, ii., 1888, p. 75. 
into actual spirilla. This polymorphism and its extent depend (as I have already shown in the case of the Bacillus pyocyaneus) upon the composition of the medium. Upon returning such altered microbes back to the potato there is a gradual return to the original state. Yet it is possible by slight modification of this method to produce permanent races. Taking beef-broth to which tartaric acid has been added, Wasserzug found that when the culture was a day or two old there was a great development of spirilla. Later, when through the production of trimethylamin the medium became alkaline, the spirilla ceased to be developed; there was a return to the coccus or shortened bacillary form. If now he did not permit the production of the alkaline trimethylamin, but made new acid growths before the cultures were more than forty-eight hours old, he discovered that the longer he persevered with his series of cultures the longer the microbe took when grown upon potato to return to the coccus form, until finally by such acid growth and subsequent heating to $50^{\circ} \mathrm{C}$. for a few minutes, all that he could obtain upon sowing on potatoes was, not a micrococcus, but a long bacillusa permanent race of such.

Or let us return again to the Bacillus pyocyaneus, which, though pathogenic, may be discussed along with other chromogenic forms.

By placing his modifications, to which I have already referred, under special conditions of heat, etc., Gessard found that he could obtain permanent races upon ordinary beef-broth, one giving the green fluorescent pigment alone, another the blue pyocyanin, another colourless. ${ }^{1}$ The same observer, studying the bacillus of blue milk (Bacillus cyanogenus or syncyanus), found that by passages through egg albumen he could obtain a race giving a deep pigment (which becomes red with alkalies, blue with acids), another race which is only fluorescent, gained from cultures that are some months old, and a third colourless race, this last either by taking extremely old cultures or by warming a recent culture to a temperature which does not cause death.

Similarly Laurent, ${ }^{2}$ working with the Bacillus ruber from Kiel (Bacillus rouge de Kiel), found that exposure of a growth to bright sunlight for three hours gave colonies which with but

1 Loc. cit.

${ }^{2}$ Loc. cit. 
few exceptions were colourless, and though with further successive cultivations there was manifested a tendency for many of the latter colonies to revert to type and develop red pigment, yet by careful selection he was able to gain an absolutely decolourized race which remained colourless, that is, upon agaragar, and in broth at a temperature of $25^{\circ}$ to $35^{\circ} \mathrm{C}$., a temperature and media at which and in which the original growth always shows a strong reddish-violet tint. On potatoes at the same temperature he was able to make thirty-two successive cultures extending over a year, and in these not the least trace of coloration ever appeared.

These facts, if alone they were all that we had to consider, would fully justify the statement that it is possible to evolve artificially species or subspecies of bacteria. But there are other facts which must of necessity be taken into account before we can arrive at any definite conclusion-facts which so far as I know apply at present to micro-organisms alone, though everything points to the belief that they are operative, and should be considered, in discussing the development of new species and subspecies, among higher organisms.

In cultivating the bacteria we are confronted with the fact that successful culture necessitates the employment of special media of growth. We have to sow the microbes in fluid or solid substances, whose composition depends upon the mode of life of the special form studied. And thus there is and can be no common soil in which all forms propagate themselves with equal facility. We are deprived of what I may term a common base. We cannot, with certainty, say that such and such a form, which we have separated out, is a distinct species, inasmuch as, grown upon a common normal soil, it presents permanent characteristics. The most that we can do is to approach, as near as possible, to the formation of such a common soil. Thus for many pathogenic and most other bacteria we find that slightly alkaline beef-broth, and beef-broth that has been rendered solid by the addition of gelatine or agar-agar, are media in which growth occurs freely, and in which, certain elementary precautions being taken, a given micro-organism retains its characters for countless "generations," retains them so completely that in the case of the majority of pathogenic microbes a series of successive cultures, if made with due precautions and sufficient 
frequency, will yield microbes which will all produce typical symptoms when inoculated into a series of rabbits, guinea-pigs, or other animals, the microbes of the last of the series of successive cultures possessing the same degree of virulence as the first of the series.

Where this is the case, are we justified in stating that the species is permanent? Upon first consideration one is inclined to say that undoubtedly we are, yet further thought brings in doubt, for this is far from being all. There is another and remarkable order of appearances to be considered, which can be exemplified from every case that I have given of the establishment of permanent races.

Take, for instance, the races of anthrax bacilli produced by Pasteur's method. These, undoubtedly, when kept upon our approximation to a common soil, namely, upon beef-broth, preserve a well-defined permanency. But select any one of these, and pass it through a series of animals of increasing refractoriness to the disease, and there is evolved a race growing equally well upon the beef-broth, whose virulence has been greatly increased. Or take Gessard's "permanent" modifications of the Bacillus pyocyaneus and the Bacillus cyanogenus respectively; grow any of the former upon the rich culture medium formed of agar-agar, glycerine, and peptone, and all develop equally into a race producing large quantities of an intense blue pigment; grow any of the latter upon broth containing 2 per cent of glucose, and all give rise to the specific blue pigment of the typical bacillus. Again, take Laurent's colourless race of the "Bacillus rouge de Kiel," and place it upon potatoes at a temperature of about $18^{\circ}$ instead of $25^{\circ}$ to $35^{\circ} \mathrm{C}$., and the coloured form reappears.

Or to epitomize. It is possible with bacteria to bring about modifications which persist when a return is made to the ordinary media of the bacteriologist (whether these be only our approximation to the normal-beef-broth, potatoes, etc.-or whether they be the bodies of one or other species of animal, mice, sheep, etc.), so that now cultivated upon these "ordinary" media, the modification preserves its characteristics, and remains markedly different from the initial or type growth upon the same media. And here we have a distinction between the races of bacteria and the races of animals under domesticity, which, returned to 
the wild state, are said to revert to type. Now with the bacteria, where such races have been developed, reversion to type may still be brought about by a further process, namely, by a further alteration of environment. I know of no case quite analogous to this among the higher animals.

It is only within strictly limited conditions of environment that the characteristics of the usual form or of a race can be preserved; overstep these limits, make certain alterations in the environment, and type and race alike are liable to vary, although the liability is perhaps the greater for the race to approximate towards the type than for the type to produce well-marked races. The only cases that I can call to mind where this law apparently does not hold good are both of modifications of the anthrax bacillus. It is possible so to attenuate the anthrax bacillus that a race is developed which is absolutely non-pathogenic even for the most susceptible of small rodents, and so far no efforts have succeeded in re-establishing the virulence of such attenuated forms. Roux's asporogenous race also would seem thus far to remain asporogenous under all conditions, although variations may be induced in its virulence. Even these cases, however, will probably be found eventually not to be exceptions to the rule.

For these reasons I have throughout spoken of types and races rather than of species and subspecies or varieties, for by employing the more uncommon terms in this connection I have attempted to guard myself against appearing to hold that among the bacteria there is anything beyond a relative permanency. A study of the observations that have been made up to the present time does not lead to the conclusion that new species are readily developed; all that it clearly indicates is that among the bacteria our employment of this term "species" must be elastic - the limit to which the individual may depart from the type (and from which it may again revert to type) is very far removed. But granting freely that not one of the cases here described records the development of a new species, this must at least be admitted, namely, that the longer the action of any one factor upon the bacterial growth, the longer the time requisite to ensure a return to the typical condition; the stronger the impress left upon any individual microbe, the longer, again, the time requisite to ensure a similar return. If, therefore, within 
the relatively short period of experiment changes so marked, changes persisting through so many generations or cell multiplications, can be brought about, surely it is not difficult to comprehend changes in the natural world whose action is sufficiently great and is prolonged through a sufficiently long period to produce races of even greater permanency, races which might be termed new species.

\section{On Natural Races}

Now apart from these results of experiments we possess already a series of data whose explanation is easiest on the supposition that we are dealing, not with forms that are wholly distinct and of separate origin, but with allied forms and natural races. Perhaps the best example is one that has been extensively discussed. Fehleisen's Streptococcus erysipelatosus, the microbe causing erysipelas, is, in microscopic appearance and in mode of growth, indistinguishable from the streptococcus which can be isolated from many boils and cases of abscess formation. Yet certainly the two micro-organisms differ in pathogenicity, differ in the symptoms they induce when isolated. Are we to say that here we are dealing with two distinct species? A few years ago all bacteriologists answered this question in the affirmative, but now most would reply in the negative, although some, among whom may be included Crookshank, ${ }^{1}$ still adhere to the old view. The observations of Eugen Fränkel would seem to indicate that truly we are dealing with what are only races. ${ }^{2}$ Fränkel obtained from a case of "universal peritonitis" a pure growth of streptococcus. There could be here no question of erysipelas. Taking some of a fifth culture of this, five months after it had been isolated, he inoculated it into a rabbit's ear and produced an exquisite bullous erysipelas, with streptococci in the lymphatics, identical with human erysipelas. The same inoculated into the peritoneal cavity gave rise to a fibrinous or fibrino-purulent peritonitis. From this it is evident that the difference between erysipelas and pyaemia, in its various forms, depends on mode, and locality, of infection and partly on the quantity of virus, on the individual, and lastly, on differences

1 Crookshank, International Congress of Hygiene and Demography, August 1891.

2 Eug. Fränkel, Centralbl. f. Bakteriologie, vi., 1889, p. 691. 
in the intensity of virulence of the races of streptococcus. ${ }^{1}$ It is interesting to note how, in clinical practice, one observes this conclusion borne out; to observe the succession of cases passing through ordinary erysipelas and acute lymphangitis, ${ }^{2}$ bullous and phlegmonous erysipelas, to acute pyaemia. Indeed, one is driven to the same conclusion with reference to the Streptococcus pyogenes that Levy arrived at after several years' work at pyogenic micro-organisms in general. ${ }^{3}$ Levy denies that anything can be prognosed from the nature of a microbe causing suppuration. "The prognosis of the process whose origin is referable to a micro-organism depends upon the virulence of the same, and the degree of virulence of pyogenic micro-organisms is subject to extraordinary change."

It may be that similar changes in virulence will explain the phenomena displayed in the case of swine erysipelas and mouse septicaemia, cholera, and the Odessa fowl disease respectively. The micro-organisms of the first pair of diseases are in appearances, size, and method of growth scarce to be distinguished; but whereas the one form produces a fatal disease in pigs, the other has no action whatsoever upon these animals; rabbits also are susceptible to swine erysipelas, while they are said not to be affected by mouse septicaemia. Still it is worthy of notice that Löffler has occasionally obtained fatal results in rabbits with inoculations of the bacillus of the latter disease, and that the bacilli of both diseases show themselves peculiarly fatal to white mice, producing similar effects. Quite recently, Lorenz ${ }^{4}$ has shown that pigs inoculated with cultures of the bacillus of mouse septicaemia are protected against swine erysipelas, and has described a third form, causing an eruptive disease in pigs, which he terms "Backsteinblättern." The bacillus of this, in mode of growth and properties, is intermediate between the other two, and of these three any one, either virulent or properly attenuated, confers immunity against the other two.

So again with the second pair of diseases. It is impossible

${ }^{1}$ A paper by Behring (Centralblatt f. Bakteriol. xii., 1892, p. 192), just published, confirms this view of the identity of the pathogenic streptococci, and shows that an animal rendered immune to one of the various races of these (vide Lingelsheim, Zeitschrift f. Hygiene, x., 1891, p. 331; gives literature of subject) is now immune to all other pathogenic streptococci.

2 Verneuil and Clado, Comptes rendus, cviii., 1889, p. 714.

${ }^{3}$ Levy, Arch. f. exp. Pathol. und Pharmak. xxix., 1891, Parts I. and II.

- Lorenz, Archiv f. wiss. u. prakt. Tierheilkunde, xviii., 1892, p. 38. 
to distinguish with certainty a preparation of the Vibrio metchnikovi from one of Koch's cholera spirillum, and the differences in the mode of growth of the two are not greater than may be determined between two cultures of the cholera spirillum of different origin. Yet Vibrio metchnikovi is pathogenic for pigeons and fowls and only affects guinea-pigs (which are susceptible to inoculations of the cholera spirillum) when inoculated in relatively large quantities. According to Gamaleia ${ }^{1}$ injections of the Vibrio metchnikovi render guinea-pigs immune to cholera. Pfeiffer denies this, though Gamaleia has reiterated the statement, ${ }^{2}$ and ascribes Pfeiffer's failure to gain immunity to the fact that he employed attenuated cultures. It must, however, be admitted that Gamaleia's statement still awaits confirmation, and, for the present, it is better to look upon the series of microbes which includes Koch's spirillum of Asiatic cholera, the Finkler-Prior spirillum of Cholera nostras, Deneke's S. tyrogenum, Miller's spirillum obtained from the mouth, and the Vibrio metchnikovi as a group of very closely allied species.

Similarly so high an authority as Professor Hueppe ${ }^{3}$ would class together into one group, as the bacteria of haemorrhagic septicaemia, a large number of bacteria which microscopically are indistinguishable, whose ends stain more deeply than the central region, whose growth upon bacteriological media is similar, and which, further, are identical in the appearance of the individual colonies. C. Fränkel would separate these into two groups, one including the bacillus of ferret plague (Eberth and Schimmelbusch), the bacillus of swine plague (Billings), that of hog cholera (Salmon), that of Danish swine plague (Selander), and the bacillus of the German "Schweinepest." All these are motile and ciliated. The other group contains forms that are identical, or almost identical, namely, Löffler's bacillus of chicken cholera, Schutz's swine plague bacillus, Cornil's bacillus of duck cholera, Gaffky's microbe of rabbit septicaemia, and Kitt and Hueppe's bacterium of "Wildseuche" (deer plague). All these only differ in regard to the animals which they specially affect.

Here, too, I would mention a most interesting observation of

1 Gamaleia, Annales de l'Inst. Pasteur, iii., 1889, p. 609.

2 Ibid. iv., 1890, p. 330.

3 Hueppe, Berliner klin. Wochenschrift, No. 9, 1890.

4. Fränkel, Grundriss der Bakterienkunde, Berlin, 1891, p. 461. 
Hueppe and Cartwright Wood. These observers gained from ordinary earth a harmless saprophytic bacillus, in appearance and mode of growth resembling closely the Bacillus anthracis. Inoculated into mice, which are of all animals the most susceptible to anthrax, pure growths of the earth bacillus induced immunity against this very fatal disease. ${ }^{1}$

\section{On the observed Modifications of Pathogenic Microbes}

There is, however, another perhaps more satisfactory way of approaching this subject of the occurrence of natural races. I refer to the actual differences in mode of growth and properties that are to be distinguished in cultures obtained from diverse typical cases of any given disease. This subject has not been worked out so fully as it deserves, nevertheless certain very interesting observations have been made. Thus the TalamonFränkel diplococcus of acute croupous pneumonia has been studied by Banti. ${ }^{2}$ Banti describes four varieties of the species Diplococcus lanceolatus capsulatus. No. 1 is the typical form described by Fränkel and Weichselbaum; No. 2 is identical in form and culture, but causes a "diplococcus septicaemia" in rabbits, with small spleen and destruction of the red corpuscles; No. 3 is similarly identical, but produces a septicaemia with moderate enlargement of spleen and diffusion of haemoglobin; and No. 4 only differs from the rest in that its virulence outside the body disappears even more rapidly than is the case with the other forms; it produces a mild septicaemia associated with albuminuria, and the animals all recover. All were obtained originally from typical cases of pneumonia, and while in the years 1886 , 1887, and 1890 the type form was alone gained from almost every case of pneumonia-and these were of a benign nature-

1 Hueppe and Wood, Lancet, December 7, 1889. [May it have been that Hueppe and Wood's harmless saprophytic bacillus obtained from earth was the B. mycoides of Thiele and Embleton referred to in Chapter III. of Part I. ?]

2 Banti, Lo Sperimentale, xliv., 1890, pp. 349, 461, 573. An observation of Nikiforoff's may be quoted in this connexion (Zeitschr. f. Hygiene, viii., 1890 , p. 531). From the lung of an influenza patient he obtained a microbe, identical with the Diplococcus pneumoniae in every respect save that it preserved its virulence for longer periods and was fully virulent for mice, while rabbits were completely refractory, whereas the true diplococcus is virulent for both mice and rabbits. [It is interesting that renewed study of the pneumococcus has established the existence of four well-defined strains.] 
in 1888 and 1889 the type No. 1 was never isolated, but the other varieties were present, and the cases were severe.

Foà ${ }^{1}$ has shown that by inoculation variation may be induced in the diplococcus. If from a rabbit that has died of inoculation pneumonia two rabbits be inoculated, one from the fresh fibrinous pneumonic exudate, the other from the cerebro-spinal fluid, it is found that the disease differs in the two. The former shows inflammatory oedema of the skin, the latter none. So, too, if the diplococcus be grown for twentyfour hours anaerobically the latter type is produced and its properties persist, although the original virulence and characters may be restored by simultaneous inoculation of this form along with the Staphylococcus pyogenes aureus and the proteus vulgaris. These studies of Foà find their counterpart in Banti's researches into acute primary meningitis. ${ }^{2}$ From two cases of this disease Banti isolated a diplococcus not to be distinguished from that of Talamon-Fränkel, except that it rapidly lost its virulence both inside and outside the body, so that when the meningeal exudation was inoculated into a rabbit, and from this a further series of passages was made, the sixth rabbit had a mild non-fatal disease.

In the case of typhoid, Babes ${ }^{3}$ has made a long series of observations, and though he handles the subject with what for him is extreme caution, it is difficult to arrive at any other conclusion than that the facts he represents can only be satisfactorily accounted for on the assumption that, granting there be a specific micro-organism for typhoid, and granting his results to be reliable, this micro-organism is capable of modifications so definite that many races are developed. Babes made numerous cultures from twelve typhoid corpses, and while in nearly every case he found the typical-form, in every case he discovered also varieties. In all he describes eighteen of these, all presenting some slight differences. These were sufficiently permanent to permit him to declare that he never saw one revert to the original form (as determined by an original culture from Berlin), although in many there was a tendency towards the loss of characteristics.

1 Foà, International Medical Congress, Berlin, 1890 (Section of General Pathology).

a Banti, Lo Sperimentale, xliii., 1889, p. 138.

3 V. Babes, Zeitschrift f. Hygiene, ix., 1890, p. 323. 
While acknowledging that these varieties, with rare exceptions, produce in small animals lesions similar to those due to the typical bacillus, he concludes that they are not specific, and that typical and atypical belong to a group possessing similar conditions of existence. He notes also that the Bacillus coli communis possesses many natural varieties. Despite this very cautious conclusion, Gaffky (who with Eberth shares the honour of having discovered the typhoid bacillus) criticised Babes severely, and suggested that all his varieties were due to secondary "Einwanderung." 1 To this Babes replied ${ }^{2}$ by showing that if so the varieties had wandered in during life, for his autopsies were made upon the fresh corpse very few hours after death. Surely rather than multiply species to the enormous extent that these conclusions would demand it is simpler, as it is more inherently probable, to hold these varieties to be races and of a common origin: races, it may be, produced by the peculiar conditions of the contest between organism and microbe. At the same time I am not prepared to go as far as Arloing, ${ }^{3}$ who declares that the bacillus of typhoid can be developed from the Bacillus coli communis in the presence of fermenting faecal matter.

The subject of the bacillus of typhoid cannot be passed over without mentioning also Cassèdebat's important paper. ${ }^{4}$ The relation of epidemics of enteric fever to the water supply has been so clearly traced that all that was wanting to afford an absolute proof of the relationship was the demonstration of the presence of the specific bacillus in the suspected sources. And this demonstration would seem to have been made by the methods of Vincent, Rodet, Kitasato, Chantemesse and Widal, Thoinot, and yet others. But Cassèdebat, working at Marseilles where enteric fever is almost endemic, states that in the water supplythe Durance-he was unable to discover the typical bacillus, although in its place he determined three forms all resembling the bacillus of typhoid in their mode of growth upon potato (which is very characteristic), and in the form of the colonies upon agar-agar plates, all equally polymorphous, and staining with difficulty, all possessing the same movements of transla-

1 Gaffky, Hygienische Rundschau, 1891, No. 12.

2 V. Babes, Centralbl. f. Bakt. x., 1891, p. 281.

arloing, International Congress of Hygiene and Demography, London, 1891.

- Cassèdebat, Annales de l'Inst. Pasteur, iv., 1890, p. 625. 
tion and oscillation, and giving much the same growths upon puncture of gelatine, while in even so minute a characteristic as the arrangement. of the cilia Löfler's method showed no difference between No. 1 and the type. (It is not stated how the others appeared under this treatment.) But there were differences of rate of growth on potatoes, in gelatine, potatojuice-gelatine, and broth, differences also in the intensity of colour of potato cultures, differences in the effect of the bacilli upon media to which aniline dyes had been added, and the result on inoculations, which were far from complete, show that on the whole No. 1 was less virulent for mice than in the type Eberth-Gaffky bacillus. From these differences Cassèdebat concludes that he is dealing with pseudo-typhoid forms, and that the results of the bacteriological examination of water must be received with very great caution, if they are to be accepted at all. I have already shown that the Eberth-Gaffky bacillus is capable of very considerable modifications, is most susceptible to change of medium, etc., and here, again, rather than accept Cassèdebat's conclusions, I would hold that the more satisfactory explanation of his facts is that he dealt with races-natural and fairly permanent races-modifications of the type bacillus of typhoid.

Turning now to cholera and its spirillum, it is already a well-known fact-to which attention was, I believe, first called by Zäslein ${ }^{1}$ - that cultures of the spirillum derived from simultaneous epidemics in different localities present recognizable differences-differences in tint, in rate of growth, in power of liquefying gelatine, etc. So there are those who declare that from the appearance of a culture they can state its origin, whether from Cairo or from Berlin, from Naples or Massowah, from Palermo or Marseilles. It has, however, been left to Surgeon-Major Cunningham to give the most remarkable example of these differences. $^{2}$ At the beginning of 1890 three of the principal hospitals in Calcutta contained cases of cholera, not differing from one another in symptoms or virulence, all giving abundance of cultivable spirilla, but these not of one but of three " species." Later, other cases were observed, in all sixteen, and from these

1 Zäslein, Deutsche med. Zeitung, ix., 1888, 759 and 771.

2 D. D. Cunningham, Scientific Memoirs by Medical Officers of the Army of India, Part VI., 1891, p. 1. 
sixteen, ten "species" were obtained, $a$ to $k$. In only four of the cases was the form present, even doubtfully, that described by Koch (Cunningham, bacillus $a$ ). In some three different comma bacilli were present at the same time.

The forms described by Cunningham may be divided into two groups. The first contains only one which does not liquefy gelatine, does not show interstitial growth in agar-agar, does not develop " cholera red " on the addition of acids, and morphologically is distinguished by its large size and great variability of form and curvature. This I feel inclined to consider as a truly different species. The other group contains all the other nine, which liquefy gelatine, are capable of interstitial growth, give the " cholera red" reaction, but all show fairly permanent differences in the rate of liquefaction of gelatine. In six the rate is distinctly rapid, in the rest it is slow. In one growth upon potato is luxuriant, in others there is rare acclimatization to this medium, in others, again, acclimatization has never shown itself. Here, then, one working where cholera is endemic, and one who is a most capable observer, who had been with Koch when he studied the disease in India, is so affected by the general view that species are constant and distinct, that the only conclusion that he can draw from these facts is that " whilst denying that the primary cause of cholera is represented by any species of intestinal schizomycete which has yet been discovered," it may be " that those whose development is favoured by the existence of the choleraic condition may exert an important influence on the ultimate outcome of individual cases of the disease." If we accept the view that the spirillum is specific I do not see any other conclusion from these observations than that here is another well-marked instance of the production of allied races.

Only within the last few days news has come from St. Petersburg that the spirillum obtained from patients affected in the cholera epidemic now raging presents marked differences in size, etc., distinguishing it from Koch's original form; while from the Institute Pasteur I hear that the microbe, isolated from some of the doubtful cases in Paris, presented no greater departure from type than is to be seen in many of the growths obtained from indubitable cases of cholera.

I might enter into the discussion of the relationship between 
human, bovine, and avian tuberculosis, or again into the differences to be made out between the bacilli of pulmonary and surgical tuberculosis (lupus, tuberculosis of bone and joints, and scrofula), but though much has been done on these subjects there is a want of well-confirmed results, and the subject is still too chaotic for safe treatment. I will conclude this relation of the occurrence of natural races with a reference to Roux and Yersin's remarkable and admirable work upon diphtheria. ${ }^{1}$ Apart from proving that the bacillus isolated by Löffler ${ }^{2}$ is specific, by showing that the sterilized medium of growth inoculated into animals will induce the characteristic symptoms of the disease (including the slowly produced paralyses), these observers made careful studies of the pathogenic qualities of the microbe. They found that, according to their origin, some cultures would kill guinea-pigs in twenty-four hours, some in sixty, some in only three or four days, or even after a longer interval, and they turned their attention to a form or forms that had been described by Löffler as the Bacillus pseudo-diphthericus. Löfler found this in the false membranes along with the virulent micro-organism, and pointed out that it is practically indistinguishable from this last, save that it has no toxic effect upon animals. Hoffmann found it also in the pharyngeal mucous membrane of cases of scarlatina and measles. ${ }^{3}$ Its discoverer considered it a separate species, and in this view most observers joined, though Klein and Flugge admitted that it was an attenuated form. The colonies on coagulated blood serum are identical with those of the diphtherial bacillus; like that, it grows rapidly at a temperature of $33^{\circ}$ to $35^{\circ} \mathrm{C}$. ; microscopically the two are the same, the staining reactions are similar, and growth in alkaline beef-broth is characterized by the same production of acidity followed by increasing alkalinity. The differences are, that it is often shorter when grown on blood serum, that the cultures on broth are more abundant, and so are those on agar-agar. It still grows at $20^{\circ}$ to $22^{\circ} \mathrm{C}$., a temperature at which the virulent bacillus ceases to proliferate, and the alterations in alkalinity and acidity of both cultures proceed more rapidly.

1 Roux and Yersin, Annales de l'Inst. Pasteur, iv., 1890, p. 385.

2 Löffler, Congress of Military Surgeons, Berlin, 1887; and Centralb. $f$. Bakt. ii., 1887, p. 105 .

3 [This form is now commonly referred to as "Hoffmann's bacillus."] 
This form is very rare in malignant cases of diphtheria-it is more abundant in benign, and becomes increasingly common as severe diphtheria progresses towards cure. But, as I have already indicated, it is to be discovered in non-diphtherial cases. At the Hôpital des Enfants Malades, Paris, from the pharyngeal mucous membrane of 45 children not affected with the disease it was obtained in 15 cases, and of 59 healthy school children at Caen, in a school where for long there had been no diphtheria, no less than 26 gave growths of this form, though it must be confessed that the colonies were few and far between. Inoculation into guinea-pigs and rabbits never led to fatal results, and yet differences were observable. Some guinea-pigs manifested a very considerable oedema at the point of inoculation, in others a slight oedema was to be seen, others presented no sign of even local disturbance. It is noteworthy that the most marked oedema was developed where cultures were employed whose origin was from cases of measles.

Oedema at the point of inoculation is one of the characteristic lesions when virulent diphtheria bacilli are injected, and Roux and Yersin found that if they attenuated virulent cultures either by the action of air and high temperature, or, again, if they preserved dried-up false membranes for five months in a cool place and in the dark, they gained colonies, some of which caused no oedema, others a little, one alone caused marked oedema. Such attenuated bacilli, like the Bacillus pseudodiphthericus, grew more abundantly at a lower temperature, and, like this, also rendered broth more rapidly alkaline. In fact, the only point distinguishing the two was that our observers succeeded in intensifying the virulence of the attenuated form, and failed to do this with the Pseudo-diphtherial bacillus. In every other respect the proof appears conclusive that this Bacillus pseudo-diphthericus is a natural race, or races, of the Bacillus diphthericus, that it is no wise a separate species of independent origin.

What is more, Roux and Yersin suggest an explanation of the onset of diphtheria - of the natural intensification, that is, of the virus in man. Just as they found that from a case of measles presenting no sign of diphtheria proper they gained a race of the Bacillus pseudo-diphthericus, which exhibited distinct, if slight, virulence, so have they noticed cases in which, through 
the access of an anginal attack, or of measles, diphtheria, which was recovering, gained fresh malignancy and became rapidly fatal.

There is another micro-organism frequently found in the mouth and saliva of healthy persons, namely, the TalamonFränkel diplococcus. May it not be that in both these cases a natural intensification of the virus is brought about by catarrhal and other affections of the upper respiratory and pharyngeal mucous membrane, and that to such intensification, rather than to the entry afresh of virulent micro-organisms, is to be ascribed the onset of these diseases?

I am well aware that in setting in order a series of facts and observations upon deviations from the normal the tendency is peculiarly strong to see in such deviations the normal, to see in the normal the exceptional, and it may be that in the preceding pages I have not dwelt with sufficient emphasis upon the fact that employing well-recognized and standard methods the typical forms of bacterial growth are easily and most usually to be separated out from cases of disease. Still I shall feel that these pages have not been written in vain if I succeed in drawing increased attention to the fact that the bacteria are organisms acutely susceptible to changes in environment, that as species they are far from presenting constant characteristics, and that to a variability which may impress itself upon a greater or less number of generations is to be ascribed, in part, the differences between successive epidemics, between the successive stages of one epidemic, and between individual cases of disease.

\section{REFERENCES}

The following papers may also be consulted :

Hansen (E. C.). Annales de Micrographie, ii., 1889, p. 214. ("On the Produetion of Varieties among the Saccharomycetes.")

Metchnikofr. Annales de l'Inst. Pasteur, iii., 1889, pp. 61 and 265. ("On a Remarkable "Spiro Bacillus' (Polymorphic) Parasitic in Daphnia.")

Wrnogradsky. Annales de l'Inst. Pasteur, iii., 1889, p. 244. ("On Polymorphism.")

HUEPPE. Berliner klin. Wochenschrift, 1884. ("On the Relationship of Saprophytic to Pathogenic Bacteria.")

Delépine (Sн.). Transactions, Pathological Society, London, 1891. ("Mutability of Pathogenic Aspergillus, as also of the Characters of the B. Leprae.")

Unva. Deutsch. Naturforscherversammlung, Halle, September 1891, and Centralblatt f. Bakt. xi., 1892, p. 638. ("Races of the Favus Fungus (Achorion Schönleinii).") 
CHAPTER II

ON THEORIES OF INHERITANCE WITH SPECIAL REFERENCE TO THE INHERITANCE OF ACQUIRED CONDITIONS IN MAN 1

QUESTIONS of inheritance at the present moment occupy a curious position in the minds of medical men and in medical literature. To judge from the medical press, we medical men are very Gallios -we care for none of these things. And yet, in family, as in consulting practice, questions concerning heredity must and do continually present themselves. In attempting to arrive at a conclusion about a given case, we are bound to ask ourselves how far the frailties or follies of progenitors are responsible for the conditions found-how far the accidents or the sins of the individual. Each succeeding day you must have this question of possible inherited defect brought before you ; constantly must you be forced not merely to inquire whether certain phenomena are matters of inheritance, but assuredly to recognize that this or other condition runs through all the members of a family and is an inherited weakness. And yet, although the lay reviews discuss the matter familiarly, and although perchance the charming partner you take in to dinner does the same, we scarce write about these things, save in connexion with one or two branches of medicine, and when we do, I have no hesitation in stating, though it is a bold statement, that much of what is written is misleading.

Even in my own subject of pathology, treating as it does of the causes, the processes, and the results of disease, in the discussion of which the laws of inheritance should obviously be

1 The first of a series of annual addresses under the auspices of the Brooklyn Medical Club, delivered May 17, 1901. Reprinted from the New York Medical Journal for June 1, 1901, and British Medical Journal. 
studied with care, if inheritance plays even a debatable part, turn to any of the text-books in our language and what do we find? A single page, or it may be but a single paragraph, is thought sufficient to introduce and to take leave of the subject. In short, from a concatenation of circumstances the medical study of inheritance is largely "taboo." Why is this ?

It depends upon more than one factor. In the first place, while, as I shall point out later, the study of man is singularly well adapted for determining certain points in connexion with inheritance, the fact that the generations of man follow each other at such relatively long intervals is against man being for most purposes a good subject for investigation. In the course of a long life the investigator can but study the characters of three, or it may be four, generations in one family, while influences acting upon the susceptible foetus in utero in man, as in all mammalia, introduce complications. The basal facts of heredity have to be made out in the lower animals, in which generations succeed each other with fair rapidity, and in which the eggs are fertilized and from the first developed outside the body.

Unfortunately, too few of us are trained biologists ; the curriculum of the past, as of the present, lays too little stress upon the value of a broad biological training as an aid in preparing us to discuss those special biological problems which constitute medical study. As a consequence the medical world in general has to depend upon the biologists proper-upon the zoologists and botanists - for its views upon heredity, and the pure and simple biologists have run riot in their lucubrations upon this subject. Do not think that I mean to belittle them or to indicate that we do not owe much to all the investigations and all the writings of the biologists of the last twenty or thirty years. The facts which they have elicited have been of the highest value. Without these facts we would be nowhere, but the contending theories elaborated by them (perhaps I should be the last to make any such criticism) have been fearful and wonderful, have started from morphological rather than physiological conceptions, and as a result have assumed shapes which would not disgrace the schoolmen of the Middle Ages. While they have appeared to collate and harmonize the facts known at a given moment, new facts have caused them to need modification, and the successive attempts to utilize the old bottles for the new wine, where they 
have not burst the bottles, have led them to assume most grotesque shapes. In fact there has been developed such a muddle that no amount of midnight oil and wet cloths bound around the temples permit the ordinary mortal to disentangle and follow the course of one theory.

This being the state of affairs, it is little wonder that we have been unwilling to apply the theories of the biologists to the problems of medicine, and this all the more because the trend of these theories has been in apparently strong opposition to medical experience. Of all the workers of late years Weismann has had the most influence upon biological thought, and his theory, if not accepted by all in its entirety-and if, indeed, now found unacceptable,-has, nevertheless, profoundly affected the general consideration of this subject of heredity. That theory is very complicated, and with Weismann's successive publications has not by any means become easier to follow or epitomize in language devoid of technicalities. Still, if not every schoolboy, at least every educated man is supposed to comprehend the general tenor thereof and its main thesis or conclusion, that acquired characters-characters acquired by the individual-are not and cannot be transmitted to the offspring. To use Weismann's own expression, "We maintain that somatogenic characters (characters originating in the cells and tissues of the body) are not transmitted, or rather, that those who assert that they can be transmitted must furnish the requisite proof. The somatogenic characters not only include the effects of mutilation, but the changes which follow from increased or diminished performance of function, and those which are directly due to nutrition and any of the external influences which act upon the body. Among the blastogenic characters (characters originating in connexion with the germ cells), we include not only all the changes produced by natural selection operating upon variations in the germ, but all other characters which result from this latter cause." 1 In natural selection is to be found the key of the phenomena of inheritance.

Now, up to a certain point, we as medical men are prepared to accept this teaching. We know from experience that acquired mutilations are not transmitted; we acknowledge that no clear

1 Weismann, On Heredity. Authorized translation by Poulton, Schönland, and Shipley, Oxford, 1889, p. 413. 
and satisfactory examples of the transmission of mutilations have been brought forward. We can realize that the loss of an arm, for example, has no direct influence upon the germ cells of the individual, and that so these germ cells if fertilized will develop into the complete individual. But there is another class of phenomena specially interesting our profession which appears to give a direct lie to Weismann's thesis. And it is, I think, this failure of the ruling theory to explain satisfactorily the phenomena in question which has been the main factor in making us as a profession not enthusiastic of late years to debate the subject.

For, accepting the theory, we must be prepared to deny wholesale the transmission of acquired defects of every order and give ourselves over to a most serious form of fatalism.

If an individual is from the first feeble-minded, that is not his parents' fault ; it is due either to an unfortunate commingling of the ids, or ancestral plasms, composing the promiscuous ovum and spermatozoon from which he is derived, or to characters which have come down to him from previous generations. If he, being diseased, begets feeble-minded children, he is in nowise to blame-acquired characters are not transmitted. Either those feeble-minded children are an accident-a spontaneous variation; or more probably they represent the summation of characters inherited from long generations. If a man or a woman becomes an alcoholic, it is not his or her fault, it is the result of inherited tendencies; and if the children of the same are of weak constitution or idiotic, again the parents are blameless : characters acquired by the parents are not transmitted, the characters of the parents must have descended to them. If a man is a criminal, again he is not to blame; criminality is atavism, is a.reversion to an earlier state, is an inheritance of characters or features peculiar to primaeval man. We are, so the popular translation of Weismann's theory goes, the descendants of criminals, or at least at a certain stage our ancestors were of an imperfect and criminal type. And if criminality appears in the family, with imperfect formation of head and brain and low mental state, that is due to the fact that by the fortuitous extrusion of certain ids from ovum or spermatozoon, the ids of the criminal ancestors have preponderated in the fertilized cell, and the result has been that the individual has 
developed possessing criminal features. However much a man abuses his soma, or body, is of little moment; the effect upon the offspring is minimal.

I put this in strong language and baldly, and it may be urged that I exaggerate the state of affairs. I do not think I do. I believe that in making this statement I but give expression to the general, if confused, ideas of the majority : nay, more, that I state the received conception of what Weismann's theory means when applied to man and to abnormal inheritance in man.

Now, if there is one conclusion to which we think experience surely leads us as medical men, it is that the sins of the father do tend to be visited upon the children even unto the thirdandfourth generation. We think we see this demonstrated day after day. But Weismann does not support this view. It is true that if we study Weismann we find that he does not state this in so many words; he admits ${ }^{1}$ that the germ plasm is not absolutely unchangeable, that the nutrition and growth of the individual must exercise some influence upon its germ cells, "but in the first place this influence must be extremely slight, and in the second place it cannot act in the manner in which it is usually assumed to take place." Certainly he does not make it clear that he believes in the distinct transmission of any order of acquired characters.

Weismann's Theory.-Weismann, I need scarce say, explains inheritance along the following lines: the germ plasm, the essential matter of the fertilized cell from which the individual develops, must in the process of fertilization come to contain portions of the germ plasm of both father and mother, brought to it by the nuclear material of the ovum and spermatozoon respectively, and the germ plasm of the father and mother must contain portions of the germ plasms of paternal and maternal grandfathers and grandmothers. And so, going back through a long series of generations, it follows, according to him, that representatives of the germ plasms of a long series of ascendants, or progenitors, are contained in the nuclear material of each ovum and spermatozoon. The constitution of a germ cell therefore may be represented, for purposes of inheritance,

1 Weismann, On Heredity. Authorized translation by Poulton, Schōnland, and Shipley, Oxford, 1889, p. 170. 
as made up of a vast number of ancestral plasms, or "ids," derived from the long line of progenitors.

I need not here explain his most ingenious demonstration of the means whereby at each successive act of fertilization a certain number of these ancestral ids are discharged, so that the ovum and spermatozoon each contains half the number originally present, and so that the number of ids in the fertilized ovum is kept.constant. I need but point out, in passing, that by this process of reduction the set of ids discharged from one germ cell is by this theory held to be different from that discharged from another germ cell of the same individual. And as the ids in two fertilized ova are not identical, as the same series of ancestors do not contribute to the germ plasm of the two, so it is that individual variation originates; the ids varying, the individuals controlled or developed by these ids tend to vary. So it is by this fortuitous commingling that spontaneous variation is apt to show itself.

Further, it has to be noted that when the ovum undergoes segmentation, and half of the nuclear material passes into one cell, half into the other, according to Weismann a certain definite series of these hypothetical ids passes into each cell, and according to the series entering each of them, so (and not by any variation in environmental influence) are determined the eventual characters of the tissues to which those daughter cells eventually give rise. The germ cells of the new individual become differentiated at a very early period, receive the full complement of the ids, and so carry on the whole series of properties inherited from the ancestors.

Difficulties in accepting this Theory.-This is a crude recapitulation of the main points of Weismann's theory. I have but mentioned those portions which especially bear upon my argument. To explain atavism, or the reproduction of characters in one generation which had not been recognizable in the previous generation but had been present in some earlier generations, you will see that the theory demands that some at least of these ancestral ids should have remained unchanged through a long period-it may be for centuries. For Darwin's $\operatorname{case}^{1}$ of the return of features peculiar to the ancestral rock pigeon, brought about by crossing barbs, spots, and fantails, is clearly a case of

1 Darwin, Origin of Species, sixth edition, p. 18. 
atavism occurring after centuries of domestic breeding and loss of the features in question. So in such a case of atavism we must, in the terms of this theory, suppose that in the act of fertilization there is a summation and preponderance of just that series of unchanged ids which now in development lead to the bringing into evidence of the atavistic ancestral features. In other words, the theory demands that the ids must be singularly stable in constitution-that they grow and multiply, but retain the same structure.

But now Weismann has to admit that, under certain conditions, the ids are modified in their structure. This admission indeed is contained in the idea that the individual hypothetical ids vary in their properties; and as, if we trace back these ancestral ids to their common source, they must all originally have been identical in structure, we conclude that at the same time they are both stable and capable of change in constitution. Here indeed is the crux of the theory. How are we to define and realize for ourselves the limits of alteration? Natural selection cannot explain the alteration, unless we fall back upon the far-away hypothesis of multitudinous separate acts of creation in the beginning of things-affording a large number of distinct idioplasms, - and even this hypothesis does not work out satisfactorily.

In the example already given of crossing of the old-established breeds of barbs, fantails, and spots, we must imagine that all the ids of each breed have been, in the germ cells of successive generations, exposed to almost identical conditions, and, as a consequence, modified along the same lines. Exposed to the same influences in the course of many generations, it is almost inevitable that all must become modified, for if there were any large number of unaltered ancestral ids contained in the germ cells it would inevitably occur that spots and atavistic forms would frequently present themselves. But this does not happen. Each of these varieties of the pigeon breeds singularly true. How, in short, are we to picture some of them passing from germ cell to germ cell through all the long years in an ancestral condition? Put to this test, the theory breaks down; we cannot picture the necessary conditions. It is, in short, an absurdity to regard the nucleus of the germ cell as containing a colony of what are, to all intents and purposes, 
separate and independent individuals, some of which have for centuries retained properties of one order, some properties of another-to conceive the germ cell as a colony of individual living beings, for this is what the theory demands. ${ }^{1}$

Driesch's Demonstration of the Incompetency of the Theory.But it may be urged, what is the use of all this argument to kill a theory already dead? For dead it is, so far as regards the ids, and Weismann's theory without the ids is like Shagpat without the identical. The brilliant observations of Driesch, ${ }^{2}$ abundantly confirmed as they have been by others, foremost among whom must be mentioned Professor E. B. Wilson ${ }^{3}$ of Columbia, and T. H. Morgan ${ }^{4}$ of Bryn Mawr, show that the conception is untenable. If in a segmenting ovum we find that normally each of the blastomeres or primitive segmentation cells gives rise to one special series of organs or tissues, but if nevertheless the ovum of sundry animals can have its cells shaken apart at the two-, four-, eight-, and even sixteen-cell stage, and each separated cell can be found capable of developing into an entire if dwarfed individual, then obviously, each time the nucleus segments there is no passage into the daughter nuclei of particular series of ids destined to lead to the development of one particular region of the body. Rather the variation in structure of the different tissues must be, to employ Driesch's words, "a function of their relative position" (ihre prospective Bedeutung ist eine Function des Ortes). The existence of these hypothetical ids is absolutely disproved. I dwell upon this theory because here I want more especially to discuss, on account of its importance from a medical point of view, this matter of the inheritance or non-inheritance of acquired characters. I hope that I have proved to you that the groundwork upon which the negative view is based is of proved unsoundness. The fact that a theory by which a position is supported falls through does not, it is true, afford proof that the position is wrong, but when we find that the dictum of non-

1 For a fuller discussion of the weak points in the Weismann-Roux Theory, regarded from an embryological aspect, vide Wilson, The Cell in Development and Inheritance, New York, Macmillan, 1898, and Creswell Shearer, Montreal Medical Journal, May 1901.

2 Driesch, Zeitsch. f. wissenschaft. Zoologie, liii., 1892, and lv., 1893, and Archiv f. Entwickelungsmechanik, 1900, p. 361 ; ibid. p. 411.

E. B. Wilson, Journal of Morphology, viii., 1893, p. 579.

4. H. Morgan, Anatom. Anzeiger, x., 1895, p. 19. 
transmission of acquired characters does not wholly accord with medical experience, we may well ask : can we gain a conception of the intimate nature of inheritance which is in accord with that experience?

Inheritance True and False.-My only regret is that, in striving to gain that conception, I shall have to inflict upon you yet another theory; my only apology, that that theory does appear to satisfy the conditions met with in man. First, however, it is necessary to lay down clearly what is not inheritance, for in medical writings and in ordinary medical parlance a terrible confusion prevails upon this point, and much that is certainly not inherited is commonly spoken of as being hereditary. There is, for example, no such thing as hereditary syphilis. There is congenital syphilis, and there are, to employ Fournier's term, inherited "parasyphilitic" lesions, but "hereditary" and " congenital" are not and must not be regarded as interchangeable terms.

The confusion is due to the common error of regarding the individual as beginning his existence at the moment of birth and not until then, so that everything occurring before that moment is grouped in one category, everything after in another. The chick, so to speak, is not a chick until it breaks open the shell; its status from the moment it ceases to be a new-laid egg-or, more strictly, the egg of commerce-until it emerges from the shell is not recognized in law, and fresh egg and chick are commodities of wholly different orders. But the individual existence of the chicken has already begun even before the egg is laid, and what is true of the chick is equally true of the human being. The individual begins the moment that fecundation is accomplished, the moment that nuclear material of the spermatozoon fuses with the nuclear material of the ovum and these twain become one. Compared with the event, birth is seen to be of secondary importance, for the intra-uterine association of the embryo with the maternal tissues is but one means employed by a restricted number of species to ensure the satisfactory nourishment of the individual during the earlier stages of development. The recognition of these facts is essential for any serious study of the problems of human inheritance. Any disturbance due to influences affecting the individual from without while in utero is acquired. It certainly must not be spoken of as 
inherited; it is an ante-natal acquirement or is of congenital origin. That alone is inherited which is the property of the individual at the moment he becomes an individual, which is a property of the germ plasms from which he originates, or is produced by the interaction of those germ plasms. The biologist has no alternative but to define inheritance according to the principle here laid down, nor have we, dealing with a limited field of biology, the right to modify terms in general scientific use for our own convenience.

Now, when we find that syphilis or tuberculosis acquired in utero during the later months is peculiarly severe and widespread in its manifestation, it is wholly unjustifiable to premise that the microbic germs of one or other disease could be present in either the conjugating ovum or the spermatozoon, could pass into one or other of the blastomeres, in a latent condition, doing no harm to the developing ovum. The ovum would surely be destroyed or at the least be monstrous. Could it conceivably be present, it is more than debatable whether we could regard such a fortuitous inclusion as a part and portion of the germ plasm, and so a strict inheritance. However, I have already, at the Academy of Medicine in New York, dwelt upon this subject. ${ }^{1}$ Suffice it to say that tuberculosis or syphilis of the new-born must from every valid consideration be an acquired congenital condition, not an inheritance. And, let me repeat, only that which is derived from the parental germ plasms is truly inherited.

It is to the germ plasm, the active matter in the germinal cells, and to the properties of that germ plasm, that we must turn in order to gain our basis for any sound theory for inheritance. Weismann has done yeoman's service in emphasizing this fact. This germ plasm it is which conveys living matter from generation to generation.

Growth and its Essential Nature.-Now, whatever life is, the fundamental phenomenon or possession of living matter is the performance of work coupled with growth-the capacity manifested by that living matter to assimilate non-living matter of certain orders, to absorb it, to endow it with like properties, to convert it into matter like unto itself, into additional living 1899.

1 Adami, "Syphilis and the Liver," New York Medical Journal, April 22, 
matter. In other words, difficult as it is to conceive or picture to oneself the details of the process, growth is essentially a process of conversion, a chemical process, and any adequate theory bearing on the phenomena of growth must primarily be along chemical lines. We are ignorant of what it is in the structure of living matter that gives it those properties ; we are, if possible, more ignorant of the physics of the process of growth, of the nature of the force which, acting upon or inherent in the constitution of living matter, leads to this continuous process of assimilation and conversion, and in our ignorance we are unable to separate the chemistry and the physics of the process; we must, that is, regard growth as a property of living matter. We must also for present purposes speak of the matter which is essential to and directly concerned in the activity of any one species or individual as a single substance which, following Nägeli, we can refer to as "idioplasm," and our conception of the individual or of the separate cell units forming that individual must be that in each we have to deal with two constituents, the idioplasm, or essential and directive living matter, and the cytoplasm, which is in the strictest sense non-living or certainly unable to exhibit the whole series of vital properties apart from the idioplasm, and which consists of various formed elements developed and influenced by the controlling idioplasm, intimately connected therewith, it is true, but at the same time not an essential part of the samethe cytoplasm varying in its composition and nature under varying conditions which affect the idioplasm, the idioplasm under all conditions retaining certain cardinal properties.

That the constitution of the idioplasm is not absolutely but only relatively constant has also to be assumed. We are bound to recognize that it is capable of undergoing modifications within certain limits without loss of its cardinal properties, and this from the following reasons: Admitting, as we must, that the highest forms of animal and vegetable life have been evolved from the very simplest, that there has been an unbroken line of development of living forms from the simplest unicellular to the most complex multicellular ; admitting also that in every act of reproduction, however simple or however complicated, the direct conveyance of the living matter of the parent into the offspring is to be demonstrated, that, in other words, the idioplasm of the primal living being has been continued on to 
successive and progressive generations; then we must admit that the idioplasm of the highest forms, judging from its powers of controlling and directing the development of the highly complicated organism, is something very much more complex than the idioplasm of the unicellular organisms; that in the course of evolution this has undergone successive accretions of properties, and this accretion of properties is the manifestation and accompaniment of increasing complexity of constitution of that idioplasm.

This idioplasm must be capable of modification, either by its environment or under the action of some law of progressive modification. The fact that there exist to-day forms of life practically identical in the main details of structure with those of remote geological ages is against the latter view; we must hold that environment determines changes in the constitution of the idioplasm.

Chemical Theories of Inheritance: the Isomeric Theory.-It must now be asked: Can we imagine a chemical substance so constituted as to be capable of modification in its molecular constitution, and so, in sundry of its properties, without undergoing complete change, without other properties being lost ?

We can. If, as Professor Walker of McGill points out to me, such relatively simple bodies as lactic and malic acids are capable of existing in more than one form-as laevogyrous and dextrogyrous and optically inactive modifications - and this with no obvious alterations in their chemical properties (though physically they show different actions upon polarized light, and physiologically we find that certain bacteria can act upon one and not the other form), then, certainly, the much more complex proteid material, which would seem surely to be the basis of the idioplasm, may present a very great number of molecular arrangements, and each of these may be accompanied by slight differences in certain physical and physiological properties.

Certain recent observations have rendered this additionally probable. By our present method of conceiving and visualizing the structure of chemical substances, we regard the carbon atom in the molecule as being situated at the centre of the tetrahedron and as capable of linking four other atoms or groups one to each of the corners or apices of the tetrahedron. A substance like malic acid having a single central carbon atom may, 
therefore, be built up in three ways, with the linked groups arranged in one relationship to each other, or in the reversed relationship, or the substance may be a combination of the two. These are all the forms we can picture as existing according to this system. But now a fourth form of malic acid has been found which is more dextrogyrous in the polariscope than is ordinary dextrogyrous malic acid. And the salts of this new form of malic acid show slight but distinct variations, in solubility, etc., from the ordinary malates. If this is so, there may yet be further molecular modifications of such a relatively simple substance as malic acid, and a fortiori idioplasm (with its multitudinous carbon atoms) may be capable of an enormous number of modifications.

The Side-Chain Theory of Inheritance.-The mode of the atomic arrangement in the idioplasmic molecule may therefore, in part, explain the variation in the properties of that idioplasm seen throughout the animal and vegetable kingdoms. I say in part, for if we assume that the structure of the individual is primarily the outcome of the structure and properties of the idioplasm, then for each different form of living being, nay, for each individual being, we have to assume a different molecular structure of the idioplasm. Or, otherwise, we have to assume that the modifications of this idioplasm are infinite in number. This, it seems to me, asks too much. The matter cannot be quite so simple. Each molecular modification may play some part, it is true, but our conception of the structure and modification undergone by the idioplasm must be more elaborate. We must, I think, formulate a theory of structure somewhat akin to that laid down by Ehrlich ${ }^{1}$ in his now well-known theory of the nature of immunity. We can picture to ourselves the primitive idioplasm as composed of a mass of material each molecule of which is formed of a central ring, to which there can be attached side-chains, and from which sundry side-chains can be detached without the central ring being destroyed.

This conception, which upon first encounter appears revolutionary and opposed to our ordinary chemical ideas, is, after a little deliberation, recognized as being but a statement, in chemical terminology, of what has been for long years the accepted physiological conception of the nature of protoplasm.

1 Vide Plimmer, Journal of Pathology, v., 1898, p. 489. 
It is, if I may so express it, the fundamental-the essentialconception of the constitution of living matter; it follows logically and inevitably the postulate of assimilation and growth. Whether we agree, with the majority, to distinguish between the idioplasm and the cytoplasm of the cell, or prefer to speak simply of protoplasm, it must, I think, be recognized by all that we are bound to assume-for the process of assimilation and, again, in order to explain the variation in structure and properties of the various cells of the organism-that there is a central basal substance to which become linked more or less permanently, or more or less temporarily, those other secondary substances, which, not in themselves protoplasm, modify the constitution of the protoplasm as a whole. And these secondary substances, we see, are necessary for the full manifestation of the properties of that protoplasm. This conception is, I acknowledge, difficult to harmonize with the prevalent elementary conceptions of chemical action and chemical constitution; but it is, nevertheless, essential for the physiologist and unavoidable. What is more (for I do not pretend to be a chemist), I learn that it is not opposed to the more recent deductions of the chemists concerning the nature and properties of the more complex carbon derivatives. In other words, it is by no means heterodox from an advanced chemical standpoint.

Accepting this view, it is not necessary to regard the molecules of idioplasm as at all times presenting their completed structure, with every side-chain attached. On the contrary, we are free to conceive the molecules being laid down and being transmitted in a relatively simple form, some of the side-chains only becoming attached when the molecules are brought into certain particular relationships with their surroundings. It is not necessary, for example, to hold that already in the ovum there is idioplasm identical in structure with that eventually present in the muscle fibres or nerve-cells developed from that ovum. Rather we must hold that in the ovum there is one common idioplasm of simple type, to which, when distributed in the various cells derived from that ovum, different side-chains become attached, according to the relationships assumed by those cells, so that the cells of different orders are controlled and formed around protoplasmic or idioplasmic molecules composed of those central rings plus varying series of side-chains. 
Indeed, I am prepared to go further and to state that the idioplasm possessing its full complement of side-chains must be regarded as ipso facto incapable of initiating cell multiplication.

I base this statement upon the fact, to which I have more than once called attention during the last few months, ${ }^{1}$ that it is only cells which are undifferentiated, or which have reverted to a simpler, less differentiated form, that are found to undergo division. Highly differentiated cells never multiply as such.

Inheritance in Unicellular Forms. - If the primitive unicellular individual formed by this controlling idioplasm divides into two to form two individuals, each half will contain a portion of the idioplasm, and if the circumstances affecting the molecules of the new generation are the same as those affecting the parent forms, then this idioplasm will continue to assimilate to itself non-living matter and to endow it with its constitution and properties, and the individuals controlled by this idioplasm will correspond to the parent form and to each other.

But if the circumstances affecting the filial idioplasm vary from those affecting the parental, then these more unstable and loosely connected side-chains will be the first to be influenced. The very act of assimilation (the surrounding medium varying in its composition) may lead to the substitution of other sidechains, to slight variation in the composition of the idioplasm. And the cell or individual developed or controlled by the idioplasm will therefore vary from the parent form, while the products of division of this second generation, containing as they do this modified idioplasm, will exhibit like structural modifications. Here we have the simplest example of the inheritance of acquired characters.

There is, however, yet another property which we have to assume. It may be laid down as one of the great laws of biology that characters which are of the most recent acquirement are those which are most unstable, and are first lost; those which are oldest are the last to disappear. In man, for example, the first signs of generalized systemic weakness and imperfect development show themselves in connexion with those properties which differentiate man from the animals most nearly allied, namely, in weakness and arrest of the higher functions

1 See the chapters "On Growth and Overgrowth" and "On the Cansation of Cancerous and other New Growths" in Part III. of this volume. 
of the nervous system, or, again, in susceptibility to certain specific diseases which are peculiarly apt to affect man, relative immunity toward which on the part of the healthy individual must be regarded as a comparatively recent acquirement. As my old teacher, James Ross, of Manchester, was the first, I believe, to point out, when there is progressive atrophy of the cells in the cortex of the brain the first motor cells to show signs of that atrophy are those governing the muscles which differentiate man from other animals, namely, the opponentes muscles of the hand.

Hence it has to be laid down that the attachment of these side-chains, which are recently acquired, is relatively unstable, that such recent side-chains are most easily detached, so that the idioplasm, and the organism developed around that idioplasm, are prone to return to their former condition or lose characters gained by recent progenitors. The more side-chains become attached, the more complicated the structure, the more unstable the equilibrium; hence the greater the liability to revert. As Professor Walker points out to me, parallel conditions are to be recognized in organic chemistry. The old-established view of the existence of "radicles" to a large extent admits this principle; certain central atomic groups in a compound are seen to be more fixed and not to undergo change when the attached groups are removed and replaced. Still more closely allied is what has been observed in connexion, for example, with aniline. The composition of this is $\mathrm{C}_{6} \mathrm{H}_{5} \mathrm{NH}_{2}$. Here the $\mathrm{H}$ atoms of the $\mathrm{NH}_{2}$ group can be replaced by other groups, by methyl $\left(\mathrm{CH}_{3}\right)$ and ethyl $\left(\mathrm{C}_{2} \mathrm{H}_{5}\right)$ groups, etc., and it is found that under certain conditions, in carrying out a series of these replacements, the last group attached is the first to be split off and replaced.

We see this principle in action in the lowest forms of life. Contrary to what Weismann has laid down regarding parthenogenesis and asexual reproduction, it is comparatively easy to impress new characters upon the bacteria. By subjecting a growth of pigment-producing bacteria to the action of a temperature just below that which will cause their death, we can bring about a loss of pigment production, so that the rapidly succeeding generations are perfectly colourless, but gradually in the course of time the cultures made from the original (heated) 
tube regain the power of pigment production. This may be in two or three days, or, again, only after several transplantations at the end of two or three weeks; and when we remember that a bacillus divides and so forms a new generation in, on the average, something considerably less than an hour, it is seen that the acquired character may be impressed upon the race for some hundreds of generations. ${ }^{1}$ The more intense the alteration to which the bacillus is subjected, the longer and the more frequently the race is subjected to the altered temperature conditions, the longer it is before there is a sign of return to the normal. Translated into the terms of this theory, heat leads the idioplasm to have certain side-chains, either modified or lost, and this modification or loss is inherited; but return to the normal environment leads the modified idioplasm in the process of growth and metabolism eventually to assume side-chains of the same composition, the conditions of growth being similar to those under which the species originally acquired the side-chain. Yet another solution, though it is one which I do not favour, is that not all of the molecules of the idioplasm undergo modification; a minority retain their original constitution and, under favourable conditions, gradually come to preponderate.

Sexual Conjugation and Inheritance.-How, next, does this theory bear upon sexual conjugation and its effects, for this is also met with in many unicellular organisms? I shall not take up the explanation of the development of male and female characteristics ; this is too large a subject, but I would discuss how fusion of the idioplasm of two individuals affects inheritance. In that fusion we have a mixture of the two idioplasms, and, as already pointed out, these idioplasms, a result of the varying influences which have acted upon them, tend to vary in certain particulars in their constitution. This fusion must be either a mere admixture, so many molecules of one idioplasm becoming admixed with so many molecules of the other, or a true chemical combination. If we presuppose a mere mixture, we are led along the lines of Weismann's theory and have to regard the idioplasm of the individuals of one generation as being composed of idioplasmic molecules or ids which have been passed down from the long line of previous generations. I have already pointed out the difficulties in which we find ourselves if we accept this

1 See the preceding chapter upon the Variability of the Bacteria. 
view. The other view largely, if not entirely, removes these difficulties, nor does it introduce any fresh crop of serious difficulties.

We may regard, then, the idioplasms from the two parent forms as undergoing a true chemical combination, ${ }^{1}$ the resultant idioplasm of the new generation being in truth a new idioplasm not possessing the identical properties of that of either parent, but being intermediate, tending in its characters and constitution toward the constitution of either one or the other according, it may be, to the number or chemical activity of the molecules of one or other parent entering into combination. Weismann supports his view by pointing out that for a certain period the maternal and paternal materials in the chromosomes of the daughter nuclei remain distinct, and reaches the bold and utterly unsupported conclusion that when the chromosomes fuse to form the irregular network pervading the nucleus, their constituents nevertheless remain distinct and sharply separable from those of the other chromosomes. But we have no evidence, in the first place, that the chromosomes alone contain the idioplasm, that chromatin and idioplasm are identical. Everything points to the fact that the idioplasm is contained in the nucleus, but we cannot with certainty advance further. It may be that the chromatin is but the cystoplasmic framework, the mechanism, as it were, by which the idioplasm is distributed.

If the germ cells of both parents possess certain loosely attached or unstable side-chains of more recent acquirement, which are of like nature, there is no sufficient reason why the protoplasm of the offspring should not also possess them. We can thus realize how it is that abnormal features present in both parents may be equally or more prominent in the offspring. But in general we must recognize that, the parents varying in different directions, the tendency of conjugation is to preserve the mean, to bring about an approach to uniformity in the constitution of the idioplasm of successive generations of one species exposed to like influences.

I need scarcely say that in these higher unicellular organisms which present conjugation the cell already presents a nucleus, and that everything indicates that this nucleus is the controlling

1 [It will be recalled from what was said in Part I. that I no longer accept this hypothesis of chemical combination. For some years I have replaced it by that of interchange of side-chains.] 
and directive body in the cell-that it is the nuclei which undergo conjugation-and that, in short, we have to recognize that the idioplasm of the individual is contained in the nucleus. It is by no means necessary to conceive that the whole of the nuclear material is idioplasm, or that the whole of the idioplasm enters into chemical combination with the molecules derived from the conjugating germ cell, molecule for molecule. I mention this in passing to indicate that it is not necessary to assume that when polar bodies are extruded, the material forming them is identical with the idioplasm of the remaining nuclear material. The difficulties in explaining polar bodies and the reduction of the nuclear substance are no greater by this than by Weismann's theory. The exigencies of time demand that I should not enter in detail into the consideration of these subjects. Rather I must give the broad outlines of the theory and pass on to consider inheritance in multicellular organisms.

Inheritance in Multicellular Forms. - Every multicellular organism arises from a single cell, the fertilized ovum, itself in all sexually produced forms the result of fusion of a male and female cell, of the ovum and spermatozoon. Studying the method whereby this one cell gives rise to the adult multicellular organism, we see that by successive acts of division this one cell gives rise to all the cells of the body. In the course of this process its nucleus divides and redivides, and this in such a way that at each division like portions of the nuclear material pass into each daughter cell. This regular distribution of nuclear material affords a sound ground for believing that there is an equally regular and uniform distribution of idioplasm into each cell. Now I have already pointed out the value of Driesch's observations in overthrowing Weismann's contention that there must be a qualitative difference in the idioplasm distributed to the daughter cells. We have absolutely no ground for believing in any such qualitative difference; on the other hand, it is a legitimate inference that the idioplasm is modified by its environment. To take the simplest example-a multicellular organism composed of a spherical mass of cells. Those cells which come to form the peripheral layer of the individual are subjected to a series of reactions quite different from the series telling upon the centrally situated cells, and it requires no stretch of the imagination to predict that in the process of assimilation and 
growth on the part of the idioplasm of these outer cells, that idioplasm tends to be altered in its constitution as compared with the idioplasm of the centrally situated cells. So that the results of division of the peripheral cells, if retained in the same environment, will tend to produce the characters impressed upon the parent cells, and, if this subjection to the special set of conditions is continued and impressed upon this order of cells for a sufficiently long period or with sufficient intensity, even when pressed or passing into other environment, the cell generations will retain these modified conditions, and, for example, cells of mesoblastic origin will tend to maintain characters different from those derived from epiblast, and this whatever the ultimate position of the cells in question.

In fact, as a first law, we may lay down with Driesch that the structure of the cells in a multicellular organism is a function of their position, and this because the position of the cell determines the modification undergone by its idioplasm. As a second law we may lay down that the greater the change impressed upon the idioplasm of these cells, and the longer that idioplasm is subjected to the conditions inducing this change, the more permanently will the daughter cells exhibit the peculiar alteration in the idioplasm, with consequent modified structure wherever they find themselves in the economy. We have, in short, to recognize that two orders of forces determine the structure of every cell in the body: (1) the previous influences acting upon its idioplasm and causing it to be of a particular chemical constitution; and (2) the position in which the cell finds itself, and the forces acting momentarily and immediately upon its idioplasm. Or, briefly, these two series of forces are inheritance and environment, and inheritance and environment determine the constitution of the idioplasm and the structure of the cells. ${ }^{1}$

1 To the worker in bacteriology the hesitancy on the part of biologists to accept environment as a most important factor in originating variation is almost incomprehensible. Nothing is more remarkable in the study of the lowest unicellular forms of life than this effect of environment in bringing about changes in character, changes which not only tell upon a limited series of generations (as I have already pointed out) but are permanent in their nature. By no means save altered environment could Hansen (Compte rendu des travaux du laboratoire de Carlsberg, v., 1900, 1; Abstr. in Ctbl. f. Bakt. 2te Abt. vii., 1901, 199), taking isolated yeast cells or "spores" (100 per cent of which, when cultivated under ordinary conditions, gave rise to spore-bearing forms) and subjecting these to the highest temperature at which growth could still occur, obtain a race or variety of yeast which now, after twelve years, 
Following this line of thought, we can understand how it comes to pass that the body cells and the germ cells in the higher and more complex organisms become so sharply divided, how it is that the body cells are no longer able to reproduce the whole organism. Their idioplasm has become altered in certain directions to such an extent that it is able, under favourable conditions, to divide and reproduce cells of like nature, but the very extent of the modification it has undergone has taken from it that constitution or structure which is necessary to allow it to reproduce each and every order of cells which together form the individual. The germ cells, on the contrary, as a function of their position in the organism, undergo no such extensive changes in constitution, their idioplasm as it grows and is distributed into the successive germ cells retains its fundamental constitution with but little alteration, and when these germ cells are discharged they and their idioplasm, brought into like relationships to those affecting the parent germ cells, undergo the like series of developmental changes, and reproduce the whole series of cells, tissues, and organs characteristic of the species to which they belong.

In the terms of this theory, therefore, inheritance essentially depends upon the chemical constitution of the idioplasm or the life-bearing or biophoric protoplasm of the germ cells, not upon the number of the separate ids or biophores or ancestral plasms or pangenes contained in the idioplasm; and variation, whether slight and individual, or extensive and leading to the production of species, is ultimately the expression of modification in the constitution of that idioplasm brought about by environment. Whereas Weismann's theory lays stress upon relative fixity in the constitution of the idioplasm, this theory admits freely the capacity for change in structure of the same. So long as the

has continued to grow under ordinary conditions without once developing spores. By no means save altered environment is it possible to explain Vincent's conversion of the absolutely harmless potato bacillus or, again, the Bacillus megatherium (by long-continued sojourn within closed collodion capsules in the peritoneal cavity of animals) into forms profoundly pathogenic, and fatal to rabbits, mice, and guinea-pigs in the course of a few hours ( $A n n$. de l'Inst. Pasteur, xii., 1898, 785).

The argument that phenomena observed in unicellular organisms cannot be applied to multicellular organisms is, to say the least, a severely strained argument. The extent to which environment acts as a factor may, it is true, be diminished in the latter, but surely it cannot be regarded as being eliminated and rendered negligible. 
surrounding conditions are unaltered the idioplasm is unchanged; alter these conditions and the idioplasm is liable to variation in constitution.

Atavism.-Lastly, in regard to atavism and reversionary degeneration of the cells of the individual, this conception of the idioplasm with attached side-chains, which are more firmly or more loosely attached, affords a perfectly adequate explanation. The more advanced the organism, the greater number of these attached side-chains; the more recent the attachment of a side-chain, the more unstable that attachment. As a consequence, any profound disturbance will, according to its intensity, tend to cause the loosening and removal of the more unstable side-chains, in general in the order of their stability of attachment. And as the structure of the individual and of the individual cells is the expression of the constitution of the idioplasm, of the germinal idioplasm, and of the idioplasm of the individual cells, so according to the intensity of the disturbance will there be greater or less reversion to an earlier stage in the developmental history.

Let us now apply this theory to those special problems which I have referred to as being of peculiar interest to us as medical men. Can acquired defects be transmitted? In seeking to answer this question, at least three orders of phenomena have to be recognized and distinguished. These are :-

1. The Non-Inheritance of Acquired Mutilations.-To these I have already referred. We cannot conceive of the direct transmission of identical lesions of this order from parent to offspring. At most we can conceive of the possibility of indirect effect where the mutilation is extensive or affects organs playing an important part in general nutrition. If there is impoverished general nutrition we can understand that this can affect the germ cells along with the other cells of the organism, that the lack of due assimilation or the excess of sundry internal secretions which, in consequence of lowered general metabolism, have been imperfectly neutralized, by telling upon the blood and lymph, may lead to modification of the idioplasm of those germ cells, with the possible resultant imperfections in the growth of the fertilized germ, everything depending here upon the combination of the modified germ plasm of the mutilated individual with that of the other parent. If the number of molecules of this 
other idioplasm or the constitution of the same is adequate to counteract the loss of side-chains in the idioplasm of the mutilated individual, there may be no recognizable effect. Or, on the other hand, the effect upon this latter idioplasm may be so serious as to lead to inherited defects in the offspring. But clearly these defects will be of a different order and a more generalized type; they will not be identical with the mutilation. There will be no direct transmission of acquired defects of this nature.

2. The Indirect Transmission of Acquired Diathesis.-With reference to diathesis, this also may be laid down, that acquired disease, and the effects caused by disease, cannot in general be transmitted in such a way that the offspring presents lesions identical with those produced in the parent, though it has to be recognized that there is the possibility of modification in that offspring due to the parental disease. There is the possibility of a certain amount of transmission, not of the identical local lesion caused by the disease in the parent, but of a modified or impaired condition of the germ plasm. We must recognize that constitutional disease, by leading to disturbance in the activity of important organs, tells not only directly upon these organs, but secondarily upon other organs. It leads, for example, to an altered condition of the blood, and so to altered nutrition of all the cells of the body. Among other cells, the germ cells may be directly affected, their idioplasm modified, and the offspring directly influenced. Conditions affecting the parents are capable of influencing and modifying the descendants. It is this which is forcibly brought home to us in our medical work. It is changes of this order which are almost inevitably neglected by morphologists, for they are not within their ken. The changes brought about in the tissues by what is essentially chronic intoxication may be so slight as to be inappreciable. Microscopical examination may reveal nothing; only by their physiological effects can their existence be recognized. It is in the study of these conditions and their effects that medicine can afford the most valuable aid in the matter of inheritance.

All infectious diseases are intoxications. If a parent is the victim of syphilis, it is obvious from febrile and other phenomena not merely that there are local toxic phenomena at the foci of growth with multiplication of the germs of the disease, but that the toxines pass into the general circulation. They may produce 
no immediate structural changes in the cells and tissues, but we have evidence that the protoplasm of various tissues is affected, although the results of the disturbance may only show themselves after long years. Indeed, the only explanation we can give of many remote effects of syphilis is this, that during the active period of the disease there has been a change wrought in the constitution of the cells of sundry tissues, slight and subtle, it may be, but sufficient to lead to premature exhaustion of the idioplasm of those cells. It would be absurd to argue that the immature germ cells lie absolutely dormant in the organism. They need nourishment; they assimilate; they are thus also apt to absorb circulating toxines, and their idioplasm must be affected in this act. Hence, while syphilis as such is not inherited, the toxines of the disease must be regarded as prone to set up molecular disturbances in the germinal idioplasm, and the offspring may show, not syphilitic lesions, but parasyphilitic lesions-various forms of arrested and imperfect development of different tissues due to the intoxication, and therewith modification of the germ plasm while still a portion of the parental organism.

Parental intoxication, therefore, is seen to be capable of directly affecting the germ cells, and if there is no direct transmission of the effects of such intoxication, certainly there are indirect effects. In demonstrating the truth of this statement, it must be freely admitted that conjugation and intra-uterine existence introduce grave complications. In fertilization it is obvious that the idioplasm of the sound parent may largely neutralise the defective constitution of that of the diseased parent, while we have constantly to guard against ascribing to defects in the germ plasm conditions acquired during intrauterine life. If the mother is the subject of any toxic state (to use the broadest possible phrase), not merely may the ovum be directly affected prior to fertilization, but in the course of foetal existence the organism of the offspring, deriving its nutrition as it does from the maternal blood, is liable to be affected and disturbed by circulating toxic substances, and the development of the different tissues to be correspondingly influenced. The only conditions we can safely study are those in which the father is the subject of disease or intoxication, the mother exempt. Nor is it easy in cases of infectious disease, or even in frank 
intoxications such as the alcoholic, to be perfectly sure regarding maternal exemption.

Paul's observations, however, upon the effects of lead-poisoning afford a most convincing demonstration along the required lines. ${ }^{1}$ Plumbism is peculiarly a trade disease. It particularly affects those following certain occupations; thus often the male wage-earning member of the family is alone exposed. Studying the history of thirty-two pregnancies in which the father was the victim of saturnine poisoning, the mother free from the condition, Paul obtained the following remarkable statistics :-

Twelve resulted in death of the foetus before term (eleven abortions, one child born dead).

Twenty children were born alive, of which eight died during the first year ; five died during the third year; one died later ; two alone were found to be living, one aged twenty years, the other only twenty-one months. ${ }^{2}$

In connexion with the effects of paternal syphilis, Fournier ${ }^{3}$ has contributed strong evidence along the same lines, pointing to the great frequency of arrested development of various orders, from intra-uterine death to infantilism. To his statistics objection may be made that certain of the infants recorded by him probably suffered from the actual disease acquired in utero, secondary to local infection either of the placenta or of the membranes. Discounting this possibility in a certain proportion of cases, his figures still remain very remarkable. But what is needed is a more searching study of these cases of defective children, the offspring of a healthy mother and an infected father, to make sure that we are dealing with parazymotic as distinct from zymotic lesions." In con-

1 Paul, Arch. gén. de méd. xv., 1860, p. 513.

- Legendre, in his Essay in Bouchard's Traité de Pathologie, vol. i. (which in the first place directed me to Constantin Paul's admirable article), gives a table of 141 pregnancies which I cannot find in the paper referred to. Possibly this is from a later article by the same anthor, but the proportion of abortions as given by him is so much larger that $I$ doubt if this can be the case.

Fournier, quoted by P. Legendre in Bouchard's Traité de pathol. $\mathbf{i}$. p. 363. Of 103 pregnancies in which the father was syphilitic, the mother healthy, 41 children were born dead, 19 born definitely syphilitic, 43 children (not definitely syphilitic) lived but a short period.

- [It is still a matter of debate as to the relative extent of these inherited, and acquired, parasyphilitic states. With the discovery of the Treponema pallidum, which occurred some few years after the delivery of this address, 
nexion with the subject, Gheorghiu, studying malformations, has pointed out the remarkable frequency with which there is, on inquiry, obtained a history not merely of the mother, but of either father or mother having been a sufferer from acute or chronic infectious disease at the time of conception. ${ }^{1}$

3. The Direct Transmission of Acquired Constitutional States.-In the above-mentioned series of phenomena we have dealt, as I say, not with the direct transmission of acquired conditions, but with the deleterious influence leading to general defects of development and due to the action of toxic agents upon germ cells prior to conception. Can we advance further and see evidences of direct transmission of acquired constitutional states? I think we can.

If, for example, an animal acquires immunity to a disease, we are convinced that the process of acquirement is a chemical process ; that the action of the toxine of the disease has been to set up certain molecular changes, certain alterations in the composition of the cell substance, so that that cell substance now responds in a different manner when brought into contact with the toxine, and once this modification in the cell substance is produced, the descendants of this cell retain the same properties; that immunity to one special disease is not merely a momentary, but is a more or less lasting state of the system. It is true that it tends not to be permanent; we see that, where it is attainable, the more prolonged and the more severe the changes set up in the process of immunization, the longer it lasts ; we recognize, further, the action of the law that properties of most recent acquirement are soonest lost, and that there is a distinct tendency for the condition, or acquired state, of the cells to pass away. Nevertheless we admit that inheritance of the acquired condition has to be granted in the case of the body cells in this connexion. Here, again, if these processes obtain in connexion with the body cells, we must logically admit their action in the case of the germ cells. The idioplasm of body and germ cell is of like origin, and must be susceptible to like influences.

there has been manifested a tendency to regard all the lesions of so-called congenital syphilis as actually of infective nature, due to the transmission of the Treponema, or Spirochaete from the mother to her offspring. This has not been proved, and, for myself, I still believe in the existence of certain inherited parasyphilitic non-infective conditions.]

1 Gheorghiu, L'Obstétrique, January 1900, p. 63. 
The toxines circulating in the blood of the individual undergoing immunization must also affect the germ cells. They must acquire immunity, and the individuals developed from them must, subject to the law of loss already noted, have the same properties. Now, as a matter of fact, this transmission of acquired immunity has been occasionally noted; where, for example, both parents (rabbits) have been rendered immune to the Bacillus pyocyaneus, the offspring have been found more refractory to pyocyaneus infection, but in general the observations have been negative. This, as I have hinted, is only to be expected on account of the easy detachment of, if I may so express it, newly-acquired side-chains. It is, however, legitimate to suppose that successive immunization through several generations will cause the new side-chains to become more and more fixed, and that racial immunity is brought about by these means, a view more probable than the alternative of mere "survival of the fittest." 1

Conversely, in those cases where immunity is not developed in the case of chronic conditions like tuberculosis, we can, along these lines, comprehend how the toxines weaken the germ cells along the same lines as they weaken the general tissues of the body; and as the resistance of the body in general to a special microbe and its products becomes less and less, so also the idioplasm of the germ cells becomes less and less resistant, and so from parental disease the offspring gains a peculiar susceptibility to one special disease. So that, in short, from disease acquired by the parents, a particular diathesis is developed, a special susceptibility to the particular form of disease.

Here Weismann would make the somewhat subtle distinction that we are not dealing with the direct transmission of acquired parental defects-that the toxines produce these results not by acting on the body cells, but by direct action on the germ cells -that the inheritance is blastogenic, not somatogenic.2 This is a sorry and almost Jesuistic play upon words. Let us grant that they are of blastogenic origin; they are nevertheless of individual acquirement. The individual consists of body plasm

1 It goes without saying that where both father and mother are immunized through successive generations and the foetus-and its germ cells-acted upon by the maternal blood and milk, the development of acquired inherited immunity should become yet more assured.

Weismann, loc. cit. p. 410. 
and germ plasm, and whether the defect tell primarily or secondarily upon the germ plasm of the individual, we have here examples of conditions acquired by the individual being transmitted to the offspring.

But we can go further. Exogenous and bacterial intoxications are not the only intoxications. We recognise yearly more and more the existence of states of truly endogenous intoxication, auto-intoxications - of disturbed states of the constitution due to disturbances in glandular activity or to excess of certain internal secretions, or of the substances ordinarily neutralised by the same. Such disturbances, acting on the germ cells, would be truly somatogenic.

If gout and the gouty diathesis are, as many hold them to be, of the nature of true auto-intoxications, if in a given percentage of cases (in France 12 per cent, according to Bouchard) the gouty state shows itself in those giving an absolutely negative history of gout in their progenitors, then we are at liberty, I think, to regard the gouty diathesis as an example of truly somatogenic acquirement of an inherited and inheritable constitutional state.

Defect in body metabolism has led to intoxication of the germ cells, and the offspring show a peculiar liability to be the subjects of intoxications of the same order. Here what is transmitted is a constitutional state, and that constitutional state may manifest itself in more than one way, but no one will deny that this is truly inheritance of an acquired condition.

We must therefore, I hold, be prepared to admit the possibility of the transmission in inheritance of certain orders of acquired constitutional conditions; we must see that it is not necessary, with Weismann, to deny strenuously the inheritance of each and every.order of acquired defect, and that along the lines of some such theory as that here outlined we gain a fuller harmony between theoretical considerations regarding the nature of inheritance and the facts as they present themselves to us day after day.

\section{Conclusion}

Within the time at my disposal it has been impossible to touch upon many aspects of inheritance which interest us as medical men-upon spontaneous variations and their trans- 
mission, upon in-breeding and marriage of consanguines, upon degeneration as distinct from atavism, upon the particular problems of inheritance of nervous conditions, to mention but a few. It seems to me, however, that this conception of the properties of idioplasm is adequate to bring together and harmonize the facts we possess concerning all of the abovementioned conditions.

Let me conclude with Weismann's apology: "Hypotheses, even when not absolutely right, may be of value in advancing our knowledge, if only they are relatively right, i.e. when they correspond with the state of existing knowledge. They are like the feelers which the short-sighted snail stretches forth on its darkened path, testing this way and that, and withdrawing them and altering the route so soon as they come across any obstacle." 1

I must ask your forgiveness for bringing before you a subject so far outside the line of general medical thought, and for having inflicted on you so much that is theoretical. That was not my intention when I sat down to prepare the paper. I had intended to indulge in the main in a destructive criticism, to point out how Weismann's and allied theories fail to satisfy certain orders of conditions presenting themselves to medical men; but as I proceeded with the task it became obvious that mere destructive criticism was valueless, that it became imperative to present an alternative theory which for many months-I may truly say years-had been simmering within me, unexpressed.

Weismann, loc. cit., Introductory Note. 


\section{CHAPTER III}

ADAPTATION AND INFLAMMATION ${ }^{1}$

(1905)

[I REPUBLISH this chapter as representing an intermediate stage, one in which, while I recognized fully the fact of the survival of the fittest, and, at the same time, was convinced that direct equilibration or adaptation was a very real factor in pathological processes, I did not see fully how to harmonize the two.

To-day my attitude is expressed in the following theses:

(i.) That individual variation is not primarily due to any inherent tendency on the part of living matter to vary. On the contrary, living matter is capable of being varied according to its environment.

(ii.) That when individuals of a species are exposed to a particular environment they do not present multitudinous variants of all orders. On the contrary, alteration of environment of a particular order gives origin to a particular order or series of variations, of which that grade will survive and be perpetuated which represents the most complete equilibration between the organism and its surroundings.

(iii.) That "chance," it is true, enters in connexion with the results of gamogenesis, but here the variation from either parental type due to amphimixis is not progressive : it remains within the limits of the properties inherent in the particular species, and what is more, with indiscriminate mating tends to become less and less marked in successive generations. Gamogenesis, that is, tends to preserve the mean, not to encourage

1 Being a reprint of a section of an article upon Inflammation, as revised in the second edition of Professor Allbutt's System of Medicine, 1905. 
the extreme. It is only those variations (and mutations) induced, not in one, but in several members of a species by subjection to a common alteration in their environment, which with gamogenesis become progressively more pronounced and are of evolutionary value.]

It will be seen that the picture of inflammation here given is very different from the old view in which the dominating idea was that inflammation is essentially an injurious process leading to cell-and tissue-destruction. Here we regard the irritant as capable of causing cell and tissue destruction, and so long as the irritant is in action so long may this destruction continue. But inflammation itself we regard as the series and sum of the reactive processes set up in the tissues, and then bringing about, not destruction, but the very reverse. Taking as our definition that inflammation is the response or reaction to injury, we are inevitably led to see that this response results in counteracting, or more exactly in tending to counteract, the deleterious effects of the irritant; the inflammatory process tends towards repair. It may not result in repair, for, as we have pointed out in several instances, too often the reaction is either inadequate or excessive. The exudation may possess but slight bactericidal powers, or may be poured out in such quantities that the microbic irritant, instead of being retained in the region of injury, is conveyed outside that region; the wandering cells, instead of destroying, may undergo destruction; they may incorporate bacteria, but not be able to annihilate them; the fixed cells may either form an incomplete cicatrix, or continue to proliferate in excess. Attempt at repair is not repair. Notwithstanding, studying the various factors involved, it is forced more and more upon us that each tends in one definite direction, and the sum of the processes is reparative.

This conception of the process of inflammation has met with considerable opposition. It is urged that to consider inflammation as an attempt at repair is teleological, i.e. is to assume that each reaction in the process is, in itself, purposeful. And, carrying this objection to its ultimate end, "you conceive," say the critics, "that the leucocyte is endowed with intelligence so that it recognizes in the microbe a foe to the organism; scents it from afar ; hunts, seizes, and digests it, and then, its duty 
done, its mission in life fulfilled, it withdraws its pseudopodia, and dies contentedly."

It is needless to say that we hold no such views regarding the intelligence of the leucocyte. At the same time we unhesitatingly regard inflammation as purposeful, every whit as much as we regard the iris, with its contraction and dilatation under different intensities of light, as subserving a purpose, or the acts of feeding and digesting as being with purpose. Inflammation is a physiological process in so far as it is the calling into action, in response to accustomed stimuli, of properties normally possessed by the tissue; it is a pathological process in so far that, while the stimuli are in kind not different from normal stimuli, in intensity they are greater. If we admit physiological purpose, we must admit pathological. This may, indeed, be laid down regarding all pathological conditions, namely, that in them we are dealing not with the effects of new and unaccustomed factors, but with the ordinary factors telling upon the tissues in an abnormal way, being either deficient or excessive in their action. Within physiological limits, the reaction to a given stimulus is nicely balanced and adequate; when the stimulus is excessive, the reaction is liable to be imperfect. The iris accommodates and adequately protects the retina within certain limits, but if the eye be exposed to too intense a light, the iris fails to arrest all the rays and the retina suffers. And so it is that, in inflammation, when the stimuli are excessive and so have become irritants, the tendency is for the reaction not to be perfectly balanced, and the ultimate result to be an incomplete counteraction of the disturbance. But, to repeat, if we recognize purpose in the one set of cases, we must recognise it in the other.

All, it will be seen, depends upon what is our conception of "purpose" in vital phenomena. That conception is teleological if and when we regard it as primary-as what may be termed an intelligent endeavour on the part of the tissue to accomplish a certain object, a predetermined end. To suppose that, in inflammation, the vessels dilate and bring about increased exudation in order to flush out the irritant is an utterly wrong and baseless idea. If, on the other hand, our conception is along these lines-that in the course of evolution those individuals survived who, by chance, let us say, happened to 
manifest this reaction on the part of their vessels in response to stimuli of a certain order, whereas those who did not were more unfavourably placed and so succumbed; that they conveyed the same power to their descendants who also possessed this advantage over individuals incapable of affording the reaction; then we can conceive the development of a race possessing a mechanism for countering a given stimulus by a given reaction, a race in which provision is made, or gained, for dealing with a given order of events; then it will be seen that what primarily is accidental becomes secondarily purposeful through the survival of the fittest and the inheritance of defensive acquirements. The tissues thus become prepared to respond to certain alterations in their environment. In other words, "natural selection" renders what was primarily accidental, secondarily purposeful.

The whole process of inflammation is an exemplification of " adaptation," and we would strongly commend the address by Professor Welch ${ }^{1}$ upon this subject to those desirous of gaining a right point of view regarding pathological processes in general. For living matter to survive, it must be adapted to its environment, and this in the first place happens through inheritance, through the survival of the fittest, along the lines laid down above.

Yet in the study of inflammation we are compelled to recognize, not merely inherited, but also individual adaptation. We cannot otherwise explain why it is that bacteria, which at first exhibit active local growth within the tissues, become eventually destroyed on the resolution of the inflammatory state, unless we acknowledge that the cells, or certain of them, acquire and, it must be, transmit, increased bacteriolytic and antitoxic properties. The facts gained regarding the development of immunity-the presence in the body-fluids of the immunized animal of substances inimical to the infective agents, which are absent, or present in but minimal amounts, in the fluids of the untreated animal-all demonstrate this individual adaptation. At the present time, indeed, workers all over the civilized world are busy in researches bearing upon this very subject, the production and mode of action of what may be termed, generically, antibodies.

1 Welch, Amer. Journ. of the Med. Sciences, 1897, cxiii. 631. 
Here I can do little more than mention certain general laws which seem to be at work in bringing about, or favouring, individual adaptation.

1. The first is that of reserve force. No cell-and no tissuenormally is in action to the limit of its powers; on the contrary, normal activity is far below what the cell is capable of performing. In other words, normal stimuli do not induce a maximal reaction, and, therefore, irritants-excessive stimuli-up to a certain limit, do not overwork, and do not lead to disintegration of the cell. Perhaps the greatest difficulty encountered by most students of medicine in accepting the facts of phagocytosis lies in this, that, regarding the tissues as normally sterile, they cannot comprehend the assumption of what appear to be totally new properties by the leucocytes and other cells in inflammation and infection, namely, the assumption, as they regard it, of phagocytic powers and the taking up of pathogenic bacteria. But, as a matter of fact, this is no new property. Throughout life the cells are engaged in digesting bacteria. We find phagocytic leucocytes passing out and free upon mucous surfacesany smear or swab from the pharynx will show these leucocytes with their contained bacteria. As Ruffer, ${ }^{1}$ Nicholls, ${ }^{2}$ and others have shown, bacteria are to be seen in the lymph-glands and along the lymphatic channels of healthy animals, and these, most often, within cells. As Ford, ${ }^{3}$ working in my laboratory, has demonstrated, using the fullest precautions against contamination, bacteria can be cultivated from the liver and kidneys of more than 50 per cent of the apparently healthy animals of the laboratory ; and that the bacteria so obtained are not contaminations is proved by the remarkable regularity with which these organs of each different species present a different bacterial flora. Having followed Ford's observations and seen the care with which they were conducted, I cannot accept the observations of those who refute his work. As Wrosczek ${ }^{4}$ has recently shown, if animals be fed with non-pathogenic germs, or germs setting up no recognizable intestinal disturbances, colonies of the species

1 Ruffer, Brit. Med. Journ., 1897, i. 1177.

Nicholls, Journ. of Med. Research, 1904, xi. 455.

s Ford, Journ. of Hygiene, 1901, i. 277, with series of tables in Trans. Assoc. Am. Phys., 1900, xv. 389.

'Wrosczek, Arch. polonaises d. sc. biol. et méd., 1903, ii. 1796 (Ref. Journ. de physiol. et path. gén., 1904, vi. 385). 
so injected are, later, to be gained from the various organs of the apparently healthy animals. The tissues are potentially sterile; that is, the leucocytes and other phagocytic cells are, throughout life, engaged in destroying bacteria which have gained occasional entrance into the tissues. ${ }^{1}$ When a few intensely virulent bacteria gain this entrance, or a large number of a less virulent form manage to grow in some one or other locality, and thus set up inflammatory changes, the abovementioned reserve force in the phagocytic cells comes into play and permits these cells to take up and digest the greater numbers or the more toxic forms. It is this circulation of potentially pathogenic microbes that explains the cryptogenic infections of internal organs.

2. The second law is that of accustomance. A cell not actually destroyed by any deleterious agency is apt to become accustomed to the presence and action of that agency. What is the basis of this accustomance it is difficult to say, though it is not difficult to suggest a hypothesis or hypotheses. Here I simply state that this is an observed law, a law best exemplified in what has been made out regarding the conversion of a negative into a positive chemiotaxis.

3. The third and very important law, somewhat closely allied to the last, is that of habit, or, as Fraser Harris ${ }^{2}$ has termed it, "vital inertia." According to this law, when once, through a given stimulus, a certain series of molecular changes is set up in a cell, those changes are liable to continue after the stimulus has ceased, and, if the stimulus be sufficiently strong or sufficiently often repeated, the cell acquires the habit, or property, of setting in action a particular series of molecular changes after a minimal stimulation. This is, perhaps, best exemplified in connexion with our subject in the production of antitoxins. It is found that, once the diphtheritic toxin, for instance, has stimulated the cells of the organism to produce antitoxins, that production continues and is wholly out of proportion to the amount of toxin introduced; while, similarly, once an animal has gained full immunity against any micro-organism, it only needs the introduction of that micro-organism into the system to induce an immediate reaction, whereas previously days or weeks had been required

1 Adami, Journ. Amer. Med. Assoc., Dec. 23, 1899.

2 D. F. Harris, Brit. Med. Journ., 1900, ii. 741. 


\section{ACCUSTOMANCE AND VITAL INERTIA 167}

for accustomance and counteraction to be adequately developed. The existence of this law was first recognized by Weigert; ${ }^{1}$ it may be said to form the basis of Ehrlich's side-chain theory of immunity.

${ }^{1}$ C. Weigert, Gesammelte Abhandl. Leipzig, 1906, 1. 


\title{
CHAPTER IV
}

\author{
THE MYELINS AND POTENTIAL FLUID CRYSTALLINE \\ BODIES OF THE ORGANISM ${ }^{1}$
}

(1906)

The polarizing microscope, simple as it is with its Nicol's prisms - the two pieces of Iceland spar which can be turned at various angles one to the other-has not been a popular instrument in medical science. I take it that my own experience is that of other medical men. I can remember well a genial and enthusiastic colleague inviting me years ago to spend the evening with him, when he showed me slide after slide of various substances exhibiting exquisite figures under the Nicol's prisms. I know I thought the results too pretty to be useful-that the instrument was peculiarly well adapted for the use of members of microscopic societies and other amateurs of microscopy, but for the physician and pathologist it was at most a toy. I would here recant this early error and would acknowledge humbly that within certain limits the polarizing microscope shows itself a most valuable aid in the detection and recognition of the nature of a class of substances within the tissues which it is difficult, nay almost impossible, to recognize by other means.

If you take a section of the fresh adrenal of man or of one of the animals of the laboratory and examine the cortex under the ordinary microscope, the parenchyma cells have, as is well known, the appearance of being in the condition of advanced fatty degeneration-the cell substance, that is, is seen to be densely packed with small fatty globules. But, as shown by Kaiserling and Orgler, examine that section between the Nicol's prisms, and sundry of the globules exhibit an exquisite black

1 Lecture delivered before the Harvey Society, New York, December 1, 1906. 


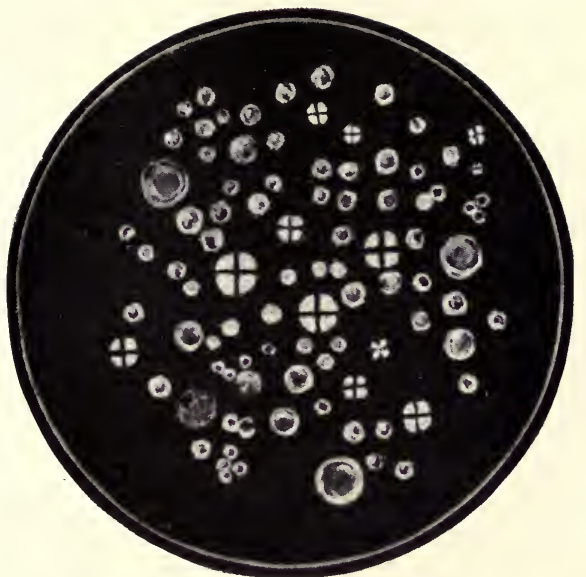

FIG. 1.-From juice of adrenal cortex of gninea-pig seen with erossed Nicol's prisns. The globnles with the black crosses are the doubly refracting myelin globules-the rest are fatty globules (isotropous). Sketch of appearances seen with the high power (Leitz, $\frac{1}{7}$ in.).

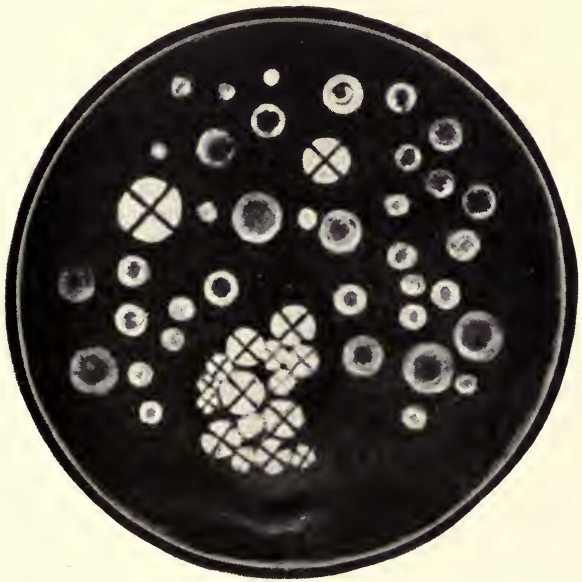

FIG. 2.-Human liver juice, expressed from piece of liver tissue acted on for 12 hours by alssolute alcohol. Large doubly refractive globules are seen under the crossed Nicol's prisms, along with abundant fatty globules. 

cross between four illuminated sectors. Smear a little of the juice of the fresh adrenal on a slide, and these can be examined more narrowly. Under the ordinary lens that juice is found filled with pure fatty globules varying in size ; with the crossed Nicol's prisms a few of these now stand out as illuminated crosses. Turn the prism round, and what had been crosses appear indistinguishable from the abundant surrounding fatty globules (Plate II. Fig. 1).

Here clearly we have not to do with ordinary fats. Neutral fats and fatty acids under no condition afford these characteristic doubly refractive globules. We are dealing with some other substance, a substance apparently acted on by water, for the addition of water to the juice causes the crosses to fade out; they disappear also if the preparation be desiccated, as again rapidly if it be treated with absolute alcohol. By that apparently they are dissolved, for treat an adrenal with alcohol and now evaporate that alcohol and at a certain stage these doubly refractive globules make their appearance to disappear again as the preparation dries up. Where an adrenal has been hardened in formalin, minute rod-like crystals take the place of these globules.

The adrenal is far from being the only organ that affords them, although it is the organ which in the normal state affords them in the greatest abundance without previous treatment of any kind. A common morbid state that often yields them in great abundance is atheroma of the aorta-one has but to scrape off a little of the broken-down material in an atheromatous plaque to find again this association of isotropous fatty and doubly refractive anisotropous globules. Or, again, pound up the liver or the spleen or the kidney in absolute alcohol, leave for a few hours, put a drop or two of the fluid on a slide, and as the alcohol evaporates these remarkable bodies make their appearance in relatively large numbers (Plate II. Fig. 2).

\section{WHAT ARE THEY AND WHAT DO THEY SIGNIFY?}

The answer to that question is rather a long story, and a round-about-one at that; nor as yet is it in my power-or any one's-to tell you its conclusion. The most I can hope to do is to interest you in the story, to show you into what by-paths of 
science it leads, and to set you guessing, and I hope some of you more than guessing, as to what is the conclusion thereof. For the matter appears to open up not a few lines of profitable investigation. I may, it is true, give you immediately an apparent answer. I can, that is, give these bodies a name. I may call them "myelin globules," and state that they are the condition assumed by myelin at a certain phase or under certain conditions. I question, though, whether this will bring much comfort. For what is myelin?

The remarkable fact about myelin is that it has been known for more than fifty years ; that within a few years of its recognition by Virchow, in 1854, it had been determined that bodies of the nature of myelin could be gained from practically every organ of the body, and this often in large amounts, and that, though this is the case, though the pains of pathologists brought myelin into the world and pathologists mothered, or fathered, it, though there is quite an extensive literature on the subject, it is rarely mentioned in polite medical society. Your writers of text-books on physiology and pathology studiously pass by on the other side without apparent recognition of its existence. This possibly because, had they recognized its existence, they could but confess their ignorance why it was there and what its function in the economy. And it has to be confessed that myelin has shown itself a most elusive substance.

If one takes fresh medullated nerve or brain substance and teases it out in water, the marrowy matter forms into drops and masses of irregular rounded contour, and as one examines these they become altered in shape, throwing out blunt rounded processes with a double contour. We are clearly not dealing with ordinary fats. Early in the last century Berzelius observed that the cerebrin which he extracted from brain matter gave similar bizarre forms; so, too, Drummond, in 1852, noted a like phenomenon with the alcoholic extract of brain matter. I find, indeed, that if fresh brain matter be placed in absolute alcohol for twenty-four hours the development of these bodies and processes becomes greatly exaggerated. Place a fragment under a cover-slip and surround with water, and long processes are shot out from the mass, curving in a most serpentine and life-like manner, and from them double contoured droplets become detached. Virchow, in 1854, called attention to the 
fact that by alcoholic extraction similar bodies could be gained from other tissues : from the blood, from yolk of egg, from the ovaries of calves, from the normal spleen, goitrous thyroid and diseased lungs. And, as in their physical properties they resembled brain marrow, Virchow gave these the class name of myelin. Whether he was dealing with one or with several substances, he could not determine; he was inclined to the view that, if not a single substance, he dealt with a group which chemically were as closely allied as the various albumins. And Virchow summed up their properties as follows :

1. When brought into contact with water they swell up, and in doing so exhibit a characteristic morphology, being seen under the microscope to develop processes of irregular and often bizarre form, globular, rod-like, or curved on themselves and variously distorted, exhibiting, as already noted, a double contour, undergoing changes of shape while under examination.

2. They are easily soluble in hot alcohol, becoming, in part, precipitated on cooling.

3. They dissolve rapidly in ether, chloroform, and turpentine.

4. They are acted on but slowly and to a slight extent by weak acids and alkalies.

5. Under the action of strong alkalies they shrink, with eventual loss of their characteristic properties.

6. Under the action of strong acids they first swell greatly and then undergo dissolution.

Now, whether recognizable immediately in the tissues or cells or cell debris so soon as water is added, or recognizable only after an alcoholic extract has been made of the tissues and such extract treated with water, bodies conforming to these postulates have been found distributed through the organism. And as a class they possess, with the limitations already laid down, the power of double refraction.

The history of the recognition of this last property affords an interesting example of the way in which valuable observations may, for long years, wholly disappear from remembrance, and that because they have been originally given to the world in the pages of an obscure journal. In 1857, if I mistake not, a society was established in Germany for the advancement of medical science, and the official organ of that association was distributed primarily, and it would seem almost entirely, among 
the members of the association. That journal, like the association, had but a brief existence. In its thirty-first number, Geheimrath Dr. Mettenheimer published his observations on myelin, noting its power of double refraction. The observations were so important that the elder Beneke, in 1862, reprinted the article in its entirety. But this happened in a monograph whose title, "The Presence, Distribution, and Formation of the Constituents of Bile," did not in the least suggest that it was concerned largely with this subject of myelin. Thus it is that, reviewing the literature for the next forty-four years, I have failed to come across a single reference to Mettenheimer's work, while Beneke's, after a year or two, appears similarly to have passed into oblivion until quite recently, when, with filial piety, the younger Beneke drew renewed attention to his father's work. In the meantime workers in different branches of biologic science made, as they thought, the independent discovery of this property of myelin-Apáthy, in 1889-90, working on the histology of the nervous system, G. Quincke, the physicist, in 1894, Müller of Marburg in 1898, and Kaiserling and Orgler of Berlin, later in the same year; and of these, from their writings, each seems to have been supremely ignorant that any one had been before him in making the observation that myelin is doubly refractive.

That all substances affording myelin forms can be shown to be doubly refractive I greatly doubt, or, more accurately, I would say that there are substances, such as the lecithins, capable of affording myelin forms of the simplest type with which so far I have been unable to gain doubly refractive globules. ${ }^{1}$ I shall have something to say later regarding these apparent exceptions.

I have here tabulated the distribution of Virchow's myelin in the organism as it has been recorded by various observers:

1 Since delivering this address $I$ have found that at least one lecithin (from egg yolk) gives with water exquisite doubly refractive figures, and that after repeated solution in chloroform and precipitation with acetone, a procedure which should remove any dissolved cholesterin. This is in opposition to Beneke's statement that egg lecithin completely purified from cholesterin gives no myelin figures. It is possible that Beneke is correct, but if so the process of separating cholesterin from lecithin must be very difficult. 


\section{TABLE A.-Showing the Distribution of Myeun Substances} IN THE ORGANISM

1. Intracellular Myelin Globules :

A. Physiologic, or associated with normal regressive processes:

Cells of suprarenal cortex . . . . Kaiserling and Orgler.

Granular cells of corpora lutea . . . Kaiserling and Orgler.

Cells of thymus gland - Kaiserling and Orgler.

Cells of mucous membrane of gall bladder . Aschoff.

B. Pathologic :

Aortic endothelium, fatty patches . Aschoff.

Atheromatous patches of aorta . . . Mettenheimer.

Lungs : Alveolar epithelium of newborn . Hochheim.

Bronchial epithelium . . . . Schmidt.

Diseased lung tissue . . . . Mettenheimer.

Kidney : Epithelium in fatty degeneration . Albrecht, Löhlein.

Epithelium after arterial ligation . Albrecht.

Crystalline lens, cataract . . . . Mettenheimer.

Tumours, cells of many cancers and sarcomas Kaiserling and Orgler.

C. Autolytic :

Lung, alveolar epithelium . . . . Albrecht, Hochheim.

Kidney and liver cells . . . . Many observers.

Skeletal and heart muscle. . . . Dietrich and Hegel.

Morning sputum . . . . Müller and Schmidt.

2. Diffused Myeurn : (Impure lecithin ?).

Myelin gained from varions tissues by digestion with alcohol; brain and nerve tissue, spleen, liver, egg yolk, blood, mesenterio chyle, pus, etc. . Virchow.

3. MYeLIN IN SecRetions: (Also gained by alcoholic extraction.) • . . . . • . Virchow. Bile.

Contents of small intestine after fatty meal . . Beneke.

\section{With what Order of Substance are we Dealing?}

My attention was forcibly directed to this class of substances through certain observations made in my laboratory by Dr. Oskar Klotz. Studying the experimental production of calcareous degeneration, he noted that if permeable celloidin capsules, containing oleic acid or neutral fats, be placed in the peritoneal cavity of the rabbit, on removal after a few days the contents give a relatively considerable proportion of calcium salts-salts which had not been there previously, which now are present in definite excess over the normal calcium contents of the rabbit's blood and lymph. The only conclusion to be reached was that in the organism under certain conditions calcium salts may become fixed by fatty substances; in other 
words, that calcium soaps become formed. From these observations he was led to study, histologically and chemically, areas of pathological calcification in the organism in order to determine if these afforded indications that the fats play a part in the process of pathologic calcification, and more particularly if there were indications of the presence of soaps as an intermediate stage in the process. He found that outside the body the stain Sudan iii affords a differential staining between neutral fats and soaps, globules of the latter taking on a paler, more yellowish tinge, and that in the zone immediately surrounding areas of active calcareous deposit he could recognize similarly globules taking on the deeper stain of neutral fats, together with others taking on the characteristic tint of soaps.

From these studies Klotz concluded that fats play an active part in the process of calcification: that, first, the affected area undergoes necrobiosis with fatty degeneration; that, next, calcareous soaps become formed, and, finally, that the fatty acid moiety of the compounds becomes replaced by the chemically more powerful phosphoric or carbonic acid, calcium phosphate and calcium carbonate being the end products. The indications were that he had not to deal with a simple calcium soap, but with a soapy compound containing calcium and, as he held, a proteid constituent. These stages could be well followed in that commonest seat of calcareous degeneration, namely, the aortic wall in the course of arterio-sclerosis. But now, happening to visit Marburg for other purposes, there Professor Aschoff pointed out to me that Dr. Klotz's description of these fatty globules, which were not fat but of a soapy nature, seen in the atheromatous area, corresponded in many respects with that of the globules seen by him in the arterio-sclerotic artery, globules which, as Mettenheimer first showed, and as Torhorst, working in Aschoff's laboratory, had independently determined, are doubly refractive. They are, in short, myelin bodies.

\section{Were Klotz's Soaps and these Myelin Bodies ONE AND THE SAME?}

It was to the solution of this question that Aschoff and I directed our attention. We found, in the first place, that the 
globules in the atheromatous aorta, which under Nicol's prisms were doubly refractive, take on the differential stain with Sudan iii; that Torhorst's myelin and Klotz's soaps are identical. The methods for isolating fats and soaps are still so imperfect, and the amount of the doubly refractive material in the atheromatous aorta relatively so small, that chemical isolation and study appeared hopeless. All that was left was to study the physical properties of various soaps and lipoid bodies so as to determine which of them approached most nearly in properties to the myelins. Thus it was that I undertook a long series of observations, in association with Professor Aschoff, beginning with the various simple soaps, to observe whether they possessed the power of forming these characteristic doubly refractive globules.

That certain soaps under certain conditions produce myelin bodies has been known for long ${ }^{1}$ and has been the subject of study, more especially by Quincke. One has but to take a drop of oleic acid on a slide and surround it with strong ammonia ${ }^{2}$ to obtain immediately a brilliant development of myelin figures, and, what is more, these figures examined between crossed Nicol's prisms are doubly refractive (Plate III. Fig. 1). We can produce " myelin forms" from an ammonia soap. This, however, is not quite the same thing as reproducing the characteristic doubly refractive spherules such as we have seen in the tissues of the organism. Briefly, I may state here that with certain simple soaps it is possible to gain these spherules, and that by very simple means, namely, by taking the pure soap with a small quantity of water on a slide, warming it until it dissolves, and then as it cools it may be that under the polarizing microscope a perfect rain of spherules shows itself. In some cases these persist for hours and, indeed, for days ; in others, depending on the nature of the soap, they are transient, appearing for a moment and immediately giving place to a brilliant white layer of formed crystalline plates.

By this means we determined that simple soaps of oleic acid give these figures-oleate of ammonia, of sodium and potassium, so also those of calcium-but here appeared to be a difference :

1 Neubauer in the 'sixties seems to have been the first to make the observation.

2 The experiment is more striking, as noted by Lehmann, if the ammonia and oil be coloured by contrasting dyes. 
the calcium globules would seem to be relatively solid, the others relatively liquid. But by no means was I able to gain the phenomenon with simple soaps of palmitic and stearic acids: on cooling concentrated solutions they passed immediately into the true crystalline form, and as these palmitic and stearic soaps are solid and definitely crystalline at the room temperature, it seemed evident that the spherules seen in the organism at room temperature could not be of palmitin or stearin compounds, or at least could not be simple uncomplicated compounds of the same. It is possible, I would suggest, that compounds containing palmitic or stearic, along with oleic, acid may be fluid at room temperature.

Here I trust that you will not misunderstand me. I do not in the least wish to suggest that the doubly refractive bodies seen in, or gained from, the tissues are simple soaps of oleic acid. The very instability of the oleates of ammonia, sodium, and potassium renders this most unlikely. All I wish to show at this stage is that we have a group of relatively simple bodies of known composition, of bodies having these curious physical properties that are likewise possessed by the myelin of the organism, and to suggest that a study of these simple cases is calculated to throw light on the more complicated. This certainly it has accomplished, and here, before referring to our studies on more elaborate compounds, it is fitting and timely that I should indicate how the study of the simple soaps afforded us what I believe to be a most important clue to the nature and properties of the myelins in general.

I have already mentioned that, studying strong solutions of the simpler soaps, these remarkable doubly refractive globules make their appearance as the solution undergoes cooling. Time and again the appearance is transient. At one moment the whole field of the microscope may flash out into a rich clustered constellation of bright crosses to be followed almost immediately by complete crystallization of the whole area. This fact alone, not to mention the doubly refractive nature of the globules, indicates that they are akin to crystals. Obviously they are not crystals proper; the form is not that which we associate with crystals; they are globular, not angular; they have all the appearances of being fluid bodies and not solid; in water they do not dissolve as do ordinary crystals, but swell up and 


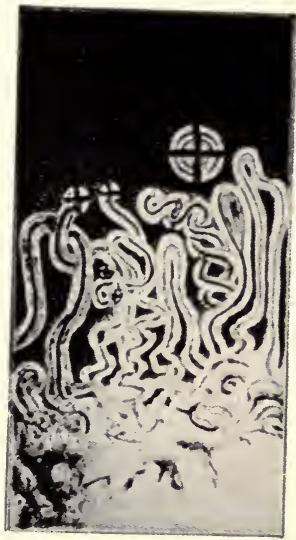

FIG. I.-The myelin processes formed by the action of ammonia on oleic acid, seen under the polarization microscope with crossed prisms.

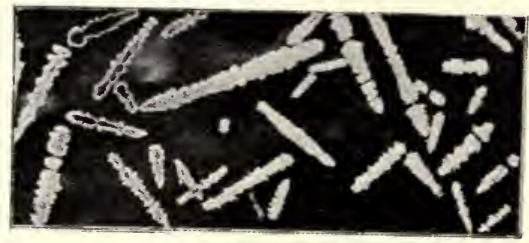

FIG. 2,-Flowing or ductile crystals of azoxybenzoic acid ethylester (alter Lehmam), Cholesterin oleate is apt to exhibit very small figures. 

gradually lose their doubly refractive qualities. This notwithstanding, they may appear as an intermediate stage in the process of crystallization of the pure oleates out of pure watery solutions.

\section{What is the Meaning of this Phenomenon?}

Not one of those who had worked on the myelins had even incidentally touched on this question. Nevertheless the solution had already been given by the physicists. To one of these, Professor Schenck, working in the very next institute at Marburg, we went with our inquiries and found that he had been busied over this very problem for the past few years. Schenck himself, it is true, had not discovered the solution; that was due to Professor 0. Lehmann, ${ }^{1}$ of the Technical High School in Carlsruhe, who two years ago had entombed his findings in a huge quarto monograph of 250 pages, a superb example of everything that a monograph ought not to be-verbose, diffuse, wandering, abundantly polemic, wanting in anything of the nature of a table of contents, let alone an index ; in short, wholly mediaeval save for its profuse and admirable illustrations (which nevertheless are devoid of legend or key), and for the valuable facts that can be dug out of its pages. Schenck, who had been working independently along the same lines, has given to the world a luminous description of the whole matter, giving clearly in a few pages all the important data and conclusions gained from the researches of Lehmann and himself ${ }^{2}$ and his pupils.

The popular impression is that a crystal is essentially a solid unyielding body. It has indeed been known for long that metals like lead and gold can, under pressure, be forced through apertures; the same is true of solid (or crystalline) sodium, of wax, paraffin, etc. But the general impression has been that change of shape in these cases is essentially brought about by translation, by the minute solid crystals of these substances gliding one on the other, or even - as shown by my colleague, Prof. F. D. Adams, in his remarkable observations on the alteration in shape of marble cubes submitted to great pressure

1 O. Lehmann, Flūssige Kristalle sowie Plastizität von Kristallen, etc., Leipzig, Engelmann, 1904.

2 R. Schenck, Kristallinische Flüssigkeiten und flüssige Kristalle, Leipzig, Engelmann, 1905. 
-by actual rupture of the crystals, the separate parts gliding the one on the other.

Undoubtedly this does happen with certain crystalline substances, but Lehmann, in 1889, first called attention to another order of phenomena. If solid cholesteryl benzoate, which is in the form of colourless crystalline plates, be heated to the temperature of $145.5^{\circ} \mathrm{C}$., it melts into a turbid fluid having the consistence of olive oil. Heated still further, as Reinitzer first showed, at $178.5^{\circ} \mathrm{C}$. it suddenly becomes a perfectly transparent fluid. Studying the intermediate stage, Lehmann found that under the polarization microscope the turbid fluid, despite its fluidity, exhibited double refraction with the crossed Nicol's prisms - a property hitherto regarded as associated with the solid crystalline state only; heated to $178.5^{\circ} \mathrm{C}$., the field became dark and isotropous, like ordinary fluids. If the opposite process were now undertaken and the heated fluid subjected to cooling, the whole field became converted into a mass of doubly refractive spherocrystals, showing here and there little dark crosses; cooled further, these gave place to plates of the solid modification, which plates grew in size until they occupied the whole field.

In fairly rapid succession other substances were determined having the same peculiarities :- other compounds of cholesterin with the fatty acid series, such as cholesteryl acetate, cholesteryl propionate, and cholesteryl oleate, compounds of oleic acid, sodium, potassium and ammonium oleate, as also methyl-, dimethyl-, and trimethylamin oleates, and various paraderivatives of anisol and phenetol. In Table B I have transcribed the list given by Schenck last year, adding thereto certain compounds found by us to possess the same properties, acknowledging that it is not complete, and that already numerous additions have been made during the last few months.

All these bodies become fluid on being heated, but the fluid examined between crossed Nicol's prisms has still the main optical features of crystalline substances; it is anisotropous. Some of these crystalline liquids are thick like olive oil, some (like $p$-azoxyphenetol) are more fluid than water. Poured into a vessel the surface becomes level; in tubes it assumes the characteristic concave meniscus of fluid bodies, and this although the constitution is crystalline. Heat to a further degree and 
the fluid becomes wholly isotropous; it gains all the physical properties attributed to, and of what we regard as, a true fluid.

table B.-Potential Fuotd Crystautine Substamons

(Modified from Schenck, with additions)

\begin{tabular}{|c|c|c|c|c|}
\hline \multicolumn{2}{|l|}{ Name. } & $\begin{array}{l}\text { Meiting } \\
\text { point } \\
\text { in degr. } \\
\text { centig. }\end{array}$ & $\begin{array}{c}\text { Clearing } \\
\text { point } \\
\text { in degg. } \\
\text { centiti }\end{array}$ & Observer. \\
\hline Silver iodide. & .. & 145 & 450 & Lehmann \\
\hline p-Azoxyanisol &.$\quad$. & 116 & 134 & Gattermann \\
\hline p-Azoxyphenetol & . & 137.5 & 168 & Gattermann \\
\hline$p$-Azoxyanisolpheneto & ol & 93.5 & $149 \cdot 6$ & Gattermann \\
\hline Azin of $p$-0xethylben & azaldehyde & 172 & 199 & Gattermann \\
\hline Anisaldazin . . & . . . & 160 & 180 & Franzen \\
\hline$p$-Methoxycinnamic a & acid. & 170 & $185 \cdot 7$ & Van Romburgh \\
\hline $\begin{array}{l}\text { Condensation product } \\
\text { aldehyde and Benz }\end{array}$ & $\begin{array}{l}\text { from Benz- } \\
\text { zidin . }\end{array}$ & 234 & 260 & \\
\hline Condensation produc & et from $p$ - & & & \\
\hline Toluylaldehyde and & d Benzidin & 231 & 300 & Gattermann \\
\hline$p$-Azoxybenzoic acid & ethylester. & $113 \cdot 5$ & 120.5 & $\begin{array}{l}\text { Vorlaender, Meyer, and } \\
\text { Dahlem }\end{array}$ \\
\hline $\begin{array}{l}p \text {-Diacetoxyltolluylen } \\
\text { Hydrocarotinbenzoate }\end{array}$ & e chloride. & $\begin{array}{r}124 \\
\ldots\end{array}$ & $\begin{array}{r}138 \\
. .\end{array}$ & $\begin{array}{l}\text { Muench } \\
\text { Reinitzer and Lehmann }\end{array}$ \\
\hline Cholesterylacetate & . & $\begin{array}{c}90 \\
100\end{array}$ & $\begin{array}{l}114- \\
114 \cdot 4\end{array}$ & Reinitzer and Schonbeck \\
\hline Cholesterylpropionate & & 98 & 114 & Obermueller \\
\hline Cholesterylbenzoate & 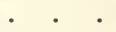 & $145 \cdot 5$ & $178 \cdot 5$ & Reinitzer \\
\hline Cholesterylbutyrate & . & .. & .. & Adami and Aschoff \\
\hline Cholesterylstearate & . & .. & .. & Adami and Aschoff \\
\hline Cholesterylpalmitate & . & .. & .. & Adami and Aschoff \\
\hline Cholesteryloleate & . & .. & .. & Reinitzer \\
\hline Potassium oleate & - & .. & .. & Quincke and Lehmann \\
\hline Sodium oleate & & .. &.. & Quincke and Lehmann \\
\hline Ammonium oleate & . & .. & .. & Quincke and Lehmann \\
\hline Dimethylammonium & oleate & .. & .. & Quincke and Lehmann \\
\hline Trimethylammonium & oleate & .. & .. & Quincke and Lehmann \\
\hline Cholin oleate &.$\quad$. & .. & .. & Adami and Aschoff \\
\hline Neurin oleate & . & .. & .. & Adami and Aschoff \\
\hline
\end{tabular}

In this intermediate stage, then, we deal with crystalline fluids, and the individual crystals are "fluid crystals"-though here a distinction is drawn by Lehmann and Schenck between "flowing" or ductile crystals (fiessende Kristalle) and "fluid" (flüssige) crystals proper (Plate III. Fig. 2). The former we encounter in crystalline fluids of the thicker, less fluid type, the latter in the more watery fluids. The former, under the microscope, are of definitely crystalline structure, needle-shaped or 
prismatic, but tending to have rounded edges and angles. If the cover-glass be pressed (as I have repeatedly confirmed) they become distorted, returning to their original shape when the pressure is removed (Plate IV. Fig. 1). The latter under the ordinary microscope show no signs of crystalline structure; they appear as masses of spherical bodies, capable of distortion, lying in a singly refracting, isotropous matrix. But one and the same substance may exhibit both forms ; there is no absolute division into substances exhibiting purely the one or purely the other, while if any of these bodies be distributed in an inert fluid matrix the individual aggregations are peculiarly apt to take on the sphero-crystalline form, appearing as doubly refracting globules -identical with those that I have described to you as encountered in the tissues.

It need scarcely be said that these observations, completely overturning the older ideas of the properties of crystals, have from many quarters been regarded as heretical, and have encountered violent opposition. I am, as I have said, no physicist, and should therefore not presume to weigh the evidence that has been tendered against these conclusions. I can only say that I have seen with mine own eyes that these spherocrystals and ductile crystals are capable of distortion (vide Plate IV. Fig. 1)-that they are not solid. A very natural suggestion has been made that we have here to deal with substances of two orders, that, on heating, a purer more crystalline matter separates out from a more inert fluid menstruum of different constitution. G. Quincke, for example, has urged that the conditions correspond with those found in emulsions, a fluid " skin " surrounding and leading to the persistence of the separate globules. Tammann has compared this stage to what is seen in an emulsion of carbolic acid in water, which from being cloudy becomes transparent on heating, and holds that here is not a true crystallization but a depolarization phenomenon. Lehmann has brought forward proof that we have to deal with true double refraction and not a depolarization phenomenon, and he and Schenck have shown that the phenomena present themselves equally well with chemically pure substances of this order. ${ }^{1}$

1 Had we to deal with emulsions, centrifugating should separate the two constituents, or, passing an electric current through the medium, the suspended particles, if of different constitution, should gather at one or other pole. Schenck has shown that with pure substances neither of these events occurs. 
Here, then, for the first time, we gain a satisfactory physical explanation for the doubly refractive globules seen in, or obtained from, the organism; they are fluid sphero-crystals.

\section{CAN WE PROCEED ANY FURTHER?}

As I have already stated, the investigation of compounds presenting this intermediate stage is a recent study, the number found is increasing with relative rapidity, and it is well within the bounds of the possible that yet other substances, constituents of the normal organism, will be found to possess it. But what is not a little suggestive is that the physicists, without any thought of physiologic problems, have already noted its existence in two groups of bodies which are normally represented in the organism, namely, the cholesterin compounds and the oleates. And studying the list of crystalline fluids and the temperatures at which the intermediate stage manifests itself, with the exception of one group these bodies pass into what, for convenience, I term the intermediate stage at temperatures far above that of the room or body; thus save for that one group they cannot be responsible. The only group containing members which afford doubly refractive globules at room temperature is that of the compounds of oleic acid. These compounds are so unstable - the oleic acid so readily undergoes dissociation-that it is hopeless or almost hopeless to gain them in a pure state, and as a consequence it is not possible to state with precision what are the points of melting and clearing. But certainly cholesteryl oleate is viscid and buttery at the room temperature, and at this can be demonstrated to afford the globules, and the simple oleates of ammonium, potassium, and sodium may likewise continue to manifest them at the room temperature, ${ }^{1}$ although in general the fields show definite crystals. Here it may be noted that the medium in which the soaps are present is capable of modifying the melting-point. To this fact I shall have to return later. Cholesteryl palmitate and stearate, I have found, both afford these globules and so exhibit the intermediate stage, but their melting-point is very definitely higher. We are led thus to

1 Evidently these myelin globules of the organism are not doubly refractive at blood heat. I could not demonstrate those of the adrenal in a warm room at the Rockefeller Institute (about $75^{\circ} \mathrm{F}$.) until the window had been opened and the room cooled down. 
exclude the simpler palmitates and stearates from the causes of the phenomenon in the organism, although the possibility must not be forgotten that bodies like certain of the lecithins which contain both oleic and palmitic or stearic acid radicals, may eventually be found to afford the reaction.

These considerations, therefore, so far as it is legitimate to carry them, distinctly favour the view that the myelin globules of the organism are probably of the nature of oleic acid compounds-are soaps of oleic acid of greater or less complexity.

It deserves pointing out that from wholly different considerations, namely, from the point of view of chemical analyses of myelin-containing substances, the earlier workers have arrived at conclusions which are approximately in harmony with ours. Liebreich, for example, analysing nerve matter, determined that the constituent which was the essential cause of the myelin figure formation-or otherwise the myelin properwas the protagon which he was the first to isolate. With Apáthy, I may add, I have found the myelin figures from nerve matter under certain conditions doubly refractive. Now protagon dissociates into lecithin, fatty acids and neurin or cholin, and while crystalline protagon treated with water merely swells, affording no myelin figures, if a drop of oleic acid under the microscope be acted on by a solution of cholin or neurin, I gained an immediate development of exquisite doubly refractive myelin figures-as exquisite as when strong ammonia acts on oleic acid. It is not therefore the protagon as such, but dissociated cholin oleate or neurin oleate ${ }^{1}$ that would seem to be the base of the myelin formation in nerve matter.

There is another body which separates out abundantly in the alcoholic extraction of nerve matter, namely, cholesterin. This in itself does not afford the intermediate state, but its compounds with the fatty acids manifest it, and it is quite possible that such compounds play a part in the myelin formation seen in fresh nerve tissues. We owe to the elder Beneke in 1862 the first recognition of the significance of cholesterin in myelin production. He showed that while olive oil treated with caustic potash afforded myelin bodies, the more cholesterin he added to the oil the better was the result; that alcoholic extract of

1 There is still some doubt regarding the identity of cholin and neurin. I have, however, gained a compound of oleic acid witn both substances. 
egg yolk freed from cholesterin gave no myelin figures; that ordinary soaps on the addition of cholesterin gave them. In other words, he produced experimentally impure cholesteryl oleate, palmitate, and stearate. He called attention to the existence of cholesterin in tissues affording myelin and concluded that in animal and vegetable tissues "ohne Cholesterin keine Myelinformen." Liebreich retorted with his observations on protagon, and Beneke's work became discredited. Nevertheless, Aschoff and I believe that Beneke, if too extreme in his dictum, was largely right, and that in many situations in the body the myelin globules are of the nature of cholesteryl oleate. This, it may be noted, as shown by Hürthle, is a constant constituent of the blood. In the atheromatous patches in the aorta, in old cataracts of the eye, and in other necrotic areas, it is a matter of familiar experience that we encounter fatty globules along with plates of cholesterin, and here, too, we meet with the myelin globules. An incidental observation on an aorta showing early atheroma impressed me greatly. The smear from a small area of slight softening presented numerous fatty globules and cholesterin crystals, but no doubly refractive bodies. I heated it gently over the flame, and on cooling there appeared abundant myelin globules, more particularly in the neighbourhood of the cholesterin platelets, which now exhibited a somewhat corroded appearance. Nay more, we would suggest that cholesteryl oleate is the source of cholesterin calculi in the gall-bladder.

Cholesteryl oleate excreted from the blood into the bile (and, as Virchow showed, myelin is present in the normal bile) may in the alkaline fluid easily undergo dissociation, the oleic acid combining to form simple diffusible soaps, the cholesterin being set free. At the last meeting of the German Pathological Association at-Stuttgart, Aschoff demonstrated the presence of the doubly refractive myelin globules in the cells of the mucous membrane of the gall-bladder.

We thus have what I regard as strong presumptive evidence that at least two groups of oleic acid compounds give rise to the myelin globules of the organism-the cholin or neurin, and the cholesterin. There is a third group deserving consideration, namely, the lecithins. Regarding these I would speak with considerable caution, while at the same time stating my con- 
viction that some of them give origin to myelin globules. These lecithins, I may remind you, dissociate into fatty acid, glycerophosphoric acid and cholin. According to Carbone, in dissociation they may give rise to fatty acids, neutral fats, and cholesterin. Here once more we have this suggestive appearance of the two substances of widely different chemical nature, cholin and cholesterin, each of which we have found associated with the development of myelin globules.

From the tissues there have been gained a di-oleo-lecithin, a di-stearo-lecithin, and a palmito-stearo-lecithin. 1 They also, it will be seen, are fatty acid compounds. They afford " myelin figures" of a simple type and doubly contoured myelin droplets, but thus far with the pure substances free from cholesterin I have been unable to gain doubly refractive globules. ${ }^{2}$ It is deserving of note that the two tissues affording myelin in greatest amounts contain normally the most abundant lecithin, namely, the brain and the adrenals, and that, as Albrecht has pointed out, the abundant "myelin " obtained from the red corpuscles is composed in the main of lecithin. More particularly is it in connexion with autolysis, and the self-digestion of tissues that the association of lecithin and the appearance of " myelin bodies" has of late been commented on from various quarters. Time forbids that I should enter at length into this most interesting field. I can only very rapidly point out that if a sterile organ be kept with all aseptic precautions at the body temperature, its cells in the course of a few hours exhibit abundant small rounded irregular bodies in their cytoplasm, possessing double contour. Coincidently, the nuclei become pale and it can be made out (Albrecht, Dietrich and Hegel) that the chromatin becomes discharged into the cytoplasm, the appearance of the myelin bodies bearing a definite relationship to the discharge of the chromatin.

Some but not all of these afford obscure double refraction. As indicated by the accompanying table from Waldvogel and Mette, while in autolysis of the liver the ethereal extract (of total fatty substances) is not greatly increased, the fatty acids and neutral fats in the cell undergo great increase at the expense of the lecithin, as does also the cholesterin.

1 According to the recent very full studies of Thudichum every true lecithin contains at least one oleic acid radical.

2 Vide note on page 172. 
TABLE C

\begin{tabular}{|c|c|c|c|c|c|}
\hline No. of Days. & Lecithin. & Fatty Acid. & Neutral Fat. & Cholesterin. & $\begin{array}{c}\text { Ethereal } \\
\text { Extract. }\end{array}$ \\
\cline { 1 - 5 } & 11.8 & 0.52 & 0.06 & 0.07 & 13.4 \\
43 & 6.82 & 1.80 & 0.96 & 1.80 & 13.0 \\
& 1.06 & 3.74 & 3.61 & 5.41 & 15.9 \\
\hline
\end{tabular}

With Dietrich and Hegel, it is difficult not to be forced to the conclusion that the lecithins with their glycerophosphoric acid are intimately associated with and derived from nuclear material with its glycerophosphoric acid; and that the myelinlike bodies in the cytoplasm are of the nature of lecithins, which lecithins undergo subsequent dissociation. My present viewwhich I admit is subject to revision-is that it is not the lecithins proper that afford the doubly refractive globules, but the products of their dissociation and more particularly those of the di-oleo-lecithins, and of the interaction between the cholin and the cholesterin and the oleic acid. For it must be kept in mind that oleic is a singularly weak acid, that its compounds are singularly liable to hydrolysis with liberation of free oleic acid. As a matter of fact, lecithin warmed with cholesterin affords with water or dilute glycerin exquisite doubly refractive myelin figures ; as, again, by acting on pure lecithin (Riedel's lecithol) with alkalies, the doubly refractive globules can be gained. Schenck, indeed, lays down that the salts (soaps) of oleic acid never exist in a chemically pure state; there is always some water and alkali mixed, free oleic acid, and free alkali. This natural impurity is very possibly a feature of importance in the myelin formation by members of this group.

Let me, in conclusion, state that I have not brought up this matter of the doubly refractive myelin globules as a method by which the existence of myelin in the tissues of the body can surely be recognized. That is by no means the case. The formation of these globules is no constant reaction. What I would emphasize is that under certain conditions, not always easily obtainable, Virchow's myelin can be shown to possess this very characteristic reaction, and that so, the myelin figures and myelin globules in the organism must be regarded as of fatty nature, and more, that these belong to that remarkable 
class of substances possessing an intermediate state in which they are present in the form of fluid or of ductile crystals.

This in itself, while a matter of interest, would not perhaps be of great importance were it not that associated with this property, as pointed out by Schenck, is a further one which we are led to regard as of great significance. Schenck has called attention to the fact that whereas ordinary crystalline substances permit of mixture with other substances to a very limited degree, all the members of this class, even when of widely different chemical composition, unite in all proportions, the meltingpoint of the mixture being then determined by the relative amounts of the two substances present. If, then, we admit that more than one substance present in the organism belongs to this class, it is by no means assured that a given doubly refractive sphero-crystal (in the adrenal, for example) is composed of a single substance. It may be an admixture of two or more. Nor is this everything. Their power of mixing with and absorbing ${ }^{1}$ other substances is very great, not to say extraordinary. With water, for example, the oleates, the lecithins, protagon, and allied bodies do not in the first place dissolve. They absorb it and swell up. Only after they have swollen up greatly does solution, or what appears to correspond to solution, show itself, for there is still debate among the physicists regarding the solubility of these bodies. What is true of water is true of a large number of other substances ; oleic acid, for example, and neutral fats are absorbed, and within certain limits, despite the presence of these foreign substances, the globules continue to exhibit double refraction. Such admixture, for example, occurs in the adrenal. Studying the adrenal juice under the polarizing microscope, one of the earliest facts that strike the observer is that the globules are of varying lustre, some bright and clear, others pale, others faint, just discernible shadows. And, in addition, one finds aberrant globules. Fig. 2, Plate IV. shows some of the forms I have seen.

Remembering that these lipoid myelins are widely distributed through the organism, this power of admixture and absorption appears to be most significant. To this Albrecht has already called attention in connexion with the abundant myelin of

' [Or in modern parlance " adsorbing."] 


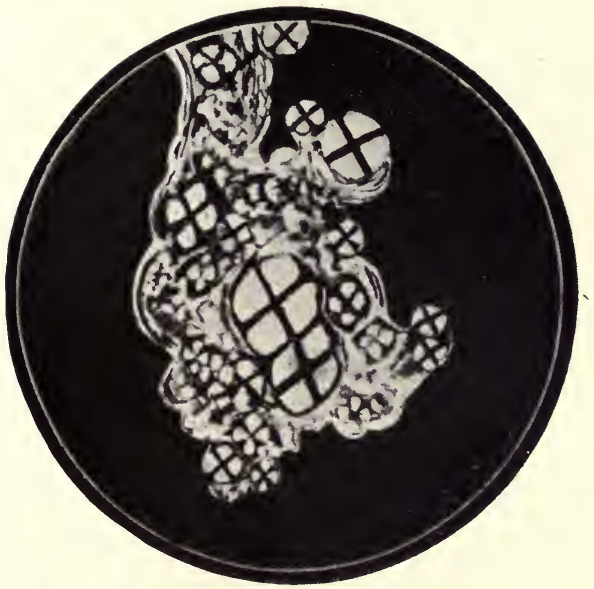

FIG. 1.-From the same material as Fig. 2, Plate II., after five days. The myelin globules were in coherent masses (from partial evaporation of the alcohol). They exhibit well-marked distortion.

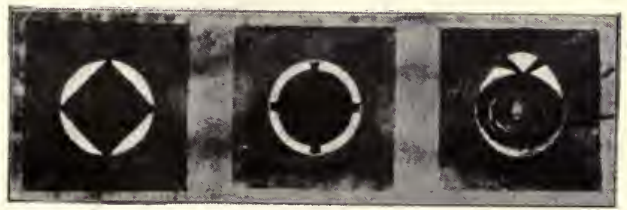

FIG. 2.-Aberrant forms of the myelin globules of human adrenal seen under the crossed prisms of the polarization microscope. 

the red corpuscles. It is these properties which favour the action of the erythrocytes as common carriers of the organism. It is not necessary that diffusible bodies become chemically combined with the substance of the red corpuscles; they may be merely absorbed and easily yielded up when the surroundings become altered.

Most suggestive of all seems to me the observations of Albrecht and Dietrich and Hegel on the one hand, that the myelin of the cells in autolysis makes its appearance in the cytoplasm coincidently with the loss of the nuclear chromatinand our own observation, that outside the body it is possible to gain union between oleic acid and nitrogenous bases, such as cholin and neurin. It is true that so far no one has been able to demonstrate the existence of protein-fatty-acid compounds. Brücke, Quincke, and Klotz have all concluded that they must exist. This demonstration of ours of the existence of cholin and neurin oleate is, I would suggest, a step in this direction.

If fats can be taken into the protein molecule-if the lecithinlike bodies of the nucleus and the cytoplasm exist there normally in intimate association with the protein constituents-then we gain a valuable insight into the most perplexing matter of fatty degeneration. Fats, that is, appearing in fatty degeneration and necrobiosis, are not necessarily or entirely due to absorption from the blood and lymph, as Rosenfeld would hold, but some at least are products of the disintegration of the complex molecules of living matter. With many workers on autolysis we have to recognize a succession of steps from the most highly organized nuclear materials through the myelins to neutral fats, fatty acids, and cholesterin. There is a myelinic preceding the fatty degeneration; or, more accurately, in true cell degeneration, as distinct from infiltrative processes, the disintegration of the cell substance may well be in two stages, bodies of the myelin type being formed first, and these being followed, with further dissociation, by the appearance of fatty bodies of simpler type. 


\section{CHAPTER V}

THE DOMINANCE OF THE NUCLEUS ${ }^{1}$

THERE are, it seems to me, two alternative reasons which should govern the choice of a topic for discussion at the meetings of Sections of the British Medical Association : either to afford to the general medical public an expression of opinion by specialists upon topics of the time, or, on the other hand, to direct the attention of the public to matters in which it is well that they should be interested. These discussions are not merely for the benefit of the participants; they are published in extenso in what has become the organ of the British practitioner throughout the world; and this public aspect must be kept in sight, nor should the debate be allowed to narrow itself into the discussion of minutiae.

It must be frankly admitted that nuclear function is not exactly a burning question of the day. Your ordinary medical man is little concerned about it; your routine physiologist is concerned in the main with mass effects; your pathologist sees, it is true, certain changes in the nucleus in various conditions of cell disturbance, but what these changes indicate are scarcely discussed in his text-books or journals. It is for the second of the above-mentioned reasons that this topic has been chosen for to-day's discussion. Though we have not what has become a topic of the time, we have a matter which it is timely to bring forward.

For years individual observers in zoology and botany, cyto-

1 Being the opening address of a discussion on the Physiology and Pathology of the Nucleus at the 74th Annual Meeting of the British Medical Association, Toronto, Angust 1906. 
logists and students of "Entwickelungsmechanik," physiological chemists and morbid histologists have been recording facts regarding the nucleus, and these facts brought together point to the one conclusion that the nucleus is the dominating structure in the cell-dependent, it is true, upon the cytoplasm, or cellbody, but nevertheless dominant. The time has come to realize that general advance lies in a recognition of these foremost properties of nuclear matter, to recognize the fact that within the unit, the cell, is the more intimate unit, the nuclear matter, so that the physiology and the pathology of the future are destined to be nuclear rather than cellular. Or, to be more exact, while the cell remains our natural unit, within that cell the modifications that have taken place must receive their explanation primarily in terms of nuclear change. Possibly this may seem to be a matter of little moment to the practitioner. So, I doubt not, appeared fifty years ago Virchow's insistence upon the allimportance of the cell. We can but say here that to the thoughtful man, ever seeking the why and wherefore of things, even if the ultimate answer is never to be reached, each successive step onwards towards that ultimate answer is a notable achievement, and this because each such step affords wider generalizations and the recognition of a fuller harmony of phenomena.

And there are other and weighty reasons, first amongst which is the opportunity this choice affords as a means of rapprochement between the physiologists and pathologists, and, if the remark be not impertinent, as a means of encouragement to the former. It is good and natural that these two branches of medicine should come together. For many years they have tended to drift apart; the problems which have interested the one have had little compelling interest for the other; and I fear it must be admitted that there has been a feeling on the part of pathologists, and of medical men in general, that the teaching in the one subject has too often not been in the direct line of preparation for the study of other branches of medical science. In short, physiologists were already embarked in the study of mass effects before the cellular structure of tissues was discovered, and they had so large a field before them that for long years organs and their properties occupied their whole attention. Modern pathology, developing later under the guidance of Virchow, has been essentially based on the cell theory; it is the cell and not 
the tissue that has formed its unit. Only now are there indications, with the development of finer methods and the relative completion of the work upon mass effects, that physiologists in general are by a natural process gravitating from the study of the tissue, its functions and its chemistry, to that of its component cells. Physiology is becoming and must inevitably become more cellular. And it is peculiarly fitting that we should inaugurate this discussion in Toronto, in recognition of the pioneer part played by Professor A. B. Macallum in emphasizing the importance of cellular physiology. It is no exaggeration to characterize Professor Macallum's long-continued work upon the nucleus, its histology and its chemistry, as the most important series of contributions to medical science that has proceeded, not merely from Toronto, but from Canada at large ; no exaggeration to refer to him as the first English-speaking physiologist to consecrate his activities to work along these lines.

It is a sincere pleasure to me, coming from another Canadian city, and occupying in this respect the vantage ground of not being a Torontonian, that I can with propriety direct attention to a matter in which Toronto is among us facile princeps. I take it that in opening this discussion I shall perform the greater service if $I$ devote myself to a rapid review of the various findings which together compel the conclusion that the nucleus is the centre of cell activity, leaving it to those who follow me to enter more particularly into the evidence of one or other order.

Such a general survey is more especially demanded because, to my knowledge, it has not yet been attempted; or more correctly, when attempted what I regard as the inevitable conclusions have not been drawn. While individual workers have demonstrated the controlling powers of the nucleus in one or other respect, there has been a curious disinclination to bring the various orders of data together and deduce their full significance. But here certain limitations must be introduced. The activities of living matter are to be divided into two categories, intrinsic and extrinsic, or vegetative and functional. The observations which have been made upon the nucleus in connexion with the vegetative activities, with cell multiplication and reproduction, are very abundant. To discuss these along with the data bearing upon the rôle of the nucleus in the functional activities of the cell would make our debate altogether too 
diffuse. It has been thought wiser, therefore, to confine ourselves, save in one respect, to the latter-the functional activities. Nevertheless, if I have correctly interpreted my duties as introducing the subject in order to place in a clear light the controlling influence of the nucleus in the life of the cell, I cannot leave these vegetative activities out of account. As opener I must as briefly as is possible, consistent with lucidity, bring forward the evidence of nuclear predominance as afforded by studies upon cell and individual reproduction. It was the studies upon mitosis that first revealed the high importance of this constituent of the cell.

We can, perhaps, best treat this section of the subject by means of a series of theses :

1. The properties which distinguish the individuals of any race or family from the individual of any other race or family are to be traced back to the constitution of a single cell, the fertilized ovum, from which that individual has been developed.

2. There must, therefore, be something in the constitution of the germ matter of the parent stock which differentiates it from the germ matter of other stocks. Nay, more, no two individuals appear to possess germ matter of absolutely identical constitution.

3. In individuals of gamogenetic origin, resulting from sexual union, the material contributed to the ovum by the paternal spermatozoon and the maternal ovum is, physiologically speaking, of equal value. As demonstrated by Mendel in his observations upon hybrids, like orders of offspring result whether the male cell of stock A be employed to fertilize the ova of stock B, or the female cells of stock A be fertilized by the male cells of stock B. ${ }^{1}$

It is evident, therefore, that matter of like order is contributed to the fertilized ovum by the two parents.

4. In studying more narrowly the process of fertilization we find that the only matter contributed correspondingly by both parents is nuclear matter. Ovum and spermatozoon are cells of widely different appearance, and the result of fertilization is that the female cell affords the cytoplasm, or cell substance, of the fertilized ovum; the male cell provides the centrosome.

1 In mammals intrauterine existence would seem to introduce a factor of differentiation. 
The nucleus of the fertilized ovum or new individual is formed of corresponding amounts of nuclear matter (chromatin) from both parents.

5. Not only is this the case, but most significantly-I shall take up a probable exception immediately-each supplies a like number of chromatin loops or chromosomes, and as the fertilized ovum undergoes development and proceeds to divide and redivide, the like process of distribution is continued, so that each separate body cell of the fully developed organism contains equivalent parts of chromatin of paternal and maternal origin.

6. We can proceed yet further and recognize that in certain species at least the chromosomes supplied by or derived from either parent while pairing with like chromosomes from the

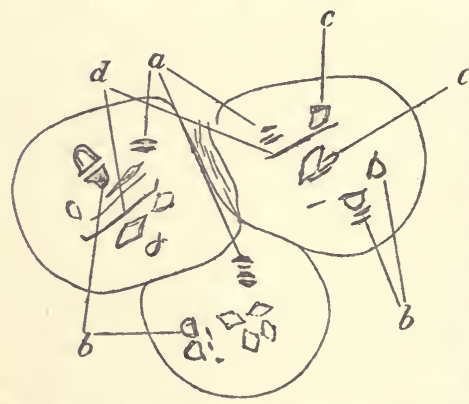

FIG. 13.-Spermatocytes from human testis (after Moore and Arnold) to demonstrate the varions forms of chromosomes contributed to the future spermatozoa, and the presence of the varions types in the different cells. These distinct types $a, b, c, d$ are always found in the human sperm mother cell when undergoing maiotic division. other parent are not all identical in appearance and size, but vary among themselves, the variation being constant; that is to say, the same types of chromosomes are found in successive generations of cells. This peculiar variation, as has been pointed out more particularly by American observers (Montgomery and Sutton), is frequent in insects in the cells which ultimately give rise to the germ cells. As Moore and Arnold of Liverpool have just shown, a like constancy is to be made out in the types of chromosomes seen in the spermatocytes of mammals, even of man himself. The constancy of the particular varieties present in individual species suggests that the chromosomes of different orders possess different properties and determine different characters, or sets of characters, in the cells to which they are distributed, and in the individual formed from the aggregation 


\section{PLATE V}
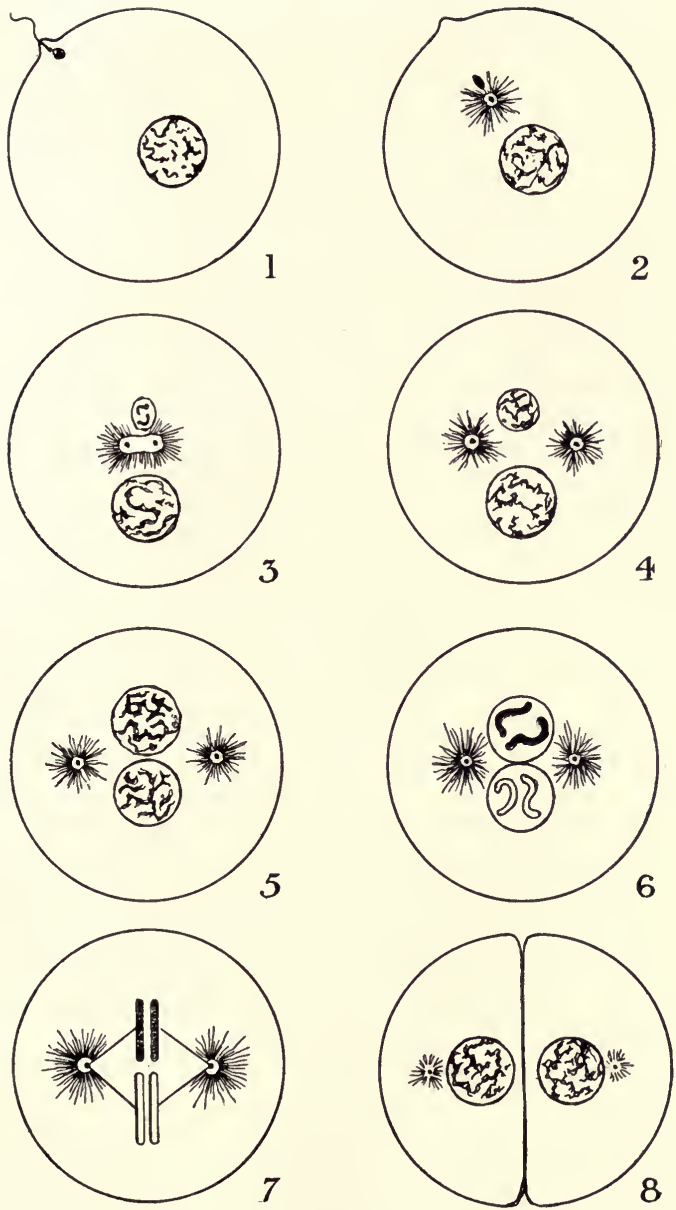

FIG. 1.- Schema of the stages of fertilization of the ovum, to indicate the respective parts played by contributions from the ovum and spermatozoa to the fertilized ovum or new individual (after Boveri).

(1) Entrance of spermatozoon into ovum. (2) Head of spermatozoon enlarging to form the male pronucleus, the neck-piece forming the centrosome of the cell. (3) Division of the centrosome; male pronucleus undergoing further enlargement. (4) Further enlargement of male pronucleus, until in (5) the male and female pronuclei are approximately equal. (6) Formation of equivalent chromosomes in male and female pronuclei. (7) Formation of nuclear spindle, equivalent chromosomes of paternal and maternal origin becoming distributed, so as eventually to pass into the two primary blastomeres of the segmenting ovum. (8) The two primary blastomeres with their nuclei, each receiving thus equivalent portions of chromatin from both parents. 

of these cells. In support of this hypothesis are the remarkable observations, first, of $\mathbf{M}^{\prime}$ Klung of Kansas, and, later, of E. B. Wilson, of New York, that the spermatozoa of sundry insects are of two orders, though there is but one type of egg. The one order of spermatozoa gives rise to males, the other to females, the difference between the two being in their chromosomes. In the maturing spermatocytes which give origin to the spermatozoa, either the one set of cells possess an accessory chromosome, or, in other cases, a particular chromosome in one half the maturing spermatozoa is large, in the other half is minute. To quote M'Klung:

"A careful consideration will suggest that nothing but sexual characters thus divide the members of one species into two well-defined groups, and we are logically forced to the conclusion that the peculiar chromosome has some bearing on the arrangement."

Here we are not discussing sex, and I do but note these observations in passing. There are other cases, not as yet fully worked out, in which, as in the aphides, there would appear to be one type of spermatozoon and two types of ova.

The natural conclusion to be reached from all these data is that the nuclear matter conveys and determines, or controls, the inherited peculiarities of the individual; further, the conveyance is through matter contained in the chromatin loops or chromosomes, while it may be that these individual loops, varying among themselves, determine particular conditions.

What we know concerning the spermatozoon points very definitely to the conclusion that the groups of chromasomes distributed to the spermatozoa derived from a single spermatocyte are not identical, each spermatozoon receiving only one half the number of chromosomes proper to the primordial germ cell, and to the cells in general of any particular species. The ovum on its part exhibits a like reduction. To inquire further into this remarkable reduction process would lead us into the discussion of variation and the Mendelian doctrine. I do but mention these matters here to call attention to the fact that not merely inheritance but variation is seen to be most intimately associated with the nuclear material, and that, if we can trust our eves, the one morphological constituent involved in and responsible for all cases of inherited peculiarities and 
gamogenetic variation is included in the nuclear chromatin. That the other constituents of the cell have an influence or can have an influence we do not deny. If in the fertilized ovum the nucleus influences the cytoplasm, so, conversely, the constitution of the cytoplasm must tell upon the nucleoplasm. The facts in our possession indicate that the latter is the subordinate process ; the influence of the nucleus is dominant. This is best indicated by Boveri's remarkable observation that if the nucleus be removed from the sea-urchin's egg and the enucleated mass of cytoplasm be fertilized by the spermatozoon of another species of echinoderm the resultant larva is of the type of the species that afforded the spermatozoon, that is, the nuclear material; this has conveyed and determined the specific properties of the individual.

Now, if this be so, it must follow that the nuclear matter controls all the essential cell activities, and this because, studied narrowly, it is seen that the morphological properties of a cell are the expression of the constitution of the cell; it is the constitution that determines the properties and functions of that cell. All are bound together every whit as much as are the properties of any given salt and the constitution of the same. What is true of the cell holds also of the multicellular individual ; the specific properties of the individual are the summation of the properties of its component cells. If, therefore, nuclear composition dominates the morphology of the individual cell it dominates, likewise, the properties of the individual.

It must now be asked: What evidence do we possess establishing that this is really the case? That evidence may be dealt with under many heads. We have to deal with the evidence afforded by : (1) the natural and experimental enucleation of cells; (2) gross changes observed in the nucleus as the result of cell activities; (3) the finer changes in the same which may be seen to follow functional activity; (4) the histological changes in the nucleus associated with morbid conditions; (5) the chemistry of nuclear and cytoplasmic matter respectively ; and $(6)$ the ferment actions of the cell and their relationship to nuclear activity.

Let me now lay before you the main data that have been gained under each of these headings, and the conclusions that may reasonably be deduced. 


\section{The Effects of Removal of the Nucleus}

The cell which, like the erythrocyte, undergoes natural loss of its nucleus may continue to exist for a considerable period, and during that time actively perform function. The mammalian red corpuscle, for example, according to W. Hunter, Quincke, and others, exists from fifteen to thirty days. While it exists we see no evidence of growth, and certainly it never propagates itself. The same holds good for cells artificially deprived of their nuclei; they do not necessarily undergo immediate disorganization ; they can be the seat of certain metabolic activities. According to Klebs, the enucleated cells of the alga, Spirogyra, can in the sunlight produce new starch granules; can, that is, synthesize starch from the carbon, oxygen, and water absorbed, the starch thus formed in the sunlight being used up in the dark; and this may continue for as long as six weeks. They may further continue to exhibit motion in response to external stimuli (Lacrymaria olor, Verworn); they may actively ingest food particles. But, on the other hand, the testimony is unanimous that higher metabolic activities are incomplete. Unlike nucleated portions of a vegetable cell, the enucleated is unable to develop a cell wall of cellulose. Among protozoa, also, Verworn has noted that enucleated pieces of foraminifera show not the slightest capacity to form the internal calcareous skeleton. If the enucleated cytoplasm of Thalassicola pelagica ingest foreign particles, it is unable to digest them wholly, and while the enucleated cytoplasm can develop a new centrosome (E. B. Wilson), it cannot give rise to new nuclear material. It may be laid down that if it can form new paraplasmic substances like starch, it cannot form new cytoplasm and cell substance proper; that is to say, it cannot increase in bulk and undergo cell division and multiplication, or, otherwise, these observations conclusively prove that the nucleus is essential, not merely for the vegetative activities, but also for the higher metabolic activities of the cell and their due co-ordination.

That the nucleus alone, deprived of surrounding cell substance, cannot regenerate the cell is another matter. It has freely to be admitted, with Verworn, Boveri, and Lillie, that there must be a certain minimal quantity of cytoplasm associated with the nucleus before regeneration can take place. But what this 
proves is not that the nucleus is not the dominating portion of the cell complex, but only that the association of nucleus and cytoplasm is essential for full cell activity. By the lack of perception of this distinction it may be noted that Verworn's treatment of the whole subject of cell processes is greatly weakened if not vitiated. His facts prove that nucleus and cytoplasm are equally essential for the full function of the cell, not that they are of equal value. We may as well argue that in the community of bees the individual drone or worker is of importance equal to the queen, because we find that the queen-bee, if separated from the rest of the community, is incapable of obtaining food for herself, and so starves to death. I shall refer later to what I regard as the right conception of the relationship between cytoplasm and nucleus.

\section{Gross Changes in the Nucleus during Activity}

Among these may be noted, (1) alteration in the position of the nucleus in cases in which there are indications of localized as distinct from diffuse cell activities, and (2) alteration in size and shape of the nucleus accompanying active function.

In the animal organism possessing cells with a body which is small in proportion to the size of the nucleus, examples of the first order would appear to be rare, though they are not entirely wanting. Thus Korschelt has shown that in the egg rays of the water scorpion ( $N e p a)$, with their cells having remarkable nuclei, long branches from two adjoining nuclei send out processes which come into close proximity. In the space between these a chitinous deposit gradually shows itself, and when the mass of chitin is fully formed the processes are withdrawn. In the plant, movement of the nucleus towards the area of new formation in the cell is relatively common; thus when there is the active formation of a thick cell membrane along one aspect of the cell, it has been noted that the nucleus becomes eccentric and approximated to the region of new development. There is a similar eccentric localization of the nucleus during the development of root hairs (Haberlandt). I need but mention instances of the second, namely, of alteration in size-they are now so well known. The earliest observations were those of Heidenhain years ago upon the different appearance of the nuclei 
of salivary glands when at rest and after stimulation. In more recent years we have had the striking observation of Hodge, confirmed by Gustav Mann, Lugaro, and others, upon the nuclear alterations in the motor ganglion cells of bees, birds, cats, and other vertebrates brought about by natural and experimentally produced fatigue.

These observations also clearly demonstrate that the nucleus is not merely the vegetative centre of the cell, but is involved in its functional activities.

\section{Finer Changes occurring in the Nucleus during the Course of Cell Activities}

If I am not mistaken it was a native of what we regard as the youngest of the civilized great countries of the worldProfessor Ogata-who first, in 1883, clearly recognized the finer nuclear changes associated with secretory activity. He called attention to the granules, or plasmosomes, appearing in the nucleus at the beginning of secretory activity-granules which take on the characters of nucleoli, and pass from the nucleus into the cell body. In these he held that the zymogen granules are developed which eventually become (part of) the protoplasm of the cell. In 1887 Lukjanow made confirmatory observations. He noticed in the secreting cell outside the nucleus the agglomeration of little spherules which in form, size, and reaction to dyes were closely related to certain nuclear bodies (Kernkörperchen). He drew the cautious conclusion that " it appears in any case that the hypothesis of a connexion between the nucleus and the cell body has in itself nothing improbable-a connexion shown outwardly by certain structural elements of the nucleus passing over into the cell body, and there undergoing further change." In the following year F. Hermann noted the apparent discharge of similar minute globules in mucous goblet cells during secretion, and also called attention to the fact that these in staining powers resemble the nucleolus. These he found were absent from the resting cell. In 1890 Professor Macallum made his first report upon similar phenomena. He pointed out that in the nuclei of developing ova of Necturus (the lake lizard, found here in Lake Ontario), as also in that of the frog, at one stage the chromatin is principally collected in 
the form of nucleoli at the periphery immediately beneath the nuclear membrane. These nucleoli are usually spherical, and vary somewhat in size. At this stage yolk granules are absent from the cell. With an indigo carmine dye he found that the nucleus and cell body stained red, whereas the nuclear bodies took on a deep blue. At what appeared to be clearly a later stage, yolk spherules made their appearance, and when this happened the whole ovum stained blue, the nuclei being diminished in size. What appeared to be an intermediate stage was seen in ova in which the nucleoli and the cell substance in their immediate neighbourhood exhibited a blue stain, while the rest of the nucleus and the main mass of the cytoplasm still stained red. It was difficult from these observations to arrive at any other conclusion than that the nuclear matter becomes differentiated into nucleolar, and that this diffuses gradually through the nucleus and then into the cell substance, the diffusion coinciding in point of time with the formation of the yolk granules. Macallum thus regarded the yolk granules as formed by the union of a derivative of the nuclear chromatin with a constituent of the cell protoplasm. And we here note that these yolk granules chemically are composed in the main of lipoid material, of lecithin, a compound to which I shall refer later. In the pancreatic cells Macallum found-and Steinhaus has made similar observations-that the nuclei possess safranophilous nucleoli, while the rest of the nucleus with double staining takes on a deeper red colour of haematoxylin. As the nucleus loses its safranophilous substance, the cell protoplasm acquires safranophilous granules. He concluded that the chromatin of the nucleus gives rise to a substance prozymogen; sometimes it is dissolved in the nuclear substance, sometimes collected in masses (plasmosomes); finally it diffuses out into the cell protoplasm, there meeting with a constituent of the latter to form the zymogen proper.

I might proceed to detail a long series of confirmatory observations by Carlier, by Bensley-made here in Toronto-by Maximow, Solger, Nicholas, E. Müller, Krause, Galeotti, Vigier, Garnier, Greenough, and others, all agreeing-save in minor details-and all bearing upon the processes seen in gland cells. All describe the smallest and first seen granules as situated in the immediate neighbourhood of the nucleus; described these as 
identical in character with the plasmosomes or nucleoli seen within the nuclear membrane, and have observed that as they pass to a farther distance from the nucleus they enlarge into definite secretory granules. It is with the exact stages of this process that there has been and still is some debate: whether they project as buds from the nuclear membrane or make their way out from pores opening into the same; whether they finally dissolve within the cell or undergo solution when discharged into the external medium. But Professors Macallum, Carlier, and Bensley are all here, and I must not further steal their fire. I would only add that what has been determined in the animal

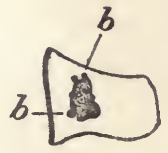

1

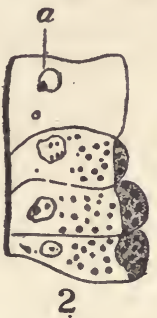

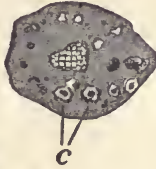

3

FrG. 14.-Cells of the salivary gland (after Maximow) to show (a) development of the plasmosomes within the nucleus, $(b)$ passage of these out of the nucleus into the surrounding cell substance, with subsequent conversion of the same into granules or globnles. Cell 3 is abnormal, showing exhaustion of nuclear material. In the cell are globules of various sizes, some still taking on the nuclear stain, others taking on a contrast stain, while others (c) show a centre taking on the stain of nuclear chromatin, with outer zone staining the same as the cell secretion.

cells holds for the plant cell also. Thus Torrey has described a succession of changes in connexion with the nucleus and cell body in the germinating maize seed associated with the production of diastase. The processes are of an identical nature: deepstaining granules are first seen in the nuclei, whence these exude in small streams into the cytoplasm; scattered at first through the cell, these later become collected at that end next to the endosperm, where they become ultimately dissolved. It is following upon their dissociation that the first action of a ferment upon the cell wall and matrix of the endosperm becomes evident.

Nor is it only in connexion with secretions possessing ferment action that we have evidence of nuclear function. In plants Schniewind Thies has observed nuclear changes in the nectar 
cells of flowers in the process of the elaboration of nectar. In animals the curious vacuoles in the nuclei of fat cells which have been known for several years have more recently been shown by Shattock to contain and to give the reaction for fat.

These data almost justify us in accepting Claude Bernard's remarkable prevision of more than a quarter of a century ago, that the cell substance is the seat of vital expenditure, while in the nucleus resides the power of organic synthesis. This does not, however, in our opinion, exactly represent the relationship, for the nucleus is also the seat of expenditure, nay, appears often to determine that expenditure. But clearly, the indications are that the higher syntheses, those associated with growth and those governing the specific enzyme actions of the different forms of cell, are determined and initiated by the nuclear matter.

\section{The Nucleus in Pathological Conditions OF THE ORGANISM}

Purposely when passing in review vegetative and proliferative phenomena I did not call attention to the evidence afforded by the study of the nucleus in cases of aberrant cell growth. It appeared advisable to consider the pathology of the nucleus by itself and from all aspects, and that, more particularly, because while the normal vegetative activities are not subjects for our discussion, the abnormal come within our purview. At this point we have to call attention to the evidence of nuclear dominance afforded (1) by cases of abnormal cell growth, (2) by cases of disturbed function.

Regarding the first of these I shall be brief.

It may be stated unhesitatingly that the majority of pathologists at the present moment regard neoplasia or blastomatosis as essentially a condition of aberrant cell growth, brought about not by the constant stimulus of intracellular parasitism, but by some primary alteration of cell environment. As a consequence of such alteration, if I may quote myself, the energies which, had the cells remained in their normal relation, would have been devoted to functional, become diverted to vegetative and proliferative activities. Your active malignant tumour cell has characteristically all the attributes of a vegetative cell, or, as it is usual, perhaps unfortunately, to express it, is of the embryonic type. 
Associated with this we find that the growing tumour exhibits abundant mitoses, and, what is more, the growth being aberrant, we find a well-pronounced tendency for the mitoses also to be irregular. We thus encounter a great variety of changes : (1) dispersion of chromosomes in the cell body as the result apparently of rupture of the threads of the achromatic spindle; (2) asymmetrical mitoses; (3) multipolar mitoses; (4) hypochromatosis with diminution either in the number or in the size of the chromosomes; (5) hyperchromatosis, with increase whether in number or size of the chromosomes; (6) associated with degenerative

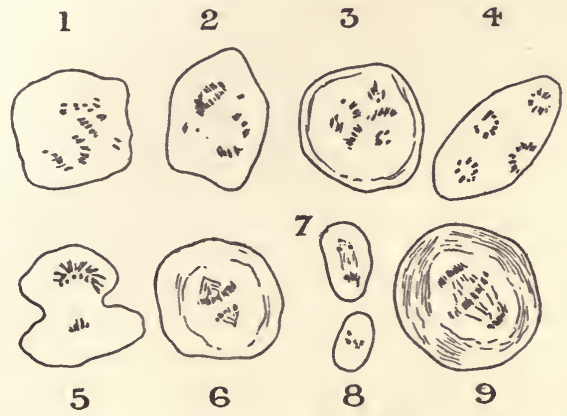

FIG. 15. - Various forms of aberrant mitosis in cells from malignant growths (after von Hansemann and Pianese). 1 and 2, Dispersed chromosomes; 3 and 4, multipolar mitoses; 5 and 6 , asymmetrical mitoses; 7 and 8 , hypochromatic mitoses ; 9 , hyperchromatic mitosis.

changes and rapidly growing tumours we may encounter the development of paranuclear bodies (Nebenkerne), sometimes of large size and modified staining properties, lying in the cytoplasm, and clearly derived from the nuclear matter.

The existence of these abnormal nuclear conditions in connexion with tumour growth is most significant. Beyond this statement, that it is difficult to arrive at any other conclusion than that there is an intimate relationship between these nuclear vagaries and the abnormal cell growth seen in malignant tumours, I feel it is unsafe to venture; for, as Dr. Bashford has frankly acknowledged, more advanced hypotheses based upon these abnormalities have not stood the test of extended investigation.

Turning now to observations upon the nucleus in pathological 
conditions other than those associated with aberrant growth, it may, in the first place, be noted that cases may be recalled bearing upon the cell when it passes into a latent or dormant condition. While we cannot go as far as Grawitz and accept the existence of "slumber cells," in which the nucleus and its chromatin have become so shrunken as to be invisible, we can, I think, note that with the arrest of cell function and passage into an inert state, the nuclei undergo shrinkage, becoming extremely small and attenuated, as in the fully formed connective tissue, fully formed fat cells, etc.

It is in association with cell irritation and the commoner acute degenerations that the nuclear changes become most evident. It is a matter of familiar knowledge that pronounced changes take place in connexion with cloudy swelling and, to employ the old term, fatty degeneration, as distinct from fatty infiltration of the cell. In cloudy swelling which so commonly accompanies the acute fevers and conditions of intoxication, we note, more particularly in the cells of secretory glands, that the nuclei, which in the first stage of irritation may become more intensely stained, rapidly lose their staining property and become indistinct, and the cell body becomes filled with granules of albuminous nature. Stolnikow was apparently the first to make accurate studies upon the changes that occur in these degenerative processes; many others have since noted the same collection of the chromatin in the region of the nuclear membrane ; the discharge into the cytoplasm (well seen in the liver cells in phosphorus poisoning); have described these little masses as first staining like nuclear substances, and later losing the nuclear stain completely, the cell body becoming filled with shell-like clear-staining globules. The more recent work of Schmaus and Albrecht, Lubarsch, and others, has confirmed and extended these observations, the former observers calling particular attention to the formation of nuclear buds, as also to the hyperchromatosis and karyorrhexis in gradual death of the cells of various organs. There are, needless to say, other changes seen in the degenerating cell-pyknosis, or contraction and clumping of the nucleus and nuclear material; karyolysis, or complete disappearance of the chromatin. These are evidently post mortem conditions (that is, in the cell), and need not here be considered. From those first mentioned it would seem that the 
cell may recover. They represent exaggerated conditions of normal processes, but where the latter stages show themselves, regeneration of the cells becomes hopeless.

As to the significance of this discharge of nuclear material, I shall have a little to say after we have discussed the chemistry of the nucleus. Professor Ewing and others will, I trust, discuss the relationship of these modified nuclear discharges to the intracellular appearances which by many have been regarded as cancer and vaccine or variolous organisms.

\section{The Chemistry of Nuclear and Cytoplasmic Matter RESPECTIVELY}

Here, in studying the chemical composition of the two components of the cell, we meet with certain remarkable facts, for not a few of which we are indebted to Professor Macallum. There are certain substances of great chemical activity bound up in the nuclei which are present to but slight extent, if, indeed, at times they can be recognized in the cell body. Notably is this the case with phosphorus (Lilienfeld and Monti, Macallum), as also with "masked" iron-iron, that is, in fairly firm combination, so that it is only loosened and made to respond to the tests for free iron after having been subjected to preliminary dissociative treatment. On the other hand, certain substances found to be present in the cell body are absent from nuclear matter. Among these, as Macallum has pointed out, are potassium and chlorides. When now we come to study the proteid contents of the nuclei, we find that these, unlike ordinary proteins of the cell body, are undigested by gastric juice, and that the undigested material consists of the nuclear network and its chromatin and the nucleoli. We owe especially to Kossel's investigations the explanation of these peculiar features. Cell nuclei, that is, contain as a main constituent a special group of proteins - the nucleoproteins. These nucleoproteins split up into albumen (histon) and nucleins, and it is these nucleins in particular that resist the action of gastric juice, and further, are characterized by high phosphorus content. These, like the nucleoproteins, are of a proteid nature; upon further decomposition they yield albumen and nucleic or nucleinic acid, and can be further broken down into the xanthin bases or purin 
bodies. It is more particularly the existence of phosphorus and these xanthin bases that differentiate the nucleus from the cell body. How the iron is combined is as yet undetermined. We know at most from Spitzer's observations that it is the iron-containing products of dissociation of the nucleoproteins that retain the oxidative properties. But clearly in the nucleus we have as essential constituents compound proteins of great complexity of organization. As Spitzer, Herter, and others have indicated, the iron is of the utmost importance in bringing about oxidative processes, while the phosphorus likewise would appear to favour oxidative changes. These and other chemical considerations tend to the conclusion that nuclear material possesses in itself potentialities superior to those of any ordinary constituent of the cell body, and again support the view that the nucleus is the centre or source of the higher cell activities.

\section{The Ferment Actions of the Cell and their Relationship to Nuclear Activity}

Jacques Loeb, indeed, has been led to the conclusion that the nucleus is the centre of the oxidative processes of the cell, and the correctness of this view has of late been demonstrated by his pupil Lillie. It would open up too large a field to detail and weigh the data indicating that nuclear matter is the essential source of those bodies which afford the enzyme actions of the cell. We would merely note in passing that it is now universally accepted that much of the cell function-I do not say all-is the outcome of enzyme action, and I would recall the data already brought forward to show that in the absence of the nucleus the higher specific cell activities are at a standstill; the evidence also of the relationship of the nucleus to the formation of zymogens.

Referring to the discharge of plasmosomes or spherules of nuclear matter into the cell body it may now be asked, What chemical processes do these indicate? It is suggestive that under normal conditions this discharge has been noted in cells affording specific secretion, and in abnormal conditions accompanied by the accumulation in the cell body of modified paraplasmic granules or globules. It is at least suggestive that in 
autolysis (the self-digestion of tissues removed from the body under aseptic conditions) we note a diffusion out of nuclear chromatin, and following upon this the formation in the cell body of myelin granules and masses. Everything indicates that these myelin masses so formed are complex lipoid bodies; they contain fatty acids, more particularly oleates, and studying the composition of what is regarded as the simplest group, the lecithins, we find that they are compounds of a nitrogenous base (cholin), with glycero-phosphoric acid and a fatty acid. Where these make their appearance in the cell undergoing autolysis (and probably in other conditions), we must conclude that the glycero-phosphoric acid is of nuclear origin, and, leaving aside for the moment the question of the seat of origin of the nitrogenous base, remembering that the nucleus of the ordinary cell is devoid of fat, we are led to regard these lecithins as combinations between matter of nuclear origin and fatty matter from the cell body. These lecithins are bodies having very remarkable properties, both chemical and physical; they have great powers of holding other substances in solution, and this is true of all the myelin bodies. It may well be that the suggestive series of nuclear changes and cell accumulations which we find in the cloudy and fatty groups of degenerations, represents successive stages in which the development and dissociation of bodies of this type play the essential part. In our studies in Montreal during the last three years on calcareous and fatty degeneration this matter of the formation of compounds of albumen and fat has constantly been brought before us. Dr. Klotz (in this following upon the conclusions of Brücke long years ago) has brought forward data favouring the view that direct union may occur between the two; but he will be the first to admit that an absolute chemical proof of the existence of such compounds is singularly difficult to adduce. It is true that, working with Professor Aschoff at Marburg, we have recently demonstrated the combination between nitrogenous bases, such as cholin, and oleic acid, but this is another matter-nitrogenous bases while built up into proteins are not proteins. But if we are not as yet wholly certain of the existence of oleates of albumen, it is a well-ascertained chemical fact that lecithin can combine directly with albumen to form albuminates. Thus lipoids of the nature of the lecithins afford us the necessary linkage bodies 
between various albumens and between albuminous and fatty acids. ${ }^{1}$ As regards their importance in this connexion we would only call attention to Preston Kyes's remarkable observations upon the part played by lecithin as complement, or linkage body, between certain serum proteids and cell proteins and snake venom. It is interesting to note how almost simultaneously during the last few months independent workers in Germany, France, the United States and England, approaching the subject from widely different points of view, have converged to the same conclusion-that the lipoids are of singular importance to the cell and in relationship to metabolic processes. We seem at the threshold and in its shadow, and see already the light within. But here at the threshold I must stop.

\section{The Nucleus and Growth}

Before closing, however, there is a question which I doubt not has arisen in your minds, and one which must be answered. "You arrogate," it will be said, " all these powers to the nucleus. What part is played by the cytoplasm?" To this I would answer that, passing further and further backwards in our endeavour to comprehend what is life, if we believe in living matter and that vital phenomena are the expression of the effects of physical and chemical forces acting upon that matter, then our ultimate conception of life must be that it is the function, or the sum of functions, of a special order of molecules. For convenience, we would term these ultimate molecules of living matter biophores. However much we strain our imagination it would seem impossible to conceive the existence within the cell of two orders of molecules of widely different type, but of equal value, which, by their interaction, initiate vital processes. We must premise that there is in each form of life one primal order of living matter. If so, the biophores must be contained either in the nuclear matter or in the cytoplasm; and as we have shown

1 The mucins would seem to represent a parallel group of carbohydrateproteid compounds, and the histological observations of Steinhaus, Maximow, and others demonstrate most clearly that nuclear matter is concerned in their development; indeed, in goblet cells, according to Steinhaus, there is a total conversion of the old nucleus of the cell into mucinogen. The figures given by this observer are of the same order as those afforded by Ewing of nuclear changes in epithelial cells in connexion with vaccinia and variola. 
that the higher vegetative powers of the cell are intimately associated with nuclear matter, it is in the nucleus that we must locate these biophores, and we must therefore regard the cytoplasm as composed of subordinate matter, and as having what must be termed subvital functions.

Now, the simplest conception that we can form of these biophores-and even in the very lowest forms of life they must be singularly complex-is that they are rings or rings of rings, carbon- and nitrogen-containing and of the benzol type. The only satisfactory conception of growth, by multiplication of these molecules, is that the pre-existing rings possess unsatisfied affinities, and attract side-chains of various ions, simple and compound, from the surrounding media, and that these become grouped in a manner identical with the grouping present in the preexisting biophore. In other words, we must regard the building of the new biophoric molecules as obeying laws of the same order as those which determine the building of ions

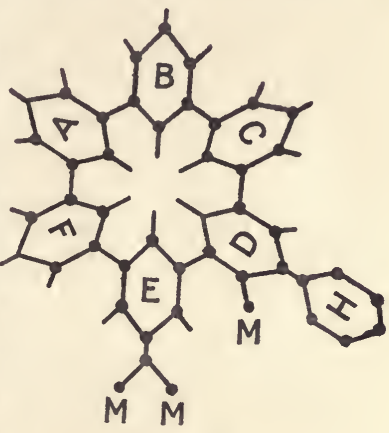

Fra. 16. out of a solution to form crystals of a particular form of salt, but with this difference, that so far we have no evidence of biophores becoming formed anew save under the influence of pre-existing biophores-we know no case of spontaneous generation. Thus, growth demands affinities and side-chain formation on the part of the biophores. As with evolution the biophoric molecules have become more complex, we would suppose that ions and radicals have become attracted and attached not in ring arrangement but in loose series and loose connexion with the biophores. As in growth new biophoric molecules are formed in association with the pre-existing, the result is an inevitable tendency towards the grouping of the biophores in a central mass surrounded by a zone of other attracted matter. With the development of such a complex system the biophoric molecules proper are no longer in direct and immediate relationship with the outer medium; 
there is interposed between the two an intermediate mass. The direct attraction of new matter is, in the main, accomplished by the intermediation of this outer cytoplasmic zone. So that eventually we reach the stage in which with increasing com-

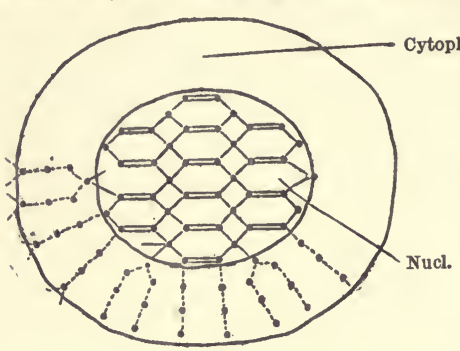

FIG. 17. plexity of organization the biophoric molecules proper, deprived of the outer cytoplasmic zone, are unable to attract ions to themselves in the proper order-these must first have been built up into particular orders of radicals within the cytoplasm. In other words, the presence of preformed cytoplasm becomes essential for the continued existence and growth of the nucleus-of the nuclear-biophoric matter. Each becomes essential for the continued existence of the cell as a whole.

This, frankly, is all hypothetical, but it is the hypothesis which seems best to throw light upon and to harmonize the data we possess regarding the function and the relative importance and nucleus and cytoplasm respectively. Nay more, it is in harmony with what we know concerning the very lowest forms of life, and their imperfect nuclear development.

I feel I shall have done some service if I have demonstrated the dominance of the nucleus and impressed you with the conviction that the future will see not merely a cellular but a nuclear pathology and physiology. From the omne vivum ex vivo to the omne ovum ex ovo and the omnis cellula e cellula of our predecessors we now reach the omne chromosoma e chromosomate of the modern student of development and see before us surely the conclusion omne biophorum ex biophoro ejusdem generis.

If this be the ultimate conclusion of the investigator, it is at the same time the point from which chemist and physicist, anatomist and physiologist, pathologist and physician ${ }^{1}$ must start to develop harmoniously, each along his respective line,

1 [And, I would add, zoologist and botanist.] 


\section{NUCLEAR AND CYTOPLASMIC RELATIONSHIP 209}

their various conceptions of vital processes, and, as the indications are that these biophores exist in the nucleus, so it is to the nucleus and its alterations that each of us, whatever his particular branch of biological science, must apply himself for the fullest intimate grasp of the succession of changes that take place in health as also in disease. 


\section{CHAPTER VI}

THE REDCCTIO AD ABSURDUM OF WEISMANN'S THEORY 1

THere have of late years been abundant theories of inheritance brought forward, but none has attracted greater attention than that of Weismann, none has been so fully worked out; and as the distinguished author of the theory in the evening of his life has given us this theory in a rounded and complete form, which has, further, been admirably translated, ${ }^{2}$ it will be well to take this as a basis.

Weismann accepts, as indeed he was one of the first to emphasize, that inheritance is conveyed by germ cells which have from the first been set apart for reproductive purposes. These germ cells as such take no part in the building up of the parental individual of whose organism they form a part; only when liberated and fertilized do they proceed to multiply, giving rise to one set of cells which form the body as a whole, and to another smaller set-the germ cells. In other words, he holds that the germ cells contain within them two constituents, the somatic or body plasm and the germ plasm. The tissues built up by the somatic plasm are mortal, subject to death; the germ plasm is potentially eternal-it is carried onward from generation to generation. Here is the first weak point in Weismann's argument $-\mathrm{a}$ false conception which vitiates the whole subsequent train of thought. The germ plasm is not potentially eternal. If, as already indicated, the individual human being derived

1 Abstracted from article upon "Inheritance and Disease" in the System of Medicine by Sir W. Osler, Bart., F.R.S., F.R.C.P., and T. McCrae, M.D., F.R.C.P., Philadelphia, Lea Bros. \& Co., vol. i., 1907, p. 36.

2 August Weismann, The Evolution Theory, translated by J. Arthur Thomson and Margaret R. Thomson. London, Ed. Arnold, 1904. 
from a solitary spermatozoon and a solitary ovum can produce on the average, as already indicated, $85,000,000,000$ other spermatozoa each resembling the primordial spermatozoon in size and properties, it is clear that-leaving the body cells out of account-the germ plasm contained in that primordial spermatozoon has multiplied itself several thousands of millions of times; or otherwise it has in the process of growth assimilated vast quantities of other material to itself, and rearranged it so that that new material has come to possess the same constitution, and, with this, the same properties as itself. With growth there is constant new formation of molecules forming the individual cells. In other words, the germ plasm is not eternal ; it is constantly being renewed. What are the nearest to being potentially eternal are the chemical and physical properties of the germ plasm. And this very fact, that growth implies constant rearrangement and assimilation of constituent molecules, makes the chemical composition "eternal" only so long as the assimilable material remains the same. To this I shall revert. Weismann, it is true, admits that there is growth; he does not, however, realize all that this necessitates.

He next demonstrates very clearly that this heritable germ plasm is contained in the nuclei of the conjugating ovum and spermatozoon, and regards as a proved proposition that the nuclear chromatin is the hereditary substance. This is present in the germ cells of every species in the form of a definite number of chromosomes which, in cells destined for fertilization, is reduced to one-half the number, so that the single nucleus-the segmentation nucleus-of the fertitized ovum contains the number of chromosomes characteristic of the cells of the individual of any particular species. The hereditary substance of the child is therefore formed half from the maternal, half from the paternal substance, and as, at each succeeding cell-division, each of the paternal and maternal chromosomes doubles by dividing, each cell of the individual contains hereditary material derived from both father and mother.

This very fact of reduction, he points out, indicates that half the chromosomes contain all the essential primary hereditary constituents, or, otherwise, that it is not the chromatin as a whole that conveys hereditary properties. The rather, this must be made up of a series of constituents or $i d s$, each of which is repre- 
sentative and capable of conveying all the paternal or maternal properties.

Let us pass back a generation. The germ cells of the parent are similarly formed by a combination of chromosomes from the two grandparents. These must be represented, as indeed must also be the chromosomes of the great-grandparents, etc. What is more, in the process of reduction he holds that certain chromosomes derived from certain ancestors are cast out, others retained, and that it is the variation in the series of retained chromosomes that in the main determines the variations between the members of the same generation. The hereditary substance in the fertilized ovum thus consists of several complexes of primary constituents contained in the chromosomes, or "idants," each of which complexes (an "id ") comprises within itself all the primary constituents of a complete individual.

Each "id" Weismann conceives as being composed of a mass of different kinds of parts, each of which bears a relation to a particular part of the perfect animal, and so to some extent represents its primary constituents, although there may be no resemblance between these Anlagen and the finished parts. These representatives of individual parts contained in each "id" he terms "determinants" (Bestimmungsstücke). In each "id," therefore, there must be as many determinants as there are regions in the fully formed organism capable of independent and transmissible variation at all stages of development-for the caterpillar stage, for example, as well as for the butterfly; determinants even for the egg, because eggs, caterpillars, and butterflies are seen to vary independently. If, as has been noted, the individual hairs on the antennae of insects are capable of transmissible variation, and if, in man, the conformation of particular teeth is inheritable, then determinants there must be for these individual hairs and teeth. If a little patch of scales on the butterfly's wing is peculiar to one variety, for those few scales there must be a determinant.

And lastly, each individual determinant must be made up of molecules of living matter, or biophores. Such biophores, he holds, must be larger than any chemical molecule; they must consist of groups of molecules, some large and complete, others simpler and more minute; so that ultimately it is the interaction of these biophores-the casting out of some from one parental 
stock, the retention of others in their containing determinants and ids-that determines variation. No two individuals contain identical groups of determinants and identical ids, and, as these control development, therefore no two individuals are identical. If in reversion the characters of an ancestral form, it may be hundreds of generations back, are reproduced, this is because in the process of reduction, followed by fusion, of the two parental germ plasms, the ancestral ids come to predominate to the exclusion or casting out of the ids of more recent generations. Why this should tend to happen in a special order of cases the theory does not venture to explain.

The reader from these data should be able to apply the theory to particular cases. It has also to be added that Weismann holds that the development of the individual from the ovum proceeds in such a way that by nuclear division it is brought about that the germ cells are assured of possessing a complete set of ids, whereas the body cells do not gain this complete set. There is a qualitative differentiation of the chromatin passing to what are to be the eventual tissues of one or other order, so that ultimately the particular determinants find themselves in control of particular groups of cells, destined to produce specific tissues or parts of tissues.

There is, we confess, something that savours of mediaeval scholasticism in this conception, something remote from our general conception of the order of natural events, and, as a matter of fact, the whole edifice of ids, determinants, and biophores collapses when confronted with the findings of physical science. Weismann's biophores, in brief, composed as he imagines them of numerous molecules, some of them complex and of large size, must be smaller than are individual atoms! We can in certain nuclei recognize rows of granules forming the individual chromosomes-little bodies $0.5 \mu$ or less in diameter-bodies considerably smaller than the micrococci of suppuration. These Weismann regards as the individual ids. Each id is, he postulates, made up of determinants, of which, as each region capable of variation is supposed to be represented by a separate determinant, there must in the human id be thousands rather than hundreds. Each determinant is made up of biophores or ultimate units of living matter; each biophore, according to him, consists of a group of molecules. Each molecule is, we may add, composed of 
numerous atoms. Now Lord Kelvin, in his convincing investigation into the size of the molecule of water (by a study of the thinnest possible films of a bubble), has proved that in a line $0.5 \mu$ in length there could be only about 150 molecules of water. Let us be generous and compute the ids as being not on the average 0.5 but $1.0 \mu$ in diameter, and, again being generous, let us compute the ultimate molecule of living matter as being only thirty
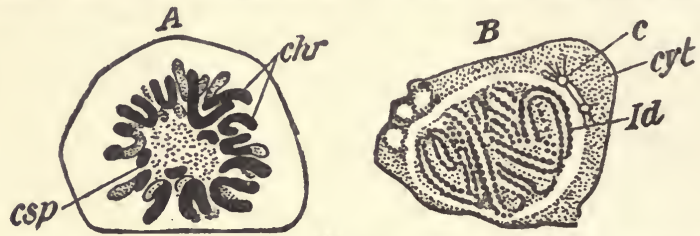

Fia. 18.

4. Nucleus undergoing mitosis, the "skein" of chromatin broken up into V-shaped loops or chromosomes.

B. Nocleus undergoing mitosis, in earlier skein stage, in which (as occasionally seen) the skein is seen to resolve itself into a double row of chromomeres (Weismann's "ids") prior to breaking up into loops.

times the size of the molecule of water-from every consideration an absurd underestimate. It will be seen upon calculation that the id (supposing it to be spherical) can contain only about as many molecules as presumably Weismann requires for one or two biophores, or at the most economical rate for a single representative determinant; and not one, or two, or three, but several hundreds of determinants ought to be compressed into a respectable id.

We have, in short, the reductio ad absurdum of Weismann's theory.

\section{ADDENDUM}

[In the second edition of my Principles of Pathology, published in 1910, with the publication of further studies by the physicists upon the size of the molecule of water, I modified the treatment of the subject as follows: 1

"We employed previously Lord Kelvin's estimate of the size of a molecule of water, pointing out that, according to his figures, in the chromomeres, or bead-like granules seen in certain chromosomes, which have been taken to represent Weismann's 'ids,' there could be stretched across the diameter only about 150

1 P. 136. 
molecules of water, and that when the highly complex molecules of the nucleo-proteins have a molecular weight of not less than 15,000 , the number of protein molecules capable of occupying this diameter must be very much smaller. But, in the opinion of many modern physicists, this estimate of Lord Kelvin's represents if anything the maximum and not the minimum possible size of a molecule of water. Nernst, indeed (Theoretical Chemistry, translated by Palmer, pp. 348 et seq.), accepts Van der Waals' calculation, based upon the molecular kinetic theory, that the magnitude of the molecule (of water) is $\frac{1}{5}$ millionth of a micro-millimeter $(0.000002 \mu)$, or otherwise that along a line $0.5 \mu$ in length there could exist not 150 but 2500 molecules of water. Even taking this estimate, Weismann's conception is still outside the limits of the possible, when the huge size of the nucleo-protein molecule is taken into account as compared with that of a simple molecule such as water.

"If the biophores are, according to Weismann's conception, not simple molecules of proteid type, but aggregations of the same, the determinants, composed of aggregations of biophores, should be recognizable under the highest powers of the microscope, and the 'id' formed in the higher animals of thousands and ten thousands (of determinants) must inevitably be a body of from 30 to 300 times the diameter of the determinant-so large, that is, that if it existed it must have been recognized from the moment the nucleus of the cell was first observed. And if, as Weismann supposes, the nucleus of the ovum contains hundreds of ids derived from numerous ancestors, that nucleus would fill the whole field of the microscope! Needless to say this is not the case; nor, we may add, does the coarseness of the nuclear structure vary materially according to the complexity of the animal. Physically, therefore, Weismann's conception is an impossibility, and, as Weismann has carried the conception of preformation to its logical outcome, it follows that in demonstrating the impossibility of his theory we simultaneously destroy all less fully developed theories of preformation.

"Determinants, in Weismann's sense, cannot exist." 1]

1 [And this despite Professor Arthur Thomson's inability to entertain the view that it is possible to dispense with any postulate of "Representative particles" (Heredity, 1912, p. 454).] 


\section{CHAPTER VII}

\section{A LECTURE ON LIFE 1}

\section{$(1905,1909)$}

To all of us mortals presents itself the question, Why are we: what is the meaning of this state of living: what is life ?-to none more often than to the physician. His duty it is to tend the lamp of life. Time and again, as day follows after day, he sees it burning low; now in danger of being blown out rudely by some all-unexpected gust; now guttering down with weak and weaker flame, flaring up momentarily, but it may be only momentarily, until the cold blue flame, scarce giving light, ushers in the darkness of death. His duty it is to keep the lamp alight and burning brightly as long as possible-to prevent that darkness. Is it surprising that he asks himself, again and again, What is life?-what is this flame to which we minister?

Think of it! Think of the countless ages-for we cannot count them-since man first became capable of abstract thought, and so became truly man! Think of the generations that have come to life, have grown up, and had their day, and passed! To each in turn this question has presented itself-to each. And direct answer has been found by none of all of them. And the generations have consoled themselves by the thought that this infinite mystery of existence, abysmal, dark, is purposeful ; that it is the God who has created life, that He knows, and that suffices; He knows and we, His creatures, cannot attain unto His knowledge. The generations have had those of robust mind, those whom this philosophy did not wholly satisfy, those who have asked why this should be. Solomon has succeeded

1 Delivered before the McGill Medical Students' Society in 1905, and redelivered by request and with additions before the Ottawa Valley McGill Graduates' Association in March 1909. 
Job, Goethe has followed Kit Marlowe, the author of the City of Dreadful Night has followed the author of the Rubáiyát, and Herbert Spencer, Lucretius; but no one has lifted the veil.

To-night I wish to range myself anew among the inquirers. I would not say we can lift the veil, for in such inquiries, as in all other investigations into nature, we can reach but to a certain point. It seems to me, however, that it is possible to penetrate farther into the mystery now than ever in the past ages. I hold it right also that, being endowed with minds, we should strive to understand all that we can regarding that which is of so deep importance. All the same, it is with no little hesitation that I have determined to make this the subject of my talk to you, and that because, however much we may desire to treat the purely scientific aspect of the subject, religion and the views we have imbibed from earliest childhood inevitably obtrude. It is not given to the majority, as it was to Darwin and to Pasteur, to separate in all humility their scientific from their religious lives and thoughts.

I can recall an open-air déjeuner à la fourchette in a little Parisian courtyard over on the "rive gauche," the sun glinting through the trees upon the napery and glassware of the table: a luncheon with Emile Roux, the great pupil of the great master. The conversation had turned upon Pasteur and his modes of work and habits of thought. That happened close upon a score of years ago, but I remember it as though it were yesterday. And Roux then traced what long years of intimate fellowship had taught him were the mainsprings of the great master's activities. He spoke of his sincerity, his earnestness, the deepseated religiousness of his character, his attachment to the Church, and the beautiful faith which dominated the family life. It was a revelation to me, and I said as much. "No," said Roux, "M. Pasteur never alludes to these matters in his writings. He holds firmly that a man's faith and his knowledge of science are two wholly different parts of his existence which it is presumption on his part to try to harmonize. Humbly and not with pride should we regard our scientific knowledge and acumen. The facts we have garnered are few compared with the vast bulk of hidden knowledge; the deductions we draw from those facts are at the most to be treated as working hypotheses, liable to be modified by further accumulation of facts." 
We are, to paraphrase Roux's words and employ Carlyle's simile, but sticklebacks in a puddle. What can the stickleback in his insignificant pool know of the workings of the great universe? Faith is essential to and inherent in our human nature: it depends upon and grows upon that which is not demonstrable: the realm of the spirit is apart from the realm of science. To presume, with this imperfect knowledge, to test and criticize revealed religion is futile, to presume upon this insecure foundation to build up our faith is absurd. Keep therefore the two apart; strive ever to gain a deeper insight into the truths of the natural world, and at the same time nourish what is spiritual within us; but do not waste time and energy in attempting to harmonize things which can only be harmonized when all is open and all is known,

And Faith, triumphant, ceases to exist, Transmuted into Knowledge absolute.

Now I am convinced that in this attitude of Pasteur there is a profound truth. The blatant infidelity of the present day is, it seems to me, founded upon this vain attempt, this inevitable failure, to harmonize knowledge and faith-things which to-day cannot be discussed the one in terms of the other. Whether the attempt be made by those deeply religious, or the reverse, the result is almost equally disastrous. At the most I would say that the studies of the individual worker upon nature and natural phenomena must inevitably influence the life and, through the life, the faith also of that individual. This, however, is one thing. To go into the market-place-or magazine-and discourse dogmatically concerning these matters is quite another.

Few, however, have attained unto this philosophy, sound though it be, and thus it is with some temerity that to-night I take up this discussion of life. Too few realize that religion is assuredly not based on matter, or, to put it in another form, that all things have their spiritual as well as their material aspect. Let me impress upon you that I have to deal with the material aspect of life only, and that doing so, while acknowledging its existence, I do not venture to discuss the spiritual aspect; that thus I do not come before you as a materialist; and if to some who have not reached thus far, if to those who cannot dissociate the spiritual from the material in living matter, it 
may seem almost impious to probe into the constitution of living matter, let me reassure them. In the old days it was accounted to Galileo as an offence against religion that he should demonstrate that the earth was not the centre of the universe ; that the sun did not travel round it, but it round the sun. We all now accept Galileo's teaching, and our religion is in no whit weakened thereby. Less than a century ago our forefathers regarded as heretics those geologists who taught that fossils were the remains of living beings, and that therefore the earth's age, instead of being an odd six thousand years, as Archbishop Ussher and others had computed, must be some hundreds of thousands of years, if not millions. Every one nowadays accepts the geologist's evidence without thereby being accounted an enemy of revealed religion. Fear not, therefore. True religion is unaffected by results of research upon natural phenomena.

So now to come to my subject-What is life? In the first place, if we analyse living matter, or, more accurately, matter that has been endowed with life, whether we take the most minute vegetable or the largest animal, from the simplest to the most complex, we gain one particular order of substances as the result of our analysis, an order only found in nature in connexion with matter that has been living, and these substances we speak of as proteids, or proteins. Save for water and certain very simple salts of sodium and potassium, these proteins are the only bodies common to all forms of matter that have been endowed with life. There are plenty of other substances which we may gain from certain orders of living matter-chlorophyll, starches, fats, and so on-but these are not universally distributed. The proteins are the one order of substances derivable from all animate bodies. We may express this in another way by saying that life is immediately associated with the presence of proteins. This, however, is not absolutely correct; we are not convinced that the proteins as such are actually present in living matter-in fact, when we isolate these proteins they do not exhibit the properties which we associate with life: they cannot move, they cannot grow, they are insensitive to stimuli. We only know that dead organic matter vields proteins. It is more correct to say that life is associated with the presence of proteidogenous matter-of matter which 
in dying, as again in certain of its activities while living, yields proteins.

So universal, so essential is this association, that clearly the first step to a comprehension of living matter must be gained through a study of proteins and their properties, for the phenomena of living are clearly bound up with the processes of association and dissociation of bodies of this particular order. Over more than fifty years the physiological chemists have been working at the problem of the constitution of these proteins. At first the problem seemed hopeless. It was found that they were formed of carbon, hydrogen, oxygen, nitrogen, sulphur, but the formula of constitution was something appalling. Common salt, $\mathrm{NaCl}$, for example, consists of one atom of chlorine (Cl) joined to one atom of sodium ( $\mathrm{Na}$ ). But in these proteins the amount of sulphur to be obtained is so minute compared with the amount of the other constituents that obviously the molecules are of enormous size. Take, for example, one of the proteins which, since it can be obtained in a crystalline form, must be regarded as among the less complex, namely haemoglobin, the protein which gives the red colour to the corpuscles of the blood. Its molecular composition is somewhere in the neighbourhood of

$\begin{array}{cccccc}\text { C } & \text { H } & \text { N } & \text { O } & \text { Fe } & \text { S } \\ 712 & 1130 & 214 & 245 & 1 & 2\end{array}$

The molecular weight of water, formed of two parts of hydrogen to one of oxygen, is 16 ; the average molecular weight of the proteins has been estimated at 15,000 , or, otherwise, this molecule is about 1000 times as weighty as is the molecule of water. I say in the neighbourhood of these figures, for no two samples yield identically the same results. It seemed impossible to think of building up experimentally such hugely complex bodies.

Next it was found that these molecules are, as I may express it, conglomerates. Haemoglobin, for example, can be split up into an iron-containing protein, haematin, and an iron-free globulin; and in the 'seventies and 'eighties a material advance was made in the study of the products of splitting up the molecules by the action of acids and of the digestive ferments. The peptones and albumoses so obtained were found to be less complex. In the 'nineties Kossel discovered a group of proteins, 
the simplest so far obtained-namely, the protones-bodies allied to the peptones, whose molecules are much simpler. Thus Sturin, obtained from the sturgeon, is

$\begin{array}{cccc}\mathrm{C} & \mathrm{H} & \mathrm{N} & 0 \\ 36 & 69 & 19 & 7\end{array}$

Only yesterday my colleague Professor Ruttan showed me a fat formed from the hydrocarbon $\mathrm{C}_{33} \mathrm{H}_{66}$ which he had built up in the laboratory; so here it will be seen that we are within the limits of possible synthesis. Kossel showed that these can be broken down into yet simpler bodies of the amino-acid group, Histidin, Arginin, and Lysin, $\mathrm{C}_{6} \mathrm{H}_{9} \mathrm{~N}_{3} \mathrm{O}_{2}$, etc. In fact, the researches of Curtius, Hofmeister, and Emil Fischer have demonstrated that the proteins in general are composed of these amino-acids-that they are compound molecules composed of these amino-acids joined in series. I do not wish to enter too deeply into so complicated a subject. I will only say that the amino-acids are compounds of carbon, hydrogen, nitrogen, and oxygen that have the structure of fatty acids-bodies of the butyric and acetic acid group-to which nitrogencontaining amine molecules (of $\mathrm{NH}_{2}$ ) have become linked, giving them the remarkable property of being at the same time basic as well as acid, so that they can enter into combination at one and the same time with acids and bases. It is this particular property that would seem to be at the bottom of their striking characteristic of forming huge compound molecules. Thus, suppose we regard them as bricks, having at one end an acid affinity which will attract and attach a basic body, and at the other a basic affinity which will attract and combine with an acid body (or perhaps better as a succession of magnets, attracted the positive pole of one to the negative pole of the other), it will be seen how thereby it is possible to build compound molecules formed of long chains of these amino-acids. And proteins are bodies of this nature.

This is no longer a matter of theory. The long-continued studies of the great German chemist Emil Fischer have in the last few years been crowned with brilliant success. Briefly, he has not only isolated a long series of these amino-acids, but, following Curtius, has been able to synthesize them, that is, to make them in the laboratory from simpler substances; but also, 
having done this, he has succeeded in linking them together in series. In one case he linked together as many as eighteen amino-acid radicles. These polypeptides, as he has termed them, in appearance, reactions (such as the characteristic Biuret reaction, which we use commonly to detect the presence of proteins), and in behaviour towards acids and alkalies, so closely resemble the true peptones that, to quote Fischer, they must be regarded as their nearest relatives. And Fischer has gone further than this. In the Faraday lecture delivered by him in London in 1907, he announced that one of the bodies artificially built up by him ( $l$. leucyl- triglycyl- $l$. tyrosin) has all the properties of the albumoses-of certain simpler proteins which we gain by the peptic and tryptic digestion of muscle.

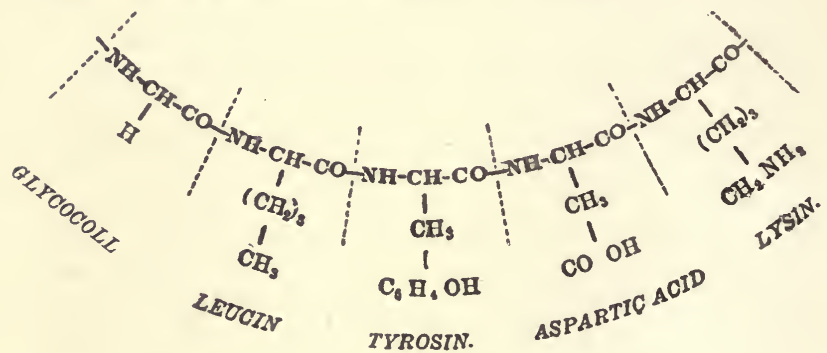

FIG. 19.

Thus at last there has been accomplished the building up of these specific organic substances which in nature are found solely as the outcome of life-nay more, form the material basis for the manifestation of life. It is the most notable achievement of the new century.

Here let me again emphasize the fact that these proteins which we are now in a position to build up, or, if you like the term, manufacture in the chemical laboratory, are inert bodies. They are not living as we understand the term: the living matter is not proteid, but proteidogenous. Can we form a chemical or physical conception of the difference between the two-between living and dead organic matter?

"Here is a fact, the meaning of which is of far-reaching significance. I show you two tubes. Each contains a small 
quantity of a white powder-about half a teaspoonful. Each powder consists of the same elements, oxygen, hydrogen, nitrogen, and carbon. One is practically harmless; the other contains within it the power of death to a thousand men. The one is quinine, the other aconitia-the alkaloid which makes so deadly the plant whose flower our ancestors called monkshood, in the far-off days when the original was often before their eyes. It is an almost startling fact that in this minute quantity of powder, hardly visible to those at a distance, there is such a potentiality of death. Picture to yourselves a thousand men. That which is in this tube would end the life of every one of them. Here is a latent power beside which the lightning flash is feeble, and to which the earthquake might give place, as far as the comparison depends on lethal certainty.

"But the resemblance in the aspect of these two substances is not all. As I said, each consists of the same elements-each is made up of carbon, nitrogen, oxygen, and hydrogen. Each consists of the elements which compose air and water, with carbon added. Why is one almost harmless and the other a most deadly poison? I might ask the question regarding many other substances composed of the same elements, but between these two the resemblance is strikingly close. The answer to my question may be given, 'It depends upon the chemical constitution.' True, but this takes us a very little way. When we discern that the difference depends upon the way in which the elements are arranged in molecules, and the molecules are grouped together, we are not much nearer an explanation. We see a little more, however, when we realize that chemical constitution means that energy is held 'latent' (as it is said), ready to be released when the elements form simpler, closer compounds. All vital function of the body depends on a like simpler, closer union of the elements which make up complex organic compounds. As far as we can see, all the energy which is released in the animal body, is released in consequence of chemical action under the mysterious influence of life. Where such closer union of the elements and such release of latent energy are going on, the process may be changed entirely by the contact of molecules of allied constitution, with latent energy on the point of release, so held as to blend with that which is being set free in the living tissue. Blending with this, it may augment or oppose. Re- 
member that difference in chemical constitution means difference in the readiness with which the elements separate and reunite and release their energy. Remember also that minute differences in constitution enable these chemical compounds then to blend with the vital action in one structure, or to be absolutely inert. It must depend on differences in the vital chemistry which underlies function, although these differences which determine affinity or indifference we can discern only by the result.

"Nerve force, as far as we can see, is the result of chemical change occurring under the influence of life in the molecules which compose nerve tissue. Chemical processes, the breaking up of complex compounds, and the formation of simpler compounds, with consequent release of the energy held latent in the former, is the constant element in the production and conduction of nerve impulses. Some chemical compounds may come into relation with the tissue in which the change is occurring without exerting the slightest influence upon it. But another substance may come even in amount inconceivably minute, whose molecules are so arranged as to fit, as it were, with the changing molecules of the living tissue. The energy the new molecules bear seems to blend with that which is in process of ordered release in the living tissue, and to blend so effectively as to derange it entirely. Such an influence as I have spoken of seems to be exerted widely in the case of aconitia. Its contact with some living nerve structures seems to be so instant and precise as to induce the production of an excess of energy, sweeping all before it; on others, to oppose the process, to induce a sudden stillness among the changing molecules, and to arrest all action. Among the nerves thus influenced may be those on which depend the action of the heart, and with a sudden spasm or a sudden stillness, the heart stops and life is ended."

I have quoted these last three paragraphs from a clinical lecture delivered several years ago by Sir William Gowers. I have not altered his words; they approach near enough to what I wish to impress upon you to serve my purpose. They lay down in a striking manner that the sole difference that we can determine, from a chemical point of view, between the living, palpitating matter and protein, between "imperial Caesar" and his own dead "clay," is brought about by chemical combination, by the entrance of certain molecules into combination with the 
living or biophoric molecules of certain controlling cells of the organism, and forthwith, from being active and reactive, these become inert-dead-protein. That some similar change takes place in connexion with the death of the tissues in general is indicated by the change in reaction when any cell passes from the living to the dead state. Living matter has a feebly alkaline reaction; with the onset of death, the reaction becomes acid. Or, otherwise, in passing from the relatively unstable proterdogenous to the dead, relatively stable proteid state, the biophoric molecules either take up alkaline molecules (or ions) from the surrounding cell sap, or give up acid ions to the surrounding fluid; they surely undergo chemical change.

Now the very constitution of the protein molecules, as revealed to us by the researches of Hofmeister and Fischer, explains how this must be. These amino-acid radicles which compose the protein molecule are all built up along the same lines. They have multiple affinities. Possibly I here delve too deeply for some to follow me, but an elementary knowledge of chemistry and of chemical nomenclature is a part of modern culture, and therefore I presume to venture, and the accompanying diagrams may help to explain my meaning. From our knowledge of the constitution of the protein molecule we may regard the biophoric or living molecule as made up of a series of amino-acid radicles joined together in ring form. Fischer's studies have taught us the mode of junction of these radicles ; it is by the acid carboxyl (CO) group of the one radicle to the alkaline amine $(\mathrm{NH})$ group of the other. To this extent the radicles or nuclei are relatively firmly united. The other components of the different aminoacids must then form free swinging or side-chains, and it is according to how these side-chains are built up that we obtain the different nuclei, or amino-acid components. These are capable of replacement and modification according to the ions or compounds attracted from the surrounding medium. They may be regarded as less stable, able to be detached and replaced.

In discussing what life is, we may therefore lay down in the first place that all vital manifestations are manifestations of chemical change in proteidogenous matter, are, in short, the outcome of arrangement of that matter with the necessary LIBERATION or STORING UP of energy. To this extent all vital phenomena 
resemble phenomena of surrounding inanimate nature; they differ from those only in degree, not in kind. There is not one vital activity which can be mentioned that demands for its explanation something over and above chemical change $;^{1}$ and, to this extent, inanimate and animate nature are one. There is, however, an apparent, most important difference between the results of vital and non-vital phenomena. This has been well put by Earl. "Every living organism may be regarded as a centre at which energy is being constantly transformed. It is by the nature of this transformation that we recognize it as a living organism. But," he continues, "the continuous operation of these transformations in the region of the organism is distinctive. In all exchanges of energy between inanimate bodies there is a speedy attainment of equilibrium, whereas the organism, so long as it lives, is incessantly disturbing the equilibrium which would otherwise arise between itself and its environment. In other words, living organisms are not ordinary conservative systems, and the extent to which they diverge from the principle of the conservation of energy is another indication to us that in the organism we come in touch with phenomena which are not yet, at all events, reduced to physical laws."

I wish to discuss how far this statement is true, for, if true, it immediately defines the difference between phenomena of animate and inanimate creation. It will be best, I think, to study the subject by analysing that property of living matter which is the most evident outcome of the incessant disturbance of equilibrium above mentioned-I mean growth.

If we seek to test the relative importance of the various forms in which vital activity manifests itself-motion, sensation, assimilation, excretion, reproduction-we are bound to see that one and all of these subserve growth. If the individual moves, an ultimate analysis shows that the primary object in motion is either to obtain more food, or, more accurately, the primary result of that movement is to approach and assimilate food-stuffs, and that food obtained is of benefit as it can be used for further growth ; or is to place itself at a greater distance from disintegrative forces. The same is true also with regard to sensation.

1 Even memory has been explained by Hering and others as a reproduction under particular stimuli of particular relationships between particular molecules, so that now they set in order an identical series of reactions in the cerebra colls. 
That is of benefit primarily in order to acquaint the individual living unit with, on the one hand, its closeness to food-stuffs, or, on the other hand, with the presence of physical or other agents deleterious to the organism. Assimilation and excretion are but the auxiliaries in the due utilization of materials which aid growth, and in removing from the organism all materials whose continued presence would disturb the process. Growth, then, is the central or essential phenomenon of life, and to understand life it is necessary that one gains a clear idea of what is the essential nature of this process of growth.

Let us then consider what growth means. It means quantitative increase in the individual matter endowed with life, increase in the living substance. That individual may consist of a single cell, may be an almost infinitesimal micrococcus, for example, or, at the other pole, say in the elephant or in the whale, may consist of a huge aggregate of countless billions of cells, all associated and depending the one upon the other. In this latter case it is the separate cells which, some or all of them, increase in size, and with this increase also in number. Each cell of such a multicellular organism is, we know, derived from a primitive fertilized ovum by repeated division of the original single cell; and in this process of division there is a partition of the bioplasm, of the vital matter. During the period of most rapid growth, in the stage of development, this increase in size of the individual cells and their multiplication is most rapid, and when we compare the adult with the ovum from which it sprang, when we know that in suitable environment, a single bacillus, for instance, dividing, can, in twenty-four hours, give rise to hundreds and thousands, not to say millions of bacilli equal in size and identical in properties to the original bacillus-one observer has estimated that in the breeding of the unicellular Rotifer, if all the possible progeny could be preserved, there would in the course of a year be developed a mass of organic living matter as large as this world of ours-we can have no doubt, not merely that growth means a heaping up, through the agency of the essential vital portion of the protoplasm, of secondary substances, not in themselves living and vital, but that that living matter itself is marvellously increased in amount. There is no other possibility open to us. But now, can we picture to ourselves the nature of such increase in the vital substance, the actual bioplasm? 
I think we can, and that by the use of current chemical conventions and symbols. The actual process must, I admit, be vastly more complicated than the diagram we employ can represent. But that doesn't matter. If, by the use of a simple diagram, we can depict and can grasp the nature of the process, then we have gained a great step in advance ; only, while using such a simple diagram, we must remember that it is but a symbol, it is like using the symbol $\pi$ to represent that interminable fraction $3 \cdot 14159265$. . . etc.

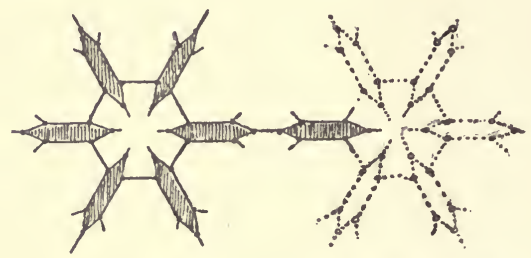

Fia. 20.-Diagram of growth of biophoric molecules.

Thus far I have pointed out that all vital processes are manifestations of energy, and that such manifestations of energy surely indicate chemical change. Thus the substance or bioplasm endowed with life may be regarded as a single chemical substance, varying, it is true, in its properties in the different species and forms of living beings. If a chemical substance, then it is formed of molecules. I have already given you the conception of the structure of the biophore or molecule of living matter. Let us reduce this to its simplest form-as a ring of carbon-containing nuclei built up after the type of a benzole ring, with which the chemists are familiar in the large group of benzene compounds. Each nucleus of such a ring may, for our present purposes, be represented by one of the more complex amino compounds already referred to. Such nuclei are polyvalent-they have, that is to say, multiple affinities which can be satisfied by the attachment of other atoms as radicles. It will be seen that to make a ring two at least of the affinities of each amino-acid nucleus must be satisfied by junction with other nuclei, leaving, however, other unsatisfied attachments. And it is in accordance with the way in which these unsatisfied arms become satisfied- 
according to these side-chain combinations-that the different benzene derivatives are formed.

It is interesting to note that even among these relatively simple carbon compounds-those familiar with chemistry will appreciate the virtue of that term "relatively "-we find already that there is indication of selective activity. I mean this, that once one of these bodies or derivatives has been formed and becomes partially broken down, it is found more easy to obtain new associations after the original type rather than new associations of a different order. Even among the simpler carbon compounds we see the faint origin of what, biologically, we speak of as habit. The same is true of radicles in general. Once certain compounds are formed, the adhesions or attachments are more close, more fixed. So now to continue. Let us suppose this simple annule of living matter with certain side-chains already attached, floating about in a fluid medium in which, through a concatenation of circumstances, various odd ions are similarly floating free. The unsatisfied arms of the ring are liable to be satisfied, that is, to attract and fix on certain other ions. All that we have to do is to suppose this particular annule attaches to one unsatisfied arm a floating ion of carbon, that this then so attaches itself to other carbon ions until a second ring is formed in association with the first. Then this ring similarly attaches to itself side-chains in the identical order seen in the first instance.

Now behold, there is built up a second annule of identical nature, which, when once formed, may break loose. In place of one annule we have two, and as the properties of any chemical compound depend upon its composition, the composition determining how, and how much, energy is liberated under certain conditions, so, if the composition of the first annule, as we agreed, was such as to confer upon it the properties we term vital, the second annule will possess the identical properties. In place of one living molecule we have two; in short, we have growth.

But stop, you will be saying. By what earthly right do you assume that chance ions floating in a fluid medium come to attach themselves one to the other in due and regular order, so as to form a ring with side-chains identical with the original ring with its side-chains, with which the first of these wandering 
ions became connected? You admit at the start that this original ring and side-chains are immensely complicated, and that our diagram represents an absurdly simple case; how can you have the face to make any such proposition?

All I can say, in reply, is that I have precedent upon my side. What happens in crystallization? You have a watery solution, say, of common salt. You now know that though you place solid sodium chloride, a definite chemical compound, into that water, in the very act of solution, the ions of chlorine dissociate themselves from the ions of sodium. Molecules of $\mathrm{NaCl}$ break up, they are no longer there as such. You now cause this solution to evaporate and become concentrated; what happens? As the water volatilizes do the ions of the gas chlorine escape into the air, leaving the heavier sodium ions behind? Not a bit of it. Inevitably, when the concentration reaches a certain point, some ions of the sodium, aided by some sharp point or inequality in the surface of the vessel, once more join themselves each to an ion of chlorine, and the process of crystallization begins. The very existence of one crystal clearly seems to cause other junctions to occur in its neighbourhood, and just that one particular series of junctions necessary to form sodium chloride, so that, although there may be present in the solution various other substances, various other ions, yet they are not attracted, they remain still in solution to a very great extent; we gain pure, or almost pure, crystals of the one substance. Here we have a process of the very same order as that which I contemplated above, a process of definite, inevitable, or selective attachment of ions in a certain order, given certain definite conditions. Certain particular ions unite and build up the molecules and crystals of one particular inevitable form, of one particular composition.

Here again the example is very simple; I might, it is true, have mentioned solutions of salts of a more complicated nature, but again I hold that the simplest case is good enough, nay, is best, upon which to base my contention, which is that we have to recognize the existence of this affinity or attraction, or whatever you please to call it, whereby certain freely floating ions, and combinations of ions under certain definite conditions, tend to attach themselves one to the other in a definite order, to form bodies of a definite composition. And in this connexion, 
is it not, to say the least, suggestive, that a fluid menstruum is essential for vital processes ? Such fluid menstruum, we now know, is essential for the breaking up of salts into their constituent ions, so as to bring about the formation of new combinations, and that in the absence of great heat. Is it not suggestive that we, for example, are over 70 per cent water; that the actively functioning, as apart from the inert tissues, contain still greater proportions-and the same is true throughout living nature; that we have in the living cell just those conditions favouring alternate ionization and crystallization of the contained molecules, and that the dominant and characteristic element present in the living matter is one which we find relatively wanting in this earth of ours, save in connexion with living matter, or matter like coal, which has been alive; and that element, carbon, is, unlike the majority, tetravalent, and therefore so peculiarly liable to form extensive and complicated attachments? It would almost seem as though all the carbon present on the surface of the earth inevitably becomes utilized to form and to give rise to living matter. The same is largely true, too, as regards the nitrogen.

In short, were I a Frenchman, I would say: La vie c'est la crystallisation. Life is the by-play of carbon-nitrogen compounds now breaking up and liberating energy, now attaching to themselves other ions, and so storing up energy, deduplicating themselves, and undergoing growth, or, as I have expressed it elsewhere, life is to be regarded as a state of persistent and incomplete recurrent satisfaction and dissatisfaction of certain proteidogenous molecules.

If we accept this view, and the more I ponder over it the more convinced am I that it is along the right lines, where is the wide difference I quoted to you as being observed between animate and inanimate nature? Where is that violent, not to say indecent, assault upon the otherwise universal and ever to be respected principle of the conservation of energy? Life and growth come under the category of chemical processes such as we are familiar with. All that we have to recognize as separating what we term animate from what we term inanimate nature is that, from the intimate constitution of carbon, it is able to form combinations of a marvellous complexity-unsatisfied compounds which, therefore, are in a state of unstable equilibrium, which 
easily break off certain side-chains already attached, thereby giving off energy, which as easily, under certain conditions of environment, attach other side-chains to them in definite order, thereby storing up energy and undergoing growth.

I would dwell for a moment upon this point made by Earl, and already referred to, namely, the remarkable condition of persistent, unstable equilibrium of living as distinguished from non-living matter. The distinction, I would say, not so absolute as he lays down. Once more, it is a matter of degree. Nonliving matter is only in a condition of relatively stable equilibrium. Our earth, for instance, taken as a unit, is only relatively stable. If astronomy teaches anything, it is that each planet, each sun, each solar system, has its periods ; that each begins in a gaseous state, a state of enormous instability, enormous liberation of energy; that from the nebulous stage, as a result of the mutual attraction and.combination of its elements, it undergoes a stage which is strictly comparable to that of growth and then settles down into partially-and only partially-independent systems, with a certain storage and a certain dispersal of energy. But our earth, for instance, is subject to progressive change, and is far from being eternal. Sooner or later in the aeons that are to come, our sun will become exhausted as an energy-distributing centre; the system will be dead. Sooner or later, in aeons far far distant, the attraction ever present between planet and sun, and sun and other suns of yet greater systems, will draw planet unto sun, and sun unto other suns, and with each act, so colossal will be the force exerted, the force of impact, that what is now solid and fixed will once more be dissipated; the equilibrium is but temporary, the return to the nebulous stage inevitable.

But true it is, all the same, that the equilibrium of living matter is most markedly unstable, and this instability is essential for active dynamic life. We are never satisfied. Render the living molecule a satisfied body, with all its side-chains complete, and unable to make attachments with other ions, so that no further interactions are possible between the molecular system and its environment, and it must come to rest, and function be at a standstill, all indications of life ceasing. It is quite possible that, as Gowers indicates, certain poisons act, and thereby induce death, by combining with the molecules of certain all-important centres in such a way as to satisfy those molecules, and so arrest 
function and further activity. Other poisons and physical agents may likewise cause death by the contrary process of decomposing and breaking down the molecules, whereby they become so gravely disorganized as to be unable to continue the progressive series of attachments and of liberation of side-chains which are the underlying features of the vital process.

I could expand this conception and dilate for long upon its many bearings. Once we accept this chemical theory of growth, if I may so term it, it is wonderful how it illuminates and harmonizes a whole host of phenomena regarding which there are hosts of theories, having this in common, that they do not adequately explain. I could spend some hours of your time applying this conception to the subjects of evolution, of descent, and of inheritance, the inheritance or non-inheritance of acquired properties, the inheritance of disease, the immunity from disease, and so on. But I will desist; it may seem to you that I have already gone too far. But in defence of myself, I am prompted to quote some words of the good old Stephen Hales, Vicar of Teddington, near London, in the reign of George I., who was the founder of modern exact physiology, based upon accurate measurements, and quantitative rather than qualitative studies. "In natural philosophy," he says, "we cannot depend on any mere speculations of the mind; we can only, with the mathematicians, reason with any tolerable certainty from proper data such as arise from the united testimony of many good and credible experiments.

"But it seems not unreasonable, on the other hand, though not far to indulge, yet to carry our reasoning a little further than the plain evidence of experiments will warrant; since at the utmost boundaries of those things which we clearly know, there is a kind of twilight cast from what we know on the adjoining borders of terra incognita. It seems therefore reasonable to indulge conjecture there ; otherwise we should make very slow advance in future discoveries, either by experiments or reasoning."

I have, it may be, conducted you to this twilight land on the borders of terra incognita. I shall be satisfied if I have set you thinking; if $I$ have indicated to you, though vaguely, that life is not a thing peculiar and apart: that it is a portion of a larger whole ; that animate and inanimate nature conform to the same laws, the same principles of chemical association and dissociation. 
Vaguely, but no less surely, we find the same laws at work throughout nature in all its aspects. The processes which determine the structure of the atom, determine the properties of all aggregations of atoms; what rules the mighty sun, rules also the less than visible microbe. 


\title{
CHAPTER VIII
}

\author{
ON HABIT, SYMPTOMS, AND DISEASE ${ }^{1}$
}

IT has struck me that it might be serviceable to take up the subject of habit in its relationship to disease : to call attention to the probability that much commonly regarded as symptomatic of functional, not to say anatomical, disturbance may, after all, have no serious anatomical basis, but be one or another manifestation of habit, and, therefore, wholly curable provided the habit can be interrupted; and to indicate how, nevertheless, habit sufficiently long continued may well induce anatomical change, from which stage onward cure can be only relative.

Placed thus on paper, there is nothing new in my text. These are truisms which we all must have had impressed upon us in the course of our work, now vaguely, now more clearly. The whole group of tics and hysterical manifestations is immediately called to mind, these affording examples of both stages. But what I want to do is to point out that the nervous system is not alone involved, and that the tissues generally are creatures of habit; further, to investigate the principles underlying habit phenomena and the anatomical or histological outcomes of the same.

This matter was brought to my attention years ago in connexion with a case of incipient pulmonary tuberculosis. The patient had, shortly after child-birth, gone rather rapidly downhill, giving the old story of profuse lactation, loss of strength, intractable cold with profuse expectoration, and afternoon rise of temperature. Everything pointed to tuberculosis, and, what

1 An address delivered before the Medical Research Club at the University of Pittsburgh, April 6, 1911. Reprinted from International Clinics. 
is "more, our ablest diagnosticians recognized a small area of dulness at the right apex; they were doubtful as to whether there was a still smaller area to the left. But no bacilli could be discovered. The patient was sent to Lakewood, and there at last, after two negative reports, a search through something like seven slides revealed a single definite tubercle bacillus, with a suspicious second. This was years before the development of the finer modern methods of diagnosis, but it has always seemed to me that here was a case in which the disease was suspected and then recognized in its earliest stage. The patient was immediately packed off to Dr. Trudeau at Saranac Lake, and from the first week put on weight, gaining fifty pounds in five months, and rising from one hundred to one hundred and fifty pounds in weight. The effect of treatment, that is to say, was immediate. Only once in the first fortnight of her stay there was a doubtful bacillus or two recognized in the sputum. From this time onward the sputum was uniformly negative. That was twelve years ago, and the patient has never shown a sign of set-back.

The point that I want to make is this: that here there was undoubtedly tuberculosis, but that of the very slightest we could then diagnose, and, with proper treatment, the bacilli, never present in any number in the sputum, disappeared within a week or two. The fever went down, the weight went up. Notwithstanding this, for more than six months-I do not believe I exaggerate when I say for at least a year-that patient not merely had a cough, but brought up, particularly in the morning, an excessive amount of thin mucoid expectoration. The cough I could understand-the healing of the tuberculous process in the lungs and the formation of fibrous tissue might well set up a certain amount of local irritation, and reflexly in this way induce cough. Nevertheless, the cough very soon took on what we term the nervous character. The patient was highly strung, and this might well be a nervous habit. But I could not well explain the abundant expectoration continuing all these months after the evident healing of the lesions, save on the theory of habit, the theory, namely, that a definite irritant had in the first place stimulated the production and discharge of mucus, with associated congestion of the peribronchial vessels, and that the irritant had continued active for a sufficiently long 
time to set up a habit of heightened activity on the part of the secreting cells, so that when the irritant disappeared and was no longer in action, the congestion remained, and with it the cells continued to secrete abundantly.

A few months ago my colleagues, Drs. Birkett and Meakins, contributed a paper, "Vaccine Treatment in Chronic Inflammatory Disease of the Accessory Sinuses of the Nose," to a most interesting discussion on "Vaccine Therapy" at the Triennial Congress of American Physicians and Surgeons at Washington. They reported a short series of cases in which from the sinuses a growth of one or other pyogenic organism was obtained prior to treatment with vaccines, and in which, as the result of the treatment, the discharge became wholly sterile. But in the majority of these cases, while the character of the fluid changed under treatment from a mucopurulent to a purely mucoid fluid, the discharge, it is noted, had continued for months, with all the distressing symptoms of hypersecretion and retention. To explain this, Dr. Meakins calls attention, first, to the chronic thickening of the submucous layer of the lining of the sinuses, as the result of continued inflammation; and, secondly, to a partial closure of the ostia by the swollen mucous membrane inducing defective drainage; thirdly, he comes to the same conclusion that I had reached in the case just described, namely, that through repeated stimuli (at first bacterial) hypersecretion has been set up, which after a time has become a true habit, independent of bacteria, as evidenced by its perpetuation after the cavity has been practically sterilized.

As I have already hinted, we are all so familiar with the establishment of nervous habits, with the development of habit tics and those graver habits of lack of co-ordination, and apparently of arrest of active communication between various centres, which would seem to be the basis of hysteria, that I must not here tire you with an enumeration thereof. It is well recognized that it is easier for nervous stimuli of different orders to travel along well-worn paths, and that thus there may be established a condition in which a minimal afferent impulse, travelling without interruption along a particular path, is sufficient to set in action first one and then another of a group of co-ordinated centres whereby a minimal stimulus may eventually produce a maximal result; per contra, the act of inhibition or arrest of 
the passage of a given impulse, if repeated, would seem to oppose so strong an obstruction to the passage of impulses along a particular path, that soon a maximal stimulus may produce no result. Here there is no anatomical change: it is a matter of habit. Put the patient under an anaesthetic and remove the inhibiting mechanism, and now stimulus is followed by the normal reflex muscular act. The worst of it is that, too often, the patient is in absolute ignorance of the fact that he or she is exerting this inhibition. I recall vividly a very delightful old lady, a woman of great personal charm, and, if I may so express it, eminently virtuous, who had been in a terrible railway accident on the north coast of Wales in which many people were killed, who received so strong a nervous shock as to be incapable of using her lower limbs, and to be bedridden for twenty years. I have said that she was virtuous; that is to say, that within a year after the accident she was awarded by the courts one hundred thousand dollars $(£ 20,000)$, and she did not, as is painfully often the case-and that in a way that, perhaps at times mistakenly, makes us contemn poor humanity-recover her powers so soon as the court had awarded her this compensation. No, she remained bedridden twenty years, and then for the first time in her reign Queen Victoria was about to visit a near-by city. The old lady had never seen the Queen, who was just of the same age, so the occasion appealed to her very peculiarly. She longed to see her, and that with a great longing; and, sure enough, the afternoon before the great event she got out of bed and walked, went to the celebration next day, and after that walked until she died.

I do not say that she walked vigorously, but if a long spell of arrested function had some effects, certainly nerve tracts had not been destroyed, or otherwise her paralysis was not due to anatomical changes in the nerve cord. It was an inhibitory habit. But, as I say, I do not want to go into these nervous conditions; these we all accept. The instances of automatic cellular activity are of more immediate interest, and once I mention one or two of these to you, I doubt not that you who are in practice will call to mind individual cases of your own which are best explained along this line. Thus my colleague, Dr. Meakins, has quoted to me more than one case in which a small dose of mercury has induced abundant salivation. We 
know that salivation is associated in the first place with discharge of the mercury from the system, but all the mercury in small doses must disappear in the course of a few days, nevertheless the ptyalism in some cases persists, and is noticeable for six months or even a year. Some cases, at least, of persistent gastric hyperacidity and excessive secretion would seem to be of the same order, as also, I would suggest, the opposed habits of constipation and looseness of the bowels, the one due to the habit of excessive absorption of the fluid matter of the faeces, the other to defective absorption. Professor Klotz has just quoted to me four cases of obstinate dysentery in which undoubtedly there had been an original bacillary disturbance, but repeated bacteriological examinations failed to disclose anything of the nature of a specific agent. There is also a singularly intractable, obstinate, and elusive intestinal condition which I would suggest is most simply grasped if we regard it as a habit disorder-a condition devoid of indications of bacterial nature, of insidious onset, becoming progressively more severe, unassociated most often with febrile disturbance, most often showing itself in the female, and then in high-strung girls verging upon the hysterical-I refer to mucous colitis. There is something striking in the way this persists once it manifests itself, and that in the absence of sign of any abiding source of irritation. I would suggest that here, following upon a catarrh of moderate intensity in an individual of unstable equilibrium, the cells of the mucous membrane of the colon have acquired the habit of excessive formation and discharge of mucin. ${ }^{1}$

1 After this address had been delivered Dr. Lichty, of Pittsburgh, called my attention to an important paper of his (American Medicine, iv., 1902, p. 223) upon the "Etiology of Mucous Colitis," in which he has drawn attention to the intimate association between abdominal ptosis and mucous colitis, and in which he draws the conclusion that with this ptosis and hypostasis and further interference with the blood supply of part, at least, of the large bowel, a condition of chronic congestion of the mucoss is set $\mathrm{up}$, with $\mathrm{a}$ disturbance of function and excretion of mucus. Dr. Lichty recognizes fully that not all cases of splanchnoptosis exhibit accompanying mucous colitis, pointing out that 2558 consecutive examinations of men, women, and children afforded 313 cases of splanchnoptosis-41 males and 272 females; but only 21 of these had mucous colitis, and he concludes that ordinarily a condition of compensation is established, such as is so often seen in the circulatory system when there is disease of the heart and the kidneys. When, however, this compensation is lost or disturbed, the symptom-complex of mucous colitis appears, and he gives instances in which, in those affected with splanchnoptosis, mucous colitis showed itself in one case after an attack of acute tonsilitis, in others after typhoid 
Perhaps here wrongfully I speak for myself, and do not represent the general views of others, but it seems to me that commonly we are apt to regard every functional act of the various tissues as an immediate response to some stimulus, and, doing this, to overlook and neglect the abundant cell activities that are truly automatic on the part of individual cells, and cellcollections or tissues; are apt not to realize that according to causation there are three orders of cell activities: (1) those determined by nervous stimulation, which we may term neurogenic; (2) those determined by direct stimulus of the individual cells by anything modifying their immediate environmentthe environmental; and (3) the automatic, namely, activities which proceed in spite of or despite absence of sustained stimuli, whether neurogenic or environmental.

Now, it is these last, the automatic activities, to which I would particularly direct your attention-to their nature, their mode of origin, and their relationship to the other two. I believe that when we come to look narrowly we find that they are quite common. It seems to me that the development of cell habit is essentially the development of cell automaticity.

Primarily, as determined by a study of the lowest unicellular form of life, and of isolated cells of multicellular animals, such as leucocytes, it is external agencies that initiate cell activities ; the nervous system is a higher co-ordinating mechanism developed in multicellular organisms, and so neurogenic cell activities are of secondary and later development. Further, we must regard all automatic activities as not of independent development, but as initiated by the individual cell becoming subjected, in the first place, to either environmental or neurogenic stimuli. To afford a basal instance : the ovum while fully matured lies latent and incapable of growth until such time as a spermatozoon, or, as Loeb has shown, alteration in the tonicity of the surrounding medium, initiates active nuclear changes; once initiated,

fever. While thus Dr. Lichty affords an anatomical basis for the supervention of mucons colitis, it will be seen that his views are not in opposition to the suggestion here put forth, but, on the contrary, tend to confirm it. Dr. Lichty, that is, recognizes that some active disorder leading to lowered vitality and increased congestion is necessary to originate the condition; that, once originated, the excessive discharge of mucns lasts for weeks and months after the exciting cause has passed away. Accepting Dr. Lichty's views, we may say that the state of chronic congestion of the colon favours the development of the habit of excessive secretion of mucus. 
these continue. All cell activities are at bottom chemical or physical changes in the relationships of the cell molecules and their constituents, and so living matter is similar to matter of all other orders in that molecular changes and activities require to be set in motion by the influence of forces acting from without.

To this broad statement it may be objected that the remarkable investigations of late years upon radium and allied bodies, notably those of Rutherford and other pupils of Sir J. J. Thomson, have demonstrated that every individual atom of matter exhibits an inherent activity of its constituent electrons, and, therefore, energy from without is not an essential pre-requisite; that in its very essence matter is a storehouse of energy, and that thus even inert non-living matter possesses the potentiality of automatic activity. Here, truly, we plunge into very deep waters. To such objections I would reply that the studies upon radium so far only exhibit the possibility of these inherent atomic activities leading to the dissociation of electrons and coincident liberation of energy, whereas the striking feature of living matter is characteristically its capacity to associate, to build up from its surroundings, other matter like unto itself. Nevertheless my colleague, Professor Barnes, who, as a co-worker with Rutherford at the time when he was making his remarkable discoveries, speaks with high authority, assures me that the activity of the electrons, so far as we can determine with our present knowledge, is wholly uninfluenced by, and presumably, therefore, not initiated by, influences acting upon the atoms from without. Up to the present, the greatest heat and the greatest cold to which radium has been subjected have not been found to influence in the slightest the rate of emanation of the radium rays. In other words, the rate of motion of the electrons is unaltered by extreme temperature changes. It may, therefore, be that in this automatic activity of the atom we have the primal basis of the automatic activities which here I am discussing; that, just as there are inherent attractions and repulsions within the atom, so there are inherent attractions and repulsions of the molecules that constitute the cell.

If this be the case, how are we to picture the development of automatic activities? In this way, namely, that the cell is not a single substance, but a complex of many, with central nuclear matter, and a cytoplasm of proteid matter which presents 
within it material of various orders, i.e. (1) bodies in the process of being broken down to provide food-stuffs, (2) the molecules not yet wholly organized or built up into the cell structure, (3) other molecules which in the dissociation of the food-stuffs are separated off as waste products, (4) other molecules which are the dissociation products of nucleus or cytoplasm, and are the resultants of functional activity, and along with these, (5) framework substances, such as fibrils and the striated material of the muscle-cell, developed as the cell becomes differentiated, the outcome of that differentiation. The activities within the nuclear membrane are, from the nature of that membrane, very different from those outside. Surface tension has also led to the development of a potential, if not an actual, membrane between the cytoplasm and the external medium.

The cell, in short, is a microcosm-a little world in itself.

We in pathology always go back to the cell to determine its elementary properties, and from them to base solidly our views regarding the disturbances that may affect collections of cells, namely, the tissues and organs of the body. Has it ever struck you that we can go much further than this? There is room for a good full essay upon the study of cytology as the essential basis of sociology and political economy. It stands to reason; it is, if I may so express it, a " dead easy " exercise in elementary logic to prove that it must be so. The nation is a collection of allied and similar individuals, and national sentiment, which expresses itself in national action, can only be the expression of the sum of individual sentiments, at most gaining impetus and direction by the interaction of the sentiment of one individual upon the sentiment of the other. It is obvious, therefore, that the political economist, in order to understand social tendencies, must base himself upon, and must first study, the individual and his tendencies. But now, what is the individual but a collection of cells? By a like process of reasoning, it is inevitable that to understand the individual we have to get right back to the unit cell, its properties, its reactions, and its interactions with the other cells of the corporation. Wherefore it follows that the only sound method of mastering political economy is through an expert study of cytology.

I might dilate upon this theme; might, for example, point out how a study of the cell throws light upon the existence of 
two great political parties, and show how the "mugwump" is the outcome of a peculiarly exact balancing in the one individual of those two opposing properties of all living matter; namely, of heredity in the strict sense, whereby, despite environment, the living matter of one generation tends to reproduce with exactitude the characters impressed upon preceding generations, and variability, whereby that living matter is keenly responsive to environment and liable to modification. In most of us one or other of these two properties is in the ascendant. In the words of Gilbert (and Sullivan), we are born "either a little liberal or else a little conservative"; in the mugwump, thanks to the parental amphimixis, the two properties are accurately balanced.

However, this is all parenthetic. What I want to impress upon you is that just as nowadays we have learned to regard the atom not as a solid, if almost infinitesimal, mass of matter, but as exhibiting the active play of numerous electrons, so, taking the cell as a unit, we must realize that it is not merely a mass of homogeneous protoplasm, but it is an extraordinary complex of molecules, a little world in itself.

We have to imagine these molecules as in a state of continuous interaction. Given a stimulus from outside, they set in motion a particular chain of interactions, and we are forced to recognize that, once started, the interaction may continue after the stimulus which has set them in motion has ceased to act. We have, in the first place, then, to recognize the existence of what Dr. Fraser Harris has spoken of as the inertia of living matter, which might perhaps more accurately be spoken of as the momentum of living matter. It is the principle whereby the wheel set rolling continues to rotate until friction brings it to rest. It is the principle that explains the latent period of muscle. If the muscle be resting, as every first-year student knows, a definite-period elapses after the passage of the stimulus down the nerve before the muscle passes from the resting to the contracting state. Here it seems to me is the first step; but something more than this is necessary to induce automatic cell action, and to gain an explanation we pass from the cell to the larger world in a search for parallel phenomena, for, as I have laid down, we may safely draw such parallels.

Centuries ago when a comet appeared in the sky it had a profound influence on those who beheld it. It was unusual, 
therefore it betokened something unusual. It was a portent, but its effect was temporary. People spoke of it after it was gone; as it were, a condition of inertia continued with steadily diminishing force after the stimulus had passed away. Then by chance in the seventeenth century a comet came into the ken of an astronomer who, through his special knowledge, was, if we may so express it, peculiarly responsive ; its presence stimulated him to a more than ordinary degree. He looked up the earlier records and found that a similar comet had been reported as flaming into prominence at regular intervals. This led him further to study the path of the comet, and not merely to determine the course of this one comet, but that of other comets and of meteorites in general. And now everybody knows all about comets, can predict their return; the series of observations of this one astronomer, Halley, has permanently and continuously affected civilized man.

So it is with the cell molecules. One particular stimulus may have but a temporary effect; another, acting upon the cell in a particular state, may initiate a particular recurrent cycle of intracellular changes, may set up a habit.

Not all influences upon cells will set in action these recurrent and cyclic changes, but undoubtedly the dominant constituents of cells, the proteins, by their very nature and complexity of structure, favour the development of cell habits. Let me illustrate. A diffusible foreign body, itself of proteid affinities, gains entrance into the blood-a toxin; and, provided that it be not exhibited in excessive amount, it is in the first place neutralized, and next leads to the presence in the blood of antitoxins. We know that the toxins gain entry into the cells; know that the cells, or certain of them, actively discharge antitoxins. There may have been not a sign of specific antitoxins in the body fluids primarily, but now they are produced in abundance-in amounts far in excess of the amount of toxin introduced. If at first they were modifications of the toxins introduced, brought about by cell activity, certainly the later crop cannot be of this nature. And here is the point: they continue to be produced days and weeks after the original toxins have been neutralized or destroyed.

It may be that our presumption is wrong, that the toxin molecules, once within the cell, persist there, acting as enzymes 
or ferments, converting one after the other molecular groups of a particular order into antitoxin molecules. These are matters not yet determined. It fits in better with our knowledge to suppose that the toxin molecules determine a modification or rearrangement of certain side-chain molecules, which in their turn lead to the building up of other side chains of like constitution. But, whatever the exact process, here is an exquisite example of a cell habit of the automatic type. Once started in their new work of producing antibodies, the cells continue to produce them, and this without external stimuli, developing them from the usual food-stuffs assimilated by the cell.

It follows, thus, that we may recognize two orders of cell habit of the automatic type : first, as afforded in my original instance, the exaltation of a property already possessed by the cells ; and, second, as exemplified by this last instance, the acquirement by the cell under abnormal environment of new properties-an acquired cell variation becoming, if I may so express $i t$, converted into a cell heredity.

Underlying both we must see a manifestation of that most potent cause of metabolism, namely, enzyme action. In other words, it is the existence of intracellular enzymes that permits both continuous and cyclic automatic cell activities. If the view be accepted which I have put forward elsewhere, namely, that organic enzymes are of the nature of detached side chains of the proteidogenous molecules-able, on the one hand, to attach themselves to the main ring; on the other, to molecules of food-stuffs, bringing about their dissociation, with eventual building up of like side-chain material in series, --then we can realize how, so long as side-chain molecules of a particular order are present in the cell, and that cell possesses its usual nutrition, the enzyme action will continue within that cell until arrested by the concentration of the products of that action; to become active again so soon as those products become used up, diffused out, or otherwise removed. Once enzymes appear or become developed within a cell, we have the conditions most favourable for continuous cell activity, irrespective of alteration in environment or external stimulus, save that afforded by the exhibition and regular absorption of food-stuffs. And when abnormal bodies of proteid type-toxins-gain entrance into the cell, I would lay down that they have affinity to side chains of the 
cell substance, and either themselves act as enzymes, or more probably form compounds of a new type within the cell which act as side chains of a new order, and are capable of building up new side-chain molecules in series, the excess of which become discharged as antitoxin molecules.

However, from the pursuit of such ideas I again must desist, for I draw you into the depths. I only wish to impress upon you that the known existence and extent of intracellular enzyme activity and the development of the same afford us a full physiological basis for the assumption by the cell of habits of activity.

Thus far I have discussed only those habits associated apparently with no anatomical or histological change in the parts that are involved in the habit. This is, however, by no means necessary, and the last few minutes of this discourse may be spent in calling attention to the habit of growth-conditions associated with distinct structural changes in the affected tissues. The whole somewhat limited group of what we term metaplasias are really growth habits. They are conditions in which, always, it would seem, under the influence of altered environment, one or other tissue undergoes a metamorphosis, and continues to develop in the metamorphosed state. I had a beautiful example of this only a few months ago, in which, apparently under the influence of chronic inflammation, it could be seen that the perichondrium of the tracheal cartilages had given origin to or had undergone conversion into cartilage cells within its substance, which cells, undergoing proliferation, had now projected outward into the submucosa to form small nodular growths, and these in their turn had undergone bony transformation. Here, then, one and the same tissue, under different conditions of environment, gave rise to connective tissue, cartilage, and true bone. Nor was this all. These multiple bony nodules projected into the lumen of the trachea, and, doing this, interfered with both the nutrition and the function of the overlying epithelium. As a result, over each nodule the mucosa, instead of being formed of a single palisade layer of columnar cells, had become converted into a well-formed squamous epithelium, while between the nodules was the normal columnarcelled epithelium.

The cells here under different environment had assumed a 
totally different habit. It may be asked whether here I am using the term in the same sense as previously, whether what I here term habit is not the result of continued alteration of environment. It may be asked whether in these cases return to the normal environment would not bring about return to the normal type of tissue, or whether this altered habit of growth persists.

To this I would answer that undoubtedly it tends to persist. As evidence I may cite the example of a region in which epithelial metaplasia is not uncommon, namely, the gall-bladder. There, as a result of the chronic irritation set up by the presence of gallstones, it is not uncommon to find larger or smaller areas of squamous epithelium taking the place of the normal columnarcelled mucosa, and this more particularly in the region of the fundus. Now, as is well known, 90 per cent or more of cases of cancer of the gall-bladder are associated with cholelithiasis, and the majority of those cancers originate in the fundal region; and the interesting point is that I have encountered (and there are several similar cases recorded in the literature) cases in which that cancer, instead of being of the adenocarcinomatous type which one expects to originate from a columnar-celled epithelium, approximated to the squamous epitheliomatous type. They were not absolutely typical epitheliomas; epithelial pearls, for example, have been wanting. My own case, for example-and others have made the same observation,-exhibited a mixture of alveolar masses of the epitheliomatous type, along with other alveoli of adenocarcinomatous appearance. But certainly these were not ordinary adenocarcinomas. There is no epithelium in the neighbourhood of the developing gall-bladder of squamous epithelial nature; no chance, therefore, that these tumours develop from a squamous epithelial cell rest. The only adequate explanation is that the metaplastic squamous epithelium has its characters so firmly impressed upon it that, when it gives rise to a cancer, its cells, as they infiltrate into the surrounding tissues, do not revert to the columnar type, but give rise to a squamous epithelial new-growth. Again an acquired variation becomes hereditarily transmissible among the cells. They have "got the habit."

Some of you may know that many years ago I applied this habit conception to the elucidation of tumour growth in general, and though in the meantime I have amplified my views, I still 
believe that my original hypothesis is sound. I would conclude by recalling this to you. There are many examples that I might take as illustrative, but perhaps the best is that worked out by my late colleague, Dr. Wolbach, ${ }^{1}$ now assistant professor at Harvard-his study of the mode of origin of that modern disease, $\mathrm{X}$-ray carcinoma. He had at his disposal material from a long series of X-ray burns, and so was able to follow well all the stages.

Paradoxically, the $\mathrm{X}$-rays have singularly little effect upon the epidermis and epidermal cells, but they influence profoundly the underlying corium. There in the earliest stage there are set up marked lesions, telling especially upon the vessels and lymph spaces-proliferation and desquamation of the endothelial cells, thromboses, and other evidence of severe vascular disturbance; and it is secondary to this that the epiderm is affected and tends to ulcerate. Those changes, to be brief, lead to a form of inflammatory fibrosis of the subepidermal tissue, and as a result the nutrition of the epiderm is gravely reduced. In some places the reduction is so great that the cells necrose, and ulceration is the result. In other places the effects are not so intense, and one gets what I would term the "poor curate" phenomenon. You will have observed that the well-fed millionaire and his wife are apt to be childless, whereas the curate and his wife have a family in inverse size to their capacity to support them. That appears to be a law of nature: there is a certain nutritive minimum at which, it would seem, the preservation of the species becomes of greater consequence than that of the individual, and multiplication ensues, to the detriment of the individual, but on the off-chance that a few out of the abundant progeny may survive. And so it is that in these cases where the epiderm is not wholly necrosed, its cells multiply; and now is observed a phenomenon apparently of the same order as that first observed by Bernhard Fischer after inoculating a mixture of olive oil and Sudan iii. into the tissues of the rabbit's ear (an observation abundantly confirmed), namely, the growth downward of the epithelial cells toward the oil. In these X-ray burns the actively proliferating epithelial cells grow downward through the dense fibrosed cutis toward the nearest source of nutrition-the underlying vessels.

2 Wolbach, Journ. of Med. Research, xxi., 1909, 415. 
But doing this, obviously, they sacrifice their function as epidermal cells. Cells growing down into underlying tissues cannot function as an epithelium. And thus, coincidently, in these cells we have the vegetative powers exalted and the functional activity depressed. Now, while there is a certain mean or level at which moderate function, by stimulating increased assimilation, may stimulate increased cell growth, it must be recognized that growth and function are diametrically opposed states of cell activity. Growth demands that matter taken as food is built up into the cell substance and becomes associated, with coincident storage of energy ; function, on the contrary, demands dissociation, with liberation of energy. And, as a matter of fact, your actively functioning cell shows no signs of proliferating. Your actively vegetative cell is of embryonic type, i.e. shows little signs of differentiation, and therefore of functional capacity. We observe, thus, that these down-growing epithelial cellsand the same is true of all early malignant growths-present coincidently depression of function and exaltation of vegetative power. And I would lay down that it is this modification of the cell activities that is the basis of neoplasia ; that what is characteristic of the true tumour is that the component cells, from one or other cause-displacement, irritation and so on,-have lost the habit of function, and coincidently, as the nutritive material taken in needs to be used up, the very accumulation of the newly formed cell substance, disturbing, as it does, the surface-to-mass relationships of the cell, becomes in itself the stimulus to cell division, in order that the due relationships may be restored. Thus is developed the habit of growth, replacing the habit of function, and it is, I hold, this habit of growth that characterizes all true tumours. It is at least suggestive that the one non-surgical method of treating malignant growths that is giving definite results at the present moment, when appropriately applied, essentially depends upon a specific reduction in the growing power of the tumour cells. It is now well established that radium and X-rays act especially upon the vegetative cells of the organism, and, characteristically, it is the actively vegetative malignant tumours, rather than the benign with their more highly differentiated cell elements, that are arrested and undergo absorption after treatment with either radium or $\mathrm{X}$-rays. 


\title{
CHAPTER IX
}

\author{
PARENTERAL DIGESTION AND IMMUNTTY ${ }^{1}$
}

ASKED to open this discussion upon immunity, I will, I think, be of most service if I place before you in outline the more recent developments in our views regarding the essential nature of the processes which lead up to the production of the immune state.

All medical men of our generation will have, doubtless, a vivid memory of the earlier phases through which we have passed. The first phase was the empirical and lasted up to the recognition of the existence of pathogenic microbes : during this it was admitted that one attack of many infections was followed by resistance to subsequent attacks, and there stood out the one solitary application, namely, Jennerian vaccination. The second phase, in the 'eighties and early 'nineties, was one of confusion, when, recognizing that the infections were of microbic causation, and being successful in isolating the causative agents, we found that each different pathogenic agent had a distinct modus operandi. On the one hand it was found that organisms like the diphtheria bacillus and tetanus bacillus in their growth outside the body produced diffusible toxins, and Behring, Roux, and others discovered that the immunity which developed was antitoxic, and on the other hand the majority of pathogenic microbes were found to produce no noticeable ectotoxins, and such immunity as was obtainable was not antitoxic but bactericidal, the fluids of the immunized animal bringing about the solution and death of the causative bacteria.

1 Contributed to the discussion upon Recent Advances in the Theory and Practice of Immunity, held at a meeting of the Montreal Medico-Chirurgical Society, December 4, 1914. Reprinted from The Canadian Medical Association Journal, July 1915. 
Rapidly following upon this came the discovery in France and Germany by Bordet and Pfeiffer, respectively, that the latter form of immunity demanded the presence of two orders of substances in the body fluids of the immunized animal. How great was the confusion is indicated by the fact that for one of these, Pfeiffer's "immune body" and Bordet's "substance sensibilatrice," the other names of "amboceptor," "fixateur," " intermediate body," "sensitizer," " preparator," "desmon," "copula," were proposed by various workers. Nor was the confusion lessened by the continuing fight between the German humoralists, who were satisfied to study the phenomena manifested by the body fluids alone, and the Franco-Russian cellularists, led by Metchnikoff, who, with broader histological insight, laid stress upon the cellular reactions to infection.

The third phase was that of the ascendency of Ehrlich's " side-chain theory" of immunity. It was found that antibodies present in the blood serum neutralized the toxins; all the indications were that chemical interaction went on between the two, but toxins were active in such extraordinary minute quantities, and also were produced in such minute quantities, that chemical methods of analysis revealed nothing beyond the probability that they were to be regarded as protein degradation products. The biological test was far more delicate than the chemical. We were, in fact, beyond the realms of chemical technique. If confusion were not to be worse confounded, it was necessary to have some working plan whereby to visualize the processes that went on in the reaction between the microorganism and its products and the organism. This Ehrlich afforded in his celebrated side-chain theory. Some may to-day criticize that theory, and may gird at its toxins, toxoids, and toxones, its haptophores of the first, second, and third orders, its end-piece and mid-piece of the complement. But unquestionably it afforded a working scheme, whereby a common basis for expression of phenomena was afforded, and, equally unquestionably, it promoted an enormous burst of activity in the study of immunity problems. What is more, although Ehrlich cautiously refrained from suggesting or premising any particular element in the cell as being provided with side-chains, his theory was based upon the only rational conception of cell metabolismthat which regards the molecule of living matter as of extra- 
ordinary complexity, and in a state of constant unsatisfaction, built up by linking on other simple molecules, and as constantly, in the performance of function, giving up or discharging into the surrounding medium these and other molecular complexes which it has elaborated.

In my Principles of Pathology, published in 1908, I called attention to certain defects in Ehrlich's theory, and pointed out how it might be brought into fuller conformity with actual knowledge of general cell activities and of enzyme action. I laid down that throughout the whole study of immunity we deal with "the methods by which living matter, whether animal or vegetable, reacts towards other living matter, whether animal or vegetable, and towards the products of the same which come in contact with it, and although," I continued, " the statement may at first encounter appear to be both novel and extreme, further thought will confirm it; the problems of immunity narrow themselves down to special problems bearing upon the assimilation and digestion of unusual proteid matter." I might have added, for my treatment of the subject was consistently along these lines, that they resolve themselves into studies of enzyme action.

Long years ago, in the early 'eighties, I remember Sir Michael Foster teaching us that the assimilation of food-stuffs evidently demanded that more complex molecules of food-stuffs were not built into the cell direct, but were first broken down into their simpler constituent molecules, and of these the molecules common to the constitution of the foreign food-stuffs and to the cells are taken up by the latter, and used for building-up purposes. This view to-day is universally accepted, more particularly as the result of Emil Fischer's studies upon the chemical constitution of proteins, and his demonstration that these are complexes formed by the union of varying proportions of mono- and diaminoacids. The Germans speak of this as the "Baustein," or buildingstone theory.

It is a familiar fact that proteids taken as food, while they disappear from the intestinal contents, are not to be detected in the blood and lymph coming from the intestinal tract. And this is true not only of the fully formed proteins, but also of the peptones and proteoses of the alimentary canal resulting from the disintegration of the larger protein molecules 
into simpler soluble proteins of the second order. Indeed we have this remarkable fact that if, instead of allowing them to be absorbed and acted upon by the intestinal mucosa, we introduce these peptones and proteoses directly into the circulation, they are found to be highly toxic. There is evidently, therefore, a pronounced difference between enteral or intestinal, and parenteral digestion, the breaking down, that is, of foreign proteins introduced into the organisms outside of, and without the intermediation of, the digestive tube.

We owe to Victor Vaughan, of Ann Arbor, and his long continued studies from 1901 onwards, the demonstration of the fact that outside the body, by the simple procedure of digestion with several times its bulk of absolute alcohol in the presence of 2 per cent of sodium hydroxide, any protein-even so apparently harmless a body as egg albumen-is split up into a poisonous and a non-poisonous moiety, the former soluble in alcohol, the latter insoluble, and this poisonous moiety, when introduced into the system other than through the intestine, is rapidly fatal in doses so minute as from 8 to $100 \mathrm{mg}$. per guinea-pig. Evidently in the process of passage through the intestinal mucosa, either this poisonous moiety of the protein molecule is detoxicated, or protein disintegration there is so carried on that it is never given off.

The high significance of these observations lies in this, that the bacterial bodies are largely compounded of proteins, that bacterial bodies similarly treated give these same poisonous and non-poisonous moieties: that the process of destruction of bacteria that have gained entrance into the tissues is one of parenteral digestion, and that the phenomena associated with parenteral digestion must therefore be closely studied in order to understand the nature of infection and the phenomena of immunity. It is this study that has ushered in the latest phase of our subject; and in this subject two names stand out particularly, those of Victor Vaughan and Abderhalden. Perhaps it would be equally correct to state that this latest phase corresponds with the study of anaphylactic phenomena, and of their relationship to immunity, for, as I shall proceed to show, the two are most intimately connected. 


\section{ANAPHYLaxis}

If I may judge from the answers received recently from the candidates for Dominion Medical Registration, anaphylaxis is evidently regarded by the majority as one of those subjects that no fellow can be expected to understand; and addressing a general medical audience it is essential to describe its broad phenomena. Briefly, then, whereas, as everybody knows, the introduction of foreign proteins into the economy is in general followed by the development of immunity, the system gaining the power of rendering harmless many times the fatal dose of that protein, it is found that, employing minute doses of the protein for the first injection, if now, at the end of a week or ten days a second dose be injected, larger than the first, but still many times less than that producing serious symptoms on first injection, then instead of showing evidences of immunity, on the contrary the animal has become hypersensitive. It may, indeed, die within three to five minutes. In the guinea-pig, which shows most strikingly these phenomena, there is an intense contraction of the muscular walls of the bronchi, whereby dyspnoea is brought about, with overfilling of the lungs so extreme that even when the chest wall is freely cut open immediately after death, the lungs remain expanded. With this there are muscular cramps and obstruction to the onflow of blood with capillary congestion leading to scattered haemorrhages. This state can be induced by inoculation of any foreign protein, even one ordinarily so harmless as egg albumen, or, on the other hand, by the employment of pathogenic bacteria and their proteid products.

Now, here is the significant point. The symptoms and lesions produced by the poisonous moiety of split protein are, as Vaughan was the first to point out, identical with those seen in anaphylaxis. In other words, anaphylaxis is due to the sudden setting free in the economy of poisonous bodies of the same nature as the poisonous disintegration moiety of proteins. On the doctrine, therefore, that like results are produced by like substances, we arrive at the conclusion that this hypersensitiveness or anaphylaxis is essentially due to a disintegration of the introduced proteins with rapid liberation of the poisonous moiety.

But the first dose introduced sets up none of these phenomena, the second does. It is obvious that, following upon the intro- 
duction of the foreign protein, the organism has gained a new power, that of splitting up the foreign protein.

It is at this point that Abderhalden's observations acquire a high significance. In 1910 Abderhalden with various pupils published a remarkable series of "serological studies by means of the optical method." Starting from the fact that the different proteins and peptones present each in the polariscope a specific index of rotation, he demonstrated first that, as determined by the polariscope, the ingestion through the alimentary tract of any particular protein has absolutely no effect upon the blood serum; its rotatory power is unaltered from the normal. But inject any of the more common proteins subcutaneously or directly into the blood, and in twenty-four or forty-eight hours remove some of the blood, separate the plasma, add to this a little of the protein, and now a remarkable change is seen : the index of rotation of the plasma undergoes progressive alteration, a clear indication that the protein is being broken down, and this is confirmed by the fact that by dialysis peptones can be separated off. In other words, within forty-eight hours after the introduction of a foreign protein, the system has responded either by elaborating a proteolytic or proteoclastic enzyme, or, it may be, by the rapid increase in production and discharge of already existing proteoclastic enzyme present in certain cells. What I would especially emphasize is the fact that the enzyme thus first liberated is not specific. It is an indifferent proteoclastic ferment: it will act not only on the particular protein inoculated, but on other proteins: it will break down indifferently globulin, casein, edestin, gelatin, and their peptones, with the evolution of toxic peptone-like bodies.

It might be laid down that this indifferent ferment first produced is the cause of the anaphylactic phenomena. Against this view is the fact that Abderhalden's ferment is recognizable in twenty-four to forty-eight hours, whereas anaphylactic phenomena are not obtainable until the sixth to the tenth day. This in itself is not absolute disproof, for one of the factors governing the rate of enzyme action is the amount of enzyme present, and this might well depend upon the accumulation of a sufficient amount of the enzyme. The amounts should be large to cause dissociation of the foreign proteid at such a rate and such an extent as will lead to the production of symptoms. 
There are, however, serious objections to this view. As pointed out by Abderhalden, the anaphylactic phenomena are specific; it is only the protein first introduced that sets up disturbance; on subsequent injection other proteins are not affected, whereas Abderhalden's proteolytic and peptolytic enzymes are active in respect to any protein. The only safe conclusion is, therefore, that in these data we have evidence of the development of two stages:

1. Elaboration and discharge into the blood plasma, within forty-eight hours, of indifferent proteoclastic and peptolytic enzymes, affording Abderhalden's phenomenon.

2. The gradual production of more highly developed specific proteoclastic enzymes, having the power of rapid dissociation of the particular protein introduced, with liberation in the course of a few minutes of sufficient toxic disintegration product or products to set up symptoms.

I should note in passing that it cannot be regarded as absolutely settled as yet whether it is the enzymes liberated into the blood plasma that are the essential cause of the anaphylactic symptoms, or whether the phenomena are due to intracellular dissociation in specific groups of cells, such as certain cell groups and centres in the nervous system. If these cells under the action of the first dose have been stimulated to produce and consequently store the non-specific enzyme, the moment the foreign protein comes into contact with their cytoplasm, or is absorbed by them, it will undergo degradation. An extraordinarily minute dose of foreign protein in this way, by acting on or being acted on by specific cells, might set up fatal results. The rapidity with which anaphylactic phenomena may show themselves, and that upon the introduction of extraordinarily small amounts of any particular protein, rather favours the latter view : it suggests that there is a selective taking up of the protein by particular cells, cells whose due and ordered action is essential for continued existence.

\section{IMMUNTTY}

What I want to bring specially before you is that the two stages above postulated lead up to a third; in other words, that anaphylactic phenomena afford us explanation of the nature of immunity. By cautious reinjection of the foreign disharmoni- 
ous protein we can pass through the anaphylactic to the succeeding stage of immunity. Now the characteristic of a true bacterial (as distinct from an antitoxic) immunity is that the body fluids gain remarkable digestive or fermentative powers. Any one who has observed Pfeiffer's phenomenon-has seen living typhoid or cholera organisms swell up and dissolve like pieces of sugar in the serum of a highly immunized rabbit or guinea-pig-cannot fail to be impressed by the extraordinary digestive powers that have been acquired by the body fluids through this process of immunization.

Everything here indicates that we deal with proteoclastic enzymes. Only now, in the immune animal, the process no longer leads to acute poisoning. I admit that more than one explanation may be sought and given for this fact, but, choosing the simplest, we see here a further evolution of the same process, namely, the development by the organism of further enzymes which disintegrate the poisonous moiety, and so carry on the degradation of the foreign protein to a further and harmless stage. It is pleasant to think that we owe to one of our own workers, Dr. Fraser B. Gurd, the first experimental evidence of the coexistence of these two orders of enzymes (lysins) in the immune animal. ${ }^{1}$ As he points out, it is not that the earlier enzymes are completely replaced : they are still active and indeed abundant, and evidence of the presence of these sensitizing bodies can be obtained in immune animals. But after they have broken down the specific protein with the production of the poisonous substance, this is immediately acted on by the new enzyme and rendered innocuous.

To me it is not a little curious that Abderhalden, Thiele, and Embleton, and the other workers in this territory, while familiar with the existence of the great numbers of individual enzymes that are to be isolated from the organism, have not taken up and considered this probability of, or recognized the indications pointing to, the production of a succession of progressively more specific and more active enzymes in the development of the immune state.

1 Amer. Jour. Trop. Dis. and Preven. Med. i., 1914, 776; Jour. Med. Res. xxxi., 1914, 205. 


\section{Enzymes AND Ectotoxins}

There is one point which, before closing, I must take up, namely, the nature of ectotoxins.

In the first full study of these ectotoxins, that, namely, by Roux and Yersin a quarter of a century ago upon the diphtheria ectotoxins, it was clearly pointed out how many properties these bodies possess in common with the group of organic enzymes: their activity in extraordinarily minute doses ; the impossibility of isolating them in a pure state ; their destruction by a temperature of $60^{\circ}$ centigrade; their precipitation by phosphates and other salts. It is not a little interesting how, notwithstanding, bacteriologists in general have shown unwillingness to accept this view. Long years ago Sidney Martin in London brought forward further evidence to the same effect, that the diphtheritic membrane was not in itself highly toxic, that it contained an enzyme whose activity gave origin to toxic albumoses, and that the internal organs, while showing no evidence of the toxin proper, might come to contain these toxic bodies. The significance of these observations lies in the fact that, as everybody knows, diphtheria bacilli are present in quantity in the membrane, and are almost absent from the internal organs. I have not come across a single leading German work on bacteriology that has taken any serious notice of these observations of one of the most brilliant and capable English workers. The stumblingblock has evidently been in the prominence obtained by the phenomena of antitoxin production. This reactive production through the agency of ectotoxins of bodies which combine with the ectotoxins to render them inert, is wholly outside our usual conception of enzyme activities, and yet it deserves pointing out that, if we take solutions containing what we recognize as enzymes foreign to the animal body, enzymes, for instance, obtained from plants, and if we inoculate these into the animal body, anti-enzymes are developed, identical in all their properties to the antitoxins. Dr. Zinsser of Columbia University, in his excellent work upon Infection and Resistance, lays down that there is an important difference between ectotoxins and enzymes in their mode of action. He states: "While the toxins are apparently bound or neutralized by the tissues they attack, the action of an enzyme seems rather to be a process in which the enzyme 
unites with the substance it acts upon, is released as this result is obtained, and freed for further action without noticeable loss of quantity."

Here there is this very confusion that I have already noted, that, namely, of dwelling only upon the combination of toxin and antitoxin in the one case, and of the action of the enzyme upon the substrate in the other. ${ }^{1}$ Only two paragraphs lower down Zinsser calls attention to the incubation period in the action of toxins, pointing out that this is longer when small doses are given, shorter when large doses are administered, but always evident. Thus in the horse he points out that it may be four or five days before the action of tetanotoxin shows itself : in mice, as De Waele points out, animals extremely susceptible to tetanotoxin, a minimal lethal dose gives an incubation period of thirty-six hours; if 3600 lethal doses be administered this is shortened to twelve hours, and whatever the dose, the interval cannot be shortened below eight or nine hours. Such facts as these cannot be explained as due to the activity of an ordinary mineral or alkaloid poison : ordinary poisons have no incubation period. It is wholly consistent with the action of a proteoclastic enzyme which, present in the blood or becoming absorbed by certain cells, by acting upon some specific proteid substrate, splits off a toxic moiety which, accumulating under the continued action of the enzyme, at length is present in sufficient amount to set up symptoms. The full proof of the enzyme nature of ectotoxins has recently been afforded by Abderhalden, who has demonstrated in vitro the proteoclastic properties of these bacterial toxins. In fact we must conclude that just as the animal body gives off free enzymes along the course of the alimentary canal, whereby foreign proteins of the food-stuffs are split up, and so made capable of absorption, so certain bacteria have a like power of discharging enzymes which can act upon the proteins of the animal economy and prepare them to be assimilated by the bacterial body, and it is in this process of disintegration of the proteins of the organism that the toxic moiety is liberated, thus inducing the symptoms of disease. It is these, and not the so-called ectotoxins, which are the immediate causative factor of these morbid phenomena.

1 [He passes over, without notice, the phase of disintegrative activity of the toxin.] 
Thus, to conclude, I would lay down the following as summing up the views here put forward as most satisfactorily harmonizing the data at present in our possession.

1. Whatever the nature of enzymes, the organism has the power of elaborating new orders of these bodies in and from its cells in response to the entrance into the tissues of foreign proteins, and potential food-stuffs in general.

2. The development of anti-bacterial immunity in an animal is essentially the development of the power of parenteral digestion by the tissues of the constituents (mainly protein) of the pathogenic micro-organisms.

3. This is rendered possible by the elaboration of a succession of (mainly) proteoclastic enzymes.

4. Three stages are to be recognized in this process :

(a) The development of indifferent proteoclastic enzymes.

(b) The development of specific proteoclastic enzymes, splitting the bacterial proteins into highly poisonous and nonpoisonous moieties.

(c) The development of toxoclastic enzymes which render the disintegration products innocuous.

5. Ectotoxins are to the micro-organism what discharged enzymes are to the animal. They have all the properties of enzymes.

6. They are not themselves toxic, but proteoclastic, and it is the products of their activity upon the proteins of the organism that are the essential toxic substances.

7. Antitoxic immunity is thus wholly distinct from antibacterial immunity. It is a process not primarily of digestion and disintegration, but, rather, of combination and fixation of enzyme, so that this is no longer capable of attacking and disintegrating successive complex proteid molecules ; or, it may be, one of development of toxoclastic enzymes by the tissues, which disintegrate the toxic proteins as they are produced, rendering them innocuous: or both. 


\section{PART III}

\section{ON GROWTH AND OVERGROWTH}





\section{CHAPTER I}

ON GROWTH AND OVERGROWTH AND ON THE RELATIONSHIP BETWEEN CELL DIFFERENTIATION AND PROLIFERATIVE CAPACITY; ITS BEARING UPON THE REGENERATION OF TISSUES AND THE DEVELOPMENT OF TUMOURS ${ }^{1}$

THERE are in medicine and other sciences not a few beliefs and ideas which we have taken up we know not how, and which in general we no more think of discussing than we do, for example, the subject of good manners. Thus, just as it is difficult, if not impossible, for us to state how or where we gained any single article of our code of personal ethics, so it is with certain of these general ideas in medicine; and while we have never discussed these beliefs, we feel individually assured that they are the current ideas of other workers along the same lines.

One of these tacit beliefs or comprehensions relates to the subject of the growth of tissues. Asked off-hand we should assuredly, each one of us, state as his familiar belief that muscle arises from muscle, epithelium from epithelium, nerve cell from nerve cell, and so on, and the mental picture which we form of the process of growth is, I fancy (though here, of course, I speak under correction), that the fully formed epithelial cell undergoes mitosis and divides into two, and so with the cells of other tissues. Yet if we think a little longer and recall what we have actually seen under the microscope, this mental picture is seen to be incorrect or, at least, imperfect. Thinking recently over this matter it has been impressed upon me that if we obtain a correct idea of what occurs during the process of growth of tissues, we not only realize that there is a very broad biological law under-

1 Published in the Festschrift in honour of Dr. Abraham Jacobi, New York, 1900, 422, and Medical Chronicle, Manchester, June 1900. 
lying this process of growth from the earliest stages of the embryo upwards, but further, applying this biological law to the subject of pathology, we gain a deeper and a fuller comprehension of certain matters bearing upon regeneration and degeneration of tissues, and, what is more, bearing very directly upon certain of the phenomena of tumour growth.

While the individual, formed as he is of a marvellous complex of various tissues, is a reproduction of the tissues and organs present in his paternal and maternal ancestors, he is the outcome and development, not of the combined fully developed tissues, nor again of any one highly differentiated cell or cell compound, but of a single undifferentiated cell-the fertilized ovum-a cell neither of the component parts of which, ovum or spermatozoon, has ever through the whole course of the ages been derived from other than similar undifferentiated cells; or, in other words, these apparently simple germ cells are capable of giving rise to the whole series of cells forming the whole mass of tissues from the simplest connective up to the most highly differentiated nerve tissue. ${ }^{1}$ If we study the process of the development of the embryo, whether in plant or animal life, we see again a somewhat similar phenomenon.

\section{"Mother Celle" and Tissue Growth}

From a very early period in such growth we recognize that certain cells alone appear to be actively dividing and to be actively proliferative, whereas other cells, the products of these, while they take on characteristic appearances, do not thus divide. Very early indeed in the developing embryo we recognize this existence of what may be termed "mother cells,"-cells which themselves remaining embryonic in type give rise by division to other cells which assume more highly differentiated characters. And this is true not only of animal organisms, but still more

1 Throughout this article I refer to cytoplasmic and not nuclear differentiation. It is possible that while the cell body of these germ cells is relatively undifferentiated, the nuclens is peculiarly highly elaborated. We have, indeed, not a few indications that this is the case. Thus it may be that nuclear and cytoplasmic differentiation, in germ and "mother" cells, and in specific tissue and "daughter" cells respectively, are in inverse ratio. We have not as yet reached a point at which any definite statement can be made in this connexion. 
obviously of plants: we have but, with Sachs, to study the growing points of plants to realize the existence of these " mother cells."

Now when we pass to the fully formed individual, we must still recognize this fact, which we are apt to pass over, namely, that the specific cells, if I may so term them, of the different tissues-that is, the highly differentiated and characteristic cells of those tissues-do not themselves give rise directly, and by division, to other specific cells, but that in each tissue there are (1) these more or less undifferentiated mother cells, which more especially have the power of proliferating, and it is the daughter cells which assume the full specific properties in the different tissues, or (2) if, as is seen to be the case in some instances, the active cells of certain not very highly differentiated tissues themselves proliferate, they only do this after a preliminary reversion to a " mother cell," or more embryonic type.

Let me here give a few examples. Immediately I mention them, every one will realize that these are facts thoroughly familiar. One of the simplest cases is that of the skin : in this it is the lowest layer of the epidermis, the Malpighian layer, whose cells undergo active proliferation, and this constantly, throughout the whole period of life, and the cells which are most active in the process are those of the very lowest layer-cells which are of a permanently embryonic type.

After injury, it is true, we may come across occasional mitotic increase, more especially in the lower animals, in the region of the prickle cells, but, when we do, we see that it is accompanied by reversion of the cell to a simpler type: the prickles or bridges disappear, the cell loses its connexion with the neighbouring cells, and passes back to a simpler stage prior to multiplication.

In bone the case is the same. Production of bone tissue is not brought about by multiplication of the pre-existing and characteristic bone cells, but by osteoblastic tissue; or, in other words, by the mother cells of bone lying in the immediate neighbourhood of the vessels of the inner layer of the periosteum, or which course through the Haversian canals and between the laminae. When through injury or otherwise a stimulation is afforded, it is these mother cells which, applying themselves to the pre-existing bone, multiply, and there governing the spaces 
around them lead to the deposit of a calcareous or bony matrix and gradually assume all the characters of typical bone corpuscles.

From the variability of the structure of the glandular organs it is difficult to lay down any general rule with regard to regeneration of glandular epithelium, so that it must be confessed that, partly on account of this variability, partly on account of the fact that the different observers upon glandular regeneration have not had this conception of mother cells before them in their studies, such glandular epithelium in the present state of our knowledge affords the least satisfactory demonstration of the principle. There are, however, so many instances concerning which we have positive information as to render it more than probable that throughout the same principle is in action.

Of the mother cells of the type seen in the Malpighian layer of the epidermis, several instances may be called to mind : the mother cells of the testicular epithelium and (though differing somewhat in plan) of the ovarian follicles, of the sebaceous and, apparently, from Tornier's studies, the mammary glands. In both of the latter organs there is, during activity, a giving off of cells, and mitosis occurs especially in the deeper, more external layers.

In this connexion should, I think, be mentioned the columnar and ciliated epithelia of mucous membranes. It is remarkable how one histological text-book after another figures such columnar epithelium as formed of a palisade of fully developed columnar cells in regular series situated upon the basement membrane, without indicating or even referring to the presence of embryonal mother cells lying between the bases of the fully differentiated columnar cells. Certainly under pathological conditions one is impressed by the fact that these basal cells are present, and that there is a development of new cells from beneath to take the place of the degenerating fully formed cells. While in the simpler acinous glands it is difficult to recognize such permanent mother cells (indeed they are probably absent in the adult), here at least they are present.

In the lymph glands we may have another arrangement. In them the mother cells are collected together in the form of small nodes in the centres of the individual follicles; a somewhat similar arrangement of foci of embryonal cells is met with in the thyroid, while in the pancreas, Langerhans's bodies or "cell 
accumulations" would seem to be of a similar nature, although this is not as yet absolutely determined. ${ }^{1}$

Closely allied to this condition is what is seen in the lung, and again in the seroustoat of the peritoneum (though neither of these, it is true, comes strictly under the category of true gland structure). In the former, certain more embryonic cells persist, especially at the angles of junction of the alveoli, and these are generally regarded as centres for the normal proliferation and regeneration of the alveolar epithelium. On the peritoneal surface also there are found clumps of smaller cells capable of active proliferation. With regard to both these cell layers, the flattened-differentiated-cells are liable, under irritation, to revert to the fuller, more rounded embryonic condition and then undergo mitosis and proliferation.

Judging from the fact that mitoses are not observed in the fundal portions of several acinous glands, while they are frequent in the neck regions of the same, it would seem at least probable that mother cells, or cells capable of reverting to the mother cell type, are situated in the latter area. But generally in acinous glands of simple type there is, as Bizzozero has pointed out, little evidence of continued proliferation under normal conditions, once they are fully formed. In connexion with these it is that more exact studies are requisite ; certainly in some, e.g. in the kidney tubules, slight continued irritation leads to the differentiated cells undergoing proliferation, but at the same time these cells are seen to revert to the simpler, more embryonic type. Thus, while confessing that it is not as yet possible to demonstrate in every case that either mother cells are present or that for regeneration the differentiated cells revert to a more embryonic type, the number of examples that can be brought forward, where either one or other of these processes is seen to occur, is so large that we may assume that a general principle obtains in connexion with all.

Passing now to another tissue, namely muscle, the process of regeneration, as pointed out by Barfurth, varies largely according to the age of the individual. Originally the muscle fibres, it is needless to say, are recognized as arising from a series of cells

1 [Despite the abundant studies upon Langerhans's bodies which have been made in the last seventeen years, the "mother cell "nature of these bodies is still a subject of debate.] 
known as sarcoblasts, relatively large cells with abundant protoplasm, the nuclei of which tend to proliferate; and along one aspect of, or generally around, the periphery there is gradually developed first a longitudinal fibrillation, and then a transverse striation. In young larval forms of amphibia, for example, after injury such sarcoblasts may be seen to be present, to undergo multiplication, and to give rise to typical muscle fibres; here, therefore, very clearly there are mother cells. The existence of such in the adult is still a matter of dispute, for in the older individuals two processes have more especially been recognized : one, that in which the fully formed muscle fibres become the seat of an active nuclear proliferation, and then in certain areas of the fibres the striation, more especially toward the end, or laterally, becomes indistinct and little buds containing nuclei are given off, which become the precursors of the new growth. Or secondly, as pointed out first by Weismann, there may be recognized, even in perfectly normal muscle of adult animals, certain occasional spindle-like bodies, consisting of short striated muscle fibres, characterized by very abundant nuclei, and, according to Kölliker and others, these bodies represent centres from which by longitudinal division new fibres are given off. Even in this case it will be seen that these bodies represent a lower imperfect stage of differentiation, and the richly nucleated mass may strictly be regarded as a " mother cell." 1

Thus from a study of the process of regeneration as seen in the different tissues in man and vertebrates generally, it is possible to lay down the following laws :-

1. The fully differentiated cells of a tissue proper never arise from cells that are themselves fully differentiated.

2. Under the normal conditions of growth and during physiological regeneration, the fully differentiated cells would seem in nearly every case to be developed from " mother cells "- undifferentiated or but partially differentiated cells which themselves throughout the term of life of the individual never attain to the full differentiation peculiar to the tissue to which they belong and which indeed they produce. For these mother cells by division give

1 [Since 1900, when this paper was written, the general consensus of opinion has veered round to a belief that these muscle spindles are not associated with regeneration.] 
origin to the daughter cells, and it is the daughter cells which attain full differentiation and form the specific cells of the tissue. More rarely the functional cells themselves by reversion to a more embryonal type can take on the properties of mother cells.

3. Under abnormal conditions, the fully differentiated functioning cells of certain tissues are capable of proliferation and giving rise to cells of like nature, but this is only after a preliminary reversion to a simpler, more embryonic type. The fully differentiated cell as such is incapable of proliferation.

4. Or, otherwise, the energy stored up by the cell may be expended in one of two directions, but not in botheither in functional activity or in preparation for proliferation; and, the structure of a cell being the expression of the activity of that cell, the expenditure of energy in either direction is attended by corresponding morphological or structural differences in the cell.

5. The more highly differentiated a cell, the more highly elaborated its structure, the less the ease with which it reverts, and the less the liability to reversion to a simpler reproductive form; the simpler the cell, the greater the ease and the greater the liability to such reversion. It is thus possible, at the one extreme, to conceive cells so simple in function and in structure that functional or reproductive activity may be called into play without recognizable preliminary structural alteration, and, at the other, cells so highly differentiated that the capacity for proliferation has become entirely lost.

The law with its corollaries here given does not so far appear to have obtained general recognition. Certainly I fail to find it explicitly referred to by writers upon morbid anatomy, and had it been currently accepted by biologists it would ere this have become part and parcel of pathological teaching. It is only after some little search and almost by chance that I find its main paragraph laid down by Kölliker in 1885, and that only, as it were, in passing, in an article not dealing directly with regeneration, but dealing with the part played by the nucleus in inheritance. In that article Kölliker states: "In all cases in which an organ or a tissue is capable of regenerating itself, it 
must contain elements of an embryonal character, or at least such elements as can take on that character." And again, in the same article: "These cells then are dependent upon the same law as, in the embryo, is the formation of organs." 1

But in the general portion of his great Handbuch der Gewebelehre des Menschen, published in 1889, I cannot find that he again refers to this principle, hence it would appear that he did not realize its wide application.

Thus, although the law when once grasped is simple, almost to the verge of being a truism, it merits being stated for once in as clear terms as possible that its high importance may be fully recognized.

\section{REgENERATION}

Applying now these considerations to certain pathological conditions, it is in the first place necessary to say but little concerning pathological regeneration and repair, for I have already applied some of the facts gained from a study of such regeneration in the development of my argument. This much, however, may be said, that the more we study the regeneration of various tissues, the more we see that the phenomena of the process fall into place in consonance with the law above laid down. The cells of a regenerated tissue are derived from the pre-existing cells (and mother cells) of that particular tissue, and the more highly differentiated the tissue the less is its capacity for regeneration.

Of all cells, those which are the most highly differentiated, namely the nerve cells, show the least capacity for proliferative regeneration; there is a remarkable lack of evidence of fully developed nerve cells having been observed in the process of mitosis, and, corresponding with this lack, when we consider the histological basis of motor, sensory, and mental acts, it is $a$ priori hard, if not impossible, to conceive a given cell in any of the higher nerve centres undergoing proliferation without there

1 Kölliker : "In allen Fällen, in denen ein Organ oder ein Gewebe fähig ist sich wieder zu erzeugen, mnss dasselbe Elemente von embryonalem Charakter enthalten oder wenigstens solche, die diesen Charakter anzunehmen im Stande sind." "Diese Zellen bedingen dann nach denselben Gesetzen, wie beim Embryo, die Organgestaltung" ("Die Bedeutung der Zellenkerne für die Vorgänge der Vererbung," Zeitschrift $f$. wiss. Zool. vol. xlii., 1885, quoted by Barfurth " Zur Regeneration der Gewebe," Arch. f. mikrosk. Anat. xxxvii., 1891, p. 424). 
being simultaneous arrest, not to say loss, of function. Everything indicates that of all the cells of the body the neurones are those endowed with the longest life period.

During foetal or larval life, prior to the attaining of full function, such proliferation has been recognized (Barfurth), or otherwise the incompletely differentiated nerve-cells may take part in the regenerative process; though it may be considered an open question whether the new development of neurones in experiments upon the spinal cord of the larval newt and other amphibia is the result of proliferation of developed neurones or of mother cells.

That such mother cells must exist even in the human nervous system has been forcibly brought home to me by a study of certain sections of the spinal cord to which Dr. Shirres, ${ }^{1}$ working in my laboratory at the Royal Victoria Hospital, recently called my attention.

These sections are from a case of porencephalus in which apparently, from all indications, the atrophy and disappearance of practically the whole motor area in the left hemisphere dated from the last month or two of foetal life. Despite this practically complete loss of the entire motor area on the left side, the resulting evidence of paralysis and disturbance of function were little more than a relatively slight want of development of the bones and muscles of the right side of the body together with paresis of the musculature of the right hand. In the cord the difference between the two motor tracts is most marked, there is entire absence of the crossed pyramidal tract on the left side, of the direct pyramidal tract on the right, and, corresponding with this, there is a most marked atrophy of those groups of cells towards the periphery of the anterior horn of the grey matter on the right side, which everything indicates as being connected with the crossed pyramidal tract and being what I may term the spinal motor centres for the upper extremity. But in sections in which this atrophy is most marked there is a distinct increase in the number of ganglion cells in the deeper and more central areas of the grey matter; here the number of cells is much above the normal, the cells are large and more numerous than those of the left side of the same section.

For our present purposes it is clear that these abundant cells

${ }^{1}$ [Studies from the Royal Victoria Hospital, Montreal], No. 1, 1901. 
cannot be regarded as due to proliferation of the atrophied cells -their relative position forbids such an assumption. Their existence, however, is strongly in favour of the view that they have been derived from mother cells in the grey substance.

The regeneration of nerve fibres is another matter. So far as regards the axones, or axis-cylinder processes themselves, it is strictly comparable with the new growth of the cell substance of the amoeba when a part of that cell substance has been removed without direct injury to the nucleus. As regards the investing sheath of the medullated nerve fibre, regeneration here is in strict accordance with the third law; there is a preliminary period of reversion; the formed substance (myelin), governed or elaborated by the cell, breaks down, the nuclei become more prominent and surrounded by an increased amount of protoplasm, and then in place of a single nucleus of a node of Ranvier one gets numerous nuclei, and the new cells evidently surround the newly developed axis cylinder as it grows downwards from the/ seat of injury.

I have already referred to the regeneration of muscle, but if we now pass to the other extreme and consider what happens in the simplest of all tissues, namely, white fibrous connective tissue, we find that even here for pathological regeneration to occur there is a preliminary stage of swelling of the connective tissue cells, the nuclei become larger and more prominent, the surrounding protoplasm becomes increased in amount, the surrounding fibrils tend to disappear, and now, only after this reversion to a simpler, more embryonic condition, do we have proliferation and the subsequent building up of new connective tissue.

To enter here into a discussion as to whether connective tissue can be formed from -wandering cells, and whether any special form of wandering cell is capable of taking part in such new formation, would be imperative if I were dealing more especially with the law that tissues arise from pre-existing specific tissue cells; here rather, dealing with the process and the law of growth, with the law of mother cells, if I may so term it, the very limits to which this article is confined must be an excuse for not dealing with this subject. 


\section{Metaplasia}

A few words, however, must be said with regard to metaplasia in general, for the law of reversion to a more embryonic type is distinctly in evidence throughout, and indeed helps us to understand how, for example, a columnar-celled epithelium can be converted into a squamous-celled epithelium, and one form of connective tissue into another; or, otherwise, metaplasia is never direct, but is only brought about by preliminary reversion to a more embryonic type, or, where mother cells are present, by the modified development of cells derived from the mother cells, the influence of environment altering the character of those daughter cells during the period of growth.

\section{NEOPLASIA}

If the principle be correct that the more highly differentiated a cell, the less its capacity for proliferation; or, in other words, the more the daughter cells depart from the type of the mother cells, the less their proliferative capacity, then the converse would seem to hold-that the more the daughter cells in a given tissue retain the characteristics of the mother cells, the greater their proliferative capacity. Or-to continue the argument-if through any cause the daughter cells in a tissue do not attain full specific differentiation, then they are peculiarly liable to proliferate and function, not as specific cells, but as mother cells. And further, as Bizzozero has pointed out, tissues in which the cellular elements exhibit frequent mitosis are those which more especially are liable to be the seat of excessive growth and tumour formation.

I am far from saying that this is the one principle concerned in the development of the blastomata, or tumours proper, but I would urge that it is one important principle. It is outside the limits of this article to consider what is the essential stimulus, or what are the stimuli, leading to neoplastic growth ; accepting, however, for the moment, that, whether temporarily or permanently, some stimulus or stimuli be in action, at least we gain a comprehension of why in the first place histoid tumours (in which one or other tissue is more or less faithfully reproduced) are essentially benign ; and in the second place why malignancy and excessive cell proliferation, which is the essence of malig- 
nancy, go hand-in-hand with tumour formation of a pronounced embryonic type.

The failure to recognize the normal existence of mother cells in those tissues which are prone to tumour formation is very obvious in reading over Cohnheim's chapter upon tumours and in following the course of the argument which led him to conclude that tumours arise from latent superfluous embryonal tissue lying either within a tissue of the same nature or heterotopic.

While we must admit the existence of such embryonal rests in order to explain the development of such tumours as, for example, myomata of the kidney and primary cancerous growths developing in bone, the permanent existence of these mother cells as the normal constituent of the tissues throughout life is wholly adequate to explain most benign and malignant tumours. To this larger conception of what is "embryonal tissue" we must, I think, inevitably come, and with Senn and others we must regard tumours as products of tissue proliferation of embryonic cells of either congenital or post-natal origin, even though we at present continue unable to state definitely what it is that immediately induces these cells to undertake excessive growth. Granting this, that in tumours we have aberrant tissue growth and that that tissue growth is due to certain cells assuming excessive proliferative properties wholly outside the needs of the economy, then such proliferating cells are to be considered as being derived :

1. From embryonic "cell rests" which have for a shorter or longer period remained latent in one or other tissue and then have taken upon themselves a rapid proliferation leading to tumour formation.

2. From the mother cells of a tissue which, remaining undifferentiated, but capable of active proliferation throughout life, now assume excessive proliferative powers, their daughter cells retaining to a greater or less extent the characters and the properties of the mother cells.

3. From differentiated cells which reverting to a simpler, more embryonic type, with this reversion gain the capacity for active and excessive proliferation.

Possibly I may add that the tendency to the development of glandular cancer in later life bears some relationship to the reversion and degeneration of gland cells at this period. As the 
tissues become exhausted, the more highly differentiated cells tend to become structurally simpler, revert, that is to say, to a simpler type, and, with this simplification of structure accompanying atrophy, there may be, I would suggest, along the lines already laid down, a greater liability for those cells to assume proliferative powers. 


\section{CHAPTER II}

ON THE CAUSATION OF CANCEROUS AND OTHER NEW GROWTHS ${ }^{1}$

JUST as to the bright spirits of the sixteenth century, in the expansion and enthusiasm of the time, everything seemed possible and men dreamt of the perfect commonwealth, so to us in this age of medical renaissance the discoveries that have been made in connexion with the causation and modes of prevention of so many important diseases appear to point to the time when the most dread scourges of humanity shall one after the other be subjugated, and our race rise to a level of physical well-being hitherto beyond the bounds of credence. So it is that, regarding the most awe-inspiring and painful of these scourges, cancer and malignant growths in general, while admitting our complete impotence to deal with these conditions save when we have the good fortune to recognize them at their very onset, we nevertheless, to-day, are not wholly cast down; rather are we sanguine. If we have discovered the cause of so fatal and widespread a condition as tuberculosis, sooner or later we hope to find a specific cause for cancer. It is, we encourage ourselves, but a question of study and of time. Analogy and the prevailing hopefulness cause us to expect to find some microbic cause, and, being in this frame of mind, we accept gladly each possible indication pointing to the infectious nature of malignant growths. Already, indeed, we seem to be on the very threshold of discoveries rich in relief to suffering humanity. Discover the cause, say we, and then inevitably we must bring the disease under the yoke.

Are we justified in taking this position? Are our studies

1 Delivered before the Yale University Medical Alumni Association, New Haven, Conn. Reprinted from the British Medical Journal, 1901. 
being directed aright? Are the arguments employed in support of this theory of the infectious origin of malignant neoplasms thoroughly sound? Do the almost innumerable observations which have been made during the last few years bear out the assumption, or have we been neglecting other important factors in the etiology of new growths in the keenness of our desire to determine some specific causative agent?

These are the matters I wish to discuss. The time, indeed, is opportune for such discussion when of late, upon this side of the ocean, two well-known surgeons like Roswell Park of Buffalo ${ }^{1}$ and Collins Warren of Boston ${ }^{2}$ have placed themselves in evidence as favouring the theory of infectious origin, and when, on the other side, a Cancer Number of that well-known journal, the Practitioner, ${ }^{3}$ with its series of articles by responsible writers dealing with different phases of the subject, most assuredly leads up to the conclusion that cancer is an infectious disease.

\section{The Parasitic Theory}

It will be well, in the first place, to adduce the main arguments in favour of the parasitic origin and infectious nature of malignant growths. These, stated briefly and impartially, are the following:

1. That the increase in frequency in malignant tumours in civilized communities during the last four decades is wholly out of proportion to the possible action of any factor, save the gradual spread of some infective agent. It is in excess of any lessening of the death-rate, and not to be accounted for merely by the increased longevity of civilized races-is not, that is, to be explained by the fact that a larger number of individuals now reach the cancer age. The increase is to be seen in country as well as in urban districts, in European as well as in American communities, and cannot therefore be attributed to any one alteration in the mode of life, to altered habits, altered environment. There is no other common factor capable of explaining the increase, hence, per exclusionem, we must fall back upon infection.

2. That the incidence of the disease is frequently found to be peculiarly localized-certain districts, mainly low-lying, are

1 Roswell Park, Trans. Amer. Surg. Assoc. xvi., 1898, p. 182.

2 Collins Warren, Boston Med. and Surg. Journ. vol. cxliii., 1900, p. 25.

- Practitioner, Cancer Number, April 1899. 
seen to be especially affected, certain villages, and even certain houses in those villages-and this apart from blood relationship between the affected individuals. The incidence is, if I may so express it, of a miasmatic type, resembling, for example, that of malaria.

3. That the lesions produced by the growth of malignant tumours within the organism are comparable with those induced by certain known infective agencies, and that a close analogy can be drawn between the tubercle and the dissemination of tuberculosis, and the primary cancer nodule and the metastatic cancerous or sarcomatous growths. Just as in chronic affections there are, as a rule, single primary foci of origin, so with the malignant neoplasms; and just as there is extension of the tuberculous process by continuity (with the destruction of the surrounding tissues and their replacement by new tissue), by the lymphatics, or by the blood stream, so it is in connexion with neoplasms and their progressive development in the organism.

4. That the more carefully material from malignant tumours is examined, the larger is the proportion of cases in which certain intracellular and extracellular bodies are to be recognized. The series of forms seen, while large, is, according to each individual observer, remarkably constant, and not to be regarded as indicative of cell-degeneration, though observers differ between themselves as to the specific series of forms. It is generally agreed that these bodies are most numerous in the young growing edge of the tumours rather than in the older central cells in which degeneration might be expected to show itself. While but a few years ago the observations of Sjöbring, Ruffer, Metchnikoff, and others led to these bodies being regarded as parasitic sporozoa, and so as being of animal nature, among upholders of the parasitic theory the trend of opinion at the present time, following Russell, Roncali, and Sanfelice, is to regard them as of vegetable origin, as blastomycetes or yeast-like growths. But within the last few weeks there have been indications that the sporozoon theory is of late being actively supported. ${ }^{1}$

1 [In the years that have elapsed since this address was delivered, as one after another other species of pathogenic microbes have been recognized, with a striking inevitability, one after another these have been announced as the causative agents of cancer-spirochaetes, amoebae, gregarines, chlamydozoa and filterable or ultra-microscopic viruses.] 
5. While the cases on record of apparent direct infection from one individual to another are so few as to be explained by the law of chance, and as being but the coincidental occurrence of the same disease in two associated individuals, and while the experimental inoculation of fresh cancer material from one individual to the other (whether these be of the same or of different species) has almost uniformly failed, nevertheless, in rare cases, this would have appeared to have succeeded; and, according to Sanfelice, the inoculation of a pure culture of a yeast isolated by him has, in a small proportion of cases, led to the production of definite neoplasms. Two factors are necessary for successful experimental inoculation-the virulence of the parasite and the susceptibility of the tissues; and it may well be that if malignant growths are brought about by parasites of a very low state of virulence, a very special susceptibility or special condition of the tissues is necessary for the inoculation to be successful. To this lack of special susceptibility of the tissues is to be attributed the frequent failure of experimental inoculation, either with cancerous material direct, or with pure cultures grown outside the body.

These, I take it, are the main arguments in favour of the parasitic origin and infectious nature of malignant growths. Stated thus, they present a very strong prima facie case in favour of the parasitic theory. There is, however, I need scarcely say, another side to the question, and each of the above arguments in turn may be, and has been, strongly assailed.

(1) Some capable observers still hold that increased longevity is capable of explaining the increase. (2) A fuller study of lowlying and estuarial regions shows that while cancer is very common in some, it is equally uncommon in others. (3) The analogy between the mode of dissemination of tuberculosis, for example, and the development of metastatic cancerous nodules is recognized by all histologists as being thoroughly unsound. (4) Further, it is difficult to refute the careful observations of Fabre-Domergue and of Pianese, ${ }^{1}$ that the so-called cancer bodies of varying types described by different observers are so many different forms of degeneration products within the cancer cells. When, by employing special staining methods which afford a differential stain for mucoid, pseudo-mucoid, hyaline, and amyloid material,

1 G. Pianese, Zeigler's Beiträge, xx., 1896. 
it can be shown that a succession of forms can be made out, passing imperceptibly from conditions within the cells which cannot possibly represent the stages in the life-history of some intracellular parasite to others, which the parasitologists regard as indicating stages in the life-history of one or other microbic form-the histological evidence that cancer is due to parasites becomes, to say the least, singularly frail.

I shall not, however, now take up these various arguments and endeavour to weigh their value; rather I would attempt to approach the matter from a different point of view, would seek to determine the relationship of malignant to other forms of growth in the organism, and from a study of this relationship would endeavour to determine whether we are justified in holding this advanced view in regard to the parasitic origin of malignant growths.

\section{Tumours Benign and Malignant}

I would in the first place ask: Can we draw a line between tumours which are essentially benign and tumours essentially malignant? The answer to this question is an unhesitating "No." If we understand by malignancy the property of local invasion of surrounding tissues, together with that of the formation of new growths of like nature in distant organs-the other associated properties being subsidiary to these two-then all growths which we classify as true tumours may take on malignant properties. Even so highly differentiated and (ordinarily) benign a neoplasm as the chondroma ${ }^{1}$ may exhibit metastases. It is true that very often the assumption of malignant properties indicates and follows a change in the morphological characters of the tumour or parts of the same. Thus the lipoma, ${ }^{2}$ as such, is not malignant, but portions of a lipoma may take on a more embryonic character, and the rapidly growing simpler cell forms may infiltrate surrounding tissues and may lead to metastases. Nevertheless, we have no doubt that this sarcomatous tissue is the direct outcome of the cells forming the primary lipoma. There is no question that here the lipoma has taken on malignant characters. It can scarcely be questioned, also, that malignancy is not a primary but a superadded property of the tumour, that

1 [A tumour composed of cartilaginous tissue.]

2 [A tumour composed of fat-cells. 
growth up to a certain point is of the benign type. Hence, if any theory of the parasitic causation of tumours is to conform to the facts already acquired by us as to the life-history of tumours, that theory must assume one of three forms, namely :

1. That all true tumours, benign as well as malignant, are of parasitic causation.

2. That infection is but one of a series of causes of tumour growth, both benign and malignant.

3. That while tumours, as such, need not primarily be of micro-parasitic origin, the assumption of malignant properties is due to infection by parasites, these leading to that active and excessive purposeless cell growth which is the basis of malignancy.

Let us consider now these possibilities. Are all tumours, benign as well as malignant, of parasitic origin?

\section{Definition of the Term "Tumour"}

Before seeking to answer this question, it is necessary to lay down a definition of this term "true tumour." This in itself is no easy matter, for into that definition for our present purposes-and, I may add, equally for general purposes-no definite statement as to causation should be admitted. So long as we are uncertain as to the causation of these growths, our definition must be strictly confined to facts. Ziegler's statement that " a tumour is a new formation of tissue possessing atypical structure, not exercising any function of service to the body, and presenting no typical limit of growth," is, on the whole, adequate, though in the existence of such forms as certain adenomata, osteomata, and chondromata the use of the term " atypical structure" requires a little explanation.

I prefer the definition of C. P. White: "A tumour proper is a mass of cells, tissues or organs resembling those normally present, but arranged atypically. It grows at the expense of the organism, without at the same time subserving any useful function." 1

1 C. P. White, Journ. of Path. and Bacter. vi., 1899. 


\section{Limitations of the Parasitic Theory}

Accepting this as our definition-and I may say that other attempted definitions agree in including or tending to include the same provisions-then immediately we are compelled to recognize that all true tumours are not of parasitic origin. There is the group of teratomata, due to the inclusion within the tissues of one individual of tissues derived from another. These tissues become organically connected with those of the host, and grow at the expense of the host, throughout subserving no function of use to that host. They form a well-recognized group, which I need not here describe more fully.

Thus, then, on the one hand there are tumours which assuredly are not of parasitic origin, but, on the other hand, we cannot go to the opposite extreme and say that no tumours are due to the action of parasites in the tissues. It may be laid down that physical and toxic agencies, when acting below the point necessary to induce cell exhaustion and cell destruction, may act as stimuli rather than as irritants, and doing this may bring about increased cell proliferation. It may be-it has been-argued that these bacteria and their products cannot be the direct cause of cell proliferation. Weigert and his pupils, for example, strenuously deny such direct action, but the fact remains that the bacterial toxins can be the initiating, indeed in certain cases an essential, cause; and the recent studies by Mallory, ${ }^{1}$ more especially upon the changes occurring in the endothelium of vessels and lymphatics during typhoid and other infectious disease, seem to prove this with absolute clearness.

Bacterial toxins, which when concentrated lead to excessive cell necrosis, in a less concentrated condition may induce active cell growth. In the central portion of the abscess, where there are abundant bacteria and their products, there is abundant evidence of cell necrosis. At the periphery, where by sundry mechanisms the bacteria are hindered from existing, and where the toxins diffusing out are less concentrated, there is evidence of active mitosis and cell growth.

All the tissue components, it is true, are not alike in their reaction. The simplest forms of cells may be stimulated to

1 Mallory, Journ. of Exper. Med. iii., 1898, p. 611, and Trans. Assoc. Amer. Phys. xv., 1900, p. 224. 
proliferate by substances which destroy or arrest the activity of the higher cells in the same neighbourhood. Thus it is that we can trace various stages of bacterial action from those in which destruction predominates to those in which, as in the infective granulomata, the higher tissue elements undergo destruction, but endothelial and connective tissue elements show, it may be in the very earliest stages of the process, well-marked proliferation.

Further than this it would seem that we cannot advance with the bacteria. In other words, so far as our present knowledge permits us to conclude, bacteria-schizomycetes-below a certain degree of toxicity of their products cannot maintain an existence in the tissues of animals. They succumb to the antibacterial mechanisms of the organism, and, succumbing, any proliferative activity they may have induced comes to an end. In plants, it is true, we meet with definite bacteria living a symbiotic existence in the rootlets, and causing well-marked overgrowths. ${ }^{1}$ It may eventually be found that bacteria are capable of initiating progressive cell growth in the higher animals, but of this power proof is so far wanting.

There are, however, other forms of life which, while of peculiarly low toxicity, are capable of existing and actively proliferating within the tissues of animals. Coccidia, for example, are peculiarly common in the rabbit, but the irritation they set up in the tissues is of so mild a type that in many regions the majority of rabbits, young and old, show the results of their presence in the tissues, and that without any sign of disturbance of general health. I need scarcely say that the evidence of their action is especially found in the liver, where, growing within the cells lining the bile ducts, they lead to a proliferation of the same with surrounding overgrowth of the connective tissue, and so give rise to what are truly "cystadenomata." 2 Similar growths of like causation have in rare instances been found in the human liver. It is to be noted that the growths so produced are benign and not malignant. For some reason-what reason remains confessedly problematical - the irritation and the reaction to

1 [Since this paper was written Dr. Erwin F. Smith of the Bureau of Agriculture at Washington has demonstrated conclusively (1907-1916) that a specific bacterial form, the Bact. tumefaciens, is the causative agent of large localized overgrowths in plants, crown galls, of beets, Paris daisy, roses, etc.]

" [An adenoma is a tumour reproducing the structure and cell arrangement of one or other type of glandular organ.] 
the growth of these microbes is not sufficient to bring about such an active proliferation and continued vitality on the part of the cells that, carried to other regions, these cells reproduce the primary growth.

The nematode worm, Bilharzia, an organism vastly higher in the scale of animal life, and one infesting a very large section of the human race, may exist within the organism for long years without setting up any very serious disturbance; but in those parts of the body which by preference it infests it is clearly capable of producing cell proliferation of an adenomatous, papillomatous, or even of a cancerous type. Living in the radicles of the portal and pelvic vessels, its abundant ova make their way mechanically (on account of their shape) through the vessel walls into the submucosa and mucosa of the lower bowel and the bladder, and so into the lumen of the intestines and the bladder respectively. Numerous cases are on record of extensive neoplasms of the rectum and bladder which are clearly secondary to the continued cell irritation induced by these ova. All, I think, are nowadays prepared, from such cases as these, to agree that there are parasitic agents capable of inducing tumour growth of a benign type; and, what is more, that this growth does not merely occur in cells which are congenitally displaced, but in those which, prior to irritation, have been portions of strictly normal tissues.

It would appear, therefore, that the evidence at present in our possession confirms the second possible theory that parasites are but one of the series of causes of tumour growth.

Now, between these two extremes-forms assuredly due to independent cell growth without microbic intervention, and forms assuredly initiated by microbic intervention-we have a very broad debatable territory, wherein we encounter the main mass of neoplasms. How are we to regard these? Do they belong to the one or to the other class?

\section{Classification of Tumours}

It will be well in the first place to attempt a rapid classification of the different forms, according to the tissues implicated ; according, that is, to the tissues and the cells which give origin to the different forms of tumours. Such a classification is 
possible. To attempt to indicate the class to which each individual tumour belongs would immediately involve us in a long and, for present purposes, absolutely fruitless discussion. And this, it would seem, very largely because a tumour of one histological type may be produced under different conditions. Carcinoma, for example, may develop in connexion with the functionless or relatively functionless cells of the ovarian dermoid ; or, again, may originate from the active and functional cells of, say, the gall-bladder or the splenic flexure of the colon.

The following classification appears to me to include every form even if this be the case, and even if at the present time we may differ as to the class in which certain varieties of tumours should be placed.

\section{A. Teratomata}

Tumours composed of the products of growth of one individual within the tissues of another individual of the same species.

I. Teratomata of the first order-Twin Teratomata. Tumours due to the continued growth, within the tissues of one individual, of the tissues and organs of another individual which has become included in the former during foetal life.

II. Teratomata of the second order-Filial Teratomata. Tumours due to the continued growth, within the tissues of one individual, of tissues and organs which are the product of growth of one of the germ cells of that individual.

(i.) Parthenogenetic. - Tumours formed of the products of the unfertilized germ cell. The more recent studies of Répin ${ }^{1}$ and Arnsperger ${ }^{2}$ most strongly support the view that ovarian and testicular dermoids can only be regarded as examples of abortive parthenogenesis.

(ii.) Gamogenetic.-Tumours formed of the products of the fertilized germ cell. The recent work of H. Peters ${ }^{3}$ has settled the angry discussion as to the nature of

1 Répin, “Origine parthénogénétique des kystes dermoldes de l'ovaire," Thèse de Paris, 1892.

2 Arnsperger, Virch. Arch. Bd. clvi., 1899, S. 1 ; see also Wilms, Deut. Arch. f. klin. Med. Iv., 1895, S. 219 ; Zeigler's Beitr. xix., 1896, S. 233 and 367.

H. Peters, Die Einbettung des menschlichen Eies, Leipzig und Vienns (Deuticke), 1899. 
the syncytial cells of the placenta ; they are, as many have long held, of foetal origin, derived from the outer layer of the foetal epiblast. They have, physiologically, well-marked powers of eroding or breaking down the uterine tissue, and through their agency it is that the villi penetrate into the maternal blood sinuses. Physiologically, that is, they possess what we regard as malignant properties. The highly malignant tumour, formed as a result of their overgrowth, the so-called deciduoma or syncytioma malignum, is thus clearly an example of cells which are the product of one individual invading the tissues of another individual. Placental moles belong also to this class.

\section{B. Blastomata}

Tumours composed of the products of aberrant growth of cells and tissues of the individual in whom they develop.

I. In which abnormal cell relationship precedes the neoplasia by a definite interval, and apparently predisposes to the aberrant purposeless growth. These abnormal relationships may be $(a)$ inherited, $(b)$ acquired, and then either of ante-natal or post-natal acquirement.

(i.) Heterochronic.-Tumours in which the primary abnormal cell relationship is due to the persistence of tissues from a previous stage of development, which tissues normally undergo atrophy and disappear. Examples : Tumours developing from the thyroglossal duct, Gärtner's duct, branchial clefts, etc.

(ii.) Heterotopic.-In which the abnormal cell relationship is due to the displacement of cells and tissues during the process of growth, so that the tumours develop from "cell rests." Examples : Cancer of accessory thyroids and other tumours developing in accessory glands, rhabdomyomata, ${ }^{1}$ and suprarenal tumours of the kidney, etc.

(iii.) Heterotrophic.-Tumours in which the abnormal cell relationship is due to unequal growth of different

${ }^{1}$ [Tumours composed of striated muscle elements.] 
elements composing a tissue. Examples: Congenital angiomata 1 and lymphangiomata, in which from obstruction or other cause the vascular elements of the tissue become unduly prominent, while the normal parenchyma of the part is imperfectly developed.

II. Tumours in which one and the same agency leads to abnormal cell relationship and to tumour growth.

(i.) Tumours in which no primary disturbance of cell relationship is to be recognized, the growth originating apparently from functional cells and tissues, and in which so far the causative agent has not been determined. This group would seem to include a very large number of malignant growths - epitheliomata of the skin, tongue, etc., carcinomata ${ }^{2}$ of the stomach, colon, and so on. The more we study the early stages of cancer the more it is impressed upon us that these would seem frequently (though by no means necessarily always) to develop from the cells of tissues that are or that have been normal and functional.

(ii.) Tumours originating from normal and functional tissues through known microbic agency, for example, coccidiosis of the liver of the rabbit, bilharzia tumours of the bladder and rectum.

Reviewing the various classes of tumours here rapidly set in order, we recognize a series with at the one extreme tumours originating in misplaced tissue, and growing and continuing to grow without microbic irritation, and at the other extreme tumours originating in normal tissues, and growing as a consequence of the low form of irritation induced by parasites. Between these two extremes some approximate and apparently belong to the former group, others show evidences of relationship to the latter.

Accepting this as the case, it must next be asked, Can we determine anything in common - a common denominator, as it were-associating these various groups? Structurally, tumours belonging to the two extremes may be of like nature and histological character, and common denominator there must be, and

1 [An angioma is a tumour composed of vessels and vascular elements.]

2 [A carcinoma is a malignant tumour containing the elements of a glandular epithelium.] 
if we can only determine it, then we can proceed to establish the true theory of tumour formation.

I need not say that there have been many attempts to form such an adequate theory, from that of Cohnheim, who, ignorant of the existence of the one group, sought to ascribe everything to "cell rests," to those of present-day writers, who, heedless of the existence of the other group, seek to ascribe everything to microbes. Neither extreme, as I have shown, is possible. I trust that I shall be forgiven if neglecting, on account of the demands of time, to put before you what I may term intermediate theories in full detail (of which those most discussed pro and con at the present time are the theories of Ribbert ${ }^{1}$ and Hansemann.) ${ }^{2}$ I here give rein to my own line of thought.

Let $\mathrm{me}$, in the first place, put before you in concise language the problem that has to be solved: (1) Certain tumours arise from misplaced cells ; (2) certain tumours arise from cells originally in normal position. What is the cause of either category of cells taking on excessive growth independent of the needs of the organism?

\section{The Relation of Growth to Functional Activity of Cells}

To solve this problem it is clear that in the first place we must have right ideas as to the nature of cell growth and proliferation in ordinary. Now, as I pointed out a few months ago (in the Jacobi Festschrift ${ }^{3}$ ), we are apt to have a vague idea, to say the least, of the nature of the normal growth of tissues. The more one studies what occurs in the various tissues, the more obvious it is that multiplication and the active performance of other function by the cell are incompatible, or otherwise, that the actively functioning and fully developed cell, as such, does not undergo mitosis and show evidences of multiplication.

In not a few tissues (the epidermis, periosteum, etc.) there are present what may be termed proliferous or " mother cells "cells which themselves throughout life do not attain full differentiation, but which give off daughter cells, and the daughter cells it is which develop into the fully differentiated functional

1 Ribbert, Das pathologische Wachstum der Gevebe, etc., Bonn (Cohen), 1896.

- Hansemann, Die mikroscop. Dingnose der bosartigen Geschwälste, Berlin (Hirschwald), 1897.

- See p. 263. 
cells. In other tissues the fully differentiated cells are capable of division and proliferation, but this only after reversion to a simpler type, or, as we term it, a more embryonic state, in which evidently their functional secretory activity is reduced to a minimum. Thus, after the injection of indigo-carmine, Martinotti ${ }^{1}$ has pointed out that in a kidney, portions of which have been removed in order to study the compensatory overgrowth of the remaining part, all the cells of the convoluted tubules in the remaining part take up the pigment, save and except those in a condition of active mitosis : these remain perfectly colourless. Even in so simple a tissue as connective tissue, the cells exhibit this return to a more "embryonic" state prior to multiplication. ${ }^{2}$

Professor Carlier of Birmingham has, I may add, noted cases apparently contrary to what is here stated; cells of the gastric glands may show mitosis and the appearance of secretory granules in their protoplasm at one and the same time. ${ }^{3}$ But these may well be stored-up granules. In a letter to me-which in consequence of the long time it would take to gain his necessary permission, I trust I may be permitted to quote- he states that in his opinion a dividing cell may be functionally active. He adds, however, that when this is the case, he is inclined to believe that the nuclear changes characteristic of mitosis become suspended for the time being.

Thanks to the researches of Hodge, ${ }^{4}$ Mann, ${ }^{5}$ and other neurologists, of Macallum of Toronto, ${ }^{6}$ and of his pupils, Scott and Bensley, and of Carlier, and of other physiologists and cytologists, we are recognizing more and more that the nucleus plays a con-

1 Martinotti, Centralbl. f. allg. Path. i., 1890.

2 Here let me urge that the use of this term "embryonic" as applied to cells in an adult organism is of questionable value, and indeed is responsible for not a little of the want of comprehension of the phenomena of normal and abnormal cell growth. I would suggest in preference the employment of the term "vegetative" or "proliferous" to include the whole series of these cells. For, strictly speaking, in these cases of reversion to a simpler state, it is a misnomer to speak of adult cells becoming embryonic, and a continuance of or reversion to this simpler histological condition is not an indication of an embryonic condition, but is essentially correlated to the mode of activity of the cell ; or, otherwise, the so-called embryonio cell is a cell which specially is in a position to proliferate, and is not in a position to perform specialised function.

s Carlier, British Medical Journal, September 15, 1900, p. 740.

- Hodge, Amer. Journ. of Psychol. iii., 1890, p. 530; Journ. of Morphol. vii., 1892, pp. 99 and 449 ; Journ. of Physiol. xvii. p. 129, 1894.

- Mann, Journ. Anat. and Physiol. xxix. p. 100, 1895.

A. B. Macallum, British Medical Journal, 1898, ii. p. 778. 
trolling part, not merely in cell division, but also in the function of the cell. With activity the nuclear chromatin becomes used up and discharged into the body of the cell, there to combine with other substances to build up prezymogens and other bodies, which are eventually discharged as the specific secretion of the cell. This being the case, we can readily understand that the higher specific functions of the cell cannot be carried on by a nucleus whose nuclear material is being utilized to its fullest in mitosis. The process of cell division and the performance of the higher functions of the cell are incompatible, and the cell engaged in the active performance of its special functions cannot undergo division.

Yet, paradoxically, under normal conditions after birth, it is the actively functioning tissue that undergoes hyperplasia and takes on increased growth. This is to be explained in most cases by the fact that the new units of that tissue are derived, not from the actively functioning cells, but from mother cells present therein ; in other cases, probably by the fact that such hyperplasia occurs where the activity is not continuous, but interrupted, growth occurring in the intervening periods of rest. One may quote, for example, the late Sir James Paget's wellknown illustration of the growth of a corn on the foot being due to an interrupted irritation of the skin by the pressure of a tight boot, that irritation which otherwise would lead, if continued, to atrophy, being removed at night, leads to hyperplasia of the epidermis.

For a cell to divide actively there must be at least temporary arrest of the specific, as distinct from the vegetative functions. Or, conversely, arrest or disturbance of the specific functions of the cell, if of such a nature as not to arrest vegetative activity, favours cell multiplication. The nuclear activities, unemployed in one direction, become diverted into another; the nuclear material, not being discharged and converted into the specific secretions of the cell, tends to become heaped up, and, accumulating up to a certain point, is then used in mitotic processes.

1

\section{Influence of Environment on Cell Activity}

While heredity surely plays an important part in determining the structure of the cell, we are forced to see that, underlying 
and determining heredity, the eventual structure, as again the specific functions of a cell, are determined by the sum of the forces acting upon that cell ; structure and function are adaptations to environment. It is not only the nutritive material absorbed by the cell that determines the characters thereof, but its position relative to other cells in the economy. From the first the cell continues to proliferate until the sum of the above-mentioned forces brings it sooner or later to a condition of equilibrium, until the amount of nutrition absorbed (and the resultant energy) is fully utilized in maintaining the cell in the status quo. And when this point is reached, the products of nuclear and cell metabolism, as they are formed, become used up in the performance of function. There is no sufficient surplus or redundancy of material to permit the cells to undergo simultaneously those material transformations which result in cell division. Disturb the environment of the cell, remove certain of the forces acting upon it so that the cell energy previously devoted to counteracting the effects of those forces may now be diverted into and employed in other directions, and then unemployed energy may be utilized for growth, or perhaps, more exactly, the material heaped up by constant assimilation, by its very presence in the nucleus, stimulates this to undergo mitotic changes. As a matter of fact, numerous examples can be adduced of overgrowth of tissues due to removal of forces normally acting upon these tissues, overgrowth which continues until such time as the sum of the forces acting upon the newly formed cells becomes equal to the utilization of the sum-total of the cell energies; then continued growth comes to an end.

This, on the one hand, namely, that removal of forces acting upon the cell from without leads to its passing from the functional to the proliferative state; or, if it be in the proliferative state, leads to its continuing in the same; on the other, increased absorption and utilization of nutritive material affords the opportunity for increased exhibition of energy, increased katabolism.

\section{INERTIA OF CELLS}

Now increased absorption and assimilation is in general a response to previous or concurrent increased katabolism and increased activity. So long as this increased assimilation 
corresponds to and makes up for the loss of substance brought about by this increased activity, for so long is there no tendency towards cell multiplication. It, however, may happen that after stimulation the amount of absorption and assimilation may be in excess of the needs of the cell. We have, in short, to recognize the existence of the principle of inertia.

Inertia, physically speaking, is one of the properties of matter in general. Now, just as according to physical terminology there are two kinds of inertia-inertia of matter at rest (or inertia of mass) and the inertia of matter in motion (or momentum)-so in relation to the protoplasm of the cell we notice the same kinds of inertia in evidence. As Dr. Harris points out, ${ }^{1}$ protoplasm which is at rest cannot be instantly caused to change that state to respond to stimuli. We have the familiar latent period, and numerous examples can be given of that functional inertia which corresponds with the inertia of movement (momentum), "the inertia that makes the wheel rotate long after you have ceased to spin it." The isolated heart of the frog will continue to beat long after its removal from the body. Hairs continue to grow after the death of the body; indeed, all cases of organs and tissues continuing to perform functions after their blood supply has been cut off are cases of functional inertia.

And coming now to the immediate problem before us, it may be said that active katabolism, with the active performance of function, leads to corresponding increased anabolism, and that if by nervous or other mechanism the performance of function be arrested, the absorption of nutrition and assimilative processes may still continue for a time. If there be continued access of nutriment, this, according to the above principle, is liable to continue over and above the needs of the cell. In other words, there is a liability for reserve material to be heaped up in the nucleus and body of the cell. It is, I would suggest, under these conditions that proliferation may replace functional activity. If the cell be not called upon to perform its normal functions, be not called upon to work after previous stimulation has led to increased absorption and anabolism, that cell is in a favourable condition to divert its energies from function to proliferation.

In this connexion I would point out that we are forced to recognize that the stimulus for the performance of special function

${ }^{1}$ D. F. Harris, British Medical Journal, September 15, 1900, p. 741. 
is not intrinsic : it does not arise within the cell but comes from without. Vegetative functions, on the other hand, including cell division, would seem to be of intrinsic origin and automatic, determined only indirectly by external conditions, directly by conditions within the cell. The normal cell, in short, stands in very much the same relationship to the organism as does the normal citizen to the body politic: the work that individual performs is determined by his position in the body politic, and is for the benefit of society at large, but at the same time the individual citizen works for himself and for the continuance of his species. The one, it is true, depends upon and is intimately connected at every point with the other function of the individual, but these two functions of citizenship and self-preservation are clearly distinct, the one determined by external conditions, the other being individual and inherent.

So long as the cell is not called upon to work, and for so long as the surrounding conditions are unaltered, we have the inertia of rest, and for so long there is no call either for increased activity and breaking down of its tissue, or for subsequent building up in excess of vegetative needs. A cell lying functionless and latent does not therefore show any tendency to proliferate. Alter these surrounding conditions and a condition of increased metabolism may be induced.

\section{Position of the "Cell Rest" Theory}

Thus a "cell rest" 1 may remain latent for years or for life, showing little or no signs of growth. The very fact that it is not in a position to perform adequate function is against growth, so long as the conditions are unchanged. Change the conditions, and this same fact that it is not in a position to perform adequate function is evidently the reason why the cells forming that "rest" show a peculiar tendency towards proliferation. They are stimulated from without by physical and other means; their relationships to other cells, whether merely of tension or of tension plus position, become altered, and the reactive increased anabolism and storing-up of cell material which cannot be used up in active work to the same extent as occurs in normally situated cells, is the essential cause why now the stored-up

1 [The persistent remains of a foetal organ, or group of cells of an organ displaced during the course of development.] 
energy becomes utilized in another direction-namely, that of multiplication. ${ }^{1}$

Here we arrive at the strongest objection to the "cell rest" theory pure and simple of tumour growth. It is one thing to have "cell rests" and foetal remains present in the various parts of the body, quite another thing to have tumour growth originating in these. It is probable that the vast majority of "cell rests" never take on an excessive purposeless growth. "Cell rests" may show signs of active proliferation from the first; they may, on the other hand, lie latent for long years, only then showing tendencies to excessive overgrowth; lastly, they may never be found in other than what I may term "a resting stage." So that, granting the existence of " cell rests," we cannot grant that these misplaced cells are the primary cause of tumour formation-at most they are a predisposing cause ; some other cause-a something acting upon the "rests" -is necessary to explain their aberrant and excessive growth. We have to demand some change in the surrounding conditions.

\section{Conditions Necessary for Cellular Hyperplasia}

Keeping in mind these two conceptions, namely, that the stimulus to increased functional activity comes from without, and that the cell in its actions exhibits marked inertia, we can thus realize the conditions under which increased cell proliferation may be excited in a tissue, whether normal or containing misplaced elements. These conditions are either: (1) that the cells be subjected to periodic irritation leading to increased functional activity, increased secretion, etc., followed by periods of rest in which there is storage of cell material to such an extent that the

${ }^{1}$ Along these same lines we best explain the proliferation of mother cells in functioning tissues; though these give rise to fully active cells, their relationships lead them to live a vegetative existence. Alterations in their surroundings brought about by increased activity of the surrounding daughter cells must tell upon their relationships, and altered tension and environment must here again lead to the same reactive increased anabolism, and this must initiate cell division. Where again we have cells once functionally active becoming through senile changes latent and somewhat atrophied, here also any stimulus, whether mechanical, chemical, or physical, acting upon those cells and calling for increased activity, may in like manner render those cells peculiarly liable to proliferate. The change of relationships in the cells brought about by their atrophy and the somewhat altered relationships of the surrounding parts may render them incapable of performing their normal functions, and increased anabolism may be followed instead by multiplication. 
vegetative activities of the cell are called into play to utilize that material in proliferation; or (2) that the irritation be of such an extent and continued for so long a period, that in consequence of the increased functional activity of the cell, of the increased secretion, and the increased blood and lymph brought to the part, the relationships of the cell to those in its immediate neighbourhood are altered to such an extent that, while there is adequate or even increased assimilable material which it can absorb, the very alteration of environment and the increased tension to which it is subjected hinder the proper performance of function, and the stored-up energy becomes diverted from the performance of specific function to proliferative activity.

Now, considering the first condition, the very property of inertia must be a preventive of sudden change from the functional to the proliferative stage of the cell, while again, the environment of the cells continuing relatively unaltered, they must easily respond to the recurrent stimulation to perform their normal functions, and responding, the tendency to multiply must be liable to arrest. Thus I am inclined to consider that while this condition may be possibly in action to induce that moderate and orderly amount of overgrowth which follows upon increased tissue activity, it is incapable of inducing or explaining neoplasia.

\section{A Starting-point common to all Forms of Tumour}

It is the second state, or condition, that affords the startingpoint for excessive local overgrowth in previously normal tissues. And, accepting this view, we at last reach the position of obtaining one common starting-point for all forms of tumour proper. This starting-point is that condition in which the cells of the part, whether functional or lying latent, upon being stimulated and as a consequence undertaking active assimilation and anabolism, cannot from their relations carry on their peculiar functions to a corresponding extent, so that the accumulated energy is instead utilized in mitotic changes and cell division, rather than in the normal katabolism.

Herein, however, we do but explain the first stage in the development of a tumour proper. How is it that once started the cells continue to proliferate? What are the conditions under which we can recognize and explain the development of 
the condition of uncontrolled proliferation? It is clear that at first at least that same stimulus which had led to increased assimilation in the parent cells must continue in evidence, for, if this were not so, then the new cells would either lead but a latent existence, or the tissue in which they are present reverting to a normal state, these cells would gain the same relationships as were possessed previously by their parent and "sister" cells ; they would develop into normal functional cells with specialized structure. We are bound, therefore, to assume that this is not the case-that the primary stimulus continues to act for a certain period, and that as a result of this continued action there is developed a colony of cells all tending actively to proliferate. But now the greater the proliferation the more inevitable must it be that a certain number of new cells assume relationships more and more removed from those proper to the parent cells. Some of these new cells, at least, must pass to a greater distance from the blood capillaries and blood supply, from the lymph channels and the terminal nerve supplying the part, and becoming thus still further removed from the ordinary relationships of the cell forming the particular tissue which has given them birth, still less are they capable of performing normal functions; still more, granted adequate nutrition, are they liable to proliferate. If becoming thus heterotopic their nourishment is cut off, they of necessity die or at least their continued proliferation is arrested. If also the very abundance of the new cells formed leads to marked increase of the pressures acting upon those cells, growth is equally arrested.

According, therefore, to $(a)$ the time of continuance of the primary stimulus (under which term, be it remembered, for the time being I here include everything capable of inducing modified cell relationships to an extent sufficient to permit continued anabolism with perverted katabolism); according also to (b) the relationship assumed by these new cells one to the other; and $(c)$ the tensions to which they are subjected, so do we have or not have the conditions favourable for continued and increasing growth and development of new cells. It is this continuance of the primary stimulus coupled with continued proliferation which gives us the second stage in the evolution of the tumour. These newly proliferated cells may exhibit various departures from the structure and appearance of the fully formed 
functional cells, according to the extent in the alteration of their relationships and the extent of the stimulus. Under one order of conditions, inertia and heredity may lead the new cells to assume specific characters very closely approximating those of the parent cells, and the more the cells are of specific functional type the slower will be the growth ; under another, the departure from type may be so extensive that it is difficult to determine from the individual cells the tissue in which they originated.

\section{Theory of Continuous Tumour Growth}

But even at this point we have not explained tumour formation. We have but reached the stage met with in infective granulomata in which destroy or inhibit the toxic cause of the cell overgrowth and that overgrowth ceases. We have still to account for the continued automatic growth of tumours proper. For such, it seems to me, there are two possible explanations. Of these the first and most obvious is that the modified relationship of the parts, or the stimulus which originated the growths in the first place, continues persistently in action. In those cases in which, apparently, modified relationships of the cells to each other are sufficient to act as the primary cause of growth, it is not, I think, possible to conceive the continuance of the same initial disturbance throughout the life of the tumour; the very growth and massing together of the cells must remove the old and introduce a new series of relationships; we cannot, for example, apply this idea of altered environment alone to explain the production of metastatic growths. It is not merely the outward relationships of the cells, but something in their constitution that can alone explain this active proliferation of cells in regions wholly away from their primary seat of growths, in regions where they are exposed to totally new conditions.

It is, however, quite possible to conceive the continued existence of microbic parasites within the new growth or within the cells of that growth, the products of which by irritating the cells and modifying their functions would continually stimulate the cells to multiply along the lines already laid down. It is possible to conceive these cells and parasites being conveyed to distant parts by the blood or the lymph stream, and when the cells come to rest the associated or symbiotic parasites still by 
their products affecting the cells in their new relationship, and thereby leading to continued growth. This, I take it, is the usual conception of those who propound the parasitic theories of cancer formation.

But herein comes the difficulty. Continuous purposeless growth is characteristic of all forms of tumours proper. Nevertheless, as I have already stated, in a very large group of tumours all the evidence we possess points surely to the fact that microbes have not initiated the growth, and are not concerned in the continuance of the growth.

It would be absurd to urge that microbic agencies play a constant part in the production of the group of teratomatous tumours. No one would suggest that such are the cause of post-operative implantation cysts, or of simple congenital dermoids, such as the little hairy dermoids upon the sclerotic, or of the different forms of angioma. And we can recognize no sharp dividing line, histologically, between the tumours just mentioned and another group including the rest of benign and malignant neoplasms. Histologically all are of the same type.

Further, we can recognize no sharp dividing line between the benign and the malignant forms of such tumours; there is no one stage in which it is possible to say, thus far one set of conditions has been at work leading to purposeless cell growth, beyond this microbic irritation enters in. In both benign and malignant tumours the growth is purposeless, and the only feature separating the two forms is the rate of proliferation and stage in which that occurs. And certainly we encounter every transition between tumours of frankly benign and those of frankly malignant type.

\section{The "Habit of Growth" in Cells}

Here let me be clearly understood. I am not arguing that parasites, intracellular or extracellular, may not be regarded as originating a certain number of tumours. I am pointing out that certain features are common to all tumours; that microbic parasites and the irritation they may induce are not common to all tumours, and that this last factor is therefore inadequate to explain those characteristics which are common to tumours in 
general. Thus it is that I am led to favour a theory which I believe is applicable to all tumours, whatever their origin. Briefly, this theory is based on the fact that cells and their descendants which for long periods have been subjected to certain influences, whereby their properties and structures have become modified, eventually retain those properties after the influences referred to have ceased to act upon them. I base it again upon that principle of inertia already indicated-a principle which some years ago (1896) in this connexion I referred to as the " habit of growth." 1

Here let me cite certain examples illustrating the existence of this principle in connexion with tumours :

It is a familiar fact that a columnar-celled epithelium, subjected to altered conditions of certain orders, is liable to become converted into a squamous, many-layered epithelium. Such transformation is often noted in the uterus that has been prolapsed and everted; it has been noted in the gall-bladder after chronic inflammation, and again in the larynx. What is more-and this is a point to which I would especially call your attentionfrom the uterine mucosa under these conditions, it has been observed that if eancer develops, it tends not to be of the columnar or adeno-carcinomatous type usual in the uterus, but to be definitely epitheliomatous and of the squamous-celled type. The development of primary epithelioma has been more than once recorded in the gall-bladder, and, as there is no squamous epithelium anywhere in the neighbourhood of the normal gallbladder, the generally accepted conclusion is that there has been a pre-existing chronic inflammatory condition, which has caused metaplasia of the columnar-celled mucosa into a stratified epithelium. So also where an epithelioma arises in the larynx, away from regions where -as along the edge of the vocal cordssuch stratified epithelium is normally present, the most satisfactory conclusion is that a similar metaplasia has preceded the cancerous development.

Now certainly in the first of these cases, and most probably in the others, long-continued irritation and modified conditions of environment have led to a change in structure, and this change has impressed itself upon the affected cells to such an 581 .

1 Adami, " The Habit of Growth," Montreal Medical Journal, xxiv., 1896, 
extent that even when these cells take on cancerous proliferation, and their descendants penetrate into the deeper tissues-away from the conditions which affected their progenitors-they still retain well-marked evidences of their acquired characters, and they produce, not a columnar-celled, but a squamous epithelial cancer. I fail to see how such cases can possibly be explained unless we accept this principle of what we may term the inheritance of acquired characters by the individual cells of the organism. Pathologists in general freely accept this as the explanation of the occurrence of primary squamous-celled epitheliomata in the uterus and the gall-bladder. Apparently, so far as I have seen, the significance of these tumours, as indicating an important property of the cancer cell, has not been hitherto realized.

It is nowadays almost needless to point out that to explain immunity we are forced to admit a similar well-marked inheritance of acquired characters by various cells of the organism. And so I urge that in connexion with cancers and with tumours in general these facts may be applied to the elucidation of tumour growth. When cells have for long been subjected to those modified conditions under which they multiply actively and rapidly, then, provided the stimulus or cause of this state acts over a sufficiently long time, the cells take on the "habit of growth." They continue to proliferate in a purposeless manner long after the factors which started the process have ceased to act. Their growth and proliferation is no longer inhibited by the performance of specific functional activities; it becomes wholly independent of the needs of the organism, and the more extreme this independence of growth and the more the cells lose the signs of their primordial function, the more malignant the growth. Provided that there is adequate nutrition it matters little where these cells find themselves; they grow for themselves. Assimilation and mitosis are the two cell functions retained and impressed upon them. They have cut adrift from the old relationships and tensions which determined the primordial activity of the parent cells. They have reverted from the specialized structure impressed upon them by that primordial activity, as by heredity, until but a trace of that structure is left. They assume the form common to cells undergoing mitosis, a form we term embryonic, and that because this is the form characterising actively proliferating cells in the embryo. This 
form, let me repeat, is not so much embryonic as proliferous. It is peculiar to actively dividing cells at all times of life.

Whatever the origin, therefore, of the tumour proper, however it is started, what makes the tumour is the assumption by the primary cells of that tumour of the habit of growth in place of the habit of work, and, according to the extent of this replacement, so do we get the vaiions grades of tumour formation from the most benign to the most malignant.

\section{Summary of Argument}

Let me now sum up the various points brought forward one after another in arriving at this conclusion. They are :

1. The katabolic activities of the cell are of two orders: those determining the relationship of the cell with the exterior, and those that are vegetative determining the continued existence and multiplication of the cell; the former excited by stimuli of various orders from without, the latter only indirectly so excited, being more directly called into play by conditions obtaining within the cell.

2. The controlling agency in at least the higher katabolic activities of the cell, both "functional" and "vegetative," is the nucleus, and nuclear activity is accompanied by breaking down and discharge, or by rearrangement of the nuclear molecules.

3. The changes which occur in the nucleus during the active performance of the specific functions of the cell are of a character so different from those observed during the process of cell division that proliferation and active performance of specific function, the one precluding the other, are obviously to a large extent incompatible. The cell engaged in the active performance of function in response to external stimulation cannot simultaneously proliferate.

4. It follows, therefore, that active cell division and cell proliferation occur only in conditions in which the cell cannot fully utilize the assimilated material (and the energy stored up in the assimilation of that material) in the performance of its specific functions.

5. Such conditions are to be met with where the tensions acting on the cell are reduced and certain energies which before 
were necessary to counteract opposing forces are freed and become thus capable of diversion from their purpose, or, again, where stimulation from without results in increased assimilation and storage of nuclear and cell material which now from any condition cannot be utilized in the performance of specific function.

6. In either case the cells will continue to proliferate so long as the primary modification of physical relationships or the primary stimulus continues to act, so long as there is adequate nutriment, and so long as the tensions exerted upon the cells do not become excessive.

7. Provided that these conditions are observed, the greater the amount of cell proliferation, the greater is the tendency for certain at least of the newly formed cells to be projected from the relations proper to cells of the tissue giving them origin, the less will be the opportunity for such cells to carry on their primordial function, and the greater the liability to proliferation.

8. The longer the cells are diverted from their proper extrinsic functions to proliferative activity, the greater the momentum acquired by them to continue performing the proliferative act until the functional activities become largely suspended and the " habit of growth" is set up.

9. When this habit of growth is inaugurated the cells can continue to grow and multiply in the complete absence of those conditions which initiated their proliferation in the first place, and we obtain that purposeless functionless cell growth characteristic of the true tumour.

10. According to the stage of cell development in which this habit becomes impressed upon the cell, so do we have the various grades of benign and malignant tumour formation.

\section{APPLICATION OF THEORY}

How now does this theory apply itself to the possible microbic origin of at least certain forms of malignant and other tumours? It applies itself thus: According to this theory, microbes and their products may be one of the causes originating localized cell proliferation in the first place, provided that (1) they bring about stimulation rather than irritation, or irritation of so mild a type that the cells are stimulated to an increased metabolism 
which does not go on to exhaustion and excessive breaking-down of their protoplasm; provided, also, that the microbes and their products continue in action for a sufficiently long time to set up the habit of growth. It is quite conceivable that such microbes might continue to exist in the tumours they originated, exerting a cumulative effect. The more the cells depart from type the greater the effect of these microbes and their products in producing a tissue of rapidly proliferative and malignant type.

This continuance and persistence of microbic action, however, must not, I think, be regarded as essential. The very fact that after all these years, and after the hosts of careful observations, we are still in very grave doubt as to whether any of the bodies seen in tumours are really parasites, the fact that no growths of these bodies have surely been obtained outside the organism, and then upon injection have induced tumour formation, although by no means proof absolute, may be quoted in favour of the view that if microbes originate malignant tumours, they do not continue in the living state.

I was not a little interested to note that while Sanfelice ${ }^{\mathbf{1}}$ was apparently able in his observations to induce the formation of neoplasms in two out of rather a long series of animals, following upon inoculation of these animals with his blastomycete-the Saccharomyces neoformans-when he came to make cultures from the tumours and from the other tissues of the animals possessing these developed tumours he was unable to gain any growths. An observation somewhat to the same effect I have come across recorded by Dr. T. Harris, ${ }^{2}$ of Manchester, in a case of cancerous growth of the bladder associated with and evidently secondary to bilharzia disease. Harris calls particular attention to the fact that although there were abundant ova of the bilharzia in the surrounding vesical tissue, the tumour itself stood out completely free from any sign of these parasites.

It is quite possible, according to this theory, that certain specific forms of microbic life originate certain forms of tumour growth-of cancer and sarcoma, for example; that, like other pathogenic microbes, these may show a predilection to attack special tissues under special conditions; and if it be true (for some doubt continues to be thrown upon the matter) that

1 Sanfelice, Centralbl. f. Bakt. xxiv., 1898, S. 155.

2 T. Harris, Trans. Path. Soc., London, vol. xxxix. p. 183, 1888. 
malignant growths are specially common in certain localities, then such microbic origin becomes eminently probable.

But if this theory be true, it does not follow that, discovering the causative microbe, we shall be able to arrest the development of cancer by antimicrobic or antitoxic means. At least, in the present state of our knowledge, I fail to see how we can. The most we can look forward to is, on the one hand, the discovery and employment of means whereby to destroy or arrest the continuous growth of cells which have taken on this functionless growth; and, on the other hand, studying their habits outside the body, to exterminate the causative agents, just as nowadays it is being attempted with marked success to exterminate the mosquitoes in some malarial regions.

I would urge, then, that at the present time, when after all these years of labour no causative agent of malignant growth in general has with certainty been determined, that line of research which promises surer results and greater profit on the part of clinicians, as well as of laboratory investigators, lies in the direction of testing various methods of arresting the growth of the tumour cells without injury to the organism in general. Herein it seems to me that $\mathrm{Coley}^{\mathbf{1}}$ has chosen the better part. But over and above all I cannot but feel that the greatest benefit to the patient, the greatest triumph and satisfaction to the practitioner, will for yet some years to come be the recognition and successful removal of malignant tumours at the earliest possible date. Aye, and what is more, the removal of benign tumours in general before they have taken on possible malignant characters.

I wish I could be more optimistic, for optimism is good and healthy, but the above deductions are the necessary outcome of the considerations I have put before you. As to the hypothesis here put forward, I am quite prepared to find that many will at first have difficulty in grasping it, but when grasped, I cannot but believe most firmly, it will be found to include and to explain the largest number of individual cases-that it will be found to satisfy the conditions of sound theory.

1 By his treatment with mixed streptococcus and pyocyaneus vaccines. 


\section{CHAPTER III}

\section{ON THE CLASSIFICATION OF TUMOURS ${ }^{1}$}

ONCE it was established by histological studies that the different forms of neoplasms arise from different tissues, it became possible to group tumours according to their origin. Once again, when, through the observations of the embryologists, it was recognized that the tissues could be grouped according to their origin from the primitive cell layers, it became possible to group tumours in the same way. This was done more especially by Waldeyer, and we obtained thus a classification of tumours into those of mesoblastic origin and those of epiblastic and hypoblastic derivation, the tumours derived from the two latter cell layers being grouped together, for it was soon found that they were of the same general type.

Here was a broad and very important generalization, and, what is more, in the then stage of histological and embryological knowledge, it appeared not only to be founded on a sure and scientific basis, but to fulfil to the fullest the needs of the worker. For it appeared to separate two sharply differentiated orders of tumours - those of connective tissue origin and connective tissue type from those of epithelial and glandular origin and epithelial and glandular type. So that for long years this distinction remained dominant; even to-day, in at least one text-book published during the last twelve months, that by Dr. Nicholas Senn, this is given as the acceptable classification.

It is, however, scarcely necessary to say that, with increasing

1 The main body of this paper was contributed as an address to the Toronto Pathological Society, January 4, 1902. Reprinted from the Journal of Pathology and Bacteriology, Edinburgh, June 1902. 
knowledge, many cases were discovered which did not fit into this scheme. A classification which brings together unlike bodies, making them members of one group, is, on the face of it, inadequate and faulty. Now, more especially during the last ten years, pari passu with a recognition of the bearing of the fuller and more recent findings of the embryologists, this classification has been found to have the above failing. It is, for example, generally accepted that the specific and characteristic cells of several tissues of the glandular type- of the kidneys, suprarenal bodies, ovaries, testes, and uterine mucosa-are of mesoblastic origin, but these, nevertheless, give rise to tumours which may and often do resemble most closely those of hypoblastic and epiblastic origin.

There has been grave doubt as to the embryogeny of the organs in question. The idea that tissues of glandular type can only be derived from the two primary cell layers is very firmly fixed, and in one direction the attempt has been made to show that the organs in question are of hypoblastic or epiblastic origin ; on the other, to make out the distinction between these organs and what have been termed "true glands." But I am only expressing the general opinion of modern embryologists and histologists when I say that all these organs now are accepted by the majority as being definitely derived from mesoblast. And thus the cancer-like tumours which originate in these organs must be accepted as being mesoblastic.

On the other hand, the gliomata have a structure which brings them into close alliance with the atypical or malignant connective tissue tumours, and yet the neuroglia, from which they are derived, is of epiblastic origin. The notochord, again, is an organ of hypoblastic origin. According to Ribbert, and the view is becoming accepted, the remains of this foetal organ may give rise to tumours somewhat resembling myxomata, ${ }^{1}$ that is to say, to tumours which, though of hypoblastic origin, are of connective tissue type. Histologically, and for practical purposes, the first series above mentioned ought to be grouped along with the adenomata and carcinomata, and the second with the sarcomata and connective tissue tumours, but the old embryological classification forces us to make the very opposite arrangement.

1 Tumours of mucoid type, resembling the connective tissue of the foetus as seen in "Wharton's jelly "of the umbilical cord. 
These difficulties have induced so strong a reaction that we have only to read the recent text-books and articles published during the last ten years to recognize that pathologists in general, nowadays, refuse to consider embryogeny in their schemes of classification, and from Thoma, or even earlier, from Hamilton in 1889 onwards, through Ribbert and Lubarsch-the list is so long that I need not give it-the tendency has been to divide the autonomous neoplasms into those of typical and atypical connective tissue appearance, and those of typical and atypical glandular appearance. Some, like Hansemann, ${ }^{1}$ would go so far as to declare that tumours must be described purely according to their histological appearance, and while certain terms in general use must continue to be employed-terms such as adenoma, sarcoma, etc.-nevertheless, the only right classification at the present time must be by the organ, the tumours originating from one or other tissue being grouped together. So that, for example, we must group together the adenomata and carcinomata of the stomach. In short, they urge that the topographical classification is the only one possible at the present time.

There is undeniably a virtue in this position, provided that it is assumed in a proper spirit and regarded in the right light; not as a final stage, beyond which it is impossible to advance, but as a temporary stage of careful collection and collation of all the facts bearing upon the tumours proper to each individual organ, to the end that we may, from the knowledge so gained, proceed to further and sounder generalizations, that we may utilize the facts so amassed, to formulate broad statements concerning neoplasms, their relationship one to the other, and their mode of growth.

But against such a position this has to be said: All these years, whatever the scheme of classification popular at one time or another, pathologists have not been idle, so that we are already in possession of an enormous amount of material, and, what is more, of accurate drawings of the same. Hence, if preconceived notions as to embryological relationships modified the earlier conclusions reached concerning one or other form, the details have been honestly described, and the descriptions and the accompanying illustrations help us to determine where the

1 D. von Hansemann, Die mikroskopische Diagnose der bösartigen Geschwoulste, Berlin, 1897, p. 22. 
earlier conclusions need correction. Nay, more, we already possess exhaustive studies upon the various forms of tumours affecting one or other organ, the mammary gland, uterus, kidney, skin, etc. Taking everything into consideration, the time ought to be ripe for attempting more than this individualizing method. So, to repeat, I believe that we have by us embryological and anatomical observations which permit us to proceed further. What is more, I believe that, for a sound classification, we must inevitably pass backwards to the developmental relationship of the different tissues, that we must accept an embryogenetic basis, but one more in consonance with our present knowledge.

It is not necessary here to dwell upon the relationship of morbid to normal processes, and to show that the former in each case are but exaggerations in one or other direction of the latter ; nor need I point out the importance of a knowledge of the development of each tissue in arriving at a determination of the modifications which may be undergone by that tissue. In his Middleton-Goldsmith lecture in New York, Minot ${ }^{1}$ has, during the last year, treated this latter subject in so masterly a manner that anything I could say would be but a feeble reflection of his admirable presentation of the bearing of embryology upon pathology. What I wish now to point out more especially is that we pathologists-and we are not by any means the only ones to blame--have during these years continued to hold fixed and stereotyped views with regard to the exact nature and development of the different germinal layers, and it has been this misconception of these layers and the changes undergone by them, and of the mode in which the various tissues have been derived from them, that has brought us to this stage of discarding classifications constructed along embryological lines.

We have, that is, held as a body, that from a given layer, as, for example, the epiblast, only tissues and tumours of one general type are developed, and in practice we have found that this is not wholly the case. We have concluded that embryogenesis is a broken reed, and this despite our willingness to discover in it the basis for sound classification.

In order to indicate how a classification which is primarily embryological can be developed, it will be necessary for me to 481.

1 “On the Embryological Basis of Pathology," Science, U.S., xiii., 1901, 
indicate rapidly what are the leading facts with regard to the earlier stages in the development of the different types of tissue, and I must recapitulate matters of a most elementary nature; nevertheless, if by doing this I can make my argument clear, I trust that I shall be forgiven.

The earliest stage to be recognized in the development of the fertilized ovum, once it has proceeded to segment, is the production of a morula, in which the blastomeres form a cluster or group of cells of the same order, with almost entire lack of differentiation. Rapidly this gives place to a second stage, in which the component cells arrange themselves into two layers, the epiblast and the hypoblast, so that, at a singularly early stage, the future epiderm and endoderm are recognizable. The next stage to be noted is that the hypoblast, or internal of the two primitive layers, gives rise by proliferation of its cells to a group or mass of cells which now lie intermediate between the primitive epiblast and the hypoblast, and form the "Anlage" of the mesoblast and of the organs derived from that layer, the hypoblast itself still remaining as a distinct lining membrane. What I would here note is that we are perfectly willing to advance thus far and recognize these two primary and the third secondary cell layer. But there, in our appreciation of embryology as bearing upon pathology, we have been strangely apt to stop.

But now, just as the hypoblast gives origin to the mesoblast, so it is perfectly legitimate for us to recognize a similar process on the part of the epiblast; for the epiblastic cells in the immediate neighbourhood of the primitive groove proliferate rapidly, and, in so doing, project in part below the original line of the epiblast, and, being forced inwards, a regular mass of cells is developed, in the central portion of which, around the spinal canal, there still remains evidence of its origin, in the form of a definite epithelial lining. This second portion becomes cut off completely from the superficial epiblast to form the mother tissue of the nervous system. Similarly, the hypoblast gives off a second localized mass of cells to form the notochord.

Professor Minot has called my attention to the fact that, while possessing special features, the cells forming the notochord throughout retain epithelial characters, that they are grouped together without an intercellular matrix, that no vessels penetrate between them, and that, although in degeneration these cells 
assume a somewhat dubious appearance, they can most assuredly not be regarded (as I find, on reading von Hansemann and other recent writers, I had not been alone in regarding them) as assuming a connective tissue type. The nature of the cells forming the chordoma of Ribbert makes him more than doubtful as to the origin of this form of tumour from notochordal remains. I have thus, in deference to his authority, modified to some extent my original statements regarding this.

The point I wish here to indicate is that mesoblast, " neuroblast," and notochord are derived from the two primitive cell layers, and the first two at least lose the lining-membrane characteristics of these two earliest layers, and take on a less differentiated condition prior to further evolution. ${ }^{1}$ At a somewhat later period the mesoblast repeats the process of differentiation, and, from being a simple undifferentiated cell mass which we may compare with the morula, certain of its cells growing outwards between the epiblast and hypoblast become arranged into a definite layer, to form or enclose the primitive body cavity. ${ }^{2}$ From this point onwards we can distinguish two structures of mesoblastic originthe mesothelium, or lining membrane portion of the mesoblast; and the mesenchyme, or, as I may term it, the mesoblastic pulp.

It will be seen that I here make no note of the separation of mesoblastic elements into archiblast and parablast, as laid down by His, and made the basis for a classification by Klebs and Williams. His's conception of the parablast, as arising from the elements of the white yolk and from the "granulosa cells," is now known to be wrong, and indeed he has himself withdrawn his earlier hypothesis as to its origin. Add to this, that so hopeless a confusion has arisen among writers as to what is archiblastic and what parablastic, that we have no option but to discard these terms. As pointed out by Minot, the recognition of the separation of the mesoblast into mesothelial and mesenchymatous elements respectively, suffices for all practical purposes to indicate

1 [To-day, with all deference to the late Professor Minot's deep knowledge, I would support my original contention that the human notochord, and the chordomas originating therefrom, assume the connective tissue type of cell relationship.]

2 [Even if the body cavity or coelum had its primitive origin as a pouching of the hypoblast, or endoderm lining the enteron, there is, to my knowledge, no clear evidence that in the body cavity of higher animals this is formed other than by a splitting of the mesoblast with subsequent differentiation of the surface cell lining into a mesothelium.] 
that which is of real importance in His's observations, namely, the recognition of the ultimate evolution of the primitive mesoblast into two distinct series of cellular constituents.

For our purpose it is unnecessary to choose definitely between the two main contending views as to the origin of mesenchyme. Whether all the primitive mesoblast first passes into a mesothelial stage, from which by further proliferation the mesenchyme is derived; or whether, on the other hand, a portion of the mesoblast does not undergo conversion into mesothelium, but continues directly to develop into mesenchyme, is for us a relatively secondary matter. The important point is that we have to recognize that the primitive mesoblast is eventually separated into these two sets of cells, and of these the mesothelium is differentiated into a layer of the lining membrane type.

At a still later date masses of mesothelial cells again accumulate, and, as was the case with the epiblast and the hypoblast in the earlier stage, they give off on either side a mass of more undifferentiated cells, and these masses form the mother tissue or Anlage of the eventual striated muscle. Later, though still in this embryonic period, with the development of the first vessels, the mesenchyme gives off a series of cells of the lining membrane type, which form the eventual lining cells, or endothelium, of the vascular and lymphatic systems.

There is still some little uncertainty as to the exact relationship of the vascular endothelium, whether it be directly derived from mesothelium or from the mesenchyme. As Professor Minot has pointed out to me, His has of late indicated that it is of relatively very early development in certain forms. On the other hand, I learn from Professor MacBride that relatively high up among the forms of animal life it may be wanting, as, again, it may only show itself at a period definitely later than the development of the vascular channels. What I have stated above, thus, may be taken as representing, as accurately as is possible at the present time, the generally accepted relationships in time of endothelial to other embryonic developments.

Thus during early embryonic life we obtain a series of differentiations of the primitive cell layers leading to the production of two sets of tissues; one which we may term the lining membrane tissues, the other the pulp tissues. I do not wholly like the latter expression, but can think of none other which more 
nearly expresses the conception which I wish here to impress on the reader, namely, that in this very earliest stage the mother cells from which certain tissues are derived already have a definite order and position, as constituting membranes, whereas the mother cells of the other group of tissues lack this definite order and exhibit no marked differentiation.

If, now, we follow up these two orders of tissues to their full development, we find that from the lining membranes are developed tissues of one character; from the pulp, tissues of a different character. These lining membranes, from whatever layer they originate, may either remain as functional membranes covering an extensive surface, or they may become modified so as to form the various highly specialized and specific constituents of various organs. To reach this latter stage the epithelium either undergoes extensive infolding, or sends downward tubular processes, which branch to a greater or less extent, or, again, which sends downward solid processes, as occur, for example, in the development of the suprarenal. In quite a large number of instances it would seem that the first process in the production of the tubular glands is one of budding, or projection downwards into the underlying mesenchyme, of solid processes, which subsequently became hollowed out and tubular (e.g. sudoriferous glands and renal tubules). Thus it comes to pass that the various glandular organs are formed of a parenchyma originating from one of the primitive lining membranes and a stroma of connective tissue which is of mesenchymatous origin. And even in cases where there is the widest divergence from the original type of lining membrane, we find that this distinction still holds, that the parenchymatous cells form layers or groups into which the vessels do not penetrate, and in which there is an absence of stroma between the members of the cell groups, the cells being at most united by bridges and by a fine cement material. While, contrariwise, regarding tissues originating from the embryonic pulp, we notice that in them the prominent characteristic is that there is an intercellular ground substance, either homogeneous or fibrillated, separating the specific cells of the tissue.

Accepting this conception of the different characters of the different tissues, it will be seen that these may be divided into two great groups, which we may term, provisionally, the lining membrane group and the body pulp group. This division 


\section{PLATE V1}

\section{Schema of Tissue Relationships}

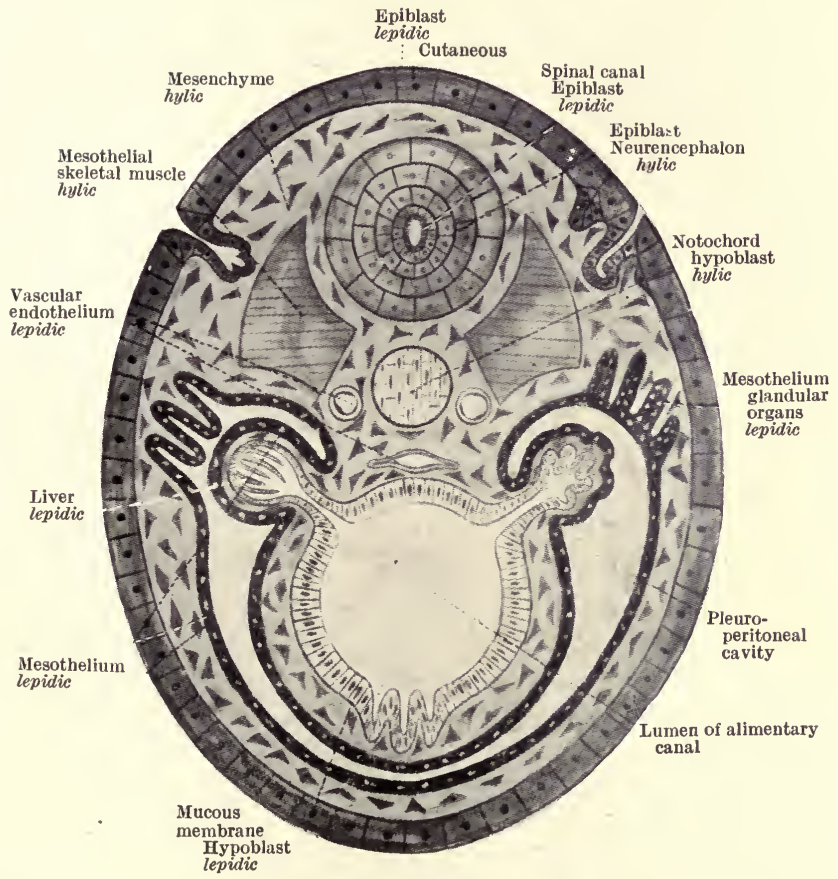



appears to me most important. While some pathologists, like Buxton $^{1}$ and 0 . Israel, ${ }^{2}$ have already noticed this distinction, I do not know that histologists and embryologists have called adequate attention to it. Though I am strongly against the coinage of new scientific terms, there are occasions when this is absolutely necessary, and this appears to be pre-eminently one of these occasions. Thus, I would term the lining membrane tissues lepidic, from $\lambda \epsilon \pi i$ s, $\lambda \in \pi i \delta o s$, a rind, skin, or membrane; and what I have termed the pulp tissue hylic, from $v^{\prime} \lambda \eta$, crude or undifferentiated material or matter. ${ }^{3}$ We can go further and subdivide each of these main groups according as to whether the tissues are of epiblastic, hypoblastic, mesothelial, mesenchymatous, or endothelial origin. On this basis we obtain the following classification of normal tissues :

\section{Lepidic or Linning Membrane Tissues}

in which the blood-vessels do not penetrate the groups of specific cells, and in which there is an absence of definite stroma between the individual cells, although such stroma, of mesenchymatous origin, may be present between the groups of cells.

1. Epiblastic.

Epidermis. Epidermal appendages-hairs, nails, enamel of teeth, etc. Epidermal glands. Epithelium of the mouth, salivary glands. Epithelium and glands of nasal tract and associated spaces. Epidermal portion of hypophysis cerebri. Lens of eye. Epithelium of membranous labyrinth of ear, anus, male urethra (except prostatic portion).

2. Hypoblastic.

Epithelium of digestive tract and glands connected with it. Specific cells of liver, pancreas, tonsils, thymus, thyroid. Epithelium of trachea, lungs, bladder, female urethra, male urethra (prostatic portion).

3. Mesothelial.

Lining cells of pleurae, pericardium, peritoneum. Specific cells of suprarenals, kidneys, testes, ovaries (Graafian follicles). Epithelium and glands of Fallopian tubes, uterus, vagina, vasa deferentia, vesiculae seminales, etc.

1 Buxton, Journ. Cutan. and Gen.-Urin. Dis. xviii., 1900, 74.

2 Israel, Berliner klin. Woch. xxxvii., 1900, 609, 644, 667.

3 I would here acknowledge my indebtedness to Principal [now Sir William] Peterson of McGill University for aid in the selections of these terms. 
4. Endothelial.

Lining endothelium of blood-vessels, lymphatics.

\section{Hylic or Primitive Pulp Tissues}

Organs and tissues in which the special characteristic is that the specific cells lie in, and are separated by, a definite stroma, homogeneous, or fibrillar, in which there may or may not be blood and lymph vessels.

1. Epiblastic.

Nerve cells, neuroglia.

2. Hypoblastic.

(Notochord. See note, p. 310.)

3. Mesenchymatous.

Fibrous connective tissues, cartilage, bone, reticulum of lymph glands, bone marrow, fat cells, involuntary muscle tissue, spleen, blood-vessels, blood corpuscles.

4. Mesothelial.

Striated muscle, including cardiac muscle.

With this conception of the two great groups of tissues, we can now proceed to classify the tumours, by which term I refer here to what Thoma has called "autonomous neoplasms." Of these there are two great orders, the Teratomata and the Blastomata. The former I have elsewhere defined as "tumours composed of the products of growth of one individual within the tissues of another individual of the same species," the latter as "tumours composed of the products of aberrant growth of cells and tissues of the individual in whom they are developed." 1 It is not necessary here to discuss the correctness of these definitions, for, however defined, I wish here to leave the Teratomata very largely out of consideration; they form a class by themselves, and whether we accept or do not accept the definition above given, we find that their mode of development and their characteristics follow-with complications-the lines about to be laid down with regard to the Blastomata. These latter form the more important class, and it is with them that I wish specially to deal.

Following this scheme of the classification of the normal tissues, we may now divide these into two main genera-the

${ }^{1}$ British Med. Journ., London, 1901, i. 621. See pp. 285, 286 of this volume. 
Lepidomata, originating from the above lining membrane tissues, and the Hylomata, originating and derived from tissues developed from the embryonic pulp.

1. Epilepidomata.

\section{Lepidomata or " Rind" Tumours}

\section{A. Primary Lepidomata}

Tumours whose characteristic constituents are overgrowths of tissues, derived directly from the epiblastic lining membranes, or true epiblast.

(a) Typical.-Papilloma, epidermal adenomata (of sweat, salivary, sebaceous, and mammary glands, etc.).

(b) Atypical.-Epithelioma proper (of skin), carcinoma of

2. Hypolepidomata. glands of epiblastic origin.

(a) Typical.-Adenoma and papilloma of digestive and respiratory tracts, thyroid, pancreas, liver, bladder, etc.

(b) Atypical.-Carcinoma developing in the same organs and regions.

\section{B. Secondary Lepidomata}

3. Mesolepidomata.

Tumours whose characteristic constituents are cells derived in direct descent from the persistent mesothelium of the embryo.

(a) Typical.-Adenoma of kidney, testicle, ovary, urogenital ducts; adenoma of uterus and prostate; adenomas originating from the serous membranes, "mesothelioma" of pleurae, peritoneum, etc.

(b) Atypical.-Cancer of the above-mentioned organs; squamous endothelioma, so called, of serous surfaces, epithelioma of vagina.

4. Endothelial Lepidomata.

Tumours originating from the endothelium of the blood and lymph vessels; endothelioma, perithelioma.

\section{Hylomata or "Pulp" Tumours}

1. Epihylomata.

Tumours whose characteristic constituents are overgrowths of tissues derived from the embryonic pulp of epiblastic origin.

(a) Typical.-True neuroma, glioma.

(b) Atypical.- "Gliosarcoma." 
2. Hypohylomata.

Tumours derived similarly from embryonic pulp of hypoblastic origin.

(?) Chordoma.

3. Mesohylomata.

A. Mesenchymal Hylomata.-Derived from tissues originating from the persistent mesoblastic pulp or mesenchyme.

(a) Typical.-Fibroma, lipoma, chondroma, osteoma, myxoma, leiomyoma.

(b) Atypical.-Sarcoma (derived from mesenchymatous tissues), with its various subdivisions, fibrosarcoma, spindle-cell sarcoma, oat-shape cell sarcoma, chondro-sarcoma, osteo-sarcoma, myxo-sarcoma, melanotic sarcoma, etc.

B. Mesothelial Hylomata.-Tumours which are overgrowths similarly of tissues derived from embryonic pulp of definitely mesothelial origin.

Rhabdomyoma.

It will be seen that in this classification I do not include the deciduoma malignum. As I have pointed out elsewhere, ${ }^{1}$ accepting the view that the syncytium is of foetal origin and not maternal, these tumours have to be classed with the Teratomata, i.e. with the tumours originating in the growth of the cells of a second individual within the tissues of an individual of the same species.

If this classification be studied, it will be seen that we have done away with that deficiency in the earlier embryological classifications whereby tumours of unlike orders and histological appearances were grouped together and those of like characters separated. Gliomata, for example, come to be placed close to the mesenchymatous tissues; the gland-like tumours of mesoblastic origin become grouped along with those of epiblastic and hypoblastic origin.

Have we, in accomplishing this, introduced any new difficulties? One objection will undoubtedly present itself, namely, that among the Mesolepidomata we have grouped together tumours some of which are of a strongly epithelial or glandular type, for example, the cancers of the uterus, with others like the endotheliomata, which tend to be distinctly of a sarcomatous type. But further consideration will show that this, instead of

${ }^{1}$ Loc. cit. See pp. 286 and 326 of this volume. 


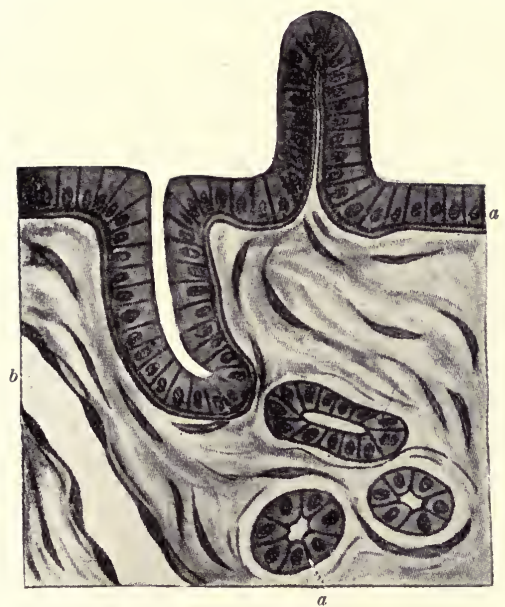

FIG. 1.-Diagrammatic representation of a lepidic tissue, $a$, with its underlying hylic connective tissıe; $b$, Capillary lined by lepidic endothelium.

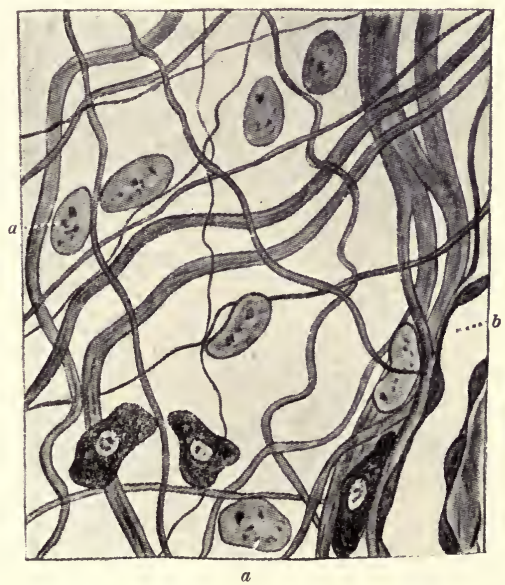

FIG. 2.-Diagrammatic representation of a hylic tissue, with intercellular ground substance of fibrillae in a homogeneous matrix separating the specific cells.

$a$, Nuclei of specific tissue cells. $b, \mathbf{A}$ capillary lined by lepidic endothelinm. 

being a weakness, is a strong point in this classification. We have, that is, to recognize that among these Mesolepidomata, as above defined, we meet with several forms of tumours of transitional type, tumours which in their least aberrant portions show characters which approximate them to the Carcinomata, and in their more aberrant portions are indistinguishable from Sarcomata. And, indeed, it is only by a study of the embryogeny of the tissues from which these tumours are derived that we gain any satisfactory comprehension of the why and wherefore of these peculiar characters.

Here let me point out that, employing the terms here introduced, based as they are upon the embryogeny of the different tissues and the tumours derived from them, we may allow the terms " carcinoma" and "sarcoma" to revert to their earlier and purely histological significance. And I would emphasize that it must not be understood that these terms, carcinoma and sarcoma, are to be regarded, and are by me regarded, as being synonymous with " atypical lepidoma " and "atypical hyloma" respectively. Rather, I would lay down that, accepting this nomenclature, we may safely speak of any tumour of the aberrant glandular type as carcinoma, whether it be of epiblastic or mesothelial origin, and any tumour of aberrant and so-called embryonic connective tissue type as sarcoma, whether derived from the mesenchyme, the epiblast (e.g. gliosarcoma), or even from the endothelium or mesothelium.

Of late years there has been an ineffectual attempt to restrict these two terms. Thus, many authorities have refused to speak of malignant adenomata of the kidney and suprarenal as being true carcinomata, and others have strenuously opposed the employment of the term gliosarcoma. Nevertheless, the same authorities, while refusing to speak of a cancer or carcinoma of the kidney, freely refer to carcinoma of the uterus, although, like the renal tubules and the suprarenal, the uterine mucosa is of mesothelial origin. In short, it has been proved impossible to employ these terms with embryogenetic limitations, and this introduction of a nomenclature which is based upon embryogeny ought, if accepted, to permit us to use them, as they ought to be used, in the purely histological sense.

It will be seen that I in no sense urge that (were it possible !) the use of these terms (sarcoma and carcinoma) be done away 
with, for, accepting the purely histological use of the terms, we can unreservedly agree with Israel that it is a matter of taste whether we speak of a given tumour as an "endothelioma carcinomatosum or sarcoma endotheliale." For routine clinical purposes they are most valuable. When a tumour has assumed a carcinomatous or a sarcomatous appearance it is coincidently locally malignant, if not in all cases generally malignant also. The terms, therefore, have a clinical significance and value. Only, let me repeat, they are valueless for purposes of relationship and classification, and must bear no embryogenetic signification.

To explain these peculiarities of lepidomatous tumours let me point out that-

1. After the embryonic period, it would seem that hylic tissues never take on lepidic characters. We have no instances, that is, in which, after embryonic life, we recognize that lining membranes or glands become differentiated from connective tissues.

2. It is generally held that the converse is also true. ${ }^{1}$ With regard to tumours we find the same principle evidently in operation.

3. We may confidently lay down that all tumours and portions of tumours containing cell layers or cell groups of the lepidic type have been derived from pre-existing lepidic tissue. Possibly this so-called principle is more of the nature of a postulate than of a proved law; we take it for granted, and may not be able to prove our position in every case. We have, that is, fairly numerous examples of neoplasms of lepidic type developing in situations in which normal lepidic tissue is not present-adenomatoid tumours of the bone, gland-like follicles in the midst of uterine fibroids, cysts, or tubular spaces lined by cubical or columnar epithelium in gliomata-and the list might be lengthened.

1 True, that is, until Beard's rather startling observations upon the origin of leueocytes is confirmed. According to this observer the first, and indeed the main, development of leucocytes is to be found as a process of proliferation and metamorphosis of the hypoblastic epithelium of the follicles of the foetal thymus gland. Beard's observations were published eighteen months ago, but to the best of my knowledge they still lack confirmation. Leo Loeb also (Arch. $f$. Entwicklungsmech. d. Organ., Leipzig, vi., 1898, and Medicine, April 1899) has thought to see connective tissue eells undergoing origin from the Malpighian layer of the skin: his observations have not gained acceptance. In lower forms of life, however, some definite cases of regeneration of hylic from lepidic tissues have of late been brought forward. 
In by far the larger number of cases of this order, either the structure of the tumour so conforms to known neoplasms, the origin of which has been traced positively to some glandular organ, that we are convinced that the growth has originated from the inclusion of a portion of such glandular tissue, or we recognize that the growth occurs in some region, in which, during foetal life, there has existed some duct or portion of lepidic tissue, in a region, likewise, in which in the adult we occasionally encounter the persistent remains of the same. But pathologists, I believe without exception, agree to the sense of this postulate ; we may not know, in all instances, what is the original tissue from which a heterotopic glandular tumour has had its origin, but we are absolutely sure that that original tissue giving rise to a glandular tumour has not been of the connective tissue type. We may, therefore, I think, lay this down with confidence, that tumours in which the cell arrangement is of the lepidic type, presenting columns or groups of cells, devoid of any stroma between the members of these columns or groups, have been developed from one or other lepidic tissue, and not from one of the hylic or pulp tissues.

4. We cannot, with equal confidence, make the converse statement, that tumours of the hylic type have always originated from hylic tissues and not from lepidic.

$4 a$. I believe that I am right in stating that lepidic tumours of epiblastic and hypoblastic origin, however rapidly they grow, however extensive and distant be their metastases, always, even in their most aberrant portions, retain lepidic properties. Wherever two or three of the specific cells of such a tumour are gathered together, they form alveoli with no stroma and no interstitial capillaries. To the best of my knowledge, no case is on record in which it has been satisfactorily proved that peripheral or metastatic growths of a typical carcinoma of epiblastic or hypoblastic origin have assumed definitely sarcomatous characters.

Possibly the careful studies now being made in connexion with the melanotic tumours originating in connexion with the skin may prove that this statement will need eventual revision. Authorities are still so much divided as to the exact origin of sundry tumours of sarcomatous type belonging to this group, that it is not possible to make an absolute statement concerning their origin. If, however, it can be proved that under certain 
conditions tumours originating from the Malpighian layer of the skin can in their growth lose their lepidic characters, i.e. can become possessed of a definite stroma passing between the individual cells, then we shall have to acknowledge that epiblastic lepidomata can, in the course of their growth, revert to a more undifferentiated sarcomatous type.

In one very interesting tumour of the prostate, examined by me some years ago, I was for a time of opinion that I could recognize such a transition. Sections taken from the prostate itself showed beautifully the existence of a very typical carcinoma almost scirrhous in appearance; passing towards the bladder the type became that of carcinoma simplex. The abundant, apparently rapid, growth, forming a projection into the bladder itself, was so wholly cellular as to resemble a round-cell sarcoma, but more careful examination showed that even here the cells were arranged in alveoli, although the stroma between the individual groups was so delicate as to be traced with considerable difficulty.

4b. With mesothelial and endothelial lepidomata the same is not always so ; the older or earlier portions of the tumour may show distinct adenomatoid or carcinomatoid charactersoccasionally the whole tumour is typically adenomatous; but more rapidly growing portions are peculiarly liable to depart so far from type, so peculiarly liable to take on the appearance of embryonic connective tissue, that it becomes impossible, basing our terminology upon histological appearances, to say whether we are dealing with a carcinoma, or a sarcoma, or a mixed growth - a carcinoma sarcomatodes, or a sarcoma carcinomatodes. More particularly the increased recognition of the frequency of endotheliomata and peritheliomata has forced us to see the difficulties in our present mode of classification. The perithelioma when developing characteristically, apparently as an endothelioma of the perivascular lymphatics, may strongly resemble an adenoma in the regular columnar arrangement of its cells, and yet other parts of the same tumour may be absolutely sarcomatous in type. And while the ordinary endothelioma, such as one so commonly meets with forming tumours in connexion with the membranes of the brain, is in general characteristically sarcomatous in structure, areas are to be detected here and there indicating its origin as a squamous proliferation 
of the lymphatic or blood-vascular endothelium. Without, I trust, taking anything from the interest and value of his forthcoming article upon this subject, I would here note that Dr. P. G. Woolley, Fellow in Pathology at McGill University, has just completed a most elaborate and minute study of a tumour, originating in the zona fascicularis of the suprarenal, in which a similar transition from adenomatoid to purely sarcomatous structure is to be followed without the possibility of doubt.1

Here, then, are tumours which, showing in the least aberrant regions indications of origin from a lining membrane or lepidic tissue, are apt to take on the appearance and structures more characteristic of "pulp" tumours.

Now this difference in behaviour between the Epilepidomata and Hypolepidomata on the one hand, and sundry of the Mesotheliomata and Endotheliomata (Mesolepidomata) on the other, is but consonant with embryological observations and the broadest biological principles. One great principle which we see constantly in evidence is that those structures and properties which are of oldest acquirement are those which are last to be lost; it is the most recent acquirement which tends to be the earliest to disappear. We see this exemplified continually in connexion with blastomas in general. The more rapid the growth-the more the cells of a tumour depart from their normal mature environment - the more do we observe that those features of the tumour cells which are specific for one or other tissue tend to disappear. In the most rapidly growing and most aberrant tumours the individual cells afford us little or no clue to the tissue of origin. It is the general arrangement of the cells that aids us in making our diagnosis, and even the general arrangement is not so much that peculiar to the fully grown tissue as that common to connective tissues in general, or to glandular or lepidic tissues in general. We recognize a reversion to an earlier, simpler, or, as we express it, embryonic type. As I have pointed out elsewhere, a distinction must be recognized between functional and proliferative activity with loss of those features which are directly associated with the performance of function.

I would now suggest that we carry the working of this principle a little farther back. The first lining membranes to be differ-

1 [Trans. Assoc. Amer. Phys. xvii., 1902, 627, and Virch. Arch. 172, $1903,301$. 
entiated are the epiblast and hypoblast: their differentiation, indeed, is one of the earliest events in developmental history; and this being the case we should expect-and we find-that tissues, whether normal or neoplastic, derived in direct line from these two layers, are singularly tenacious of their properties as lining membranes, and so it is that Epilepidomata and Hypolepidomata always show evidences of their lepidic nature. We should not expect-and we do not find-that where this direct line has been departed from, where, for example, hypoblast has given off masses of cells to form mesoblast, and the epiblast similar masses to form the neuroblast, that, in reversion, tissues derived from mesoblast and neuroblast respectively should again enter upon the lining membrane stage. Where in the process of development an organ or part is formed by the cells of tissue of a higher order assuming a less differentiated condition, and from this lower state proceeding to develop along special lines, we do not find that in reversion and degeneration that tissue passes beyond the less differentiated stage, and then proceeds to show characters of a primary more differentiated condition. Thus it is that the mesenchymatous tumours and sarcomata in general show no tendency to assume lining membrane or lepidic characters, even though, without exception, all these tissues have primarily arisen as derivatives from either epiblastic or hypoblastic lining membrane.

If occasionally in gliomata we find cysts lined with columnar epithelium, this is not an example of such reversion to the more primitive epiblastic characters of the glial tissue. Those who have studied cases of this order have, without exception, ascribed such conditions to inclusions of rests of embryonic tissue containing portions of the Anlage of the central nervous canal. ${ }^{1}$

But now, coming to the mesoblast, we know that it is at a later date in the history of the embryo that this becomes differentiated into mesothelium and mesenchyme, and the development of the mesothelium is in the direction of increased specialization. Thus we should expect-and we find-that in processes of a reversionary type these more lately acquired characters are more capable of being lost, so that growths formed

1 [I have since pointed out (Principles of Pathology, vol. i. Ist edit. p. 564) that in gliomas areas of necrosis with autolysis of the dead tissue come to form cysts lined by a false epithelium. The lining cells become modified as a function of their position, but present no basement membrane.] 
from organs of mesothelial origin are more liable to pass back, and to assume characters approaching those of the primitive mesenchyme and mesoblast, than are growths from hypoblastic and epiblastic organs to revert to what we might term the morula stage. And if it be correct to regard the endothelium as a still later development from the mesenchyme, then we can understand how it is that Endotheliomata are peculiarly liable to take on the characters of the primitive pulp tissue from which endothelium became differentiated.

Israel ${ }^{1}$ recognizes fully this same dependence of the characters of the endotheliomata upon the embryogeny of the mother tissues, for he remarks (the italics are mine): "Diese (endotheliale) Deckzellen haben sich nicht unter allen Umstanden in ihren Eigenschaften von diejenigen ihrer Intercellularmasse bildenden Stammesgenossen so weit entfernt, dass nicht auch sie gelegentlich wieder befähigt wurden, Intercellularmasse hervorzubringen, deren Qualität von den ererbten Eigenthumlichkeiten abhängig ist. . . . Gelegenliche Vorkommnisse in den Endothelgeschwülsten und auch bei gewissen entzündlichen Neubildungen zeigen, dass die Fähigkeit Intercellularsubstanzen zu produciren, manchen in Tumoren gewachsenen Endotheldescendenten, nicht unwiederbringlich verloren gegangen ist, wie den Epithelien. Das ist aber auch der für die Diagnose praktische bedeutsamste Unterschied endothelialer Krebse gegenüber den epithelialen, und er macht von allen die Übergangsformen vom Endotheliom zum Sarkom verständlich."

I am far from saying that this is the one and sufficing cause why certain orders of the Mesolepidomata have this marked tendency to assume more sarcomatous characters. I do not think that this is everything; nevertheless it does, I think, materially aid us to understand why this peculiarity in the progressive development of these tumours manifests itself ; it is one factor. Indeed, it is not all the Mesolepidomata which present these same tendencies. To give one example: we never, to my knowledge, find that carcinomata of the uterus, either in their more rapidly growing parts or in their metastases, show other than well-developed cancerous structure. In fact, there is singularly little distinction to be drawn between the characters of cancers originating from the uterine mucosa and

1 Israel, 0., loc. cit. p. 668. 
those of epiblastic and hypoblastic origin. The same is true with regard to the tumours of the Fallopian tube. And, so far as I see, we have to lay down also that the high grade of specialization and differentiation of the lining cells of a membrane is accompanied, pari passu, by a lack of capacity to undergo reversion to the simplest type. While, for example, the glial cells are apt to undergo rapid proliferation and form tumours of a simple cellular type, true Neuromata are extraordinarily rare, and in general we may lay down that the high degree of differentiation which has been reached by the neurone has taken from it, to a very large extent, the power of proliferation. This is, it is true, an extreme example. The cells of the uterine mucosa are not nearly so highly differentiated ; they are, however, distinctly more specialized than are endothelia and the cells lining the serous cavities. And, I would add, more differentiated than, for example, the cells of the cortex of the suprarenal, which but attain an arrangement in solid columns resembling that seen during the process of development of certain other glandular organs.

Thus it may be that simplicity of type is one factor determining why certain tumours revert from a more carcinomatous to a more sarcomatous type. I mention this as a possible factor, and would not dwell too strongly upon it; rather I would admit, and that willingly, that here we are in the region of analogy and hypothesis. Just as we are unable to explain why in one case, in a given organ, we have produced, for example, a relatively benign adenoma, in another, in that same organ, an actively growing and malignant carcinoma; so it may be that full consideration will show that here also we have to recognize, without possibility of explanation, that, in connexion with tumours of one organ, the lepidic properties are retained with remarkable persistence, while in tumours of another organ, derived from the same cell layer, these same properties are lost with comparative ease. But it seems to me not without its use to point out tentatively a possible factor in the development of the different properties of different tumours. As a group it has to be admitted that mesothelial and endothelial tumours exhibit this tendency to assume a more sarcomatous appearance.

We are thus justified in separating Lepidomata into two main divisions-the primary lepidomata, wherein we include 
the tumours derived from tissues of direct descent from the epiblast and hypoblast, and the secondary or transitional lepidomata, which include tissues of indirect descent from the same, and which may as a consequence show what I may term transitional characters. Making this division, I leave it open as to whether we speak of the tumours of the first order only as the true carcinomata, and refer to those of the second order as at most carcinomatoid, or speak of all tumours of what I may now without confusion refer to as having lepidic characters, as being carcinomata. My preference, as I have already stated, is for employing this term purely in a histological sense.

Recognizing that many years have passed since I was engaged in the active study of embryology, I have not ventured to publish this paper without consulting those most capable of pronouncing authoritatively upon the embryological problems here involved; and I would here express my sincere thanks and sense of deep obligation to Professor Charles Sedgwick Minot of Harvard, and Professor Carl Huber of Ann Arbor, for their most kind criticism and suggestions in connexion with the views here elaborated. I very gladly acknowledge also that I owe more particularly to a correspondence with Professor Huber, now some months ago, my recognition of the importance, from a pathological point of view, of distinguishing between the mesothelial and mesenchymatous derivatives of the mesoblast. 


\section{CHAPTER IV}

\section{SYNCYTIOMA MALIGNUM : ITS BEARING UPON THE ESSENTIAL NATURE OF MALIGNANCY ${ }^{1}$}

ASKED most courteously to contribute from a distance something to the debate upon the nature of cancer, and recognizing the difficulties under which both my audience and myself must labour when I accept, it has seemed to me better not to attempt an academic essay covering the whole territory of the possible or presumed relationship of parasites to malignant growths, but to consider more in detail one small portion of the vast field before us, in the hope that this will not already have been traversed by other participators in the debate: in the hope, further, that the deductions which may logically be drawn from the study of a single form of tumour may throw light upon the essential nature of tumours in general. And in advance let me say that I am well acquainted with the ancient Greek parable of a certain man who, having a house to sell, circumambulated the city bearing in his hand a brick as sample. I trust that when my few words have been delivered the brick will not be thrown in my face.

Until recently we have been in the dark as to the relationship between the embryo and the maternal tissues in the womb; now certain important points are well established. The observations of H. Peters, of Vienna, upon the earliest human ovum which has thus far been discovered in utero-an ovum of about the end of the first week-have proved in a manner admitting of no dispute (when compared with what we know concerning mammalian ova in general) that even at this early date the cells

1 A contribution to a discussion, held by the Chelsea Clinical Society, upon Cancer. Reprinted from the Clinical Journal, June 18, 1902. 
of the ovum have a marked influence upon the uterine mucosa at the spot where the ovum becomes arrested. The epithelial cells of that mucosa are so acted upon that they become dissolved and disappear, and the ovum from being on the surface sinks down into a depression, becomes imbedded in the uterine wall, so that now it lies in close apposition to the capillaries underlying the epithelium. These observations have been largely confirmed by my late colleague, Dr. J. C. Webster, now of the University of Chicago.

This is but the first step in the formation of the placenta. The outer layer or layers of the epiblast of the rapidly growing embryo, termed by Hubrecht the Trophoblast, continues this process of erosion and infiltration in a most remarkable way. This trophoblast literally eats into the maternal tissue opposed to it, forming at first solid cellular processes, purely epiblastic ; later, as the chorionic mesoblast and the allantois with its vessels become developed, these processes gain a mesoblastic and vascular core; so are evolved the characteristic chorionic villi. Both the more primitive solid processes and the villi, through this phagocytic, or more truly extra-cellular-digestive, action of the trophoblast, make their way into the maternal uterine veins and venous sinuses, whereby the cells of the embryo come to lie within the maternal blood-spaces and gain their nourishment, and nourishment for the embryo in general, directly from the maternal blood.

There was for some years violent debate, more especially in Germany, as to the nature of the trophoblast, whether it was of foetal or maternal origin. This culminated in an important debate between anatomists, zoologists, gynaecologists, and obstetricians at the 1897 meeting of the German Naturforscherversammlung. The most that the most violent opponents of the foetal view can now bring forward is that not all the cells considered by some as trophoblastic, or syncytial, are of foetal origin. Some, they say, are maternal. Nay, more, in the course of a most painstaking and minute study of the development of the rabbit's placenta, my colleague, Dr. Chipman, ${ }^{1}$ has shown in a conclusive manner that these trophoblastic or syncytial

1 Through the liberality of the Governors of the hospital, Dr. Chipman's Edinburgh thesis, with its abundant photographio illustrations of this and kindred points, [was] published in the series of Studies from the Royal Victoria Hospital. Montreal [No. 2, 1902]. 
cells, when they gain entrance into the maternal blood sinuses, passing along the walls, digest and replace the endothelium of those sinuses, so that eventually there is developed a most complicated system of passages lined by cells of foetal origin and containing maternal blood; or almost, in the words of Matthias Duval, the placenta is to be regarded as "a maternal haemorrhage encysted by foetal tissue." By this remarkable "adaptation" the foetus gains nourishment from the maternal blood.

I have described this at some little detail because I wish to impress upon you that here, as a normal or physiological condition, we have passing those identical processes of invasion and infiltration which we have been accustomed to regard as peculiar to, nay, as the essential feature of malignant growth. The only difference between what is here seen and malignancy is one of degree, or perhaps, more correctly, of orderliness. This infiltration is due to the inherent properties of the syncytial cells. Nor would this appear to be by any means the only case of antagonistic "phagocytic" cellular activity. Metchnikoff has of late been engaged in collecting evidence to prove that such activity is fairly general within the organism, and is the basis of senile changes.

Under ordinary conditions this syncytial invasion is strictly limited; it only affects a definite area of the uterine wall, and with parturition and the separation of the placenta the whole area of invasion is separated off and discharged. In other words, to explain these normal phenomena (if the phrase be permissible), we have to recognize the existence and interaction of two forces - on the part of the foetal cells of invasive properties, on the part of the maternal tissues of protective properties.

Having laid this down, I may now approach my main point. Occasionally-and apparently not so very occasionally, for Marchand collected from the literature some sixty-five cases recorded between the beginning of 1895 and the middle of 1898these syncytial cells, after normal labour, are found to take on aberrant growth, to trespass beyond the placental site, to infiltrate extensively the uterine walls, the vaginal tissues, the pelvic tissues in general, and, what is more, to form secondary growths in distant organs, the lungs, the spleen, the brain, and so on. These syncytial cells are large and characteristic; there is nothing quite like them. We have, that is to say, as nearly 
perfect histological evidence as it is possible to possess that at least one group of primary malignant tumours of the uterus-a group, I may add, presenting "exquisite" or "eminent" malignant properties-consists of the aberrant growth of foetal cells within the maternal organism.

This vic of the foetal nature of the cells of the deciduoma malignum was, I need scarce say, violently opposed for many years by an important section of pathologists; but now Marchand, whose opinion cannot be passed over, has been forced to accept the view : in short, no other view is possible at the present time. The typical deciduoma is a syncytioma or chorioepithelioma malignum. I greatly doubt whether any committee of the London Obstetrical Society could be found in these latter days to report, as one reported only five years ago, that a group of specimens of this form of tumour was of connective tissue origin, and so sarcomatous.

Can we explain this most remarkable form of neoplasm by any parasitic theory? To do this it is obvious that we must start from the assumption that micro-parasites, in some way or other, exalt the already existing invasive properties of the syncytial cells, so that now they invade and infiltrate to an excessive extent. That must be the starting-point.

For myself I am perfectly prepared to accept this much, namely, that parasites and their products are capable of stimulating cell growth. I see that in his recent Milroy Lectures Mr. C. Powell White discovers a poorly defended spot in my argument published last year, ${ }^{1}$ in that there I make this same admission, while simultaneously I lay down that the vegetative and proliferative activities of the cell are inherent, the functional activities set up by stimulation from without. Upon first consideration the objection àppears valid. Further consideration, I think, shows that it does not hold. We can imagine stimuli leading to building-up-anabolic-processes in the cell, processes which, under ordinary conditions, are preparatory to functional and katabolic processes, which, in the absence of circumstances favouring katabolism, favour cell proliferation. Now, in connexion with this very form of tumour we are considering, it is not a little interesting to note that the growth does not occur in the placenta during the period of pregnancy, during the period, 
that is, when the syncytial cells are actively performing their functions of absorption and excretion, but afterwards, when these same cells, not having been shed, are left in the condition of gaining nourishment-of being stimulated from without alsoand of having no opportunity to perform their normal functions. Under such conditions microbic products might favour overgrowth. It will be seen that the two statements are not contradictory.

But is it necessary to call in micro-parasites to explain the aberrant growth? There, I confess, looking at the matter in the abstract, I feel more than doubtful. For, in the first place, it will be seen that this assumption-and remember that it is still only an assumption, and that, consequently, one is permitted to discuss it in the abstract-this assumption demands that microbes of one or other order have the peculiar power of so acting upon the cells of one organism-the embryo or foetusthat they invade the tissues of another organism-the mother. Our knowledge of the phenomena of transplantation and implantation shows that it is not necessary to call in such external agencies. That micro-parasites should have this power is, to say the least, unexpected. At most we must admit that it is remotely possible.

In the second place, one of the favourite arguments of those who hold parasitic theories is the similarity or analogy between the local growth and metastases of malignant neoplasms, and, in the case of bacterial infection, the primary focus of infection, its local extension and metastatic, granulomatous, or abscess developments. Undoubtedly the parallelism is close, so close that we may admit parasitism as the active agent in both conditions. Indeed, these syncytiomas demonstrate most convincingly why this is so. Bacteria are, we know, the causative parasites in the one: what these syncytiomas show, and show without possibility of denial, is that the trophoblastic cells-the tumour cells-are the parasites in the other. They are cells of foreign origin; it is they that invade, they that gain entrance into the blood-stream, that get carried to remoter parts of the organism, and there set up degenerative and reactive processes, and so bring about a condition of affairs resembling what is seen when bacteria are the invading agents. The tumour cells are the parasites; and if we admit this-and we must admit it-then the analogy becomes absolutely valueless as an argument in favour 
of the micro-parasitic origin of malignant neoplasms. To urge that in order to induce the aberrant growth there must be parasites within the parasites, is to pile Ossa on Pelion-it is supererogatory. ${ }^{1}$

Nevertheless, these considerations, while demolishing the argument based upon analogy, do not wholly do away with the possibility that micro-parasites play some part in the production of these and other malignant growths. There is yet another method of approaching the subject.

As I have already laid down in discussing the normal growth of the syncytium, we have to see that there are two factors constantly opposing each other - the invasive powers of the syncytial cells and the self-protective powers of the maternal tissues. This is true, also, of the abnormal growth of the same. It is possible, therefore, that the aberrant growth of the syncytioma may depend not so much upon an exaltation of the invasive powers of the component cells as upon a lowering of the selfprotective powers of the surrounding maternal tissues. Indeed, the observations of Beatson and others, even if therapeutically they have not been crowned with complete success, can only be regarded as demonstrating that this second factor has to be taken into account. Alteration of general metabolism following upon removal of the ovaries does at times arrest malignant tumour growth elsewhere. At the present time I feel even more strongly than I expressed myself a year ago that it is along the lines of research into the exaltation of the protective mechanism of the organism, and into the diminution of the proliferative powers of the tumour cells, that our energies should now be directed, and coincidently I note that the last twelve months have not yielded any more promise than showed itself then of distinct help to be gained from this weary and unsatisfied hunt after specific cancer parasites.

I do not take the stand of denying the existence of such. In this special connexion we can observe a parallelism between the virulence of the microbe in bacterial disease and the protective powers of the organism on the one hand, the invasive powers of the cancer cells and the protective powers of the organism on

1 It is worthy of note, further, that in the known cases where we have intracellular parasitism-e.g. coccidiosis-we have no sign of the cells themselves taking on these parasitic functions. 
the other. But have we any sound grounds for assuming that the presumed cancer parasite acts by stimulating and augmenting the invasive powers of the cells, or by doing the reverse, namely, by lowering the vitality of the tissue about to be infiltrated ?

Looked at thus closely, it will be seen that this conception of parasite acting within parasite leads to marvellous complications. I may be wrong, but I think that I have noted time and again that when we determine fundamental laws and fundamental phenomena they are wonderful in their simplicity, so that now when $I$ find that a conception followed up leads us deeper and deeper into the mire, I shrewdly suspect that the conception is wrong. So it is with the parasitic theory of malignancy as now held by so many. It may be right, some one may discover the germ or germs, but neither on theoretical grounds nor on the results of practical observations can I base myself with any satisfaction. Certainly Gaylord's results upon this side of the Atlantic do not carry conviction, and neither he nor Plimmer, so it seems to me, have proved that their bodies are any other than degenerative products, the abundant presence of numerous forms of which in tumours was first demonstrated by Fabre-Domergue, and later and most fully by Pianese. ${ }^{1}$

My inclinations at present, it will thus be seen, in the absence of more definite discoveries, lead me to doubt very gravely the permanent presence of micro-parasites in malignant growths; nor do I think that a study of the deciduoma malignum can lead to any other than a firm belief that alterations in cell properties and assumption of the parasitic habit by cells, I will not say, is at the bottom of malignancy-for we have still to determine what initiates the alteration in property-but must be recognized and must be taken as the basis for future advance.

Thus, to sum up what, I think, may be legitimately deduced from a study of the syncytioma malignum :

1. There exists one form of tumour of highly malignant type in which the infiltrating cells are not those of the organism itself, but are derived from another organism.

2. The infiltrative and invasive properties of these cells are not a new acquirement, but are an exaltation of properties normally possessed by them; or, more exactly, under normal

1 Such bodies, described as Blastomycetes, have, I should add, been figured by Rossi-Doria as found by him in two cases of deciduoma malignum. 
conditions we observe that there is an interaction of two forces: the invasive properties of these cells, the protective properties of the surrounding maternal tissues, by which interaction the extent of invasion of the cells is strictly limited to the placental site.

3 . The development of the syncytioma malignum must therefore be attributed to either an increase in the invasive properties of the syncytial cells, or a lessened resistance on the part of the maternal tissues, or a combination of the two.

4. If micro-parasites play any part in the production of the tumour, that must be either by exalting the infiltrative powers of the one or by lowering the resistant powers of the other.

5. Proof positive of the existence of such specific micro-parasites is still wanting, and in its absence it is difficult to conceive how specific micro-parasites should bring about these results.

6. Admitting that micro-parasites and their products are capable of inducing cell proliferation, we must also admit that other external agencies have the same capacity, so that micro-parasites, at most, may be one of the causes of aberrant cell growth.

7. The prevalent conception of cancer parasites, as existing within the cancer cells, involves the idea of malignant growths being the product of parasites acting within parasites; for, as shown by this study of the syncytioma, the tumour cells themselves are essentially parasitic in the organism.

In short, tracing the present popular idea to its legitimate conclusion, the most that can be said for it is, as the association of parasitic ideas may already have reminded some of my audience, that it is in harmony with the great generalization of the plagiaristic poet, that-

Great fleas have little fleas upon their backs to bite 'em, And little fleas have lesser fleas, and so ad infinitum.

Is this generalization also to be applied to explain the action of pathogenic bacteria? Have they their stimulant parasites?

I am willing to see, in the long-continued action of microparasites, a process which may, like other modes of stimulation, initiate aberrant and neoplastic cell growth, but beyond this point I cannot advance. We seem to be asked to contemplate a most extraordinary state of affairs, so that I cannot accept the view that micro-parasites are in constant action in malignant growths, and are essential for the extension of the same. 


\section{CHAPTER V}

UNIPOTENTIALITY, PLURIPOTENTIALITY, AND TOTIPOTENTIALITY OF CELLS : A NOTE UPON THE CLASSIFICATION OF TUMOURS ${ }^{1}$

A FEW years ago I published a paper upon the classification of tumours based upon the embryogeny of the different tissues. ${ }^{2}$ That classification, I confess, was somewhat elaborate in appearance, although simple in principle, based upon the fact that each primitive cell layer gives rise to tissues of two orders, to denote which I was compelled to introduce a new set of terms. I did not like to do this, nor was it my idea that these terms should in any way attempt to replace in general practice those honoured by long use. Nevertheless, mere length of use has brought about such vagueness in the employment of the latter that for scientific and exact purpose they have very largely lost their primitive value. These terms notwithstanding, it is some satisfaction to see that that classification is coming to be accepted by writers of systemic works on pathology as the most rational so far proposed. To-day I wish to call attention to what I regard as a further advance in our conception of the relationship of the different forms of tumour which permits us to make in some respects a still more exact classification.

It may be remembered that in my older classification I divided neoplasms into two great groups of the teratomas (the tumours due to the development within the body of one individual of tissues and parts belonging to another individual) and the

1 A paper read before the Pathological Section of the Canadian Medical Association, Montreal, September 1907.

Journal of Pathology and Bacteriology, iv., 1902, 243 [pp. 305 et seq. of this volume]. 
blastomas (or tumours due to the aberrant growth in the organism of one individual of cells and tissues of that individual himself). So far as it went this division was fairly satisfactory : it left, however, a certain group of tumours in the debatable ground. I refer more particularly to that group which has been studied so ably by Wilms, the group to which he has given the name of "Mischgeschwülste," or mixed tumours, and to that section of the Mischgeschwülste to which the name embryoma has been applied. The type example of this growth is to be found in connexion with the kidneys of children and young individuals. Here there develops a cell-mass formed of a mixture of several distinct elements. There may be striated and plain muscle, gland tubules of renal type, cells of connective tissue type, of a sarcomatous type, and, very rarely, bone cells or cartilage cells have been encountered. Wilms has pointed out very clearly the mode of origin of these tumours. The Anlage of the glandular cortical portion of the permanent kidney is of mesoblastic origin, and at a very early stage in the embryo this "nephrotome" is cut off or differentiated from the myotomes, or cell-masses lying on either side of the median line which will eventually give origin to the main musculature of the trunk axis and to the bone and cartilage of the vertebral column. Now, there have been cells at a yet earlier stage which have been the ancestors both of the future muscle cells and of the glandular portion of the kidney cells, and these ancestral cells have, by progressive multiplication, given origin to both. We can best comprehend the tumours in question by supposing that in the course of development one or more of these ancestral cells has become snared off, or has come to occupy an unusual position with regard to its fellows, so that its development cannot follow the normal line. We may suppose that such a cell becomes carried along into the developing future kidney and that in time that cell begins to grow, and in growing retains the properties and the potentialities given to it at its origin. Such a "cell-rest," to apply Cohnheim's term, in its proliferation will tend, therefore, to produce both muscle cells and renal epithelium, and the tumour derived from it will of necessity be of a mixed type.

We encounter mixed tumours of a similar nature in several parts of the body-in the parotid, in connexion with the genital tract, and so on-and it is along these lines that they gain their 
simplest explanation. Where are we to place these tumours? The cells that give origin to them have not the power, even under the most favourable circumstances, to reproduce all the different forms of tissue; they have not the potentiality to form, even in the most favourable circumstances, the complete individual. And, on the other hand, there are no signs in these tumours of a combination of tissues derived from all three germinal layers. There may, indeed, be only the representative of one layer, the mesoblast. But we have in this order of tumour two or more distinct forms of tissue, in addition to the connective tissue stroma. They are not teratomas, they are not typical blastomas.

It is here that the terminology introduced by the embryologist Barfurth, in his Handbuch der Embryologie, appears to me to be of singularly high value and to afford the basis of an adequate classification. Barfurth has pointed out that, following the development of the typical ovum, one recognizes a first stage in which each individual blastomere or product of the cell division of that ovum may be shaken apart from its fellows, as has been done by Driesch, Roux of Breslau, E. B. Wilson, Morgan, Jacques Loeb, and many others, and each cell so separated has the power of giving origin to a complete, even if somewhat dwarfed, individual. Such cells he terms totipotential.

Following upon this stage, he notices that as the cells of the dividing ovum develop into the different germinal layers these cells no longer possess the individual power of giving origin to the complete individual. But, obviously, in this next stage the individual cells of the primitive streak region in differentiating into epiblast, mesoblast, or hypoblast, according to their position become the ancestors not of a single tissue, but of various groups of tissues. If epiblastic in position, they give origin to the cutaneous, glandular, and nervous elements ; even if at an early stage they give off cells which become mesoblastic, and so originate members of the group of what we term familiarly the connective elements. Nor is this capacity to give origin to more than one form of tissue confined only to the familiar three-layer period. The cells may be regarded as retaining this capacity throughout the whole of what Ballantyne has termed the germinal period of the embryo, until, that is, they become so far differentiated by division and relative site that they give origin to the matrices and anlagen of the different organs of the body. We 
have already given an example of this type of cell in what we said regarding the primitive cells of the myotomes. Such cells Barfurth terms pluripotential.

With progressive development, once the anlagen of the different tissues have been laid down the cells composing these become more and more differentiated, and now those cells have the capacity to produce one type of tissue only: they become unipotential.

Consideration will show that tumours group themselves into three great groups exactly corresponding to those three groups of cells laid down by Barfurth. As regards tumours derived from the parasitic growth within the body of one individual, of the products of a separate ovum-twin teratomas-and "filial " teratomas derived from aberrant growth of cells of the germinal type, the products of the reproductive organs of the individual, the cells from which these tumours originate are most simply regarded as being totipotential. It is a far less simple conception to suppose that such tumours are derived from the segregation of a group of cells derived from all three primitive layers. That conception has now been wholly given up.

Similarly we may regard the whole group of mixed tumours of the Wilms type, the embryomas, as derived from pluripotential cells. If we speak of the first class as teratomas, we may conveniently refer to these as terato-blastomas, to differentiate them from ordinary tumours formed of one specific type of constituent, with a framework or stroma of indifferent connective tissue and blood-vessels. The latter we must regard as derived from unipotential cells. These we may continue to speak of as the blastomas.

This method of regarding tumours appears to me both simple and straightforward and helpful in dispersing the doubt and muddle that has existed regarding these transitional types and their relationship.

We may thus classify new growths as follows :-

I. Teratomas.-The products of the growth within one individual of what is primarily or potentially another individual.

(1) Twin or Germinal Teratomas.-Due to the growth within the tissues of the one individual (the host) of the products of another fertilized ovum, coeval with the ovum giving origin to the host. 
Example: Foetal inclusions.

(2) Fitial Teratomas.-Due to the growth within the tissues of the one individual of the products of a totipotential cell derived from that individual.

(a) Blastomeric Teratoma, due to the segregation of a (totipotential) blastomere in the early embryonic or "germinal" period (Ballantyne) and subsequent growth.

Examples: Three-layered epignathus and congenital sacral teratoma.

(b) Germ-cell Teratoma, due to independent, aberrant growth of a totipotential germ cell at any period after the germ cells, as such, become segregated from the somatic cells of the embryo, and before the nuclear reduction processes take place which lead to the production of oöcytes and spermatozoa.

Examples: Ovarian and testicular dermoids.

II. Terato-blastomas. - The products of growth of a segregated pluripotential cell of the individual.

Examples: Two-layered and simpler forms of epignathus and "congenital sacral teratoma"; also "Mischgeschwülste" (embryomas of Wilms) of kidney, parotid, etc.

III. Blastomas.-The products of growth of a segregated unipotential cell.

(1) Teratogenous, due to continued aberrant growth of unipotential cells of one individual (the embryo, or, rarely, of a teratoma) within the tissues of the other (the parent).

Examples: Placental moles and chorio-epithelioma malignum. Carcinomas, etc., originating in ovarian dermoids.

(2) Common, derived from unipotential cells of the host.

Examples: The ordinary neoplasms formed of one type of tissue-fibroma, adenoma, etc., sarcoma, endothelioma, carcinoma, etc.

It is these blastomas that can be subdivided according to my previous classification into the lepidic or lining membrane tumours (lepidomas) and the hylic or matricial tumours (hylomas), whether of epiblastic, hypoblastic, or mesoblastic (mesothelial and mesenchymatous) development.

IV. Blastomatoid Growths. - There is yet a fourth class of new growths so called, not coming into any of the above categories, 
which remains to be noted. I refer to those conditions in which not individual unipotential cells of a tissue but the whole tissue undergoes a local overgrowth, resulting in the formation of tumours that are (1) ill-defined, (2) tend to be diffuse or multiple, and (3) to retain in their structure the ordinary tissue relationships. These are the conditions of idiopathic "Riesenwuchs" of some authorities. They are commoner and more varied than, I think, is usually imagined. Examples of such conditions are: fibromatosis (multiple fibroids), lipomatosis, chondromatosis (multiple ecchondroses) and osteomatosis (multiple exostoses), myelomatosis (myeloma multiplex), gliomatosis, lymphomatosis (including lymphatic and myelogenous leukaemia), etc. Whether the termination "omatosis " should be applied to these conditions is debatable. It is that which, apart from this recognition of the distinction here drawn between these conditions and the blastomas proper, has hitherto been employed to designate the members of this class, and this so generally that to introduce another terminology seems a work of supererogation. Such growths form a link between the tumours proper and the hypertrophies. 


\section{CHAPTER VI}

ON THE RELATIONSHIP BETWEEN TUMOURS PROPER (BLASTOMAS) AND HYPERBLASTOSIS 1

To-DAY more fully than ever before it is realized that to comprehend the abnormal we must first understand the normal. Thus it is that modern research into the etiology of cancer is more and more occupying itself with inquiries into the phenomena of normal growth. The results already gained from these inquiries render it timely to reconsider a particular form of overgrowth, to which German authorities have given the name "Riesenwuchs." This is so commonly regarded as blastomatous, as belonging to the tumours proper, that neither in English nor, to my knowledge, in French has an adequate term been so far afforded. Merely to translate the German term and speak of "giant growth" conveys no well-defined meaning to the English mind. C. P. White, it is true, has labelled it "progressive hypertrophy," but this is a description rather than a name: I, too, have spoken of it as "blastomatoid," but the expression is adjectival and not substantive. And yet, as I hope to show, this type of tissue overgrowth has properties so characteristic as to separate it sharply from the true blastomas, to necessitate its recognition as an order apart, and to demand a precise name whereby to ensure that recognition. Nay, I would say further that it is a notable aid to our understanding of the etiology of malignant growths to make this recognition.

Here, to emphasize the distinction, it must be pointed out that judged by the many definitions that have been afforded of

1 Communicated to the Pathological Section of the Seventeenth International Medical Congress, London, August 1913. 
a "true" or autonomous tumour our stereotyped conception of such is that it originates as a circumscribed overgrowth of cell elements, not exercising any function of service to the body, or at least becoming separate from the normal tissues in its physiological and functional relationships. Even if we cannot with Cohnheim regard it as derived always from a matrix of superabundant or erratic deposit of embryonic elements, we all, I think, are accustomed to accept Ribbert's view that it is selfconfined, dependent upon the organism for its nourishment, but otherwise largely if not quite independent. That is our stereotyped mental picture of what constitutes the tumour proper.

Let me approach my subject from what may appear to be a novel, but what I believe to be the correct, standpoint.

The researches upon the functions of ductless glands pursued with increasing activity during the last twenty years have demonstrated in a wholly unexpected manner that sundry of these glands have a remarkable influence over the growth of particular tissues. This is now so well recognized that it is needless for me here to give a detailed statement. Briefly, the outstanding results are these :

1. That specific ductless glands and their internal secretions influence the growth, not of all tissues equally, but of particular tissues. Thus the experimental removal of the whole of the anterior portion of the pituitary is associated with defective growth of the bones, whereas, per contra, excessive development of the anterior portion of the same gland is associated with excessive growth of bone. Overgrowth of the adrenal cortex is more particularly associated with premature development and overgrowth of the organs of generation. Hypoplasia of the thyroid is associated more particularly with overgrowth of the subcutaneous connective tissue; hypopituitarism with localized or generalized adiposity along with genital deficiency.

2. Such overgrowth or arrest of growth of particular tissues may have associated with it a coincident overgrowth of associated tissues and parts. In osseous giantism associated with excessive development of the anterior portion of the pituitary we find coincident increased development of surrounding tissues; along with the premature development of the essential organs of generation seen to accompany benign adenomatous tumours of the adrenal cortex we note an over-development of the second- 
ary organs of generation, as also of the muscular system. But this associated growth must be regarded as secondary and co-ordinate. In each of these cases we are struck by the fact that one particular tissue shows excessive growth, whereas other associated tissues, while presenting increased growth, have that growth proportioned rather than over-proportioned to the excessive development of the particular tissue.

3. While recognizing thus that excess or defect of particular internal secretions exercises this specific action on particular tissues, it is noteworthy that the particular tissues do not present a universal hyperplasia or hypoplasia throughout all areas of their distribution. In acromegaly, for example, it is the bones of the face, hands, and feet that are more particularly involved; in pituitary giantism the bones of the limbs show excessive growth rather than those of the trunk. Let it be admitted that mechanical and other possibly deeper reasons exist for this regional overgrowth of one or other tissue. Let us even admit that, as has been suggested, in acromegaly it is a plethoric blood supply, or an activity of the blood-forming organs, in short a primary haemic change that induces bony overgrowth; it still remains that under the influence of altered internal secretions the growth of one or other tissue is seen to lack proportion as regards the relative regional development of that tissue, just as it lacks proportion as between that tissue and the other tissues of the body.

From this group of cases we pass to another so similar in basal properties that we must, I think, conclude that it is of the same type, the group, namely, to which it has been customary to limit the name "Riesenwuchs." Of this the most typical example is adiposis and the allied conditions. Even where adiposis is generalized every pathologist is forced to recognize that there is an individual variation in the laying down of the fatty tissue. Some cases, for instance, presenting a large panniculus adiposus exhibit but a meagre deposit of fat in the mesenteries and omentum; and vice versa. We encounter, however, striking examples of local overgrowth of the fatty tissue. I need but recall the symmetrical lipomatosis seen more often in males, involving it may be especially the neck, the submaxillary, or parotid region, but in other cases seen in the mammary region, the perineum and scrotum, or the inguinal region. With these must be noted the characteristic distribution of the fatty overgrowths in 
Dercum's disease (adiposis dolorosa). While these may be nodular in type, more frequently the deposits while localized are diffuse over the supraclavicular, inframammary, and lower scapular regions. How regional is this distribution is frequently noticeable in the extremities when, to quote Sir Dyce Duckworth, " the hands appear to come out as from a cuff, and the foot from a pantaloon." To the same order belongs the remarkable group of perirenal, retroperitoneal, and mesenteric lipomas, so called. These are one and all overgrowths of the fatty tissues normally present in these regions. They are not, let me emphasize, blastomas proper. They are diffuse hyperplasias which only from their extreme extent give the impression of being distinct tumours, but if carefully examined they are seen to respect the boundaries of the normal tissue, and in fact to pass imperceptibly into the normal fatty tissue around, wrthout any sign of limiting capsule. They cannot be regarded as autonomous, independent developments; they do not come within the accepted definitions of tumours proper, or blastomas. They are conditions of hyperblastosis, that is to say, of the state of hyperplasia of an individual tissue.

As I say, these localized regional overgrowths of fatty tissue constitute the type example of "Riesenwuchs," but what is of particular interest for the development of my thesis is that as a class they appear to be due, not to any local irritation, but to internal secretory disturbances, to some lack of equilibrium between the internal secretions, resulting, as in our previous group of cases, not necessarily in a generalized but in a regional overgrowth of this particular tissue. Notably in the case of Dercum's disease, almost every case which so far has come to autopsy has been characterized by thyroid or pituitary changes or both, while conversely, if I may so express it, we have the authority of one whom I may term the leading authority on obese states and their treatment-Chune Fletcher-that administration of thyroid extract is the one method of treating Dercum's disease that yields favourable results.

Passing to the other members of this group it is true that so far we possess no distinct evidence that they too are associated with internal secretory or metabolic disturbances. Anatomically, however, they present the same general characteristics, and this in so striking a manner that we are forced to consider them as 
belonging to the same class. Let me enumerate rapidly the more important members, only treating with somewhat more detail conditions which, while not generally included as coming under this category, not only, I hold, are rightly so included, but find their proper place and proper relationships when so included.

One prominent and characteristic sub-group is in association with the nervous system. In this belongs a most striking form of "Riesenwuchs," which until recently has been regarded as a fibromatosis. I refer to that condition of multiple subcutaneous and perineural growths to which so many names have been given: molluscum fibrosum, multiple neuro-fibromas, neurofibromatosis, etc. The observations of Durante, Kohn, Bard, and Veroçay taken together demonstrate convincingly, I think, that these growths are hyperplastic developments of the cells of the sheaths of Schwann, of cells, that is, of neuroblastic origin. These overgrowths beginning often in early life, and developing slowly over long years, respect the normal boundaries of the nerve sheaths, merge imperceptibly at either pole, without defining capsule, into the tissues of the nerve along which they have developed, and in every respect conform in their properties with the multiple fatty growths already enumerated. Closely allied embryogenetically is the condition of gliosis or gliomatosis. Here we have the same slow progressive growth, the same diffuse nature and lack of delimitation; indeed, my own experience leads to the conviction that the majority of the so-called gliomas belong to this category. What is perhaps the most well-marked example of this condition is seen associated with, and apparently underlying, the condition of syringomyelia.

Passing over certain less important examples such as leiomyosis or leiomyomatosis (which, I would point out, is the more correct nomenclature for what gynaecologists and modern textbooks wrongly term adenomyoma of the uterus), and endotheliosis (such as is seen notably in the spleen in Gaucher's type of splenomegaly, and some cases of Banti's disease), ${ }^{1}$ I would at greater

1 There can now be no question as to the functional, or, indeed, superfunctional nature of this striking overgrowth of the sinus cells in the spleen, since Banti has demonstrated that operative removal of the organ terminates the anaemia-prevents, that is, the excessive destruction of the red corpuscles. (These cells lining the splenic sinuses possess normally the property of taking up and destroying the red corpuscles. When they are developed in excess the destruction becomes also excessive.) 
length call your attention to a most important group of hyperblastoses, those, namely, affecting the lymphatic tissues and the bone marrow.

That I may not be accused of forcing my point, I would here quote the description of one of these allied conditions given by a recent writer whose position is sufficiently indicated by the fact that my quotation is taken from the "Referat" which he was invited to give before last year's meeting of the Deutsche Pathologische Gesellschaft. "The lymph nodes," states Professor Eugen Fränkel, " are liable to be most intensely affected, swelling up into huge packets, and when it is the more superficial lymph nodes that are involved, an immediate diagnosis can be made. Often enough at autopsy it is determined that besides the peripheral lymph nodes the internal collections are implicated : those at the hilus of the lungs, in the mesentery, in the retroperitoneal tissue, exhibit similar change. It is in no wise necessary that the nodes throughout the body are involved to the same degree, although total exemption of one or other group is scarcely ever observable. . . . The spleen also shows in general a notable increase . . . indeed at times the enlargement of this organ predominates to such a degree that the lymphoid enlargement passes relatively into the background. . . Cases, however, are not infrequent in which the spleen remains small." And Fränkel points out that microscopically we deal in these cases with what is purely a hyperplasia of the lymphoid tissue. This is a description of the condition which from a primary misfortune in nomenclature, from fastening the attention upon the outcome rather than upon the underlying state, has for years bcen a source of confusion: the condition, namely, described by Cohnheim as pseudoleukaemia, by others as aleukaemic leukaemia, or as the pre-leukaemic stage of leukaemia. For now many years my teaching has been that lymphatic leukaemia is a blastomatoid condition, ${ }^{1}$ and I willingly accept as the preferable nomenclature that supported by Aschoff, Schridde, Hirschfeld and Nägeli, namely, lymphadenosis or lymphadenia. The time, indeed, has come when, for clear thinking, the term leukaemia should be relegated, by clinicians and pathologists alike, to its proper symptomatic rank : we should speak of lymphadenosis with or without leukaemia,

1 Vide Adami, Principles of Pathology, first edition, vol. i., 1908, p. 678 et seg. 
distinguishing, I should add, between lymphadenosis (lymphatic leukaemia) and myelosis (myelogenous leukaemia). For what is true of the lymphoid tissue proper obtains also in respect to the elements of the bone marrow; these also may undergo diffuse regional hyperplasia, with the complication that in the marrow there exist elements of more than one type, and one or other of these may exhibit hyperplasia. Thus in general lymphadenosis the lymphocytic or lymphoblastic elements of the bone marrow may be coincidently involved. In what I think we may term myelosis proper (myelogenous leukaemia) it is the myelocytes that in the main are hyperplastic, and this to such an extent that the immature myelocytes are discharged into the blood stream, and, at times, such is the stimulus to the formation of this type of cell that organs like the spleen and liver resume the power they possessed in embryonic life, and once again become the site of myelocyte production.

The limitations set to communications before this Congress forbid that I should do more than sketch the broad outlines of my subject. I can merely state that lymphadenosis (leukaemic and aleukaemic lymphatic leukaemia) and myelosis (myelogenous leukaemia) are system diseases, hyperblastoses of the lymphoid and myeloid tissue respectively of the whole organism, which, under the influence of localization and regional intensity of the process in the different areas of the body, are apt to induce numerous variations in the facies of the disease. Saying this it is necessary, parenthetically, to exclude Hodgkin's disease from this group of hyperblastoses : with the majority of recent workers, I regard this as of irritative and chronic inflammatory origin, as a lymphogranulomatosis.

We must now pass on to the consideration of another feature of these hyperblastoses, which for the sake of clearness I have so far studiously kept in the background. I refer to their liability to present malignant change. This may exhibit itself either as a primary or a secondary phenomenon, and may be of localized origin or generalized. It is characteristic not only of the lymphadenoses and myeloses, but of the hyperblastoses as a group, that, instead of the constituent cells being of fully-formed adult type, they may either locally or diffusely exhibit actively vegetative or "embryonic" characters. This, after all, is only what might be expected from what we know of the general phenomena 
of growth: it is the cell that has normal relationships that is most apt to attain and to retain complete differentiation. Hyperplasia connotes cell proliteration, and where two cells take and retain the place of one, one, if not both, of those cells must fail to preserve the normal relationship to nutrient vessel, stroma, etc. Hyperplasia thus favours anaplasia of at least a portion of the cell elements of the affected part. Thus we find that a portion of or all the cells of a gliosis may take on a more sarcomatous type (I use the term here strictly in a histological sense); areas of a liposis (e.g. of a retroperitoneal "lipoma ") or of a leiomyosis may become sarcomatous; and as regards the myeloses and lymphadenoses, we observe a very interesting set of conditions.

The so-called multiple myeloma, for example, has all the features of a hyperblastosis - excessive development occurring in certain bones only, and absence of limitation save by the natural boundaries of the involved areas - with this in addition, that the constituent cells are of "embryonic" character, so embryonic that here and there they are liable to exhibit active malignancy, and may not merely absorb the bony trabeculae but may infiltrate the periosteum and surrounding tissues, and even, if rarely, may give rise to metastases in other organs at a distance, or to quote Berlinger, "myeloma is becoming to an increasing extent regarded as a systemic disease of a malignant type." So vegetative is the type of cell in many of these cases that, as well known, there is active debate regarding their origin, whether they belong to the lymphoblastic or to the myeloblastic type. The indications appear to be more and more convincing that there may be a specific hyperblastosis involving each distinct element of the bone marrow - the lymphoblasts, the myeloblasts, and the erythroblasts (as in Ribbert's well-known case of megaloblastic overgrowth which he held to be an erythroblastoma (more accurately an erythroblastomatosis).

Of peculiar interest in this connexion are the more recent observations upon Chloroma. Here there are the same regional ill-defined overgrowths most often occurring in early life, and involving particularly the skull, ribs, or sternum. Constantly where the blood has been examined, the picture has been that of leukaemia, with predominance of the large or relatively large non-granular mononuclear cell, although in a small proportion 
of cases there have been granular mononuclears. The picture has been that of either acute lymphatic or acute myelogenous leukaemia. By the employment of the oxidase (indophenol) test, ${ }^{1}$ which differentiates between lymphocytes and myelocytes, my colleague, Professor Burgess, has demonstrated clearly that the marrow growths and the characteristic blood cells in this condition are myelogenous, not lymphogenous. The condition is a myelomatosis, or, to use ordinary terminology, an "acute myelogenous leukaemia," and confirming Schultze, Longcope and Cooke, and others, Burgess points out that cases of so-called acute lymphatic leukaemia with " large lymphocytes" are truly cases of acute myelogenous leukaemia (or strictly of acute myelomatosis with leukaemia). ${ }^{2}$

Parallel to these conditions affecting the bone marrow of particular localities with their liability to malignancy, we may cite the not infrequent mediastinal tumour, which originating in the thymus (and perhaps sometimes in the mediastinal lymph nodes) shows a striking liability to become locally malignant, infiltrating all the surrounding tissues.

From these intermediate forms we pass on by imperceptible gradations to cases of primary malignant hyperblastosis, to cases of diffuse lymphosarcomatosis and myelosarcomatosis.

If the views here laid down and the relationships of this group of conditions be correct, we arrive at certain interesting conclusions. Namely, and first, that whatever be the essential cause of the autonomous blastomas, we have in these hyperblastoses a group of diffuse overgrowths which by analogy must be regarded as due to disturbances of metabolic equilibrium; which, further, in their simple non-malignant stages at least, may possibly be combated eventually (certainly not to-day) along the lines of organotherapy. Secondly, that every transition is observable in this series between the development of overgrowths of fully-differentiated tissue, non-malignant grades of anaplasia, and diffuse malignant infiltrative growths. This

1 Burgess, Journ. of Med. Research, xxvii., 1912, 133.

2 I must, however, disagree with my colleague in regarding leukaemia as a blood metastasis. The symptom leukaemia is not an index of malignancy; the discharge of leucocytes into the blood is not of the nature of a malignant infiltration; on the contrary, it is best regarded as the outcome of chemiotactic phenomena, as an attraction of marrow cells by something circulating in the blood. There may be extensive lymphadenosis or myelosis without leukaemia, or leukaemia may be present for a time, and then disappear-and reappear. 
suggests strongly that the causation of malignancy is not to be sought for in the entry and action of external agencies, but in stimulation of the growth properties of specific tissues by changes in what I may term tissue equilibrium. And lastly, that the more we study, the more we become impressed by the fact that the number of conditions of hyperblastosis, whether simple or malignant, is relatively considerable, so considerable as to deserve separate consideration. 



\title{
APPENDIX I
}

\section{EXPERIMENTS WITH B. TYPHOSUS re ADAPTATION}

\section{BY}

\author{
F. B. BOWMAN, ${ }^{1}$ M.B. (Toronto),
}

Major, C.A.M.C., O.C. No. 1 Canadian General Laboratory, Folkestone.

AT the request of Lieutenant-Colonel Adami, the following experiments were conducted to prove or disprove certain conclusions reached by him regarding the effect of environment on certain cultural reactions of micro-organisms.

Owing to the short time which was allowed for making these investigations before the date set for the delivery of the Croonian lectures, it was very questionable whether results of any interest would be obtained. However, the following notes and charts seem to bear out the contentions made by him, and to prove that instead of chance variations in reaction we were dealing with direct adaptation of the organism to its environment.

No investigation of the biochemistry or the raison d'être of results will be made, but simply a statement of facts from observation of the reactions from day to day.

It is well known of course that certain bacteria in process of growth cause fermentative reactions with different sugars, that is that certain sugars would seem to be assimilable by certain organisms, and that other sugars are useless as nutriment for their regular growth and multiplication. The typhoid-colon group perhaps illustrates this faculty better than any other, and for this reason B. typhosus was used in this work.

1 Major Bowman delivered his charts and results personally to me on the morning of the delivery of the lecture, in which reference was made to them. Upon forwarding the proof of these charts to Major Bowman, with the suggestion that without explanatory notes they appeared somewhat bare, he writes: 19/10/17: "Perhaps the enclosed could replace the proof you have sent me. However, I have changed the proof slightly if you should still use that, and have initialled corrections." It is these expanded notes that are here given.

The observation given in the final paragraph $\mathrm{ph}_{\mathrm{j}}$ is new to me, and deserves further investigation. The probability is that the sugar in the neighbourhood of the colonies had been used up, and that so acid production had ceased.J. G. A. 
A pure culture of B. typhosus was obtained from Colonel Harvey of the Royal Army Medical College. This organism was found to agglutinate specifically in 1-5000 dilution. Fermentation tests were then done and observations made for several days, and it was found to ferment only mannite and glucose (see Chart I.). Azolitmin broth (sugar free) was used as a base, and the different sugars added to this medium.

\section{CHART I}

(Acid Production)

\begin{tabular}{|l|c|c|c|c|c|}
\hline \multicolumn{1}{|c|}{ Sugar. } & 24 Hours. & 48 Hours. & 72 Hours. & 4 Days. & Remarks. \\
\hline Glucose & ++ & ++ & ++ & ++ & Culture used re- \\
Lactose & - & - & - & - & $\begin{array}{l}\text { acts specifically } \\
\text { with glucose and }\end{array}$ \\
Saccharose & - & - & - & - & mannite only. \\
Mannite & ++ & ++ & ++ & ++ & \\
Dulcite & - & - & - & - & \\
Isodulcite & - & - & - & - & \\
\hline
\end{tabular}

Now, the question at issue seemed to be whether by reducing the nutriment in the culture medium, i.e. the peptone, and at the same time adding a non-fermentescible sugar, the organism would grow by adapting itself to the food present in the medium. This would be shown by fermentative reactions.

A culture medium of very low nutritive value was prepared as a base, i.e. $0.5 \mathrm{cc}$. sugar-free peptone broth, added to $100 \mathrm{cc}$. of distilled water, sterilized, and coloured with azolitmin. Cultures of B. typhosus sown in this medium grew very slowly, but by adding a fermentescible sugar in even a very small amount, growth became much more rapid with prompt change in colour from blue to red. By adding a non-fermenting sugar the growth was very slow.

It was decided at first to gradually withdraw a fermentescible sugar from the medium, and to substitute one non-fermentescible, and to plate at daily intervals. Because of the short time at our disposal this was only continued for a few days, but the results were encouraging.

The following procedure was finally adopted :

$100 \mathrm{cc}$. flasks of dilute peptone broth were prepared as above, and 1 per cent isodulcite added, this being non-fermentescible, and the whole sterilized on three successive days with steam, and azolitmin added to colour. At the same time azolitmin-isodulcite agar was prepared, only sugar-free broth being used.

Several flasks of dilute azolitmin isodulcite broth were inoculated with B. typhosus. In 24 hours any change in reaction was noted, 
and plate cultures were made, using azolitmin isodulcite agar. These individual plates were themselves observed for several days.

In 48 hours a second plate was made from each flask and so on for 6 days. The following Chart II. illustrates what occurred graphically.

\section{CHART II}

\begin{tabular}{|c|c|c|c|}
\hline \multirow{2}{*}{ Time. } & \multicolumn{3}{|c|}{ Isodulcite-azolitmin Agar Plate Cultures from 100 c.c. Flasks. } \\
\hline & $\begin{array}{l}24 \text { Hours' } \\
\text { Growth. }\end{array}$ & $\begin{array}{l}48 \text { Hours' } \\
\text { Growth. }\end{array}$ & $\begin{array}{l}72 \text { Hours' } \\
\text { Growth. }\end{array}$ \\
\hline $\begin{array}{l}24 \text { hours } \\
48 \text { hours } \\
72 \text { hours } \\
4 \text { days }\end{array}$ & $\begin{array}{l}\text { No change in } \\
\text { colour } \\
\text { do. } \\
\text { do. } \\
\text { Slight pink tinge }\end{array}$ & $\begin{array}{l}\text { No change in } \\
\text { colour } \\
\text { do. } \\
\text { do. } \\
\text { Slight pink tinge }\end{array}$ & $\begin{array}{l}\text { No change in } \\
\text { colour } \\
\text { do. } \\
\text { do. } \\
\text { Pink tinge }\end{array}$ \\
\hline 5 days & $\begin{array}{l}\text { Marked growth. } \\
\text { Distinct pink halo } \\
\text { around colonies } \\
\text { Marked growth. } \\
\begin{array}{l}\text { Distinct pink } \\
\text { coloration }\end{array}\end{array}$ & $\begin{array}{l}\text { Marked growth. } \\
\text { Distinct pink halo } \\
\text { around colonies } \\
\text { and some colora- } \\
\text { tion of medium } \\
\text { do. }\end{array}$ & $\begin{array}{l}\text { Marked growth. } \\
\text { Distinct pink halo } \\
\text { and coloration } \\
\text { of medium } \\
\text { do. }\end{array}$ \\
\hline
\end{tabular}

In 4 days there was no change in colour in the flask culture, but in 5 days a very slight pink could be noticed, which had not increased in 6 days. It will be seen that no change occurred even after 3 days in the 24-hour, 48 -hour, or 72-hour plates, and only a slight change in the 4-day plates. However, marked growth and distinct fermentation occurred in the 5-day plates, and in the 6-day plates.

It would seem that direct " adaptation to environment" had occurred. On examining these plates by chance three weeks later it was seen that they were blue again, and apparently the organism had lost its affinity for isodulcite, and was growing again on the agar without producing acid. 


\section{APPENDIX II}

\section{SIR E. RAY LANKESTER REBUKES RUDENESS : A CORRESPONDENCE IN THE PAGES OF THE BRITISH MEDICAL JOURNAL}

\section{From the British Medical Jodrnal, July 14, 1917}

\section{To the Editor of the British Medical Journal}

SiR-It would take an undue amount of your space and of my time were I to state fully the grounds which I have for regretting the tone and the matter of Dr. Adami's two Croonian lectures published by you in your issue of June 23. Nevertheless I ask your permission to lay them briefly before your readers. Those grounds may be classed as matters of taste and matters of fact. With regard to the first, Dr. Adami offends $(a)$ by citing without my permission (and in a garbled form) a private communication made by me to him ; (b) by professing that " the time is ripe " for him to instruct the biological world in elementary facts as to the experimental modification of the activities and forms of pathogenic bacteria which (as I had pointed out to him) are really familiar to biologists, and are not and never have been-as he persists in asserting, in spite of plain information to the contrary-treated with "superb indifference" and neglect in this country; (c) further by comparing Professor Bateson, for the purpose of vulgar ridicule, with a bumble-bee in a greenhouse; and also $(d)$ by making use of the unworthy method of suggestio falsi in recklessly stating that the evolution of a new property by direct acquirement is " contrary to the hypotheses and dogmas of Professor Bateson and Sir Ray Lankester." My objection to this is that Dr. Adami must know, if he knows anything about the matter, that Professor Bateson's views and mine on this subject have little in common. It is unfair to both of us to suggest that they are identical, whilst it is merely rhetorical abuse to speak of those views as " dogmas." Further, it is the fact that Dr. Adami was categorically informed by me eighteen months ago that the frequent evolution of a new property in a race of bacteria by " direct acquire- 
ment" was maintained by me forty years ago, and supported by facts published by me and at that time novel, concerning the peachcoloured bacterium (B. rubescens or roseo persicinum) and the frequent pleomorphism of the bacteria, and that $I$, in common with many other biologists-including my regretted friend, Élie Metchnikoffhave continued to hold and advocate that view in spite of the adhesion of " medical bacteriologists " to Koch's doctrine of the fixity of bacterial "species."

Dr. Adami now endeavours to give his Croonian lectures a flavour of novelty by claiming for some medical bacteriologists who have recently accepted the long-known views of myself, Warming, Zopff, and Metchnikoff, the merit of a new discovery. He actually, at this late hour of the controversy, sets out, whilst announcing himself as a "militant" reformer and missionary, to teach us what we have done our best to teach him from his student days onwards.

So much for matters of taste. Now as to some of the matters of fact misrepresented by Dr. Adami.

(a) Under the heading, "Nature of variation" (p. 838) Dr. Adami confuses the term "variation" and "variability," and thereby renders all his argument "suspect." No one disputes (as Dr. Adami asserts that some do) that variability is a primary quality of living matter inherent and not acquired. On the other hand, no one denies that actual variations are brought about by the influence of forces acting from without upon this labile variable living matter.

(b) Farther on (at the top of p. 840) Dr. Adami states that I deny that there can be external influences of such a nature that specific variation may be induced by them. I have never at any time denied, but on the contrary always maintained, the truth of this elementary proposition. Biologists do not require Dr. Adami to pose, as he says, "under the shade of Harvey," and to cite wellknown facts in order to be persuaded of this. It is really unfortunate that Dr. Adami should pretend that these facts are unknown to those whom, with some cryptic implication, he terms "academic biologists."

(c) Moreover, Dr. Adami is hopelessly wrong in his use of Herbert Spencer's term " direct adaptation." He says that the worker in pathogenic bacteriology is impressed with the fact that "direct adaptation " is one of the basal phenomena of living matter. This is the great discovery which he thinks it his duty to teach to academic biologists. He is singularly unfortunate, for he proceeds at once to show that he has never understood what Herbert Spencer meant by " direct adaptation." Dr. Adami says that direct adaptation is "specific modification in response to a specific alteration in environment." That is not so. As Mr. Herbert Spencer is at some pains to point out, a specific modification in response to a specific alteration in environment is not necessarily an "adaptation." It may in 
certain cases happen to be so, but on the other hand it may have no such quality. Such a modification may be destructive of the life of the organism, or it may be disadvantageous rather than adaptive, or it may be, so to speak, neutral and without significance. Such specific modifications in the case of the simplest living matter have, it seems probable, never been directly adaptive, but some of the many modifications so set up would, under some of the many further changes of environment, prove of value in the struggle for existence to the primitively simple living thing so modified, and would lead to its survival by natural selection. This is called by Mr. Herbert Spencer "adaptation by indirect equilibration" as contrasted with "adaptation by direct equilibration." I need not pursue the subject further. It is sufficiently clear that Dr. Adami is under the illusion that mere modification of an organism in response to change of environment is described by the term " direct adaptation," which it is not. Accordingly in this case also, as in regard to the words "variation" and "variability," he misunderstands what other people have said on the subject on which he lectures, and, in consequence, solemnly gives utterance to propositions which have no serious meaning.

(d) Dr. Adami proceeds to maintain that the retention of its changed character by a strain of experimentally modified bacteria multiplying by fission is an example of the "transmission" of an acquired character. He is probably aware that it is very widely admitted that no case of the transmission of what are called " acquired" characters from parent to offspring has been demonstrated in so far as those higher animals and plants which multiply by means of specialized egg cells and sperm cells are concerned. The well-known retention of induced change of character in very simple fissiparous organisms does not go far towards rendering it probable that transmission occurs in the case of elaborate multicellular organisms with specialized reproductive cells. Dr. Adami offers us a dissertation on the word "individuality," which is of no assistance in the matter, and later proceeds to state that Weismann "violently opposed" the doctrine of the transmission of acquired characters. This is a baseless charge. Weismann was a patient investigator, and anything but a "violent" controversialist. $\mathrm{He}$ came to the conclusion that not only had no case of such transmission on the part of higher organisms been demonstrated, but that the mode of development and structure of the reproductive cells was such as to make it improbable that such transmission could be brought about. Nevertheless, Weismann would have examined fairly and judicially any attempted demonstration by a competent investigator of an instance of the transmission of such characters, and so at any time would the " academic biologists" of this country. Weismann would not have been interested in Dr. Adami's recent 
orations, since he was well acquainted with the life-history of both Protophyta and Protozoa.

It would not be right, since Dr. Adami has made a point of alluding to me, that I should leave his statements unnoticed, as I should have done had he not referred to me by name.-I am, etc.,

E. RAY LANKESTER.

Londox, W., July 4.

\section{From the British Medical Journal, July 21, 1917}

\section{To the Editor of the British Medical Journal}

SIR-Sir E. Ray Lankester, it appears, falls foul of the term " academic biologist." By labelling a man as " academic" it is in general meant to imply that such a one is more concerned with upholding the teaching and tradition of the Schools than with the advance of his subject. Had I wished to demonstrate to your readers what I meant by this term, I could not possibly have afforded a more perfect instance than, by his letter in your last issue, Sir Ray has himself presented.

Take, for example, his treatment of my use of the term " direct adaptation," ascribed to Spencer, and of my demonstration that this surely exists among the bacteria. Herbert Spencer wrote (Principles of Biology, 1898 edition, vol. i. page 528): "There go on in all organisms certain changes of function and structure that are directly consequent on changes in the incident forces-inner changes by which the interchanges are balanced and equilibrium restored. But ... we see that the modified conditions to which organisms may be adapted by direct equilibration are conditions of certain classes only. Besides direct there must be indirect equilibration." Where is the difference between my " specific modification in response to a specific alteration in environment within limits to be presently ${ }^{1}$ laid down" (Sir Ray manages to leave out the phrase in italics) and Spencer's " certain changes . . . that are directly consequent," etc. ? Later, in the abstract of my second lecture, which was in Sir Ray's hands, it is pointed out that experiments can be so made as to remove all possible question of chance variation and survival of those forms alone which had exhibited variation in a favourable direction (Spencer's indirect equilibration), so " that there was within certain limits direct adaptation in the Spencerian sense, direct equilibration

1 In my fourth lecture. By the closing paragraph of my first, as again by the invitation sent him to be present at the series, Sir Ray was advised that other lectures were to follow in which my theme would be developed, but of this he takes no notice. 
between the organism and its environment." Sir Ray, it will be observed, passes this over in complete silence, and makes no reference to my further demonstration of direct adaptation in the matter of acquirement of pathogenic powers. But by a casuistic mingling of Spencer's statements and his own opinion he implies that I confuse direct and indirect equilibration, and states that $I$ hold the view that mere modification of an organism in response to change of environment is in every case "direct adaptation." This is the method of the academic biologist, not of the seeker after scientific truth.

I freely admit that Sir Ray registers two definite hits. First as to the confusion between "variation" and "variability." The two are distinct, and the use of the latter in the circumstances was inaccurate. It will be observed that the section is headed "The Nature of Variation." I have before now employed the simile that explosiveness, or explosibility, is one of the properties of nitroglycerine, but that it requires a force from without to produce an explosion of this body. It would have been more accurate had I written, "whether we deal with an inherent tendency to vary, or a capacity on the part of living matter to be varied." But every fairminded reader will realize that this was the drift of my argument, and will see that the misuse of the word variability weakened instead of strengthening it. So, also, to those of us who have met Weismann I confess that "vigorously" rather than "violently" would have been the more appropriate adverb. But this again has no bearing on the main argument. His hits are "outers."

As to the other more personal matters in Sir Ray Lankester's letter, these again are all evasions of the main issue, such as a controversialist employs to darken counsel. They turn upon a triangular correspondence between X (an old friend of Sir Ray's), Sir Ray, and myself, in which, at the request of X, I wrote my views upon adaptation to him; X showed my letter to Sir Ray ; and Sir Ray's reply, while addressed to me, was forwarded to $\mathrm{X}$ to read and send on to me. To quote loyally the sense of a statement is not to "garble" that statement, with what that implies, and I challenge Sir Ray to publish the correspondence in full elsewhere, to show that my reference was not substantially correct, and that I was not justified in my action. My two letters are, and have always been, at his disposal for this purpose.

For myself I desire no German naval victory in which, before the action is fully developed, the fleet returns in triumph to its home port sheltered by a cloud of inky smoke. Nor do hard hits irritate me so long as they are clean. But I do feel most strongly that this matter of adaptation and its mechanism is a matter that is not the possession of zoologists and biologists alone, for them to dream dreams about and hold unseemly parochial wrangles over at meetings 
of the British Association. It is one in which medical men and the community at large are to-day very immediately concerned, one in which our voice has a right to be heard and our experience to be seriously weighed and considered, instead of being contemptuously spurned as coming from outside the pale; one in which we look for dependable leadership from men of the status of Sir Ray Lankester, and not receiving it must take the lead ourselves. To quote from Herbert Spencer's final words on the subject, ${ }^{\mathbf{1}}$ " And now I must once more point out that a grave responsibility rests on biologists in respect of the general question (inheritance), since wrong answers lead, among other effects, to wrong beliefs about social affairs and to disastrous social actions. In me this conviction is increasingly strengthened. Though the Origin of Species proved to me that the transmission of acquired characters cannot be the sole factor in organic evolution, yet I have never wavered in the belief that it is a factor, and an all-important factor. And I have felt more and more that, since all the higher sciences are dependent on the science of life and must have their conclusions vitiated if a fundamental datum given to them by the teachers of this science is erroneous, it behoves these teachers not to let an erroneous datum pass current."

To understand the full significance of what is here written I would ask my readers to turn to Sir Ray's letter of last week's issue and read it once again.-I am, etc.,

Loxpon, W.

J. G. ADAMI, Lieut.-Colonel, C.A.M.C.

\section{From the British Medigal Jovrnal, August 4, 1917}

\section{To the Editor of the British Medical Journal.}

SIR-Dr. Adami is suffering from an illusion. I have never had, and at present have not, the intention of discussing a scientific theory with him. His manners and methods render that impossible. My purpose in writing to you was to expose (as I explained in my letter of July 14) the offences against the laws of social intercourse of which he has been guilty in making public use of a confidential communication from me without my permission and in using vulgar ridicule and rhetorical abuse when entrusted by a learned and dignified College with the privilege of addressing it. I also took occasion to show that Dr. Adami erroneously claimed novelty for the view that the activities of the bacteria are susceptible of change under changed environment-a view which forty years ago I was one of the first to advance, although Dr. Adami goes out of his way to declare

1 In the Appendix to the last edition of the Principles of Biology. 
"without rhyme or reason" that I am opposed to it. I showed that his confusion of thought on this and related matters of fact is due to his misapprehension of the significance of the words "variation," "variability," and " adaptation."

Dr. Adami admits the offences and the blunders to which I have drawn attention; indeed he cannot deny the plain evidence of his own words. There is not (as Dr. Adami erroneously asserts) a "main issue" or "main argument" beyond these facts, in which I am concerned.

When a man stands convicted on his own confession, as Dr. Adami does, he either has the grace to express his regret and offer an apology for his offences and blunders, or he has not. Dr. Adami has not shown that grace; until he has, I decline to pursue the matter any further. He writes airily about " registering hits," and "outers," and "a German naval victory" as though the College of Physicians and the columns of a great medical journal were a sort of children's playground in which he is at liberty to " run amok" with a pretence of importance accompanied by violence to bystanders, and then run away without apology or penalty.

Even after his exposure Dr. Adami continues to write with regrettable flippancy. He commences his letter to you of July 21 by stating that by " academic" he means a man who " is more concerned with upholding the teaching and tradition of the schools than with the advance of his subject." And then he is so far reckless of his own reputation for discrimination and knowledge of character as to apply this description to me. He forgets that others can judge of the aptness of his definition and illustration, and also that in his first lecture he ventured to invoke "the shade of Harvey," one of the greatest of " academic biologists." $-I$ am, etc.,

E. RAY LANKESTER.

London, W., July 26.

\section{From the British Medical Journal, August 11, 1917}

\section{To the Editor of the British Medical Journal}

SIR-It is a piteous exhibition that Sir Ray Lankester has made of himself, and were it not that he has again touched upon points of personal honour I would have preferred to be silent and not further discover his shame. But by his deliberate misrepresentations and reiterated and unfair attempts to place me in the wrong, he has left me no option. He forces me to point out:

1. That he repeats and does not withdraw his accusation " that Dr. Adami erroneously claimed novelty for the view that the activities 
of the bacteria are susceptible of change under changed environment." I made no such claim. On the contrary, I called attention to the fact that Pasteur, Roux, and Chamberland had demonstrated changes of this order. It was not necessary for me to inform my audience that the demonstration was afforded in the early 'eighties, or that Pasteur died before this century opened. What I did claim was that " the latter-day investigations in medical science" showed that certain of the above-mentioned changes were of the nature of direct adaptation, or direct equilibration-a very different matter.

2 . That he repeats the charge that I misapprehend the significance of the word "adaptation," and states that I admit the blunder. Far from making any such admission, I, on the contrary, proved to the hilt, by a reference to Herbert Spencer's own words, that the misapprehension was his, that my use of the term was consistent and correct, and that it was he and not I who misused it. He must himself admit, now that the heat of the moment has passed, that this is not clean fighting. It is inexcusable.

3 . That as for his repetition of the charge of an offence against the laws of social intercourse by making use of a confidential communication, I must point out, in fuller detail than in my last, that it was Sir Ray Lankester himself who, while knowing my address, by transmitting his letter, addressed to me, to a third person for prior perusal, converted what would otherwise have been a private into an open correspondence. I have his letter of transmission before me as I write. It may interest him to know that previous to the delivery of my first lecture I put the case before two friends of his, both men of distinction, one of them a Fellow of the Royal College of Physicians. Both held that I would be justified in referring to the correspondence, and this, in the case of one of the two, after he had read the manuscript and seen the exact terms of the reference.

It will be observed that Sir Ray Lankester takes no notice of my challenge that he should publish this earlier correspondence and prove that I had, as he asserted, "garbled" my reference to his views. He cannot afford to refuse to discuss so vital a matter as this of the evidence recently obtained regarding direct adaptation with its bearing upon heredity and social matters of the first order. $\mathrm{He}$ cannot do this without tacitly resigning his position as a leader. To preserve his own honour I again ask him to publish the triangular correspondence already referred to, that the points at issue may be clearly defined.

Surely I need say no more. - I am, etc,

J. G. ADAMI.

Londow, W., August 6. 
. 


\section{INDEX}

Abderhalden, and ansphylaxis, 38; serological studies by the optical method, 91, 265 ; on enzyme nature of ectotoxins, 259

Abrin, 47; effects on offspring, 62

Accustomance, law of, 166

Achorion schoenleinii, 23

Acquired characters, Weismann on non-transmissibility of, 134; as distinct from inherited, 140 ; thermogenic acquirements, 151 (note)

Acquired constitutional states, direct transmission, 157

Acquirement of conditions of defect, 66,153

Acromegaly, 342 ; entiquity of, 16 (note)

Adami and Aschoff, 82

Adams, F. D., 177

Adaptation, direct, Sir E. Ray Lan. kester on, $10,355,357,361$; Lamarck's views, 10; the crucial experiment, 351 et seq.

Adaptation, in the bacteria, 15, 28 et seq.; to increased temperature, 40 ; of harmless bacteria to growth in the tissues, 41 ; in protozos, 45 ; to disease-producing agencies in higher animals, 45 et seq.; leucocytic, 53; and inflammation, 116 et seq.

Adenoma, malignant, of kidney, 317 ; of suprarenal, 317

Adenomyoma of nterus, 344

Adiposis, 342

Adsorption by fluid crystals, 186

Albrecht, 184, 187

Alcohol, effects on offspring, 63

Algae, marine, antiquity of, 17

Algonkian limestones, mode of formation, 17

Amboceptor, 53, 251

Amino-acids, 74, 221
Amphimixis, 13, 94

Anaphylaxis, 254 et seq.; its nature, 38 ; relation to immunity, 42 ; and inheritance, 67 ; mechanism of, 92 ; a stage in development of immunity, 256

Anaplasia and depression of function, 249

Anaspides, 18

Andrewes, F., on streptococci from throat, 24, 36

Antibodies, 50

Antitoxins, production of, 48, 50, 244 ; and toxins, relation of, 50

Apathy, 172, 182

Arnsperger, 285

Arthritis, rheumatoid, antiquity of, 16; in tertiary horse, 16

Aschoff, J., on myelins, 174; their relationship to gall-stones, 183 ; on compounds of nitrogenous bases and fatty acid, 205; on lymphadenosis, 345

Atavism, 137; explained by sidechain theory, 153

Atom, size of, 214

Anto-intoxications, inheritance of, 159

Autolysis and myelin production, 187

Automaticity of the cell, 240

Axolotl, conversion to Amblystoma, 67 (note)

Babes, V., 125

Bacillus anthracis, 35, 115, 119, 124

botulinus, 23 (note)

" coli, 126; mutations of, 29

" cyanogenus (syncyanus), 117

" diphtheriae, 129

" hoffmanni, 129

" leprae, 39

" megatherium, 152 (note); induced virulence of, 37 
Bacillus mycoides, 39

\begin{tabular}{|c|c|}
\hline & perturbans, 31 \\
\hline & prodigiosus, 56, 111, 116 \\
\hline & $\begin{array}{l}\text { pseudo-diphthericus. Seo } B \text {. } \\
\text { hoffmanni }\end{array}$ \\
\hline & $\begin{array}{c}\text { pyocyaneus, } 109,111,113, \\
117,158\end{array}$ \\
\hline & $\begin{array}{r}\text { ruber (of Kiel), 110, 113, 114, } \\
117,119 \text { (of Plymouth), } 113\end{array}$ \\
\hline & $\begin{array}{l}\text { rubescens. See } B . \text { roseo- } \\
\text { persicinum }\end{array}$ \\
\hline & $\begin{array}{l}\text { tuberculosis, retention of pro- } \\
\text { perties, } 57 \text {; strains of, } 25\end{array}$ \\
\hline & $\begin{array}{l}\text { typhosus, } 28,109,112,125 \text {; } \\
\text { and adaptation, } 351 \text { et seq.; } \\
\text { mutations of, } 32\end{array}$ \\
\hline & zopf \\
\hline
\end{tabular}

Bacillus of swine erysipelas, 116; of haemorrhagic septicaemia, 123

Bacteria, what constitutes the individual, 12; antiquity of, 16; pathogenic, allied non - virulent strains, 24; experimental production of specific variations, 33; changes in fermentative powers, 36; variability, 103 et seq.; fixity of species, 104; polymorphism, 108; chromogenic, 110, 112, 147; production of races, 114 ; natural races, 121 ; of haemorrhagic septicaemia, 123; in healthy tissues, 165

Bacterial species, doctrine of fixity of, 24

Bacterium calcis, 17

Ballantyne, 336

roseo-persicinum, 108, 355

Banti, on races of pneumococci, 124

Banti's disease, 344

Barber, 29

Barfurth, on proliferation of nerve cells, 271; on regeneration of muscle, 267 ; on totipotential, pluripotential, and unipotential cells, 336

Barnes on activities of the electrons, 241

Bashford, 201

Bateson, W., his doctrine of evolution by loss, 6,34 ; his statical conception, 97 ; on backward evolution, 97

"Baustein" theory, 252

Bayliss, W. M., 86; on unicellular organisms, 12

Beard, J., 318 (note)

Beatson, 331

\section{Beneke, 172, 182}

Berlinger, 347

Bernard, Claude, on unicellular organisms, 12; on nucleus and cell substance, 200

Bernard of Chartres, 5 (note)

Bilharziosis, 284, 303 ; antiquity of, 16

Billings, F., 37

Biophores, 206; their constitution, 77; growth of, 80; interaction between, 95

Bioplastio cell activities, 84

Birkett and Meakins, 237

Bizzozero, 267; on neoplasia, 273

Blastomas, 335, 337; classification, 286 ; and hyperblastosis, relationship between, 340 et seq.

Blastomatoid growths, 338, 340

Blastomycosis, 21

Bone, proliferation of, 265

Bordet, on nature of bacteriolysis, 251

Boveri, 193, 195

Bowman, F. B., 33 ; experiments with B. typhosus re adaptation, 351

Bretonneau, 42

Brücke, 187, 205

Brunton, Sir L., and Macfadyean, 30, 111

Buchner, 109

Burgess, 348

Buxton, on the two orders of tissues, 313

" Cancer bodies," 278, 332

Cancer, causation of, 276 et seq.; parasitic theory, 278, 302, 329, 333

Carbone, 184

Carcinoma, definition of, 317 ; sarcomatodes, 320 ; of uterus, 32

Caries, antiquity of, 16

Carlier, 198; on cell proliferation and secretion, 289

Carrière, on effects of tubercle bacillus toxins, 62

Cassèdebat, 126

Cell activities, neurogenic, environmental, and automatic, 240

Cell and tissue differentiation, 93

Cell heredity, 59, 245, 247

"Cell rests," 274, 288, 293, 335

Cell, functional versus vegetative activities, 84, 191, 269, 293; dogenerations and the nucleus, 202 ; automaticity of, 240 ; paraplasmic substances, 242; and enzyme action, 245; metaplasia, 246; 
depression of function (anaplasia), 249 ; influence of environment upon, 290 ; inertia, 292; hyperplasia, conditions originating, 294; inheritance of acquired characters by, 300 ; microbic stimulation of growth of, 329 ; as the parasite in malignant neoplasms, 330 ; unipotent, pluripotent, and totipotent, 334 et seq.

Centrosome, regeneration of, 195

Ceratodus, 18

Chance and variation, $x$; in nature, 30

Chalk, mode of formation, 17

Chantemesse and Widal, 112

Charrin, 109

Chipman, W., 327

Chloroma, 347

Cholera, antiquity of, 20, 21

Cholesteryl oleate, 181

Cholin oleate, 182

Chordoma, 306

Chorio-epithelioma malignum.

See Syncytioma

Chromatin, conveyor of heritable matter, 78

Chromosomes, different forms of, in cell, 192 ; accessory, 193

Coccidiosis, 283, 331 (note)

Cohnheim's theory, 274, 288, 293, 341

Coley, 304

Colitis, mucous, 239

Collie, Sir J., 58 (note)

Complement, 53

Conditions of defect, acquirement of, 66

Congenital versus inherited conditions, 140

Conjugation and inheritance, 148

Conservation of energy, and life, 226, 231

Continuity of the germ plasm, 83, 210

Correns, 95 (note)

Creighton, 19

Crookshank, 121

Crystallization, process of, 230

Crystals, fluid and flowing, 179; fluid, adsorption by, 186

Cunningham, D. D., 127

Curtius, 221

Cyanophyceae, antiquity of, 17

Cytology and sociology, 242

Dallinger, 40

Dallingeria drysdalei, 40 (note)
Darwin, Charles, the pangenesis hypothesis, 69,72 ; atavism by crossing pigeons, 137, 153

Darwin, Erasmus, 6

De Bary, 85

De Waele, 259

Deciduoma. See Syncytioma

Dedifferentiation and proliferation, 265 ; in tumours, 321

Defects, acquired, non-inheritance of, 153

Degenerations, cellular, 202

Dercum's disease, 342

Diathesis, inheritance of, 60,154

Dietrich and Hegel, 184, 187

Differentiation of tissues, 93

Digestion, enteral and parenteral, 253

Dinwiddie, 25

Diphtheria, origin of, 42 ; antitoxic immunity, 49 : variations in virulence, 104

Diphtheroid bacilli, 24

Diplococcus pneumoniae, 112 ; races of, 124, 131

Direct adaptation, proof of, in pathogenic bacteria, 44

Drew, 17

Dreyer, 55

Driesch, 139

Ductile crystals, 179

Ductless glands, influence of, upon growth, 341

Durante, on neurofibromatosis, 344

Duval, Matthias, 328; and Couret, 39

Earl, on life and the conservation of energy, 226, 232

Ectotoxins, diphtherial, 258; of tetanus, 259 ; shown to be enzymes, 259

Ehrlich, on strains of typhoid bacilli, 28 (note); on immunity against ricin, 48; on orders of cell poisons, 50 ; side-chain theory of immunity, 144,251

Electrons, 241

Elephant, evolution of, 19

Elliot, Hugh, 10 (note)

Embryoma, 335, 337

Endothelioma, 318, 320, 321, 323

Entamoebae, adaptation in, 46

Enteral and parenteral digestion, 253

Enteric fever, immunity against, 51

Environment and acquirement of properties, 151 ; influence of, on cell activities, 290 
Enzyme action, 86 et seq.; and the nucleus, 204; as the basis of cell acquirements, 245

Enzymes, proteoclastic, indifferent, and specific, 256 ; and antitoxins, 258

Eohippus, 19

Epidermis, proliferation of, 265

Epithelioma of gall-bladder, 59, 299; squamous, of larynx, 299

Equilibration, direct and indirect, 10, 357

Erythroblastomatosis, 347

Erythrocyte, life period of, 195

Eurypteridae, 18

Evolution of new diseases, 41

Exaltation of virulence, 35,116

Faber, Kniest, 40

Fabre-Domergue, 279, 336

Fatty degeneration and the myelins, 187,205

Favus, 23

Fear neuroses, 58

Ferment actions. See Enzyme action

Fertilization of enucleated egg, 193

Firmin-Didot, 5 (note)

Fischer, B., 248

Fischer, Emil, 74, 221

Fletcher, Chune, 343

"Flowing crystals" and "fluid crystals," 179

Fluctuations, 28, 29

Fluid crystals, 168 et seq.

Foà, 125

Ford, W. W., 51 ; on bacteria in healthy tissues, 165

Foster, Sir Michael, on digestion, 252

Fournier, 156

Fränkel, C., 116 (note), 123

Fränkel, E., 121; on leukaemia, 345

Fränkel and Simmonds, 109

Frothingham, 25

Fuligo, 46

Functional activities, 84

Gaffky, 126

Galton, Francis, on non-inheritance of mutilations and use acquirements, 72

Gall-bladder, epithelioms of, 247

Gamaleia, 123

Garwood, 17

Gaskell, W. H., studies upon verte- brate descent, 4 ; on anabolism and katabolism, 85

Gaylord, 332

Geikie, Sir A., 18

Geddes, Sir Auckland, 16 (note)

Germ cells, extrinsic and intrinsic influences on, 68 ; influence of position on, 152

Germ layers, 309

Germ plasm, continuity of, 83,210 ; and somato-plasm, 93; and the nucleus, 191 ; multiplication of, in spermatocytes, 211

Gessard, 111, 117, 119

Gheorghiu, 157

Giant growth, 340

Gland cells, proliferation of, 266

Glioma, 306, 324 ; false epithelium in, 321 (note)

Gliosis, 344

Goodsir, 23

Gout, inheritance of, 159

Gowers, Sir W., on structure and properties of alkaloids, 222-4

Grawitz, 202

Growing point in plants, 265

Growth, 79, 227; and the biophores, 80 ; its essential nature, 141; of bioplasm, 227; and crystallization, 230 ; habit of, 247,298 ; and overgrowth, 263 et seq.; and functional activity, 288; giant, 340 ; relationship of ductless glands to, 341

Gurd, Fraser, 93; on lysins, 257

Haberlandt, 196

Habit, the law of, 55, 166; and symptoms, 57 et seq.; movements, 58 ; of growth, $59,247,298$; symptoms and disease, 235 et seq.

Haemorrhagic septicaemia, 123

Hales, Stephen, on the value of hypothesis, 233

Halley's comet, 244

Hamilton, D., 307

Hansen, 151 (note)

Harris, Fraser, 243, 292; on law of inertia, 55, 166

Harris, T., 303

Haureau, 5 (note)

Heidenhain, R., 196

Hering, on memory, 226 (note)

Hermann, F., 197

Herter, 204

His, W., on archiblast and parablast, 310 
Higgins, C., 37

Hodge, 197, 289

Hodgkin's disease, 346

Hoffmann, 129

Hog cholera, 22

Holman, 36

Hofmeister, 75

Horse, evolution of, 19

Horsley, Sir Victor, 63 (note)

Hort, 23

Hrdlicka, 20

Huber, C., 325

Hubrecht, 327

Hueppe, 112, 123; and Wood, 124

Hunter, W., 195

Hürthle, 183

Hylic tissues, 313, 314

Hylio tumours (hylomss), 315

Hyperblastosis, 340 et seg.

Hyperplasia, 294

Hysteria and habit, 58, 235, 237

Id, size of, 214

Idioplasm, 142

Immune body, 53, 25l

Immunity, an adaptation, 47 et seq. ; antitoxic, 47 et seq.; bacteriolytic, 51; the mechanism of, $90 \mathrm{et} \mathrm{seq}$.; inheritance of, 158; antitoxic and bacteriolytic, 250; as a special case of the digestive process, 252 ; and anaphylaxis, 256 ; bacteriolytic, stages of, 256 ; stages of, 260

Individuality in the bacteria, 12

Inertia of the cell, 55, 166, 243

Infectious diseases, antiquity of, 15 et seq.

Inflammation and adaptation, 161 et seq.

Inheritance, of acquired properties, doctrine of, history, 6 ; of acquired conditions in higher animals, 60 et seq.; of acquired conditions, influence of hormones, 68; theories of, 132 et seq.; true and false, 140 et seq. ; physico-chemical theory of, 143 et seq. ; effects of conjugation, 148; part played by cell nucleus, 149 ; in multicellular forms, 150 ; of diathesis, 154; of infections, 154 ; indirect, 155; of acquired constitutional states, 157 ; of immunity, 158; of endogenous intoxications, 159

Intoxications, endogenous, inheritance of, 159
Israel, 0 ., on the two orders of tissues, 313 ; on properties of the endotheliomas, 323

Jequirity, 47

Joannes Sarisberiensis, 5 (note)

Kaiserling and Orgler, 168

Kamen, 109

Kammerer's experiments, 66

Karyolysis, 202

Katabiotic cell activities, 84

Kelvin, Lord, on size of the atom, 214

“Kernkörperchen," 197

Kidney tubules, proliferation in, 267

Klebs, 195, 310

Klein, E., 105

Klotz, O., on B. perturbans, 31 ; on production of calcium soaps in organism, 173; on protein fattyacid compounds, 187; on assumption of habit in dysentery, 239

Koch, R., on fixity of bacterial species, 25

Kölliker on muscle proliferation, 268; on regeneration, 269

Korschelt, 196

Kossel, 74; on chemistry of the nuclens, 203

Kroon, 50

Krumweide, 26

Kurth, 108

Kyes, Preston, 206

\section{Lacrymaria olor, 195}

Lamarck, on nerve paths, 58; on inheritance of identical induced change, 69

Lamarckian doctrine, ix, 10

Langerhans's bodies, 266

Lankester, Sir E. Ray, and Lamarckism, 10; on Lamarck and Darwin, 69 ; on B. roseo-persicina, 108; rebukes rudeness and is rebuked, 354 et seq.

Laurent, 110, 117

Lead poisoning, effects on germ cells, 61, 156

Leech, D. J., 89 (note)

Lecithins, 184, 205

Lehmann, O., on fluid crystals, 81, 177

Leishman's experiment, 54

Leiomyomatosis, 344

Lepidic tissues, 313

Lepidio tumours (lepidomas), 315; 
primary and secondary or transitional, 325

Levy, 122

Leucocytes, and development of immunity, 42 ; and adaptation, 53 ; phagocytic activities of, 166

Leukaemia, 345

Lichty, 239 (note)

Liebreich, 182

Life, a lecture on, 216 et seq.; and crystallization, 231 ; definition, 231

Lillie, 195, 204

Limestones, mode of formation, 17

Limulus, 18

Lingula, 18

Lipoids, 186, 205

Lizé, on nitrate of mercury poisoning, 62

Loeb, Jacques, 204 ; effects of alteration of tonicity of medium, 240

Loeb, Leo, 318 (note)

Löfller, 116, 122, 129

Lorenz, 122

Lubarsch, 202, 307

Lugaro, 197

Lukjanow, 197

Lustig, 62

Lymphadenosis, 345

Lymph nodes, proliferation in, 266

Macallum, A. B., 289; on cell-chemistry, 190; extrusion of nucleolar matter, 197; on chemistry of the nucleus, 203

MacBride, E. W., on influence of hormones on the germ cells, 69 ; on origin of the endothelium, 311

Mackenzie, 33 (note)

McKlung, 193

Malignancy in the hyperblastoses, 346

Malformations, influence of parental infection in causation, 157

Mallory, 282

Malm, 116

Mann, Gustav, 197, 289

Marohand, 328

Marmorek, 35

Marsh, 19

Martin, Sidney, on toxic albumoses, 258

Martinotti, 289

Massini, 31

Maximow, 198

Meakins on assumption of habits, 238

Measles, in Pacific Islands, 21

Melanotic tumours, 319
Memory, 226 (note)

Mendel, and the Mendelian doctrine, 9

Mendelism and the biophores, 95

Meningococcus, allied strains, 24

Metabolism, 85

Metaplasia, 246; and cell habits, 58 ; the law of reversion, 273

Metchnikoff, on tetanotoxin, 51; on phagocytosis, 53; and Bordet, 53; on cancer parasites, 278, 332; on phagocytosis by tissue cells, 328

Mettenheimer, 172

Mesenchyme, origin of, 310

Mesothelioma, 320, 321

Microbacillus prodigiosus, 111, 113

Micrococcus indicus, 110, 111

" pneumoniae. See Diplococcus

, pyogenus, 114

Minot, Sedgwick, on the embryological basis of pathology, 308; on origin of endothelium, 311 ; on the notochord, 309

Mischgeschwülste, 335, 337

Modifications, 28 ; transient, of bacteria, 108

Molluscum fibrosum, 344

Momentum of living matter, 243

Monboddo, Lord, 6

Montgomery, 192

Moodie, 16

Moore, Norman, 20

Moore and Arnold, 192

Morgan, T. H., 139

Morris, Sir H., 20 (note)

"Mother cells," 264, 288; and neoplasia, 273; their proliferation in functioning tissues, 294 (note)

Mouse septicaemia, 122

Mucous colitis, 239

Mucous membranes, proliferation of, 266

Müller (of Marburg), 172

Müller, R., 31 (note)

Muscle, proliferation in, 267 ; regeneration, 267

Musgrave and Clegg, 46

Mutations, 28 et seq.

Mutilations, non-inheritance of, 153

Myelins, the, 168 et seq.

Myeloma, multiple, 347

Myelosis, 346

Myxomycetes, adaptation in, 46

Nägeli, 108, 142

Natural selection, $\mathbf{x}$ 
Nautilus, 18

Neoplasia, and cell habits, 59; and the nucleus, 200 ; and the habit of growth, 247; and anaplasia, 249; and dedifferentiation, 273; benign and malignant tumours, 280 ; the primary cause, 295; the " habit of growth" theory, 301 ; microbes as one causative agent, 302

Nepa, 196

Nephritis, Epidemic War, 24

Nernst, on size of atom, 215

Nervous habits, 237

Neubauer, 175 (note)

Neurin oleate, 182

Neurofibromatosis, 344

Neurogenic cell activities, 240

Neuroma, 324

Neurones, existence of "mother cells" for, 271

Nicholls, A., 165

Nikiforoff, 124 (note)

Nitrate of meroury, effects on offspring, 62

Nucleolus and cell activities, 198

Nucleoproteins, 203

Nucleus, and cell activities, 79, 289 ; and inheritance, 149; dominance of, 188 et seq.; and germ plasm, 191 ; in cell growth and multiplication, 191 ; effects of removal, 195; relationship to cytoplasm, 195, 207; changes during activity, 196; and functional activities, 196; and secretion, 197; in pathological conditions, 200 ; chemistry of, 203; and enzyme actions, 204

Ogata, 197

Ontogeny and phylogeny, 93

Osler, Sir W., 28 (note)

Osteoblasts, 265

Osteomyelitis, 16

Paget, Sir James, 290

Palaeopathology, 16

Parallel induction, 66

Paranuclear bodies, 201

Paraplasmic substances, 242

Parasitic theory of cancer, 278, 302, 329,333

Parenteral digestion, and immunity, 250 et seq.; and enteral digestion, 253

Park, Roswell, 277

Pasteur, on adaptation in bacteria, 31 ; asporogenous races of anthrax bacillus, 35 ; method of protection against rabies, 41; and Thullier, 116 ; on science and religion, 217

Pasteur, Chamberland, and Roux, 115,119

Paul, Constantin, on lead poisoning, 61,156

Pearson, Karl, 63

Peckham, Miss A. W., 31

Penfold, 31

Perithelioma, 320

Peters, H., 285, 326

Pfeiffer on Vibrio metchnikovi, 123; on nature of bacteriolysis, 251

Pfeiffer's reaction, 52, 257

Phagocytosis, 53

Phytotoxins and bacteriotoxins, 49

Pianese, 279, 336

Picardy sweat, 19

Piltdown skull, 16 (note)

Placental syncytium, 286

Plasmosomes, 197, 204

Plimmer, 332

Pneumococcus. See Diplococcus

Polypeptids, synthesis of, 74, 222

"Poor curate" phenomenon, 248

Porencephalus, 271

Protagon, 182

Proteidogenous matter, 74, 219

Protein fatty-acid compounds, 187

Proteins, their constitution, 73 et seq., 220,225 ; the essential constituent of living matter, 219

Prozymogen, 198

Pseudoleukremia, 345

Pulmonary epithelium, proliferation in, 267

Purpose in vital phenomena, 163

Pyknosis, 202

Pyorrhoea alveolaris, antiquity of, 16

Quincke, G., 172, 175, 180, 187, 195

Rabbit, in Australia, 21

Races, production of, in bacteria, 114

Radziowski, 52

Regeneration, 270 et seq.

Reid, Archdall, on alcohol and the race, 63 (note)

Renault, R., 17

Répin, 285

Reserve force, 165

Reversion, 269 ; senile, and neoplasia, 274 
Ribbert, $288,307,341$; on erythroblastoma, 347

Ricin, 47

"Riesenwuchs," 339, 340, 342

Römer, 50

Roncali, 278

Root hairs, 196

Rosenfeld, 187

Rosenheim, 33 (note)

Rosenow, on induced modifications in streptococci, 36 ; on elective localization of streptococci, 43

Rossi-Doria, 332 (note)

Ross's law, 57, 147

Roux, E., on loss of spore formation, 115, 120; on Pasteur, 217; and Yersin, 49, 129, 258

Ruffer, Sir M. A., on palaeopathology, 16 ; on bacteria in healthy tissues, 165; on cancer parasites, 278

Russell, 278

Rutherford, Sir E., 241

\section{Salamandra maculosa, 66}

Sanderson, Sir J. Burdon, on phagocytosis, 54 (note)

Sanfelice, 278, 279, 303

Sarcina erythromyxa, 113 " ventriculi, 23

Sarcoblasts, 268

Sarcoma, definition of, 317 ; carcinomatodes, 320

Schenck, 67; on fluid crystals, 177; on adsorption by fluid crystals, 186

Schiller, 109

Schloss and Foster, 39

Schmaus and Albrecht, 202

Schoenlein, 23

Sedgwick, A., 84

Senn, N., 274, 305

Sex and the accessory chromosome, 193

Shaw, W. V., 39

Shell shock, 58

Shirres, D. A., 271

Side-chain theory of inheritance, 144

Sjöbring, N., 278

S. Joaquin Valley, 21

"Slumber cells," 202

Smith, Elliot, 20

Smith, Erwin F., on crown galls in plants, 283 (note)

Smith, Theobald, 25

Soaps and myelin, 175

Sociology and eytology, 242
Sparrow, in North America, 21

Spencer, Herbert, on inheritance of acquirements, 6 ; on the determinants of the peacock's tail, 73; and direct adaptation, 355,357 , 359

Spermatozoa, multiplication of, 83 , 211

Sphero-crystals, 181

Spirillum cholerae, 52, 111, 112, 113, 123, 127

Spirillum Finkler-Prior, 113

" metchnikovi, 53, 113, 123

Spirogyra, 195

Spitzer, 204

Splenomegaly, 344

Stahl, 46

Staphylococeus pyogenes, 114

Steinhaus, 198

Stockard's experiments, 63

Stolnikow, 202

Streptococcus, exaltation of virulence, 35,40 ; elective localization of, 43 ; erysipelatosus, 121

Strong, 21

Sudhoff, 20

Survival of the fittest, 11

Sutton, 192

Sweating sickness, 19, 42

Swine erysipelas, 116

Syncytioma malignum, 286; its bearing in nature of malignancy, 326 et seq.; demonstration of its nature, 328

Syncytium (placental), 286

Syphilis, antiquity of, 20 ; mode of origin, 42 ; not inherited, 140 ; parasyphilitic inheritance, 155; Fournier's observations, 156

Teleological conceptions, what constitute, 163

Terato-blastomas, 337

Teratomas, 282, 285, 334

Tetanotoxin, 51, 259

Thalassicola pelagica, 195

Thiele and Embleton, 39

Thies, S., 199

Thoma, 307

Thomson, Arthur, 215 (note): on determinants, 71 (note)

Thomson, Sir J. J., 241

Thompson, D'Arcy W., on fortuitous variations, 11 ; on growth, 79 ; on fluid crystals, 82

Thudichum, 184 (note) 
Tics, 58, 235

Tissues, the, lining membrane and pulp tissues (lepidio and hylic), 311

Torhorst, 174

Tornier, 266

Torrey, 199

Toxins as canses of cell proliferation, 282; and antitoxins, relation of, 50

Trench fever, 22, 42

Trench shin, 22, 42

Trophoblast, 327

Tuberculosis, antiqnity of, 16 ; bovine, in $\operatorname{man}, 26$; not inherited, 141; inheritance of diathesis, 158; pulmonary, assumption of babit in, 235

Tuberculous diathesis, inheritance of, 61

Tumours, causation of, 273 et seq. ; benign and malignant, 280 ; definition, 281; due to parasites, 283 ; in plants, 283; starting - point common to all, 295 ; the " habit of growth " theory, 301 ; microbes as a causative agent, 302 ; melanotic, 319 ; the cells as parasites, 330 ; mixed, 335

Tumours, classification of, 305 et seq.; embryogenetic, 284; Waldeyer's classification, 305 ; by cell potency, 334 et $8 \mathrm{eq}$.

Twort, 31

Van Tieghem, 17

Variability, of bacteria, 103 et seq.; in protozos, Weismann on, 106; transient, 108

Variation, chance and, $x$; inherent or acquired, 6 ; influence of sexual conjugation, 13; by loss of factors, 34 ; in pigment production by bacteria, 56 ; and variability, 355 , 358

Variations, favourable, 10 ; fortuitous, 11 ; impressed, 28 ; impressed, as against chance, 33 ; specific, experimental production of, in bacteria, 33

Vaughan, Victor C., on protein split products, $38,91,253$; anaphylaxis, 254

Vegetative activities, 84

Veroçay, 344

Verworn on the enucleated cell, 195 ; on nucleo-cytoplasmio relationship, 195

Vibrio metchnikovi. See Spirillum

Vincent, 37; on B. typhosus, 109 ; on $B$. megatherium, 152 (note)

Von Chauvin, Marie, 67 (note)

Von Hansemann, 59; on tumours, 288 ; on classification of tumours, 307

Virchow on cells as vital units, 85; on myelin, 170; and the development of pathology, 189

Virulence, exaltation of, 35, 116 ; development of, in non-pathogenic bacteria, 39

Vital inertia, 55, 166

Walcott, C. D., 17

Waldeyer, 305

Waldvogel and Mette, 184

Walker, 143, 147

Walker, Ainley, on mutations, 29 (note); on changes in fermentative powers of bacteria, 36; on adaptation by bacteria, 43 (note)

Walter, 66

Warren, Collins, 277

Wasserzug, 116

Watson, 62

Webster, J. C., 327

Weigert, C., on law of inertia, 55, 167 ; on cell activities, 85; on cell proliferation, 282

Weismsnn, A., against the inheritance of acquirements, 6; his influence, 72 ; on biophores, 80 (note); on continuity of the germ plasm, 83, 210 ; on variability in protozoa, 106; his theory of inheritance, 134, 136 et seq.; on somatogenio influences on germ cells, 136; on blastogenic inheritance, 158; on the value of hypothesis, 160 ; the "Reductio ad absurdum," 210 et seq.; on muscle spindles, 268; Sir E. Ray Lankester on, 356

Welch, W. H., on adaptation by bacteria, 43,164

Whitman, 84

White, C. P., definition of true tumours, 281 ; on microbic stimulation of cell growth, 329 ; on progressive hypertrophy, 340

Willey, A., 18 (note)

Williams, 310

Wilms, 335 
Wilson, E. B., 139; on accessory chromosome, 193; on regeneration of centrosome, 195

Wolbach, on X-ray carcinoma, 248

Woolley, P. G., on tumours of adrenal cortex, 321

Wright, Sir Almroth, on opsonins, 54

Wrosczek, 165
X-ray cancer, 248

Yeasts, thermogenic production of races, 151 (note)

Zäslein, 127

Ziegler, 281

Zinsser, 258

THE END 



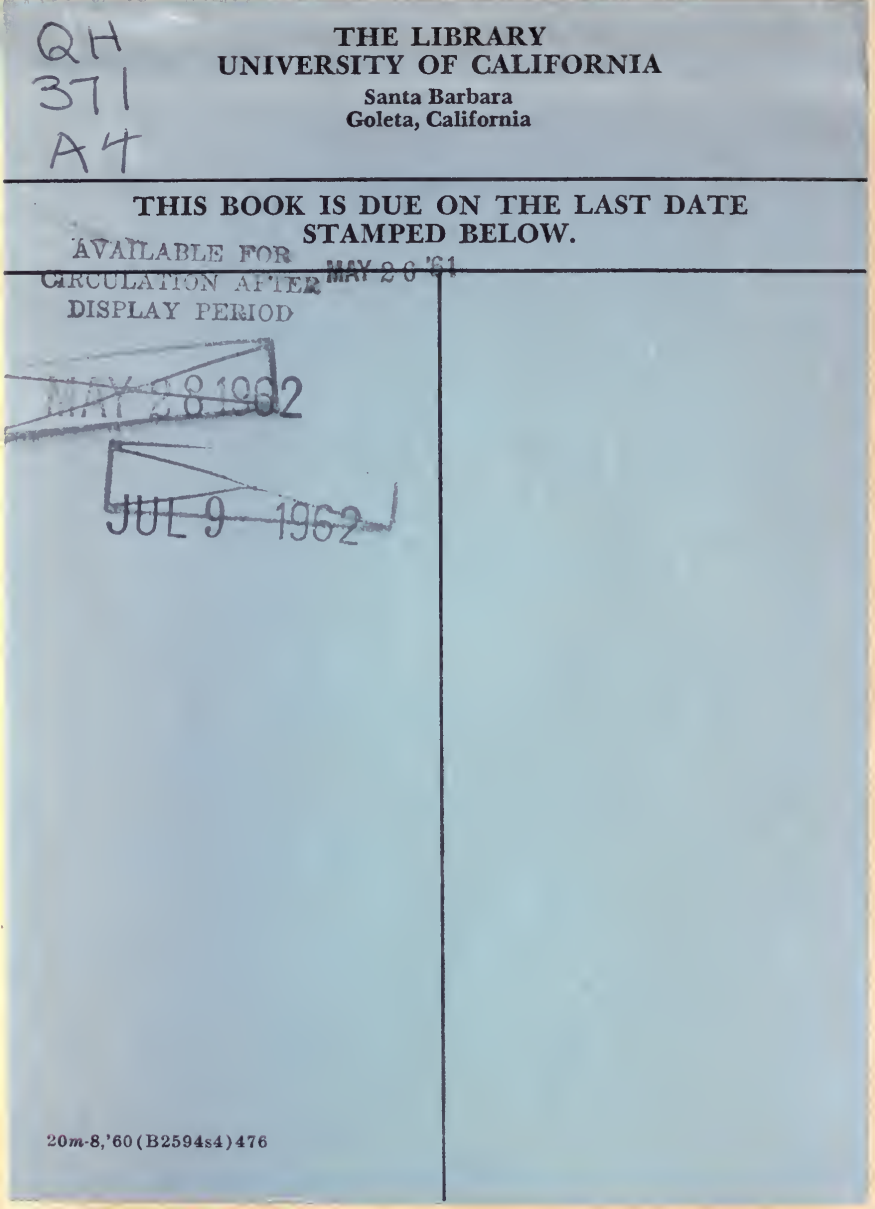


UC SOUTHERN REGIONAL LIBRARY FACILITY

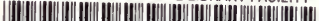
AA 0000770347 


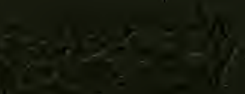

